\title{
WestVirginiaUniversity
}

THE RESEARCH REPOSITORY @ WVU

Graduate Theses, Dissertations, and Problem Reports

2015

\section{Electrode Reaction Pathway in Oxide Anode for Solid Oxide Fuel Cells}

Wenyuan Li

Follow this and additional works at: https://researchrepository.wvu.edu/etd

\section{Recommended Citation}

Li, Wenyuan, "Electrode Reaction Pathway in Oxide Anode for Solid Oxide Fuel Cells" (2015). Graduate Theses, Dissertations, and Problem Reports. 6075.

https://researchrepository.wvu.edu/etd/6075

This Dissertation is protected by copyright and/or related rights. It has been brought to you by the The Research Repository @ WVU with permission from the rights-holder(s). You are free to use this Dissertation in any way that is permitted by the copyright and related rights legislation that applies to your use. For other uses you must obtain permission from the rights-holder(s) directly, unless additional rights are indicated by a Creative Commons license in the record and/ or on the work itself. This Dissertation has been accepted for inclusion in WVU Graduate Theses, Dissertations, and Problem Reports collection by an authorized administrator of The Research Repository @ WVU.

For more information, please contact researchrepository@mail.wvu.edu. 


\title{
Electrode Reaction Pathway in Oxide Anode for Solid Oxide Fuel Cells
}

\author{
Wenyuan Li \\ Dissertation submitted to \\ Benjamin M. Statler College of Engineering and Mineral Resources \\ at West Virginia University \\ in partial fulfillment of the requirements \\ for the degree of \\ Doctor of Philosophy \\ In \\ Mechanical Engineering \\ Xingbo Liu, Ph.D., Committee Chairperson \\ Xueyan Song, Ph.D. \\ Edward M. Sabolsky, Ph.D. \\ Nick Wu, Ph.D. \\ Kirk R. Gerdes, Ph.D. \\ Department of Mechanical and Aerospace Engineering \\ Morgantown, West Virginia \\ 2015
}

Keywords: solid oxide fuel cells, oxide anode, $\mathrm{H}_{2}$ oxidation mechanism, catalytic activity, overpotential

Copyright 2015 Wenyuan Li 


\title{
ABSTRACT
}

\section{Electrode Reaction Pathway in Oxide Anode for Solid Oxide Fuel Cells}

\author{
Wenyuan Li
}

Oxide anodes for solid oxide fuel cells (SOFC) with the advantage of fuel flexibility, resistance to coarsening, small chemical expansion and etc. have been attracting increasing interest. Good performance has been reported with a few of perovskite structure anodes, such as $(\mathrm{LaSr})(\mathrm{CrMn}) \mathrm{O}_{3}$. However, more improvements need to be made before meeting the application requirement. Understanding the oxidation mechanism is crucial for a directed optimization, but it is still on the early stage of investigation. In this study, reaction mechanism of oxide anodes is investigated on doped $\mathrm{YCrO}_{3}$ with $\mathrm{H}_{2}$ fuel, in terms of the origin of electrochemical activity, rate-determining steps (RDS), extension of reactive zone, and the impact from overpotential under service condition to those properties.

$\mathrm{H}_{2}$ oxidation on the YCs anodes is found to be limited by charge transfer and $\mathrm{H}$ surface diffusion. A model is presented to describe the elementary steps in $\mathrm{H}_{2}$ oxidation. From the reaction order results, it is suggested that any models without taking $\mathrm{H}$ into the charge transfer step are invalid. The nature of $\mathrm{B}$ site element determines the $\mathrm{H}_{2}$ oxidation kinetics primarily. $\mathrm{Ni}$ displays better adsorption ability than Co. However, $\mathrm{H}$ adsorption ability of such oxide anode is inferior to that of Ni metal anode. In addition, the charge transfer step is directly associated with the activity of electrons in the anode; therefore it can be significantly promoted by enhancement of the electron activity. It is found that $\mathrm{A}$ site $\mathrm{Ca}$ doping improves the polarization resistance about 10 times, by increasing the activity of electrons to promote the charge transfer process.

For the active area in the oxide anode, besides the traditional three-phase boundary (3PB), the internal anode surface as two-phase boundary (2PB) is proven to be capable of catalytically oxidizing the $\mathrm{H}_{2}$ fuel also when the bulk lattice is activated depending on the $\mathrm{B}$ site elements. The contribution from each part is estimated by switching the electrolyte to change 3PB kinetics. Compared to $\mathrm{Ni}$, Co doping activates the bulk oxygen more significantly, promoting the reaction at $2 \mathrm{~PB}$. The active surface reaction zone is found to be enlarged by the electrolyte with high oxygen activity (SSZ vs. YSZ) when charge transfer is one of the RDS. Due to the larger exchange current for charge transfer in 3PB with SSZ electrolyte, the adsorption gradient zone is broadened, leading to enhanced surface reaction kinetics. The potential application of such finding is demonstrated on SSZ/YSZ/SSZ sandwich, showing largely improved electrode performance, opening a wide door for the utilization of electrolytes that are too expensive, fragile or instable to be used before.

The bulk path way in $2 \mathrm{~PB}$ reaction can be affected by overpotential in terms of local vacancy concentration, built-in electrical field and stability. It is proven that an uneven distribution of lattice oxygen is established under operation conditions with overpotential by both qualitative analysis and analytic solution. An electrostatic field force is present besides the 
concentration gradient in the anode lattice to control the motion of oxygen ions. Compared to the usual estimation based on chemical diffusion mechanism, the real deviation of ionic defects concentration under polarization from the equilibrium state near electrode/electrolyte interface is smaller with the built-in electrical field. The overpotential is demonstrated to be able to open up or shut down the bulk pathway depending on the ionic defects of electrodes. The analysis on the bulk pathway in terms of local charged species and various potentials provides new insight in anion diffusion and electrode stability. 


\section{ACKNOWLEDGEMENTS}

First of all, I would like to thank my advisor Dr. Xingbo Liu. He innovatively trained me as a scientist from a starter. I feel so grateful to him for his patience, support and guidance through out the course of my Ph.D. study.

Secondly, I am indebted to Dr. Mingyang Gong. He helped me from my first day in the States, guided me in research and talked me out of confusion. He set me a good example in how to do research. I am also indebted as much to Dr. Greg Collins. He sacrificed lots of his time and effort to pave the path for my study. He provided crucial suggestions and made novel constructions to make my research possible.

Next, I would like thank my committee members, Dr. Xueyan Song, Dr. Nick Wu, Dr. Edward Sabolsky and Dr. Kirk Gerdes for their constructive suggestions on my work, thank Dr. John Zondlo for the help on cell measurement.

My warmest thank to my wife Bo, with her company in this journey full of highs and lows I am not alone. Life is complete with her.

At last, I would like thank all my group members, Dr. Hui Zhang, Meng Yao, Jianhua Yan, Xinxin Zhang, Youkun Tao and et al. Because of them, the memory is sweet. 


\section{TABLE OF CONTENTS}

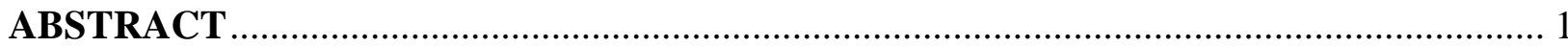

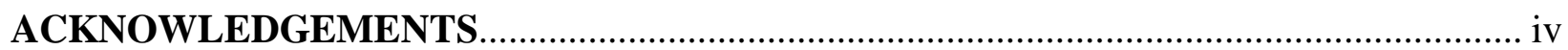

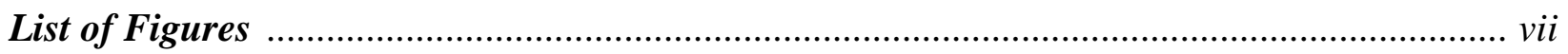

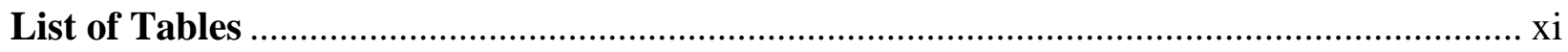

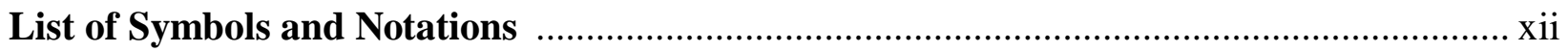

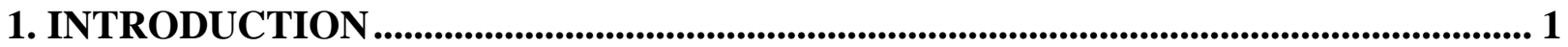

2. LITERATURE REVIEW ................................................................................................................. 3

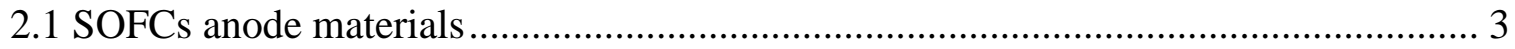

2.1.1 Conventional Ni anode ………………………...................................... 4

2.1.2 Perovskite oxide anodes............................................................................ 7

$2.2 \mathrm{H}_{2}$ oxidation pathway in traditional Ni/YSZ anode ................................................ 17

2.3 Broadened reaction zone in oxide anodes .............................................................. 23

2.4 Influence on performance of overpotential ............................................................ 23

3. RESEARCH OBJECTIVES ............................................................................................... 29

4. EXPERIMENTAL METHODS ........................................................................................................ 31

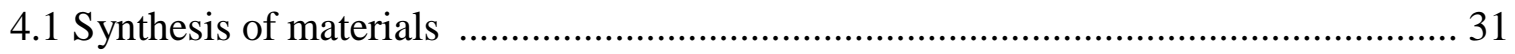

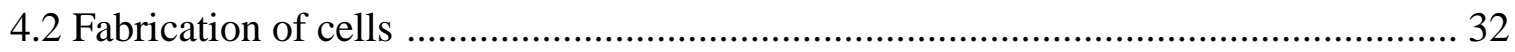

4.3 Electrical and electrochemical characterizations ...................................................... 33

4.4 Material structure characterization ……………………...................................... 34

5. FACTORS CONTROLLING $\mathrm{H}_{2}$ OXIDATION ON DOPED YCrO $\mathrm{Y}_{3} \ldots . . . . . . . . . . . . . . . . . . . . . . . . . . .35$

5.1 Phase purity, compatibility and electrical conductivities .......................................... 36

5.2 Factors determining catalytic activity in $\mathrm{H}_{2}$ oxidation ............................................. 43

5.3 Rate-limiting steps on doped $\mathrm{YCrO}_{3}$ anodes …………….................................. 47

5.4 H-must charge transfer reaction ...................................................................... 53 


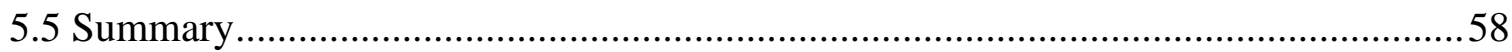

\section{EXTENDED ACTIVE AREA DUE TO LATTICE VACANCY AND ACTIVE}

\section{ELECTROLYTE}

.

$\mathbf{0}$

6.1 Manifest of 2PB contribution in the ionic conductive oxide anode .........................61

6.2 Extended surface adsorption area due to active electrolyte ..................................... 74

6.3 Demonstration of practical application for active electrolyte................................ 79

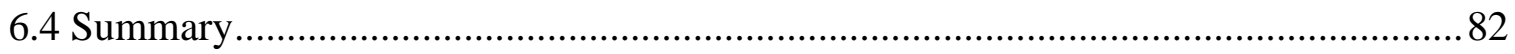

\section{ACTIVATION/DEACTIVATION AND STABILITY OF THE BULK}

PATHWAY UNDER OVERPOTENTIAL ..........................................................................84

7.1 Oxygen transport at oxide anode bulk: 1-dimensinal model .................................85

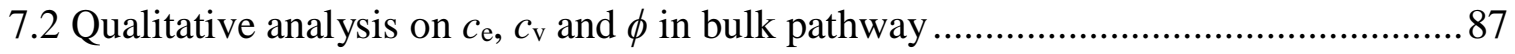

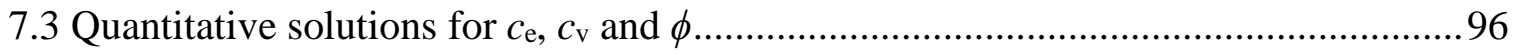

7.4 Experimental verification through the $\mathrm{h}-\mathrm{V}$ type MIEC electrode ........................... 106

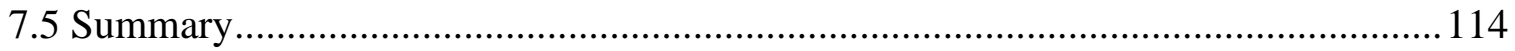

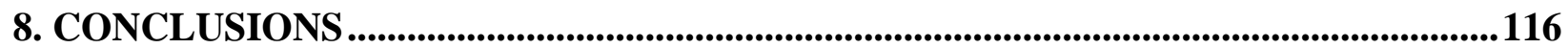

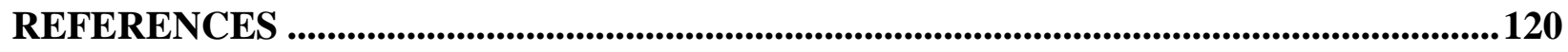




\section{List of Figures}

2.1 Schematic diagram of SOFC 3

2.2 SEM pictures of the surface and cross section of Ni/YSZ cermet anode, surface (a) and cross-section (b). .5

2.3 Deposited carbon on Ni-YSZ cermet: (a) carbon fiber, (b) Ni-YSZ cermet ......................6

2.4 Increasing of polarization resistance of $\mathrm{Ni} / \mathrm{YSZ}$ anode at $1000^{\circ} \mathrm{C}$ with different concentration of $\mathrm{H}_{2} \mathrm{~S}$ added into $79 \% \mathrm{H}_{2}+21 \% \mathrm{H}_{2} \mathrm{O}$ fuel ............................................

2.5 Schematic diagram of $\mathrm{ABO}_{3}$ perovskite structure ..................................................

2.6 Schematic of Ni pattern sample on single crystal YSZ (a), and SEM image of Ni on YSZ (b).

2.7 Polarization resistance vs. 3PB length on the Ni pattern sample deposited on single crystal YSZ

2.8 Schematics of possible reaction paths of Ni/YSZ discussed in the literature .20

2.9 Ni surface limiting reaction mechanism of $\mathrm{H}_{2}$ oxidation on $\mathrm{Ni} / \mathrm{YSZ}$ anode .20

2.10 $\mathrm{H}_{2}$ oxidation model in Ni/YSZ system by Bieberle et al. (a) schematic, (b) corresponding elementary steps

2.11 Elementary reaction steps for $\mathrm{H}_{2}$ oxidation by Vogler et al .......................................22

2.12 Different scenarios of charge transfer on $\mathrm{H}_{2} /$ YSZ 3PB ..........................................22

2.13 The linear (a) and logarithm (b) plots of V-I relationship for charge transfer reaction in MIEC electrode calculated from different surface coverage and surface local overpotential by Fleig et al

2.14 Polarization resistance of LSM cathode under cathodic and anodic treatments by Wang et. al. .26

4.1 Diagram of powder synthesis with sol-gel method …..............................................

4.2 Configuration of Van der Pauw measurement …..........................................................33 


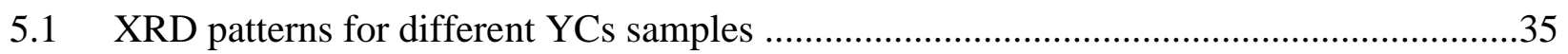

5.2 Morphology of $\mathrm{YCCC}$ sintered at $1100^{\circ} \mathrm{C}(\mathrm{a}), 1200^{\circ} \mathrm{C}(\mathrm{b}), \mathrm{Y}_{0.8} \mathrm{Ca}_{0.2} \mathrm{CrO}_{3}(\mathrm{c})$ and YCCN (d) sintered at $1200^{\circ} \mathrm{C}$

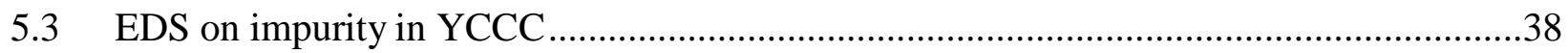

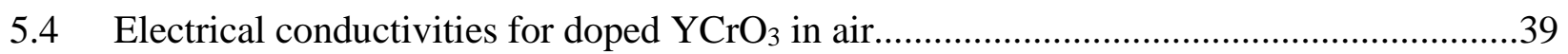

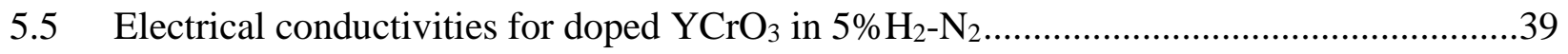

5.6 XRD patterns for compatibility between YSZ and chromites in the electrode

preparation conduction and electrochemical testing condition

5.7 Morphology of YCCC (a), YCCN (b) and the microstructure of YCCC/YSZ (c), YCCN/YSZ (d) electrodes

5.8 EIS of (a) $\mathrm{Y}_{0.8} \mathrm{Ca}_{0.2} \mathrm{CrO}_{3}$ and (b) $\mathrm{YCC}$ in wet $\mathrm{H}_{2}$ at different temperatures

5.9 Performance for YCCC and YCCN on YSZ electrolyte in wet $\mathrm{H}_{2}$

$5.10 P_{\mathrm{H} 2}$-dependent polarization resistances of YCCC (a) and YCCN (b) in $750^{\circ} \mathrm{C}$ on YSZ

5.11 Reaction orders of the overall polarization resistances for YCCC (a) and YCCN (b) for YCCC and YCCN on YSZ electrolyte in wet $\mathrm{H}_{2}$ .46

5.12 Equivalent circuit used to fit the EIS of YCCC and YCCC anodes .48

6.1 XRD patterns for compatibility between YSZ and chromites in the electrode preparation conduction and electrochemical testing condition

6.2 Microstructure of YCCC/SSZ (a), YCCN/SSZ (b) electrodes..

6.3 $P_{\mathrm{H} 2}$-dependent polarization resistances of YCCC (a) and YCCN (b) in $750^{\circ} \mathrm{C}$ on SSZ

6.4 $P_{\mathrm{H} 2}$ dependency of overall $R_{\mathrm{p}}$ for YCCC-SSZ (a) and YCCN-SSZ (b) from 650$850^{\circ} \mathrm{C}$

6.5 Electrode polarization resistances of YCCC and YCCN on SSZ and YSZ

6.6 Polarization resistances of YCCC and YCCN electrodes tested under OCV condition in air at $850^{\circ} \mathrm{C}$ 
6.7 Arrhenius plots for polarization resistances of four kinds of electrodes under

various $P_{\mathrm{O} 2}$ values

6.8 $\quad P_{\mathrm{O} 2}$ dependence of the overall polarization resistances for four different electrodes measured in oxidizing atmospheres.

6.9 Schematic diagram of reactions for LSCF electrode.

6.10 Improvement of electrode performance for YCCC and YCCZ upon change YSZ

to SSZ electrolyte

6.11 Comparison between $R_{\mathrm{p}}$ for YCCN-SSZ (a), YCCN-SSZ/YSZ/SSZ (b) and

YCCN-YSZ symmetrical cells (c) measured in wet $\mathrm{H}_{2}$ at different temperatures

7.1 Schematic diagram for MIEC anode operation (a), the ionic flowing and equipotential lines at MIEC anode near the interface area, (b) and the 1-D model derived based on it (c)

7.2 Logical flowing diagram for the possible distribution of electronic defects and the existence of galvanic potential in MIEC bulk

7.3 Three scenarios for the defects distribution in MIEC anode under steady state with current $I_{0}$

7.4 Distributions of concentrations and potentials under OCV (a) and steady state (b)

7.5 Electron (a) and vacancy (b) and galvanic potential distributions in a $1 \mu \mathrm{m}$ $\mathrm{La}_{0.3} \mathrm{Sr}_{0.7} \mathrm{TiO}_{3}$ anode film as the e- $\mathrm{V}$ type.

7.6 Limiting current in LST and the electron (a) and vacancy (b) and galvanic potential distributions (c).

7.7 Profiles for $c_{\mathrm{h}}(\mathrm{a})$, (b), $\phi$ (c) and $r_{\mathrm{E} / \mathrm{C}}(\mathrm{d})$ in $\mathrm{h}-\mathrm{V}$ type with acceptor doping 0.4/unit cell and 0.02/unit cell of $c_{\mathrm{h}}$ at surface

7.8 Profiles for $c_{\mathrm{e}}(\mathrm{a}), \mathbf{0}_{\mathbf{i}}^{\prime \prime}(\mathrm{b}), \phi(\mathrm{c})$ and $r_{\mathrm{E} / \mathrm{C}}(\mathrm{d})$ in e-O type with donor doping 0.3/unit cell and 0.1 /unit cell of $c_{\mathrm{e}}$ at surface

7.9 Profiles for $c_{\mathrm{h}}(\mathrm{a}), \mathbf{0}^{\prime \prime}(\mathrm{b}), \phi(\mathrm{c})$ and $r_{\mathrm{E} / \mathrm{C}}(\mathrm{d})$ in h-O type with acceptor doping

$0.1 /$ unit cell and $0.2 /$ unit cell of $c_{\mathrm{h}}$ at surface

7.10 The configuration of measurement (a), cross-sectional of LSCF/GDC (b) 105 


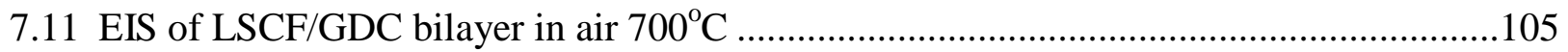

7.12 DC resistance under constant current loading for LSCF/GDC bilayers (a), and the

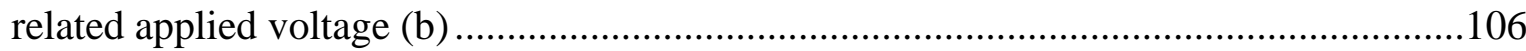

7.13 Calculated profiles for (b) in LSCF under chemical diffusion only assumption based on the same experimental conditions

7.14 Calculated profiles for $c_{\mathrm{h}}(\mathrm{a})$, (b), $\phi(\mathrm{c})$ and $r_{\mathrm{E} / \mathrm{C}}(\mathrm{d})$ in LSCF based on the experimental conditions 108

7.15 Schematic drawing of oxygen defect profiles in anode and cathode, vacancy in anode (a), interstitial oxygen in anode (b), vacancy in cathode (c), interstitial oxygen in cathode $(\mathrm{d})$ 110 


\section{List of Tables}

2.1 Electrical conductivities of titanate-based perovskites ...................................................

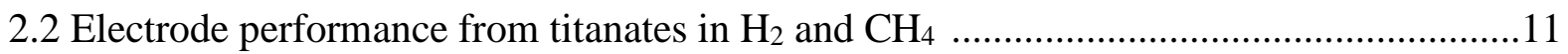

2.3 Electrical conductivities of vanadate-based perovskites .................................................13

2.4 Electrical conductivities of chromite-based perovskites ...................................................15

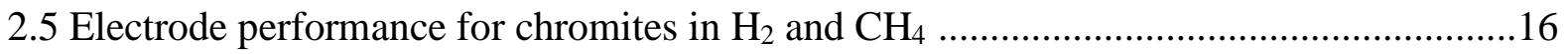

5.1 Composition of the impurity at spectrum 1 in YCCC ..........................................................

5.2 $R, C$ and $f_{0}$ for HF and LF arcs after fitting YCCC and YCCN anodes tested in at $850^{\circ} \mathrm{C}$, and the corresponding $E \mathrm{a}$ as well as reaction order $(n)$ in the temperature

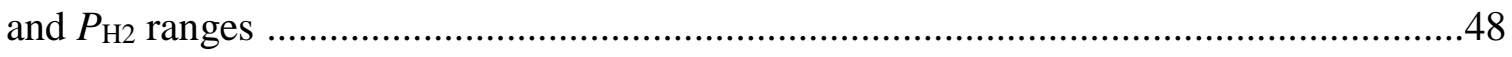

5.3 A model for $\mathrm{H}_{2}$ oxidation reaction at YCs anode. .......................................................49

6.1 Fitting results for YCCC and YCCN anodes on SSZ tested in wet $\mathrm{H}_{2}$ at $850^{\circ} \mathrm{C}$, and the corresponding $E \mathrm{a}$ and reaction order $(n)$.

6.2 Summary of $R, C$ and $f_{0}$ for these four electrodes tested in air at $850^{\circ} \mathrm{C}$, as well as $E \mathrm{a}$ in the temperature range of $650 \sim 850^{\circ} \mathrm{C}$. 


\section{List of Symbols and Notations}

\begin{tabular}{|c|c|}
\hline 3РB & Three-phase boundary \\
\hline $2 \mathrm{~PB}$ & Two-phase boundary \\
\hline ECR & Electrical conductivity relaxation \\
\hline EIS & Electrochemical impedance spectroscopy \\
\hline GDC & $\mathrm{Gd}_{0.2} \mathrm{Ce}_{0.8} \mathrm{O}_{2-\delta}$ \\
\hline LSM & $(\mathrm{LaSr}) \mathrm{MnO}_{3 \pm \delta}$ \\
\hline LSGM & $(\mathrm{LaSr})(\mathrm{GaMg}) \mathrm{O}_{3-\delta}$ \\
\hline LSCF & $(\mathrm{LaSr})(\mathrm{CoFe}) \mathrm{O}_{3}$ \\
\hline LSCM & $\mathrm{La}_{0.8} \mathrm{Sr}_{0.2} \mathrm{Cr}_{0.5} \mathrm{Mn}_{0.5} \mathrm{O}_{3-\delta}$ \\
\hline MPD & Maximum power density \\
\hline MIEC & Mixed ion and electron conductor \\
\hline ORR & Oxygen reduction reaction \\
\hline RDS & Rate determining step \\
\hline SOFC & Solid oxide fuel cell \\
\hline SSZ & Scandium stabilized zirconia \\
\hline TEC & Thermal expansion coefficient \\
\hline YCC & $\mathrm{YCr}_{0.8} \mathrm{Co}_{0.2} \mathrm{O}_{3}$ \\
\hline YCCC & $\mathrm{Y}_{0.8} \mathrm{Ca}_{0.2} \mathrm{Cr}_{0.8} \mathrm{Co}_{0.2} \mathrm{O}_{3}$ \\
\hline YCCN & $\mathrm{Y}_{0.8} \mathrm{Ca}_{0.2} \mathrm{Cr}_{0.9} \mathrm{Ni}_{0.1} \mathrm{O}_{3}$ \\
\hline YSZ & Yttrium stabilized zirconia \\
\hline $\mathrm{B}-\mathrm{V}$ & Bulter-Volmer \\
\hline V-I & Voltage-current \\
\hline$C$ & Capacitance \\
\hline$c$ & Concentration \\
\hline$D$ & Chemical diffusion coefficient \\
\hline e & Electron change \\
\hline$\vec{E}$ & Electrical field \\
\hline$E_{\mathrm{a}}$ & Activation energy \\
\hline$E_{\mathrm{N}}$ & Nernst potential \\
\hline$f_{0}$ & Characteristic frequency \\
\hline$F$ & Faraday constant \\
\hline
\end{tabular}




\begin{tabular}{|c|c|}
\hline$I$ & Current \\
\hline$J$ & Current density \\
\hline$k$ & Surface exchange coefficient \\
\hline$k_{\mathrm{B}}$ & Boltzmann constant \\
\hline$n$ & Reaction order \\
\hline$P_{\mathrm{H} 2}$ & Hydrogen partial pressure \\
\hline$P_{\mathrm{O} 2}$ & Oxygen partial pressure \\
\hline$R$ & Reaction rate \\
\hline$R_{\mathrm{p}}$ & Polarization resistance \\
\hline$z$ & Formal charge \\
\hline$\alpha$ & Symmetry factor \\
\hline$\varepsilon$ & Relative permittivity \\
\hline$\varepsilon_{0}$ & Vacuum permittivity \\
\hline y & Electrode overpotential \\
\hline$\theta$ & Surface coverage \\
\hline$\mu$ & Electrochemical potential \\
\hline$\rho$ & Local charge density \\
\hline$\sigma$ & Conductivity \\
\hline$\phi$ & Galvanic potential \\
\hline \multicolumn{2}{|c|}{ Subscripts } \\
\hline 0 & Steady state \\
\hline $\mathrm{ct}$ & Charge transfer \\
\hline $\mathrm{e}$ & Electron \\
\hline $\mathrm{i}$ & Oxygen ion \\
\hline $\mathrm{h}$ & Eletron hole \\
\hline $\mathrm{v}$ & Oxygen vacancy \\
\hline
\end{tabular}




\section{Chapter 1}

INTRODUCTION

Industrial development improves people's lives at the expense of increasing consumption of energy and severe environmental consequences. Of various solutions to promote energy utilization efficiency, SOFCs have attracted intensive attention due to their intrinsic high efficiency in chemical-electrical energy convention.

Besides the most commonly used Ni/YSZ (yttrium stabilized zirconia) anode, an array of oxide materials have been investigated as anode candidates for SOFCs in consideration of the advantage in fuel flexibility, structure stability during redox process and long-term reliability. As most effort has been focused on the output performance of those materials, the main aspect missed out so far is the understanding of the operating mechanism.

Through nearly four decades, the anode reaction mechanism is being studied on Ni/YSZ and other noble metal anode, such as Pt and Ag. But the results on those metal anodes cannot be interpreted into oxide anodes directly. First of all, oxygen as the oxidant is supplied by the electrolyte only in those metal anodes because none of them is confirmed with significant oxygen ion conductivity, even though Pt is found to conduct oxygen slightly through grain boundary at relative low temperature. In contrast, the conduction of oxygen in oxide anodes are highly possible through lattice oxygen vacancy or interstitial oxygen or grain boundary hyperstoichiometry oxygen. Secondly, surface adsorption process in metal anode simply involves $\mathrm{H}$, and lots of simulation work has been done in order to illustrate the correlation 
between the adsorption ability and the chemical bonding. However, those results would be different on oxide anode provided that oxygen in principle could escape from lattice, becoming an adsorbed atom on the surface, which reacts with adsorbed $\mathrm{H}$. In addition, the adsorption ability of metal element in the oxide anodes could be heavily dependent on its oxidation state, leading to different trends from the pure metal anodes. In addition, a long distance diffusion process in $\mathrm{Ni} / \mathrm{YSZ}$ is not common as the primary reaction area is confined to $3 \mathrm{~PB}$. In contrast, the ionic conductivity in oxide anode could enable a broadened reactive zone where a significant bulk diffusion process occurs. Based on the knowledge from cathode investigation, such broadened area influences the performance greatly in electrode with good ionic conductivity. Similarly, it will influence the anode performance also when particular conditions are met. Judged by the experimental and simulation studies for cathode where a larger body of data set is available on this topic, such pathway can be activated by the overpotential applied to the electrode under steady state. Therefore, a new bulk pathway in the anode which varies under different flowing current is newly present in oxide anode, and no such information can be lent from traditional metal anode.

In the present study, Cr-based perovskite is chosen as the oxide anode. The oxidation mechanism including surface process, activity of bulk oxygen, dominant reactive zone, variation of bulk pathway and the new insight on stability under the influence of overpotential and etc. are investigated experimentally and analytically. 
Chapter 2

LITERATURE REVIEW

\subsection{SOFCs anode materials}

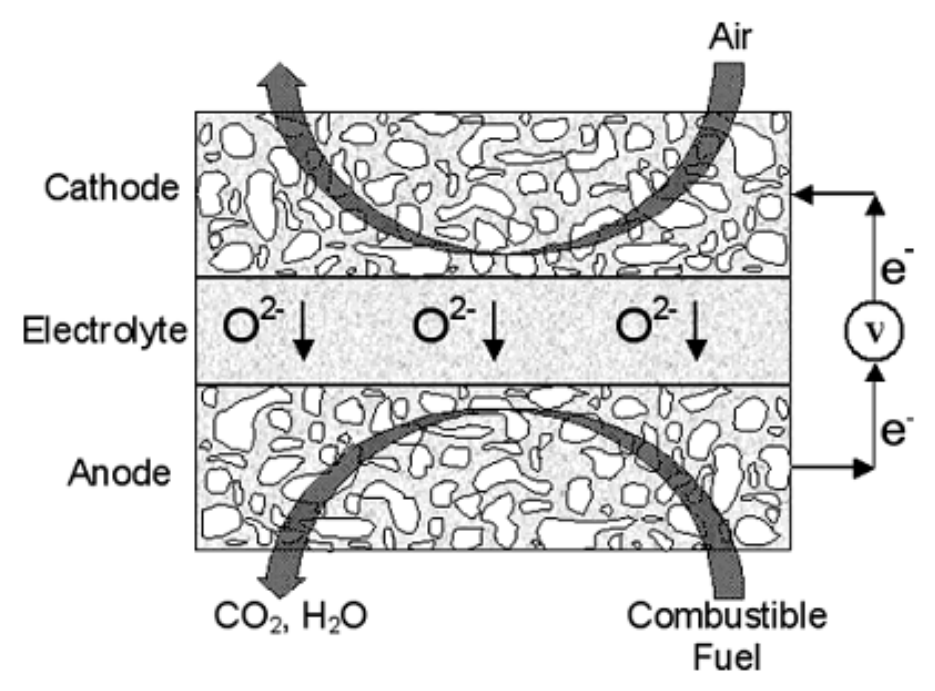

Fig. 2.1 Schematic diagram of SOFC.[1]

Solid oxide fuel cells converting chemical energy directly to electrical power offers advantages over other techniques in the intrinsically high conversion efficiency and minimal environmental impact. The state-of-the-art SOFCs consist of YSZ electrolyte, Ni/YSZ anode and lanthanum strontium manganite (LSM) cathode. Fig. 2.1 shows the operation principle of SOFC with oxygen conductive electrolyte. Fuel is catalytically oxidized at anode by the oxygen transported through electrolyte. Taking $\mathrm{H}_{2}$ fuel oxidation as an example, the anode reaction can be written as

$$
\mathrm{H}_{2}+\mathrm{O}^{2-} \rightarrow \mathrm{H}_{2} \mathrm{O}+2 \mathrm{e}^{-}
$$


As illustrated by this simple equation, the following features with anode materials can be drawn:

$>$ Tolerant to reducing atmosphere, e.g. up to around $10^{-24}$ for $\mathrm{H}_{2}$.

Electronic conductive to lead away accumulated electrons.

Catalytic activity in terms of adsorbing and dissociating fuel like $\mathrm{H}_{2}$.

Possible catalytic activity that comes from activating oxygen.

Considering the structure of fuel cell, the followings are also required:

Chemical stability with other components.

Thermal expansion matching with other parts.

\subsubsection{Conventional Ni anode}

The Ni/YSZ cermet is the most commonly used anode in SOFC with $\mathrm{H}_{2}$ fed as fuel. Such cermet more than merely meets most of the requirements mentioned above, but even exhibits lots of compelling properties as an excellent anode. For example, Ni/YSZ can be prepared with a simple and efficient dry-pressing method in both lab and industrial scales. Fig. 2.2 shows a typical porous structure of Ni/YSZ anode. Ni/YSZ shows very good chemical compatibility. They are neither reactive nor immiscible with each other in a wide range of temperature, enabling cost-efficient co-sintering fabrication method and long-term stability. Ni also shows closely matched thermal expansion coefficient (TEC) with YSZ, therefore avoiding damaging 
stress to build up in the interface which may lead to cracking or delamination eventually. Most importantly, besides those merits, $\mathrm{Ni}$ shows excellent catalytic activity towards $\mathrm{H}_{2}$ oxidation. Because of such excellence, when operating Ni/YSZ anode at high temperature $\left(800-1000^{\circ} \mathrm{C}\right)$, the resistance associated with anode is very small, and the major part of the resistance comes from the ohmic resistance of electrolyte and polarization resistance of cathode.
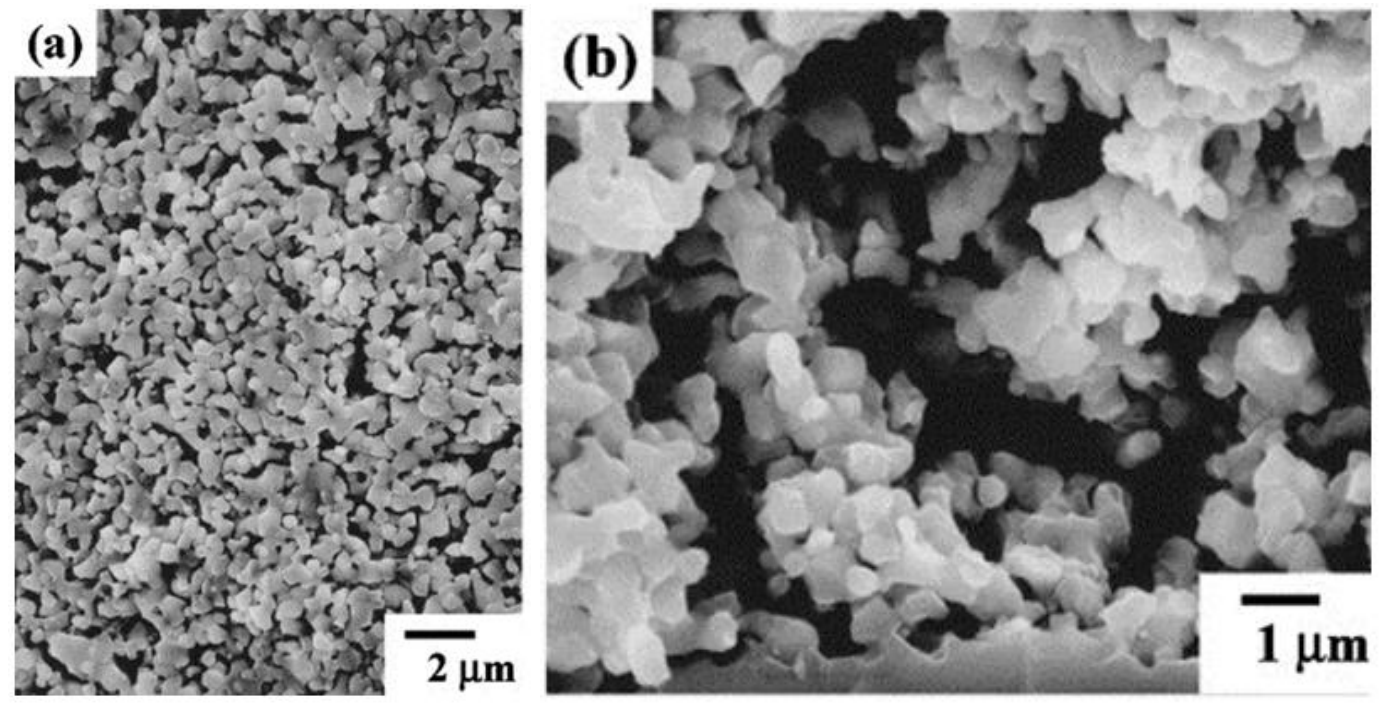

Fig. 2.2 SEM pictures of the surface and cross section of Ni/YSZ cermet anode, surface (a) and cross-section (b).[2]

However, Ni/YSZ anode degrades in hydrocarbon and impurity containing syngas quickly due to coking and poisoning by contaminants such as $\mathrm{S}$ as shown in Fig. 2.3 and 2.4. To operate this anode on $\mathrm{CH}_{4}, \mathrm{CH}_{4}$ needs to be reformed externally or internally with high vapor content in the feeding gas. Fuel containing a few $\mathrm{ppm}_{2} \mathrm{~S}$ which is common in the natural gases, can also kill $\mathrm{Ni}$ by physical and/or chemical adsorption of $\mathrm{H}_{2} \mathrm{~S}$ on the surface and the sulfidation of Ni.[3] Various strategies have been developed to eliminate those detrimental effects when using $\mathrm{Ni}$ in hydrocarbon fuels, including coating $\mathrm{Ni}$ with $\mathrm{CeO}_{2}$-based material, replacing $\mathrm{Ni}$ with 
$\mathrm{Cu}$ or other oxide materials and etc.[4] Those approaches are effective in certain extent but also suffer from particular drawbacks. For example, $\mathrm{CeO}_{2}$-based deposits protect the activity of $\mathrm{Ni}$ by adsorption and reaction with sulfur. The consumption of $\mathrm{CeO}_{2}$ hints it is not a solution once and for all. $\mathrm{Cu}$ displays much better coking-resistance than $\mathrm{Ni}$, which probably originates from the inert nature of $\mathrm{Cu}$ in catalyzing the $\mathrm{C}-\mathrm{H}$ bond. In that case, it is not surprising to find low catalytic activity of $\mathrm{Cu}$ in boosting the oxidation reaction of hydrocarbon. Cu-based anode always requires extra catalyst to be added in to promote the kinetics, which by itself will be another major investigation interest in SOFC. Another drawback associated with $\mathrm{Cu}$ metal anode is the degradation at high temperature owing to the propensity of $\mathrm{Cu}$ coarsening, usually leading to damage in the electronic conducting network and then increasing in anode ohmic resistance. Therefore, exploration of novel alternative materials to overcome these barriers of the conventional Ni-YSZ anode is of significance in furthering the progress of SOFC application.
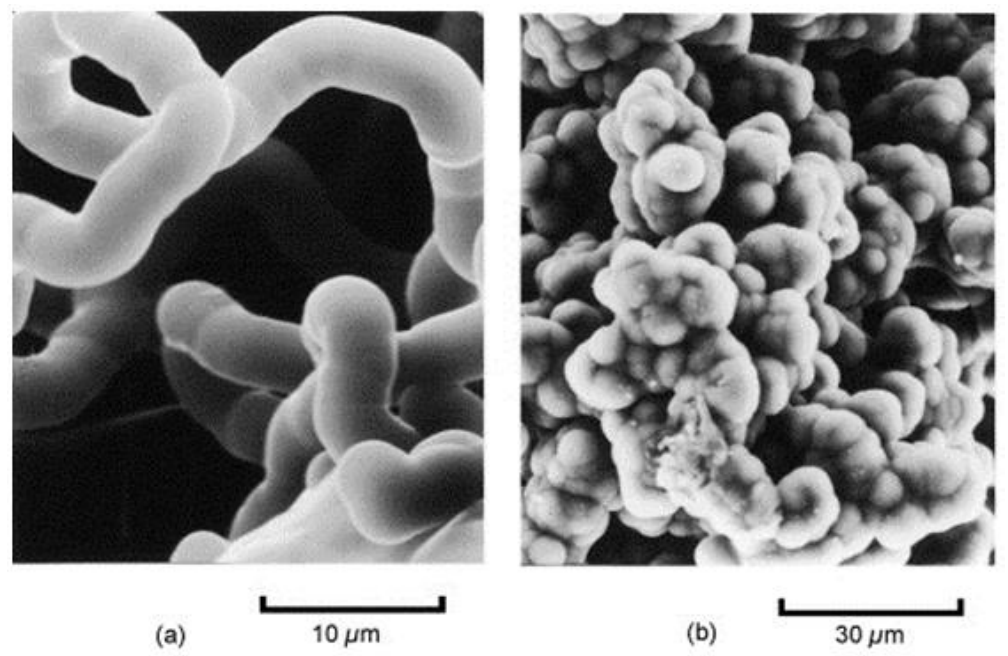

Fig. 2.3 Deposited carbon on Ni-YSZ cermet: (a) carbon fiber, (b) Ni-YSZ cermet.[5] 


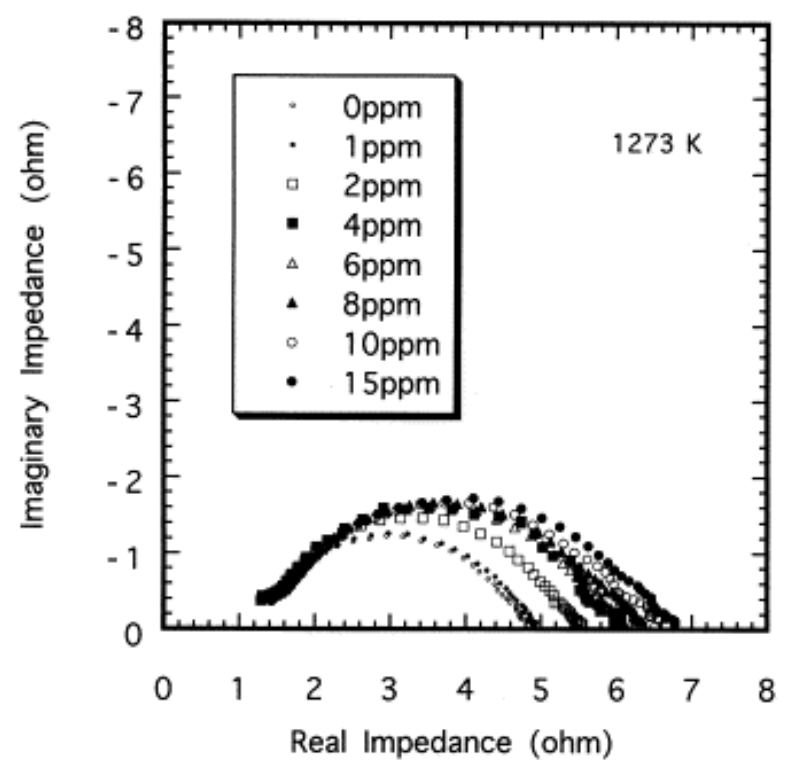

Fig. 2.4 Increasing of polarization resistance of $\mathrm{Ni} / \mathrm{YSZ}$ anode at $1000^{\circ} \mathrm{C}$ with different concentration of $\mathrm{H}_{2} \mathrm{~S}$ added into $79 \% \mathrm{H}_{2}+21 \% \mathrm{H}_{2} \mathrm{O}$ fuel.[6]

\subsubsection{Perovskite oxide anodes}

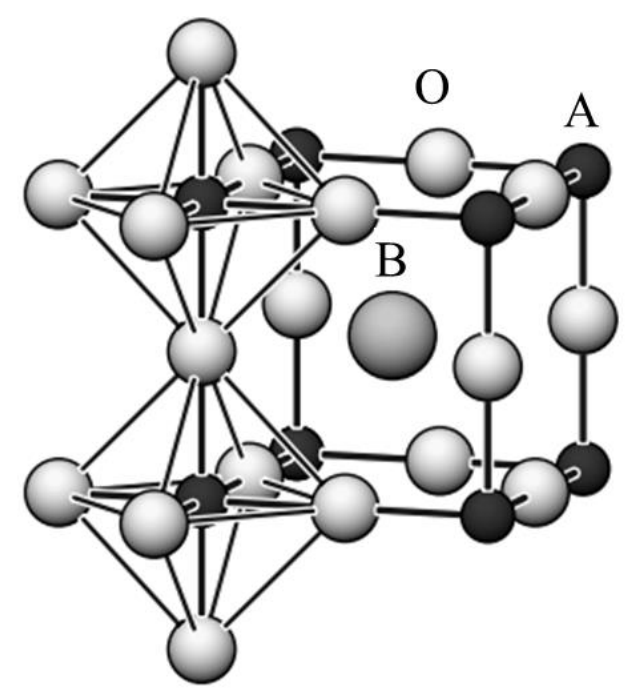

Fig. 2.5 Schematic diagram of $\mathrm{ABO}_{3}$ perovskite structure.

Due to the flexible choices at A and B sites with respect to not only wide size variety but also different valence combination, perovskite oxides are largely adjustable in terms of the 
electronic, ionic conductivities, TEC, catalytic properties, chemical stability and etc.[7] The schematic representation of the lattice structure of perovskite is shown in Fig. 2.5. The A site is usually rare earth elements with bigger radii, B site element transition metals with small radii. The big tolerance of oxygen vacancy in the lattice entitles such structure with interesting transport property. The stability of perovskite towards $P_{\mathrm{O} 2}$ mainly depends on the B site elements as rare and alkaline earth elements are relatively more stable. To accommodate the stability requirement of the anode site, $\mathrm{Ti}, \mathrm{V}$ and $\mathrm{Cr}$ are the most suitable choices for the $\mathrm{B}$ site. At $1000^{\circ} \mathrm{C}$, the decomposing $P_{\mathrm{O} 2}$ is $10^{-15}, 10^{-17}, 10^{-7}$ and $10^{-1}$ for $\mathrm{Mn}, \mathrm{Fe}$, Co and Ni respectively,[89] which are too high to be used at anode in large amount. But $\mathrm{LnTiO}_{3}$ and $\mathrm{LnCrO}_{3}$ keep unchanged in the testing $P_{\mathrm{O} 2}$ range down to $10^{-22}$.[8]

Titanates---Titanates show intrinsic n-type conductivity which increases with decreasing $P_{\mathrm{O} 2}$. Generally oxide materials fall far back compared to metal in terms of electronic conductivity even at SOFC operation temperature. Titanate conducts electron by the redox of $\mathrm{Ti}^{3+} / \mathrm{Ti}^{4+}$ in small-polaron hopping mechanism. $\mathrm{SrTiO}_{3}$ possesses marginal electronic conductivity due to the lack of intrinsic electron carriers; therefore it serves as parent material for modification. La is the most popular Sr-site dopant due to the similar atom size and yields apparent improvement. Although $(\mathrm{LaSr}) \mathrm{TiO}_{3}$ system exhibits $1 \sim 4 \mathrm{~S} / \mathrm{cm}$ when sintered in air, it increases to the order of $1000 \mathrm{~S} / \mathrm{cm}$ when sintered in $\mathrm{H}_{2}$.[10] The summary of electrical conductivities of titanate with different dopant choices and levels are presented in Table 2.1. 
Table 2.1 Electrical conductivities of titanate-based perovskites.

\begin{tabular}{|c|c|c|c|}
\hline \multirow{2}{*}{ Sample composition } & \multicolumn{2}{|c|}{ Electrical conductivities (S/cm) } & \multirow{2}{*}{ Ref. } \\
\hline & Reducing & oxidizing & \\
\hline $\mathrm{La}_{0.1} \mathrm{Sr}_{0.9} \mathrm{TiO}_{3}$ & $3\left(1000^{\circ} \mathrm{C}\right)$ & $1\left(1000^{\circ} \mathrm{C}\right)$ & [11] \\
\hline $\mathrm{La}_{0.1} \mathrm{Sr}_{0.9} \mathrm{TiO}_{3}(\mathrm{R})$ & $80\left(1000^{\circ} \mathrm{C}\right)$ & $0.004\left(1000^{\circ} \mathrm{C}\right)$ & [11] \\
\hline $\mathrm{La}_{0.2} \mathrm{Sr}_{0.8} \mathrm{TiO}_{3}$ & $3\left(1000^{\circ} \mathrm{C}\right)$ & $1\left(1000^{\circ} \mathrm{C}\right)$ & [11] \\
\hline $\mathrm{La}_{0.2} \mathrm{Sr}_{0.8} \mathrm{TiO}_{3}(\mathrm{R})$ & $200\left(1000^{\circ} \mathrm{C}\right)$ & $0.03\left(1000^{\circ} \mathrm{C}\right)$ & [11] \\
\hline $\mathrm{La}_{0.3} \mathrm{Sr}_{0.7} \mathrm{TiO}_{3}$ & $4\left(1000^{\circ} \mathrm{C}\right)$ & $1.3\left(1000^{\circ} \mathrm{C}\right)$ & [11] \\
\hline $\mathrm{La}_{0.3} \mathrm{Sr}_{0.7} \mathrm{TiO}_{3}(\mathrm{R})$ & $200\left(1000^{\circ} \mathrm{C}\right)$ & $0.01\left(1000^{\circ} \mathrm{C}\right)$ & [11] \\
\hline $\mathrm{La}_{0.4} \mathrm{Sr}_{0.6} \mathrm{TiO}_{3}$ & $16\left(1000^{\circ} \mathrm{C}\right)$ & $0.004\left(1000^{\circ} \mathrm{C}\right)$ & [11] \\
\hline $\mathrm{La}_{0.4} \mathrm{Sr}_{0.6} \mathrm{TiO}_{3}(\mathrm{R})$ & $360\left(1000^{\circ} \mathrm{C}\right)$ & $0.03\left(1000^{\circ} \mathrm{C}\right)$ & [11] \\
\hline $\mathrm{SrTi}_{0.99} \mathrm{Nb}_{0.01} \mathrm{O}_{3}$ & $0.4\left(800^{\circ} \mathrm{C}\right)$ & $0.06\left(800^{\circ} \mathrm{C}\right)$ & [12] \\
\hline $\mathrm{SrTi}_{1.09} \mathrm{Nb}_{0.01} \mathrm{O}_{3}$ & $0.16\left(800^{\circ} \mathrm{C}\right)$ & $0.16\left(800^{\circ} \mathrm{C}\right)$ & [12] \\
\hline $\mathrm{La}_{0.4} \mathrm{Sr}_{0.6} \mathrm{TiO}_{3}$ & $1\left(800^{\circ} \mathrm{C}\right)$ & $2 \times 10^{-5}\left(800^{\circ} \mathrm{C}\right)$ & [13] \\
\hline $\mathrm{La}_{0.4} \mathrm{Sr}_{0.6} \mathrm{Ti}_{0.8} \mathrm{Mn}_{0.2} \mathrm{O}_{3}$ & $0.1\left(800^{\circ} \mathrm{C}\right)$ & $2 \times 10^{-2}\left(800^{\circ} \mathrm{C}\right)$ & {$[13]$} \\
\hline $\mathrm{La}_{0.4} \mathrm{Sr}_{0.6} \mathrm{Ti}_{0.6} \mathrm{Mn}_{0.4} \mathrm{O}_{3}$ & $0.1\left(800^{\circ} \mathrm{C}\right)$ & $2\left(800^{\circ} \mathrm{C}\right)$ & [13] \\
\hline $\mathrm{La}_{0.4} \mathrm{Sr}_{0.6} \mathrm{Ti}_{0.4} \mathrm{Mn}_{0.6} \mathrm{O}_{3}$ & $2\left(800^{\circ} \mathrm{C}\right)$ & $20\left(800^{\circ} \mathrm{C}\right)$ & [13] \\
\hline $\mathrm{Y}_{0.08} \mathrm{Sr}_{0.92} \mathrm{Fe}_{0.2} \mathrm{Ti}_{0.8} \mathrm{O}_{3}$ & $0.08\left(700^{\circ} \mathrm{C}\right)$ & $0.14\left(700^{\circ} \mathrm{C}\right)$ & {$[14]$} \\
\hline $\mathrm{Y}_{0.08} \mathrm{Sr}_{0.92} \mathrm{Fe}_{0.4} \mathrm{Ti}_{0.6} \mathrm{O}_{3}$ & $0.11\left(700^{\circ} \mathrm{C}\right)$ & $0.03\left(700^{\circ} \mathrm{C}\right)$ & [14] \\
\hline $\mathrm{Sr}_{0.85} \mathrm{Y}_{0.15} \mathrm{Ti}_{0.95} \mathrm{Ca}_{0.05} \mathrm{O}_{3}$ & $37\left(800^{\circ} \mathrm{C}\right)$ & - & [15] \\
\hline $\mathrm{Sr}_{0.85} \mathrm{Y}_{0.15} \mathrm{Ti}_{0.95} \mathrm{Co}_{0.05} \mathrm{O}_{3}$ & $45\left(800^{\circ} \mathrm{C}\right)$ & - & [15] \\
\hline $\mathrm{Sr}_{0.85} \mathrm{Y}_{0.15} \mathrm{Ti}_{0.95} \mathrm{Zn}_{0.05} \mathrm{O}_{3}$ & $13\left(800^{\circ} \mathrm{C}\right)$ & - & [15] \\
\hline $\mathrm{Sr}_{0.85} \mathrm{Y}_{0.15} \mathrm{Ti}_{0.95} \mathrm{Mn}_{0.05} \mathrm{O}_{3}$ & $6\left(800^{\circ} \mathrm{C}\right)$ & - & [15] \\
\hline $\mathrm{Sr}_{0.88} \mathrm{Y}_{0.08} \mathrm{TiO}_{3}$ & $64\left(800^{\circ} \mathrm{C}\right)$ & - & [15] \\
\hline $\mathrm{La}_{4} \mathrm{Sr}_{8} \mathrm{Ti}_{11} \mathrm{MnO}_{38-\delta}$ & $7.8\left(900^{\circ} \mathrm{C}\right)$ & - & [16] \\
\hline $\mathrm{La}_{4} \mathrm{Sr}_{8} \mathrm{Ti}_{11} \mathrm{Mn}_{0.25} \mathrm{Ga}_{0.75} \mathrm{O}_{38-\delta}$ & $7\left(900^{\circ} \mathrm{C}\right)$ & - & [16] \\
\hline $\mathrm{La}_{4} \mathrm{Sr}_{8} \mathrm{Ti}_{11} \mathrm{Mn}_{0.5} \mathrm{Ga}_{0.5} \mathrm{O}_{38-\delta}$ & $0.9\left(900^{\circ} \mathrm{C}\right)$ & $0.001\left(900^{\circ} \mathrm{C}\right)$ & {$[17]$} \\
\hline $\mathrm{La}_{4} \mathrm{Sr}_{8} \mathrm{Ti}_{11} \mathrm{Mn}_{0.75} \mathrm{Ga}_{0.25} \mathrm{O}_{38-\delta}$ & $7.7\left(900^{\circ} \mathrm{C}\right)$ & - & [16] \\
\hline $\mathrm{La}_{4} \mathrm{Sr}_{8} \mathrm{Ti}_{11} \mathrm{GaO}_{38-\delta}$ & $6.8\left(900^{\circ} \mathrm{C}\right)$ & - & [16] \\
\hline $\mathrm{La}_{0.33} \mathrm{Sr}_{0.67} \mathrm{Ti}_{0.92} \mathrm{Mn}_{0.08} \mathrm{O}_{3}$ & $5.1\left(870^{\circ} \mathrm{C}\right)$ & - & {$[18]$} \\
\hline $\mathrm{La}_{0.33} \mathrm{Sr}_{0.67} \mathrm{Ti}_{0.92} \mathrm{Mn}_{0.08} \mathrm{O}_{3}$ & $0.3\left(870^{\circ} \mathrm{C}\right)$ & - & [18] \\
\hline $\mathrm{La}_{0.33} \mathrm{Sr}_{0.67} \mathrm{Ti}_{0.92} \mathrm{Mn}_{0.08} \mathrm{O}_{3}$ & $0.6\left(870^{\circ} \mathrm{C}\right)$ & - & [18] \\
\hline $\mathrm{La}_{0.33} \mathrm{Sr}_{0.67} \mathrm{Ti}_{0.92} \mathrm{Mn}_{0.08} \mathrm{O}_{3}$ & $2\left(870^{\circ} \mathrm{C}\right)$ & - & [18] \\
\hline $\mathrm{La}_{0.33} \mathrm{Sr}_{0.67} \mathrm{Ti}_{0.92} \mathrm{Mn}_{0.08} \mathrm{O}_{3}$ & $7.3\left(870^{\circ} \mathrm{C}\right)$ & - & [18] \\
\hline $\mathrm{La}_{0.33} \mathrm{Sr}_{0.67} \mathrm{Ti}_{0.92} \mathrm{Mn}_{0.08} \mathrm{O}_{3}$ & $1.8\left(870^{\circ} \mathrm{C}\right)$ & - & [18] \\
\hline $\mathrm{La}_{0.33} \mathrm{Sr}_{0.67} \mathrm{Ti}_{0.92} \mathrm{Mn}_{0.08} \mathrm{O}_{3}$ & $6.8\left(870^{\circ} \mathrm{C}\right)$ & - & [18] \\
\hline
\end{tabular}

Note: (R) sample prepared in reducing atmospheres. 
Although titanate usually shows fair electrical conductivity, the catalytic activity is limited. The maximum power density (MPD) for a $\mathrm{La}_{0.4} \mathrm{Sr}_{0.6} \mathrm{TiO}_{3}$ anode with YSZ electrolyte reaches only $25 \mathrm{~mW} / \mathrm{cm}^{2}$ at $900^{\circ} \mathrm{C}$ in $\mathrm{H}_{2}$.[10] Due to the stability of $\mathrm{Ti}$, very few oxygen vacancies are present in the lattice, which limits the role of LST to a pure electron conducting phase without much catalytic activity. On the other hand, Ti-site substitution can be adopted to improve such drawback in some extent. Multiple elements have been tried in $(\mathrm{LaSr}) \mathrm{TiMO}_{3}$ (M=Al, Fe, Ga, Mg, Mn and Sc).[18] In the blanket study of B-site dopants, it was verified that the anode kinetics is heavily affected, with Sc-doped LST compound yielding the best performance. Table 2.2 summarizes the performance of titanate anodes operated in $\mathrm{H}_{2}$ and $\mathrm{CH}_{4}$. Even though advances are progressively made as can be seen, more optimization on the performance still need to be carried out before those compounds can be used.

Table 2.2 Electrode performance from titanates in $\mathrm{H}_{2}$ and $\mathrm{CH}_{4}$.

\begin{tabular}{|c|c|c|c|}
\hline \multirow{2}{*}{ Sample composition } & \multicolumn{2}{|c|}{ Polarization resistance $\left(\Omega \mathrm{cm}^{2}\right)$} & \multirow[t]{2}{*}{ Ref. } \\
\hline & $\mathrm{H}_{2}$ & $\mathrm{CH}_{4}$ & \\
\hline $\mathrm{La}_{0.4} \mathrm{Sr}_{0.6} \mathrm{Ti}_{0.6} \mathrm{Mn}_{0.4} \mathrm{O}_{3}(\mathrm{C})$ & $0.35\left(855^{\circ} \mathrm{C}\right)$ & $0.8\left(855^{\circ} \mathrm{C}\right)$ & {$[13]$} \\
\hline $\mathrm{La}_{2} \mathrm{Sr}_{4} \mathrm{Ti}_{6} \mathrm{O}_{18}$ & $2.97\left(900^{\circ} \mathrm{C}\right)$ & $8.93\left(900^{\circ} \mathrm{C}\right)$ & {$[19]$} \\
\hline $\mathrm{La}_{4} \mathrm{Sr}_{8} \mathrm{Ti}_{11} \mathrm{MnO}_{38-\delta}(\mathrm{C})$ & $0.3\left(950^{\circ} \mathrm{C}\right)$ & $0.7\left(950^{\circ} \mathrm{C}\right)$ & {$[20]$} \\
\hline $\mathrm{La}_{4} \mathrm{Sr}_{8} \mathrm{Ti}_{11} \mathrm{Mn}_{0.5} \mathrm{Ga}_{0.5} \mathrm{O}_{38-\delta}(\mathrm{C})$ & $0.2\left(900^{\circ} \mathrm{C}\right)$ & $0.57\left(900^{\circ} \mathrm{C}\right)$ & {$[17]$} \\
\hline $\mathrm{La}_{2} \mathrm{Sr}_{4} \mathrm{Ti}_{5.7} \mathrm{Sc}_{0.3} \mathrm{O}_{19-\delta}(\mathrm{R})$ & $0.5\left(900^{\circ} \mathrm{C}\right)$ & $1.2\left(900^{\circ} \mathrm{C}\right)$ & {$[21]$} \\
\hline $\mathrm{La}_{2} \mathrm{Sr}_{4} \mathrm{Ti}_{5.5} \mathrm{Sc}_{0.5} \mathrm{O}_{19-\delta}(\mathrm{R})$ & $1.4\left(900^{\circ} \mathrm{C}\right)$ & $4.1\left(900^{\circ} \mathrm{C}\right)$ & {$[21]$} \\
\hline $\mathrm{La}_{0.1} \mathrm{Sr}_{0.9} \mathrm{TiO}_{3}(\mathrm{R})$ & $510\left(800^{\circ} \mathrm{C}\right)$ & - & {$[22]$} \\
\hline $\mathrm{La}_{0.2} \mathrm{Sr}_{0.8} \mathrm{TiO}_{3}(\mathrm{R})$ & $350\left(800^{\circ} \mathrm{C}\right)$ & - & {$[22]$} \\
\hline $\mathrm{SrTi}_{0.97} \mathrm{Nb}_{0.03} \mathrm{O}_{3}$ & $700\left(800^{\circ} \mathrm{C}\right)$ & - & {$[22]$} \\
\hline
\end{tabular}




\begin{tabular}{|c|c|c|c|}
\hline $\mathrm{Sr}_{0.94} \mathrm{Ti}_{0.9} \mathrm{Nb}_{0.1} \mathrm{O}_{3}(\mathrm{C})$ & $52\left(850^{\circ} \mathrm{C}\right)$ & - & [23] \\
\hline $\mathrm{Sr}_{0.88} \mathrm{Y}_{0.08} \mathrm{TiO}_{3}(\mathrm{C})$ & $2.9\left(800^{\circ} \mathrm{C}\right)$ & - & [24] \\
\hline $\mathrm{Sr}_{0.9} \mathrm{Ti}_{0.8-\mathrm{x}} \mathrm{Ga}_{\mathrm{x}} \mathrm{Nb}_{0.2} \mathrm{O}_{3}(\mathrm{R})$ & $1.3\left(800^{\circ} \mathrm{C}\right)$ & - & {$[25]$} \\
\hline $\mathrm{La}_{0.33} \mathrm{Sr}_{0.67} \mathrm{TiO}_{3}(\mathrm{C})$ & $1.4\left(850^{\circ} \mathrm{C}\right)$ & - & [18] \\
\hline $\mathrm{La}_{0.33} \mathrm{Sr}_{0.67} \mathrm{Ti}_{0.92} \mathrm{Mn}_{0.08} \mathrm{O}_{3}(\mathrm{C})$ & $5.5\left(850^{\circ} \mathrm{C}\right)$ & - & {$[18]$} \\
\hline $\mathrm{La}_{0.33} \mathrm{Sr}_{0.67} \mathrm{Ti}_{0.92} \mathrm{Fe}_{0.08} \mathrm{O}_{3}(\mathrm{C})$ & $4.8\left(850^{\circ} \mathrm{C}\right)$ & - & {$[18]$} \\
\hline $\mathrm{La}_{0.33} \mathrm{Sr}_{0.67} \mathrm{Ti}_{0.92} \mathrm{Al}_{0.08} \mathrm{O}_{3}(\mathrm{C})$ & $3.7\left(850^{\circ} \mathrm{C}\right)$ & - & {$[18]$} \\
\hline $\mathrm{La}_{0.33} \mathrm{Sr}_{0.67} \mathrm{Ti}_{0.92} \mathrm{Mg}_{0.08} \mathrm{O}_{3}(\mathrm{C})$ & $26\left(850^{\circ} \mathrm{C}\right)$ & - & {$[18]$} \\
\hline $\mathrm{La}_{0.33} \mathrm{Sr}_{0.67} \mathrm{Ti}_{0.92} \mathrm{Ga}_{0.08} \mathrm{O}_{3}(\mathrm{C})$ & $2.9\left(850^{\circ} \mathrm{C}\right)$ & - & {$[18]$} \\
\hline $\mathrm{La}_{0.33} \mathrm{Sr}_{0.67} \mathrm{Ti}_{0.92} \mathrm{Sc}_{0.08} \mathrm{O}_{3}(\mathrm{C})$ & $2.9\left(850^{\circ} \mathrm{C}\right)$ & - & {$[18]$} \\
\hline
\end{tabular}

Note: (R) sample prepared in reducing atmospheres, (C) composite anode used.

Vanadate---vanadate stands out by the even better electrical conductivity. $\mathrm{SrVO}_{3}$ shows metallic conductivity behavior and reaches $\sim 1000 \mathrm{~S} / \mathrm{cm}$ at peak value. La partially substituted strontium vanadate $\left(\mathrm{La}_{1-\mathrm{x}} \mathrm{Sr}_{\mathrm{x}} \mathrm{VO}_{3}, \mathrm{LSV}\right)$ display electrical conductivities in the range of 100 10000 S/cm in the fuel cell operation temperature. The electrical conductivities of various V-based perovskites are summarized in Table 2.3. Such excellent property guarantees wide investigation on those compounds aiming for anode candidate. Due to the multivalent of vanadium cations from +2 to +5 , several compositions exists for vanadate depending on the synthesis conditions. When synthesized in air, $\mathrm{AV}_{2} \mathrm{O}_{7}$ is the most common product.[26-27] Orthovanadate is usually formed in the modestly oxidizing atmosphere.[28-29] For the viable structure that can be used in $\mathrm{SOFC}, \mathrm{AVO}_{3}$ perovskite needs to be synthesized under reducing gases. In our previous experimental study on LSV, it was formed in $5 \% \mathrm{H}_{2}$ balanced by argon gas at $1250^{\circ} \mathrm{C}$. The composition $\mathrm{La}_{0.8} \mathrm{Sr}_{0.2} \mathrm{VO}_{3}$ possesses an electrical conductivity of $\sim 800 \mathrm{~S} / \mathrm{cm}$ 
at peak value. Nevertheless, such perovskite structure as prepared is highly susceptible to oxidizing atmosphere, and can be easily oxidized back to the original oxides with $\mathrm{V}$ being +5 at the operation temperature. This process is irreversible at the same temperature even with $\mathrm{H}_{2}$ fed to the anode. The propensity of vanadate to stay in higher oxidation state places strict requirement in the synthesis, cell assembling and operation process in terms of $P_{\mathrm{O} 2}$ control.

LSV produces proper anode performance in $\mathrm{H}_{2}$ and $\mathrm{CH}_{4} . R_{\mathrm{p}}$ of $9 \Omega \mathrm{cm}^{2}$ is obtained on the LSV anode at $900^{\circ} \mathrm{C}$.[30] Interesting enough about such compound is the tendency shown by LSV towards the catalytic oxidation of $\mathrm{H}_{2} \mathrm{~S}$. It was reported that the performance of full cell with $\mathrm{H}_{2}$ can be increased from $\sim 50$ to $\sim 200 \mathrm{~mW} / \mathrm{cm}^{2}$ by mixing $5 \% \mathrm{H}_{2} \mathrm{~S}$ to it. The selectivity of LSV on $\mathrm{H}_{2} \mathrm{~S}$ and the corresponding constructive performance results make $\mathrm{ABO}_{3}$ vanadate promising sulfur-tolerant anode nominees or electrocatalyst decoration for the traditional anode. In the end, compared to the performance concerns, perhaps the more severe problem associated with vanadate is the high susceptibility to oxidizing atmospheres.

Table 2.3 Electrical conductivities of vanadate-based perovskites.

\begin{tabular}{llll}
\hline \multirow{2}{*}{ Sample composition } & \multicolumn{2}{l}{ Electrical conductivities $(\mathrm{S} / \mathrm{cm})$} & - Ref. \\
& Reducing & oxidizing & [31] \\
\hline $\mathrm{La}_{0.7} \mathrm{Sr}_{0.3} \mathrm{VO}_{3}$ & $120\left(800^{\circ} \mathrm{C}\right)$ & $300\left(25^{\circ} \mathrm{C}\right)$ & {$[31]$} \\
$\mathrm{La}_{0.8} \mathrm{Sr}_{0.2} \mathrm{VO}_{3}$ & $45\left(800^{\circ} \mathrm{C}\right)$ & $120\left(25^{\circ} \mathrm{C}\right)$ & {$[31]$} \\
$\mathrm{La}_{0.9} \mathrm{VO}_{3}$ & $2.9\left(800^{\circ} \mathrm{C}\right)$ & $3.3\left(25^{\circ} \mathrm{C}\right)$ & {$[32]$} \\
$\mathrm{CaV}_{0.5} \mathrm{Mo}_{0.5} \mathrm{O}_{3}$ & $500-1800\left(25-800^{\circ} \mathrm{C}\right)$ & $10^{-5}-10^{-4}\left(800-900^{\circ} \mathrm{C}\right)$ & {$[33]$} \\
$\mathrm{SrV}_{0.5} \mathrm{Mo}_{0.5} \mathrm{O}_{3}$ & $280-450\left(25-900^{\circ} \mathrm{C}\right)$ & $10^{-9}-10^{-5}\left(500-950^{\circ} \mathrm{C}\right)$ & \\
\hline \hline
\end{tabular}




\begin{tabular}{llll}
\hline $\mathrm{Ce}_{1-\mathrm{x}} \mathrm{Ca}_{\mathrm{x}} \mathrm{VO} 3(\mathrm{x}=0.1,0.2$, & \multicolumn{1}{c}{${ }^{\circ}$} & $10^{-3}\left(700^{\circ} \mathrm{C}\right)$ & {$[34]$} \\
$0.3,0.4)$ & $2-13(700 \mathrm{C})$ & $15\left(700^{\circ} \mathrm{C}\right)$ & {$[35]$} \\
$\mathrm{Ce}_{0.85} \mathrm{Sr}_{0.15} \mathrm{VO}_{3}$ & $2.7\left(700^{\circ} \mathrm{C}\right)$ & - & {$[35]$} \\
$\mathrm{CeVO}_{3}$ & $0.09\left(600^{\circ} \mathrm{C}\right)$ & - & {$[36]$} \\
$\mathrm{Ce}_{0.9} \mathrm{Sr}_{0.1} \mathrm{~V}_{0.5} \mathrm{Cr}_{0.5} \mathrm{O}_{3}$ & $6.5\left(850^{\circ} \mathrm{C}\right)$ & - & {$[37]$} \\
$\mathrm{SrVO}_{3}$ & $800\left(800^{\circ} \mathrm{C}\right)$ & - & {$[37]$} \\
$\mathrm{La}_{0.3} \mathrm{Sr}_{0.7} \mathrm{VO}_{3}$ & $770\left(800^{\circ} \mathrm{C}\right)$ & - & {$[37]$} \\
$\mathrm{La}_{0.5} \mathrm{Sr}_{0.5} \mathrm{VO}_{3}$ & $300\left(800^{\circ} \mathrm{C}\right)$ & - & {$[37]$} \\
$\mathrm{La}_{0.7} \mathrm{Sr}_{0.3} \mathrm{VO}_{3}$ & $150\left(800^{\circ} \mathrm{C}\right)$ & - & {$[37]$} \\
$\mathrm{LaVO}_{3}$ & $5.5\left(800^{\circ} \mathrm{C}\right)$ & - & {$[38]$} \\
$\mathrm{Ce}_{0.9} \mathrm{Sr}_{0.1} \mathrm{VO}_{3}$ & $0.4\left(700^{\circ} \mathrm{C}\right)$ & & \\
\hline
\end{tabular}

Chromites---Due to the strong preference of 6-coordination in the octahedron, chromites display an extremely good stability towards a wide range of $P_{\mathrm{O} 2}$, enabling the possibility of being used as oxide anode candidate. Doped lanthanum chromites [39-42] have been investigated extensively as interconnect in the first place due to the high electronic conductivity at both oxidizing and reducing atmospheres. However, poor catalytic activity was found on those electronic conductors if no further modification is made. For instance, a polarization resistance of $\sim 90 \Omega \mathrm{cm}^{2}$ was obtained on $\mathrm{LaCaCrO}_{3}$ at $850^{\circ} \mathrm{C}$ in $\mathrm{H}_{2}$.[43] Decoration with transition metal at B site is necessary from a viewpoint of practical application. $\mathrm{La}(\mathrm{CrM}) \mathrm{O}_{3}(\mathrm{M}=\mathrm{Mn}, \mathrm{Fe}, \mathrm{Co}, \mathrm{Ni})$ have been prepared and examined for the catalytic activity on hydrocarbon fuels.[44] Most of the compound display good coking resistance, expect for Fe. Carbon deposition was found on the surface of electrode grains under SEM when running $\mathrm{LaSrCrFeO}_{3}$ in $\mathrm{CH}_{4}$-containing gases at temperature over $900^{\circ} \mathrm{C}$. Of those dopants, $\mathrm{Ni}$ showed best results towards $\mathrm{CH}_{4}$ oxidation. However, one concern associated with B site doping is the exsolution of dopant element under reducing atmosphere. It has been documented by Arai et al.[45] in the perovskite catalyzing CO 
oxidation studies that the activity of perovskite in the oxidation of $\mathrm{CO}, \mathrm{CH}_{4}$ was less influenced by the nature of the fuels, but mainly hinged on the redox ability of the B site element, which was essentially correlated to the reducibility as long as another critical criteria are met. In this sense, high catalytic activity generally coincides with the less stability in the operation conditions. Indeed, it has been reported that $\mathrm{Co}$ and Fe exsolution were observed when treated in reducing conditions for a prolonged period of time. The reducibility of those dopants ranges in order $\mathrm{Ni}<\mathrm{Co}<\mathrm{Fe}<\mathrm{Mn}$.[8] Due to such phenomenon, the amount of substitutes is highly limited as far as the long-term operation is concerned. Of those choices, Mn shows a wider level substitution without giving rise to immediate stability concern. But small amount of Mn has not promoted such material to a new level with high performance. The polarization resistance of $\mathrm{La}_{0.8} \mathrm{Sr}_{0.2} \mathrm{Cr}_{0.8} \mathrm{Mn}_{0.2} \mathrm{O}_{3}$ in wet $\mathrm{H}_{2}$ turns out to be $\sim 50 \Omega \mathrm{cm}^{2}$ at $850^{\circ} \mathrm{C}$.[46] However, the turning point appears when increasing $\mathrm{Mn}$ level to $50 \%$ percent. $\mathrm{La}_{0.8} \mathrm{Sr}_{0.2} \mathrm{Cr}_{0.5} \mathrm{Mn}_{0.5} \mathrm{O}_{3-\delta}$ (LSCM) as specific recipe has been proposed by Tao et al,[39] and shown a relatively encouraging performance among those oxide anodes. $R_{\mathrm{p}}$ of 0.5 and $0.8 \Omega \mathrm{cm}^{2}$ was achieved in wet $\mathrm{H}_{2}$ and $\mathrm{CH}_{4}$ at $900^{\circ} \mathrm{C}$ respectively. It also shows good stability towards both wet $\mathrm{H}_{2}$ and $\mathrm{CH}_{4}$ atmospheres. Though comparatively good electrode performances were obtained with YSZ/LSGM electrolytes on methane, the output without any addition of noble metal or $\mathrm{CeO}_{2}$ is still far from the acceptable level for practical application. Another weakness of such material is the intrinsic ptype conductivity, which means lower electrical conductivity will be yielded at reducing condition compared to the oxidizing atmosphere owing to the consumption of holes by the formation of oxygen vacancy. It is reported to be $\sim 30 \mathrm{~S} / \mathrm{cm}$ for air but reduces to $\sim 1 \mathrm{~S} / \mathrm{cm}$ in $\mathrm{H}_{2}$. Low conductivity as such basically deprives it of being used as anode-supported cell. Table 2.4 summarizes the electrical conductivity of Cr-based perovskites. To overcome such difficulty, $\mathrm{Cu}$ 
is brought forth as additive to enhance the conductivity. A maximum output of $520 \mathrm{~mW} / \mathrm{cm}^{2}$ in $\mathrm{CH}_{4}$ was achieved in the Cu-LSCM anode.[47] Other strategies to make use of the merit of LSCM include impregnation to the Ni/YSZ anode backbone, or co-impregnation of Ni, LSCM to achieve resistance towards coking but meanwhile retain the requested electrode performance.[48-49] Table 2.5 displays the performance of $\mathrm{Cr}$ perovskites in $\mathrm{H}_{2}$ and $\mathrm{CH}_{4}$.

Table 2.4 Electrical conductivities of chromite-based perovskites.

\begin{tabular}{|c|c|c|c|}
\hline \multirow{2}{*}{ Sample composition } & \multicolumn{2}{|c|}{ Electrical conductivities $(\mathrm{S} / \mathrm{cm})$} & \multirow{2}{*}{ Ref. } \\
\hline & Reducing & oxidizing & \\
\hline $\mathrm{LaCrO}_{3}$ & - & $0.34\left(700^{\circ} \mathrm{C}\right)$ & {$[50]$} \\
\hline $\mathrm{La}_{0.7} \mathrm{Mg}_{0.3} \mathrm{CrO}_{3}$ & $0.17\left(800^{\circ} \mathrm{C}\right)$ & $3.4\left(800^{\circ} \mathrm{C}\right)$ & {$[51]$} \\
\hline $\mathrm{La}_{0.75} \mathrm{Sr}_{0.25} \mathrm{CrO}_{3}$ & $7.1\left(800^{\circ} \mathrm{C}\right)$ & $59\left(800^{\circ} \mathrm{C}\right)$ & {$[51]$} \\
\hline $\mathrm{La}_{0.7} \mathrm{Ca}_{0.3} \mathrm{CrO}_{3}$ & $1.6\left(800^{\circ} \mathrm{C}\right)$ & $50\left(800^{\circ} \mathrm{C}\right)$ & {$[51]$} \\
\hline $\mathrm{La}_{0.7} \mathrm{Ba}_{0.3} \mathrm{CrO}_{3}$ & - & $2.7\left(800^{\circ} \mathrm{C}\right)$ & {$[51]$} \\
\hline $\mathrm{La}_{0.75} \mathrm{Sr}_{0.25} \mathrm{Cr}_{0.5} \mathrm{Mn}_{0.5} \mathrm{O}_{3}$ & $0.22\left(800^{\circ} \mathrm{C}\right)$ & $28.8\left(800^{\circ} \mathrm{C}\right)$ & {$[51]$} \\
\hline $\mathrm{La}_{0.8} \mathrm{Sr}_{0.2} \mathrm{Cr}_{0.5} \mathrm{Mn}_{0.5} \mathrm{O}_{3}$ & $1.3\left(900^{\circ} \mathrm{C}\right)$ & $38\left(900^{\circ} \mathrm{C}\right)$ & [41] \\
\hline $\mathrm{La}_{0.7} \mathrm{Sr}_{0.3} \mathrm{Cr}_{0.5} \mathrm{Ti}_{0.5} \mathrm{O}_{3}$ & $0.02\left(800^{\circ} \mathrm{C}\right)$ & - & {$[52]$} \\
\hline $\mathrm{La}_{0.95} \mathrm{Ca}_{0.05} \mathrm{Cr}_{0.5} \mathrm{Co}_{0.5} \mathrm{O}_{3}$ & - & $2.3\left(700^{\circ} \mathrm{C}\right)$ & {$[53]$} \\
\hline $\mathrm{La}_{0.95} \mathrm{Ca}_{0.05} \mathrm{Cr}_{0.8} \mathrm{Ni}_{0.2} \mathrm{O}_{3}$ & - & $63\left(700^{\circ} \mathrm{C}\right)$ & {$[50]$} \\
\hline $\mathrm{La}_{0.8} \mathrm{Ca}_{0.2} \mathrm{Cr}_{0.8} \mathrm{Fe}_{0.2} \mathrm{O}_{3}$ & - & $9.2\left(700^{\circ} \mathrm{C}\right)$ & {$[54]$} \\
\hline $\mathrm{La}_{0.8} \mathrm{Ca}_{0.2} \mathrm{Cr}_{0.5} \mathrm{Fe}_{0.5} \mathrm{O}_{3}$ & - & $6.8\left(700^{\circ} \mathrm{C}\right)$ & [54] \\
\hline $\mathrm{La}_{0.8} \mathrm{Ca}_{0.2} \mathrm{Cr}_{0.2} \mathrm{Fe}_{0.8} \mathrm{O}_{3}$ & - & $12\left(700^{\circ} \mathrm{C}\right)$ & {$[54]$} \\
\hline $\mathrm{La}_{0.85} \mathrm{Ca}_{0.15} \mathrm{Cr}_{0.8} \mathrm{Co}_{0.2} \mathrm{O}_{3}$ & - & $25\left(700^{\circ} \mathrm{C}\right)$ & {$[55]$} \\
\hline $\mathrm{La}_{0.85} \mathrm{Ca}_{0.15} \mathrm{Cr}_{0.5} \mathrm{Co}_{0.5} \mathrm{O}_{3}$ & - & $130\left(700^{\circ} \mathrm{C}\right)$ & {$[55]$} \\
\hline $\mathrm{La}_{0.85} \mathrm{Ca}_{0.15} \mathrm{Cr}_{0.2} \mathrm{Co}_{0.8} \mathrm{O}_{3}$ & - & $400\left(700^{\circ} \mathrm{C}\right)$ & {$[55]$} \\
\hline $\mathrm{LaCr}_{0.8} \mathrm{Ni}_{0.2} \mathrm{O}_{3}$ & - & $8.2\left(700^{\circ} \mathrm{C}\right)$ & {$[56]$} \\
\hline $\mathrm{LaCr}_{0.6} \mathrm{Ni}_{0.4} \mathrm{O}_{3}$ & - & $26\left(700^{\circ} \mathrm{C}\right)$ & {$[56]$} \\
\hline $\mathrm{LaCr}_{0.4} \mathrm{Ni}_{0.6} \mathrm{O}_{3}$ & - & $83\left(700^{\circ} \mathrm{C}\right)$ & [56] \\
\hline
\end{tabular}


Table 2.5 Electrode performance for chromites in $\mathrm{H}_{2}$ and $\mathrm{CH}_{4}$.

\begin{tabular}{|c|c|c|c|}
\hline \multirow{2}{*}{ Sample composition } & \multicolumn{2}{|c|}{ Polarization resistance $\left(\Omega \mathrm{cm}^{2}\right)$} & \multirow{2}{*}{ Ref. } \\
\hline & $\mathrm{H}_{2}$ & $\mathrm{CH}_{4}$ & \\
\hline $\mathrm{La}_{0.75} \mathrm{Ca}_{0.25} \mathrm{Cr}_{0.9} \mathrm{Mg}_{0.1} \mathrm{O}_{3}$ & $21\left(850^{\circ} \mathrm{C}\right)$ & - & [43] \\
\hline $\mathrm{La}_{0.7} \mathrm{Ca}_{0.32} \mathrm{CrO}_{3}$ & $86\left(850^{\circ} \mathrm{C}\right)$ & - & [43] \\
\hline $\mathrm{La}_{0.8} \mathrm{Sr}_{0.2} \mathrm{Cr}_{0.97} \mathrm{~V}_{0.03} \mathrm{O}_{3}$ & $5\left(850^{\circ} \mathrm{C}\right)$ & $30\left(850^{\circ} \mathrm{C}\right)$ & [43] \\
\hline $\mathrm{La}_{0.8} \mathrm{Sr}_{0.2} \mathrm{Cr}_{0.97} \mathrm{~V}_{0.03} \mathrm{O}_{3}$ & - & $28\left(850^{\circ} \mathrm{C}\right)$ & [57] \\
\hline $\mathrm{La}_{0.8} \mathrm{Sr}_{0.2} \mathrm{Cr}_{0.97} \mathrm{Fe}_{0.03} \mathrm{O}_{3}$ & $1.15\left(850^{\circ} \mathrm{C}\right)$ & $1.79\left(850^{\circ} \mathrm{C}\right)$ & [58] \\
\hline $\mathrm{La}_{0.75} \mathrm{Sr}_{0.25} \mathrm{Cr}_{0.95} \mathrm{Ru}_{0.05} \mathrm{O}_{3}$ & $68\left(860^{\circ} \mathrm{C}\right)$ & $170\left(855^{\circ} \mathrm{C}\right)$ & [59] \\
\hline $\mathrm{La}_{0.75} \mathrm{Sr}_{0.25} \mathrm{Cr}_{0.5} \mathrm{Mn}_{0.5} \mathrm{O}_{3}$ & $1.4\left(800^{\circ} \mathrm{C}\right)$ & $2.3\left(800^{\circ} \mathrm{C}\right)$ & [60] \\
\hline $\mathrm{La}_{0.75} \mathrm{Sr}_{0.25} \mathrm{Cr}_{0.5} \mathrm{Mn}_{0.5} \mathrm{O}_{3}$ & $2.5\left(800^{\circ} \mathrm{C}\right)$ & $11\left(800^{\circ} \mathrm{C}\right)$ & [61] \\
\hline $\mathrm{La}_{0.75} \mathrm{Sr}_{0.25} \mathrm{Cr}_{0.5} \mathrm{Mn}_{0.5} \mathrm{O}_{3}$ & - & $2.62\left(900^{\circ} \mathrm{C}\right)$ & [62] \\
\hline $\mathrm{La}_{0.75} \mathrm{Sr}_{0.25} \mathrm{Cr}_{0.5} \mathrm{Mn}_{0.5} \mathrm{O}_{3}$ & $1.1\left(800^{\circ} \mathrm{C}\right)$ & $8.1\left(800^{\circ} \mathrm{C}\right)$ & [63] \\
\hline $\mathrm{La}_{0.75} \mathrm{Sr}_{0.25} \mathrm{Cr}_{0.5} \mathrm{Mn}_{0.5} \mathrm{O}_{3}$ & $0.18\left(900^{\circ} \mathrm{C}\right)$ & - & [64] \\
\hline $\mathrm{La}_{0.7} \mathrm{Sr}_{0.3} \mathrm{Cr}_{0.8} \mathrm{Ti}_{0.2} \mathrm{O}_{3}$ & $40\left(857^{\circ} \mathrm{C}\right)$ & - & [52] \\
\hline $\mathrm{La}_{0.8} \mathrm{Sr}_{0.2} \mathrm{CrO}_{3}$ & $256\left(850^{\circ} \mathrm{C}\right)$ & - & [46] \\
\hline $\mathrm{La}_{0.8} \mathrm{Sr}_{0.2} \mathrm{Cr}_{0.8} \mathrm{Mn}_{0.2} \mathrm{O}_{3}$ & $51\left(850^{\circ} \mathrm{C}\right)$ & - & [46] \\
\hline $\mathrm{La}_{0.75} \mathrm{Sr}_{0.25} \mathrm{Cr}_{0.5} \mathrm{Fe}_{0.5} \mathrm{O}_{3}$ & $1.15\left(850^{\circ} \mathrm{C}\right)$ & - & [58] \\
\hline
\end{tabular}

In the particular kind, $\mathrm{YCrO}_{3}$ perovskite has been examined as possible interconnect material as they display advantages over the $\mathrm{LaCrO}_{3}$-based materials in terms of the chemical expansion and compatibility with YSZ electrolyte.[65-71] In addition of working as interconnect, $\mathrm{YCrO}_{3}$ based materials have been evaluated as potential anode after multiple doping at $\mathrm{A}$ and $\mathrm{B}$ sites: an anode made from $\mathrm{Ca}$ and $\mathrm{Co}$ doped $\mathrm{YCrO}_{3}$ lately has demonstrated an encouraging performance in $\mathrm{H}_{2}$, and more importantly, displayed good tolerance towards $20 \mathrm{ppm} \mathrm{H}_{2} \mathrm{~S}$.[72] Such preliminary information suggests that $\mathrm{YCrO}_{3}$-based perovskite could be a promising parent 
material for anode aiming at $\mathrm{H}_{2} \mathrm{~S}$ containing fuel. However, compared to the Ni/YSZ anode, those oxide anodes are inferior in terms of certain critical factors, such as electrical conductivity and output performance which is usually 10 times smaller than $\mathrm{Ni}$ anode. Even thought the unique advantages of oxide anode over $\mathrm{Ni}$ anode are the coking resistance and sulfur poison tolerance, the performance is inevitably a key role that determines the possibility of application and need to be enhanced further to meet the requirement. Understanding the oxidation mechanism on those oxide anodes will be crucial to point out limiting factors and the possible direction to improve them. However to the best of our knowledge, besides the electrode performance research, no investigation regarding the anode reaction mechanism on those oxide materials has been reported. Before plumping into this topic, it is worth digressing for a moment on the mechanism research of $\mathrm{Ni} / \mathrm{YSZ}$ anode accumulated over several decades in hope of building guidelines for oxide anode study later.

\section{2 $\mathrm{H}_{2}$ oxidation pathway in traditional $\mathrm{Ni} / \mathrm{YSZ}$ anode}

To identify the reactive zone on Ni/YSZ anode, Gauckler et al. fabricated the Ni pattern anode on YSZ electrolyte as shown in Fig. 2.6, and found that the polarization resistance is inversely proportional to the 3PB length as displayed in Fig. 2.7.[73] From that study along with a series of other $\mathrm{Ni}$ electrode investigations, [74-77] it is clear that for the $\mathrm{Ni}$ metal anode catalytic reaction takes place only at the $3 \mathrm{~PB}$ area. Considering that $\mathrm{Ni}$ is electronic conductive and YSZ ionic conductive, this result is consistently reasonable.

But still, nothing can occur literally at one dimension. This begs the question that of YSZ and $\mathrm{Ni}$, which surface is or whether both surfaces are active near the 3PB. In fact, models favor 
each of them can be found readily in literature. Morgensen et al.[78] summarized them as in Fig. 2.8. The first scenario as shown in Fig. 2.8a was argued by Morgensen and many others as the main mechanism for the $\mathrm{H}_{2}$ oxidation reaction considering the general knowledge of the active interaction between $\mathrm{Ni}$ and H.[78] The second scenario was introduced by Mizusaki et al.[79] based on the findings that a compact $\mathrm{Ni} / \mathrm{YSZ}$ anode also showed reaction rate much bigger than 0, which in fact showed every limited 3PB length that could only come from the imperfection of the Ni film covering YSZ substrate. Citing the tremendous difference of exposed YSZ surface between the compact Ni/YSZ and Ni pattern anode, they concluded that the RDS of $\mathrm{H}_{2}$ oxidation was controlled by the surface process on $\mathrm{Ni}$ as illustrated in Fig. 2.9.[79] The last scenario in Fig. 2.8c was proposed by Minh et al. as a possibility but without a body of experimental evidence.[80] In particular, on the Ni side, by varying the thickness of the Ni strips in the pattern electrodes, it was found that the reaction rate increased with the thickness until several microns. [81] It was thus concluded that the active length on $\mathrm{Ni}$ could be on the order of submicron to micron.
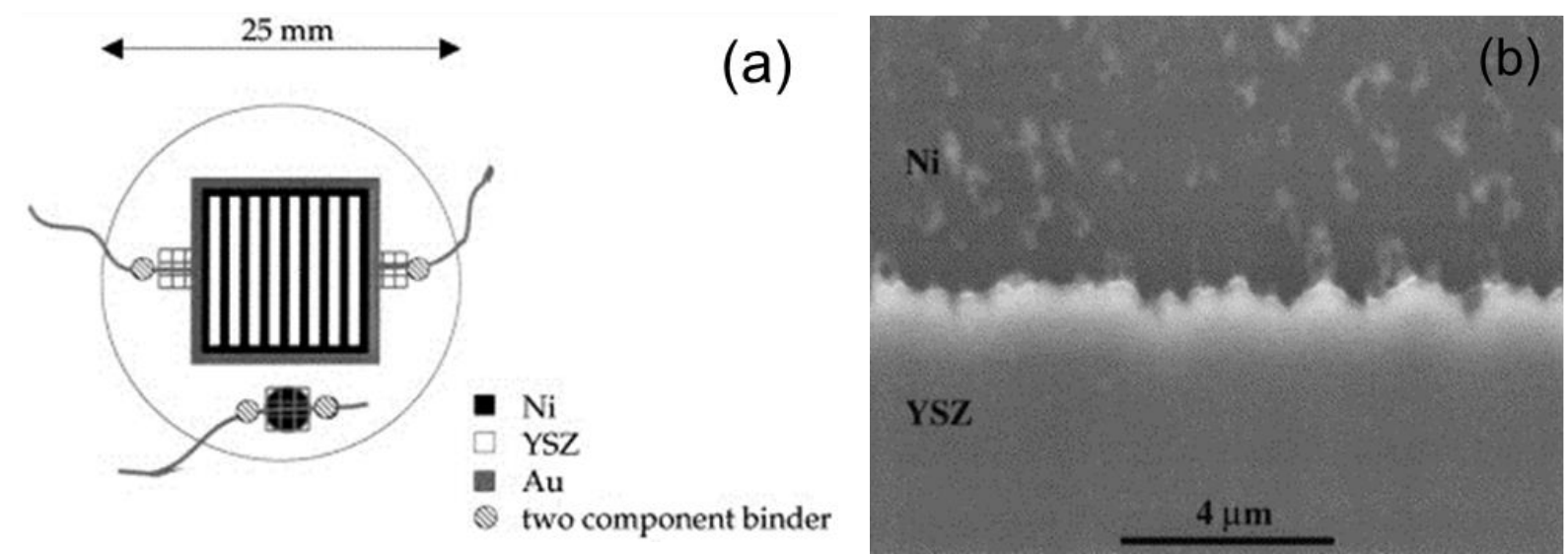

Fig. 2.6 Schematic of Ni pattern sample on single crystal YSZ (a), and SEM image of Ni on YSZ (b).[73] 


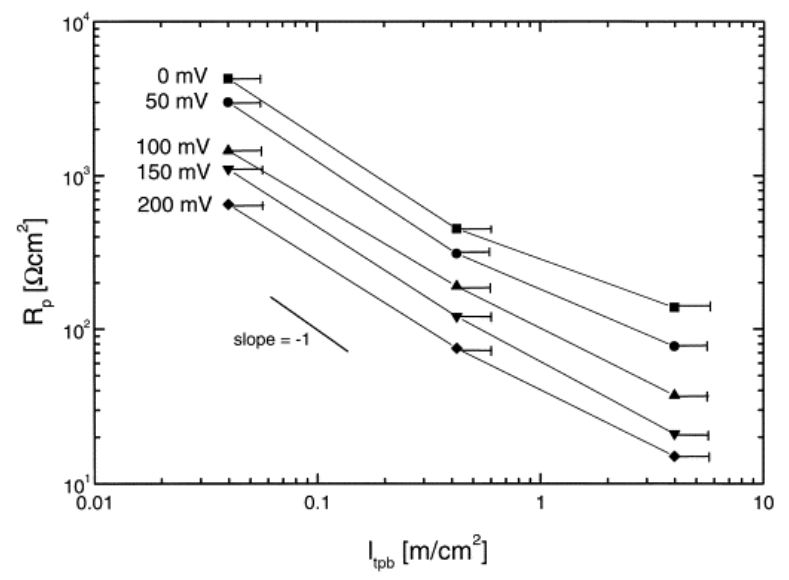

Fig. 2.7 Polarization resistance vs. 3PB length on the Ni pattern sample deposited on single crystal YSZ [73]
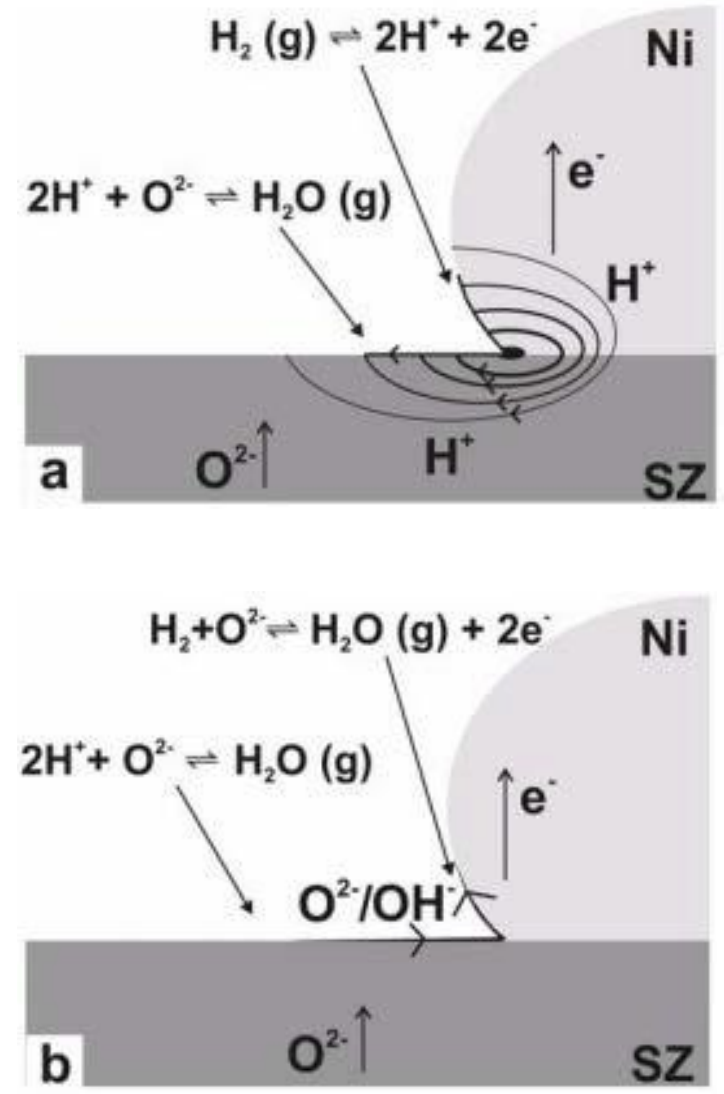


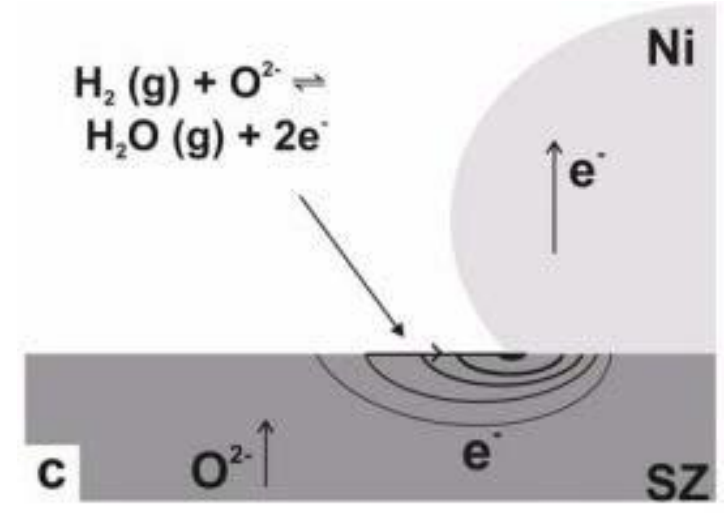

Figure 2.8 Schematics of possible reaction paths of Ni/YSZ discussed in the literature, (a) $\mathrm{H}_{2}$ adsorption on the $\mathrm{Ni}$ results in the formation of $\mathrm{H}^{+}$ions, then migrate to the site along the surfaces or though bulk Ni and bulk YSZ to formation $\mathrm{H}_{2} \mathrm{O}$ in the surface of YSZ. (b) $\mathrm{O}^{2-}$ or $^{-} \mathrm{OH}^{-}$ migrates from YSZ to $\mathrm{Ni}$ along surfaces and finally form at $\mathrm{H}_{2} \mathrm{O}$ on Ni surface. (c) $\mathrm{H}_{2}$ is adsorbed on YSZ surface then reacts with lattice oxygen to form $\mathrm{H}_{2} \mathrm{O}$ at $\mathrm{YSZ}$ surface, electron transport to the Ni through the surface bulk of YSZ.[78]

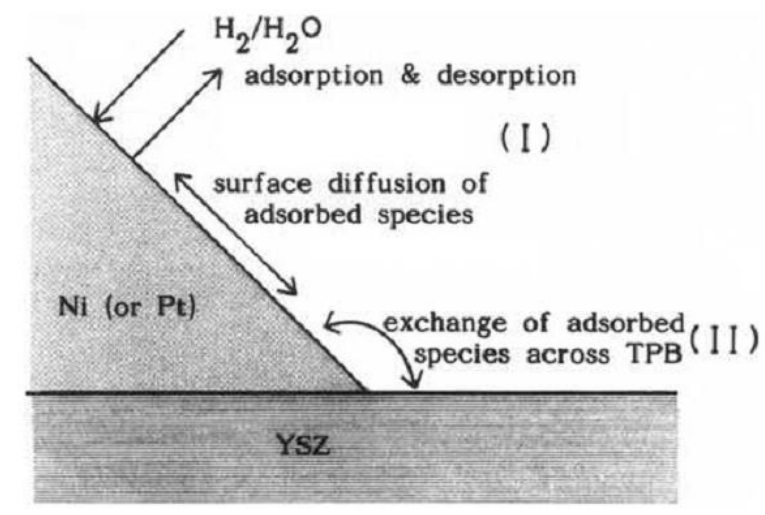

Fig. 2.9 Ni surface limiting reaction mechanism of $\mathrm{H}_{2}$ oxidation on Ni/YSZ anode.[79]

Secondly, what are the elementary steps? Bieberle et al.[82] proposed a complete reaction model as shown in Fig. 2.10 combining the results from $\mathrm{H}_{2}$ and $\mathrm{H}_{2} \mathrm{O}$ interaction with $\mathrm{Ni}$ solid surfaces and the previous modeling on $\mathrm{Pt}, \mathrm{H}_{2}-\mathrm{H}_{2} \mathrm{O}$ system.[83-86] The simulation was compared with several set of experimental data. As concluded in the end, though good consistency was found with some data sets, a rather extensive collection of data was required to unambiguously interpret the kinetics of this system. In particular, the activity of the electrolyte surface needed to 
be considered with quantitative data concerning the adsorption and removal of $\mathrm{H}$ and $\mathrm{OH}$ as its effect on the kinetic had been speculated in several references.[76, 87-88] Further, Vogler et al.[89] proposed a reaction pathway in their reaction-diffusion models based on Bieberle's study as shown in Fig. 2.11. Such model features 7 different scenarios of charge transfer in form of spillover of adsorbates between Ni and YSZ surfaces at 3PB, which are illustrated in Fig. 2.12. It was found that only one mechanism involving $\mathrm{H}$ spillover mechanism from Ni to YSZ to react with $\mathrm{O}$ or $\mathrm{OH}$ yielded good agreement with the complete set of experimental data. Such observation had been confirmed later by Bessler in their combined experimental and theoretical model anode study for the $\mathrm{H}_{2}$ oxidation mechanism. Four steps were proposed as RDS at high temperature in this electrochemical process: hydrogen spillover to oxygen, water association on YSZ, water desorption from YSZ and surface diffusion of adsorbed $\mathrm{OH}$ ions on YSZ surface. And they would reduce to $\mathrm{H}$ spillover as the single RDS at low temperature $\left(\mathrm{T}<=500^{\circ} \mathrm{C}\right)$. Those studies, though not embraced all the views of $\mathrm{H}_{2}$ oxidation on Ni/YSZ, outlined the major part of results in the reaction mechanism investigations.

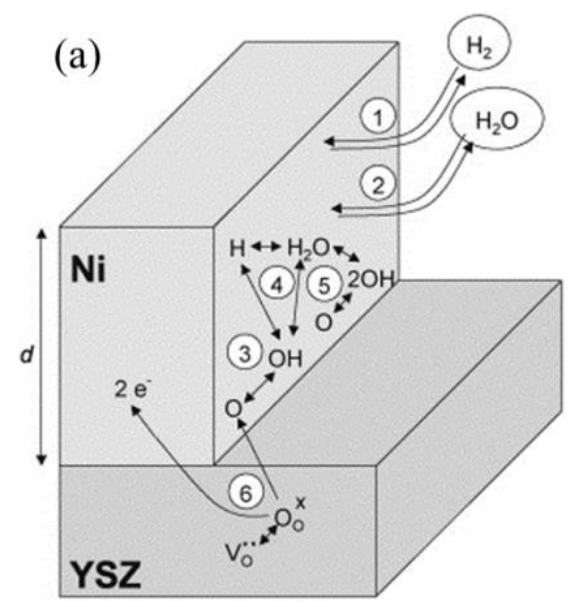

$$
\text { (b) } \begin{aligned}
& \mathrm{H}_{2(\mathrm{~g})}+2 \mathrm{ad} \underset{k_{-1}}{\stackrel{k_{1}}{\leftrightarrow}} 2 \mathrm{H}_{\mathrm{ad}} \\
& \mathrm{H}_{2} \mathrm{O}_{(\mathrm{g})}+\mathrm{ad} \underset{k_{-2}}{\stackrel{k_{2}}{\leftrightarrow}} \mathrm{H}_{2} \mathrm{O}_{\mathrm{ad}} \\
& \mathrm{O}_{\mathrm{ad}}+\mathrm{H}_{\mathrm{ad}} \underset{k_{-3}}{\stackrel{k_{3}}{\leftrightarrow}} \mathrm{OH}_{\mathrm{ad}}+\mathrm{ad} \\
& \mathrm{H}_{2} \mathrm{O}_{\mathrm{ad}}+\mathrm{O}_{\mathrm{ad}} \underset{k_{-4}}{\stackrel{k_{4}}{\leftrightarrow}} 2 \mathrm{OH}_{\mathrm{ad}} \\
& \mathrm{H}_{2} \mathrm{O}_{\mathrm{ad}}+\mathrm{ad} \underset{k_{-5}}{\stackrel{k_{5}}{\leftrightarrow}} \mathrm{OH}_{\mathrm{ad}}+\mathrm{H}_{\mathrm{ad}} \\
& \mathrm{O}_{\mathrm{O}}^{x}+\mathrm{ad} \underset{k_{-6}}{\stackrel{k_{6}}{\leftrightarrow}} \mathrm{O}_{\mathrm{ad}}+\mathrm{V}_{\ddot{\mathrm{O}}}+2 \mathrm{e}_{\mathrm{Ni}}^{-}
\end{aligned}
$$

Fig. $2.10 \mathrm{H}_{2}$ oxidation model in Ni/YSZ system by Bieberle et al. (a) schematic, (b) corresponding elementary steps.[82] 


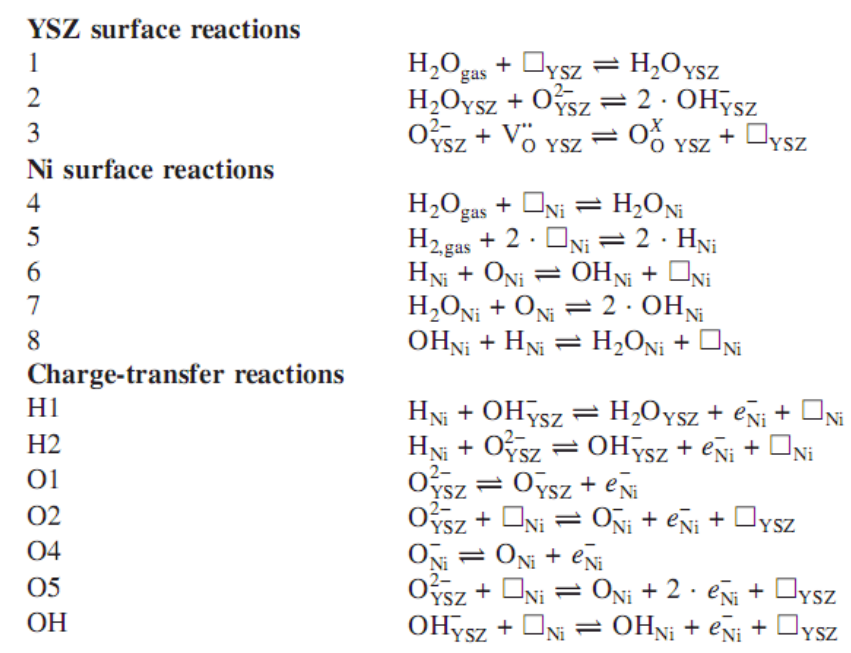

Fig. 2.11 Elementary reaction steps for $\mathrm{H}_{2}$ oxidation by Vogler et al.[89]
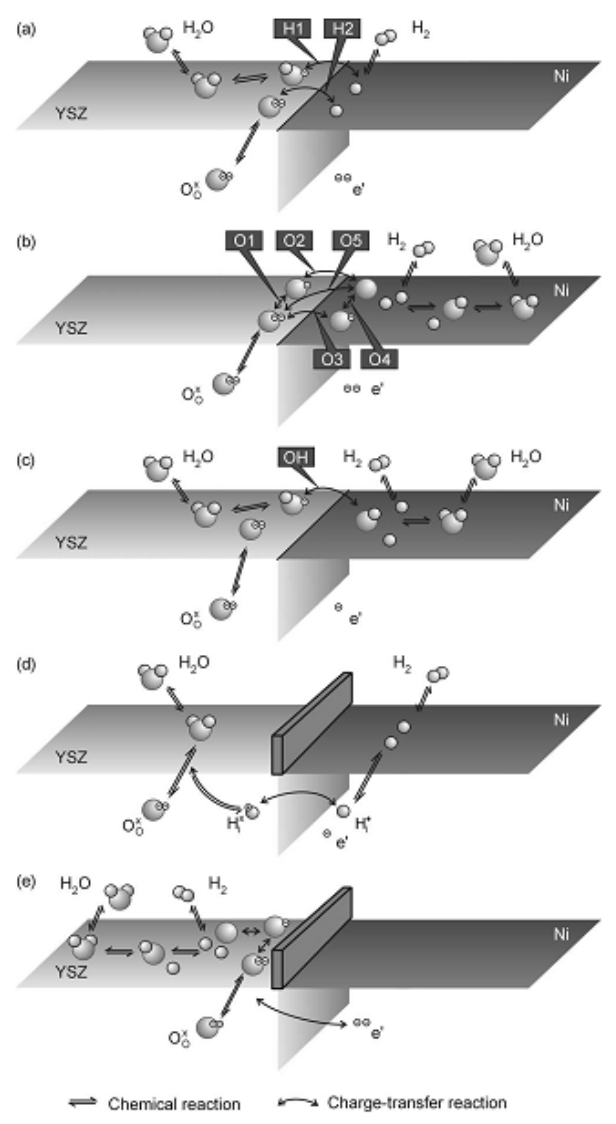

Fig. 2.12 Different scenarios of charge transfer on $\mathrm{H}_{2} / \mathrm{YSZ} 3 \mathrm{~PB}$ by Vogler et al.[89] (a) spillover of hydrogen from Ni surface to an oxygen ion or hydroxyl ion on YSZ surface, (b) charge transfer reactions with and without spillover of oxygen ions from YSZ surface to Ni surface, (c) hydroxyl spillover from YSZ surface to Ni surface, (d) charge transfer by an interstitial proton, (e) charge transfer and chemical reactions on the electrolyte surface only. 


\subsection{Broadened reaction zone in oxide anodes}

While the active site for oxidation reaction in Ni metal anode is limited to the 3PB vicinity, the oxide anode might be able to extend such area to a broader area due to the oxygen conductivity of the anode. It is proven that mixing ionic conductive electrolyte with metal anode will extend the 3PB from anode/electrolyte interface to a 3-dimension network in the anode. Similarly, by using a MIEC anode the active site centering at the 3PB line could be broadened to several micrometers away which could be a substantial expansion considering the width of $3 \mathrm{~PB}$ active area is usually believed to be less than 100 nanometers. It has been reported that tremendous improvement is achieved with MIEC cathode materials, like $(\mathrm{SmSr}) \mathrm{CoO}_{3}$ or $(\mathrm{LaSr})(\mathrm{CoFe}) \mathrm{O}_{3}$. With the significant ionic conductivity, the broadened active are on those cathode is estimated to be several to tens of microns. For the oxide anode, with appropriate doping choices, oxygen ion conductivity can be expected from those materials by creating oxygen vacancy in the lattice. Therefore, besides diffusion of $\mathrm{H}$ towards 3PB by the surface, oxygen from electrolyte can also be transported by the anode bulk pathway to areas away from $3 \mathrm{~PB}$, making those sites active for $\mathrm{H}_{2}$ oxidation. In the present time, theoretical modelling or experiment verification on such properties of anode materials are still sparse, therefore is one of the principal investigation interest of this study.

\section{4 nfluence on performance of overpotential}

Because of the simplicity in thermodynamic, a large portion of the electrode research was conducted under equilibrium conditions.[72, 90-91] Through those studies, general principles about the anode properties, such as the catalytic difference between various materials, possible reaction mechanisms and etc. have been pointed out. However, with applied overpotential, the 
local electrical status, surface adsorption and even local chemical composition will be altered, which in turn may impact the reaction kinetics, the activation or deactivation of broadened active zone according to the intrinsic correlation to the overpotential, and durability of electrode in long-term operation.

To more clearly evaluate this topic, we can first geometrically divide the reaction pathway into surface process, including hydrogen (dissociative) adsorption, ionization and association between $\mathrm{H}, \mathrm{O}$ and $\mathrm{OH}$, bulk process---the transport of oxygen species toward $2 \mathrm{~PB}$, and interface process---ion transfer from electrolyte to anode. Among these three subsequent processes, as pointed out in several polarization studies, ion transfer at the MIEC/electrolyte interface is dependent on the oxygen activity of interface composition. Fast transfer process can be obtained by using appropriate electrolytes, like GDC or LSGM,[92] therefore is less critical and complex. As for the surface process, tremendous effort has been devoted to understanding the very nature of it in order to promote the output of electrode with overpotential, or to further guide novel composition and structure designs. Major advances in terms of identifying the correlation between the reaction kinetics and surface local composition/electrical conditions, influence of the oxygen defects in electrode bulk and etc. have been elucidated by different groups. 

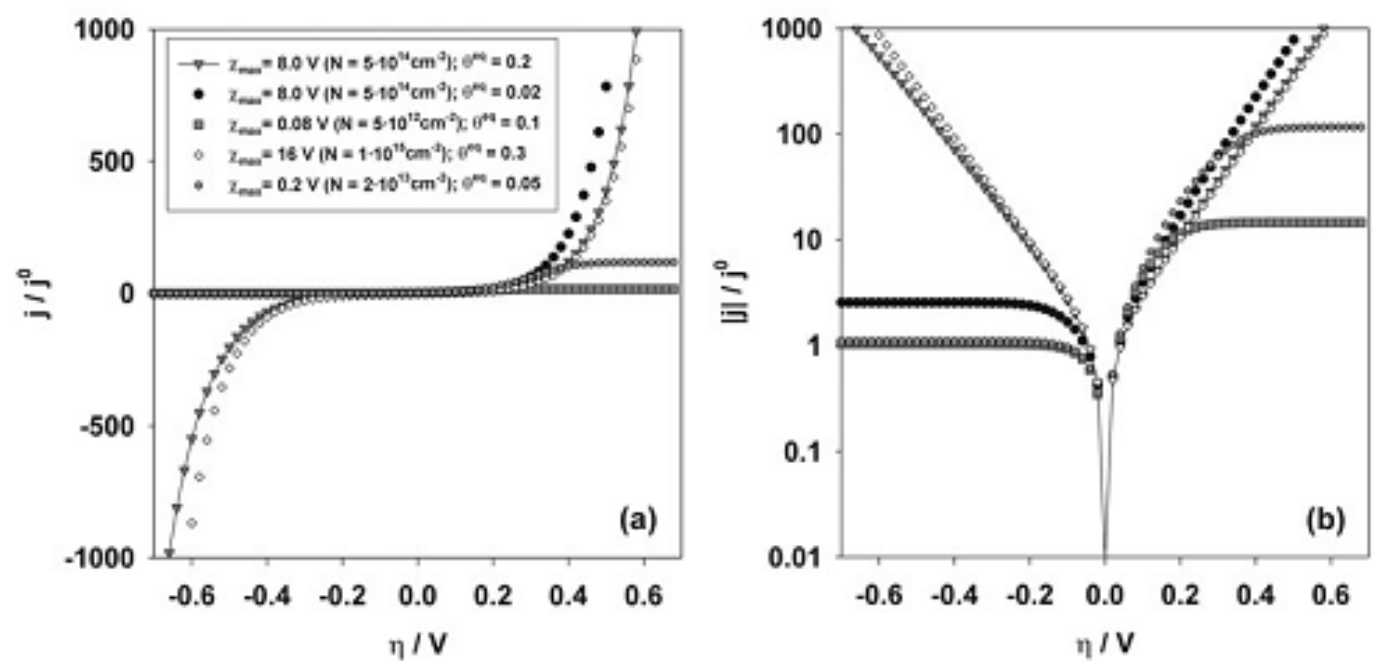

Fig. 2.13 The linear (a) and logarithm (b) plots of V-I relationship for charge transfer reaction in MIEC electrode calculated from different surface coverage $(\theta)$ and surface local overpotential $(\chi)$ by Fleig et al.[93]

First, for the surface process, the overpotential is capable of influencing any charged species on the surface directly. Since such intrinsic correlations between the element reaction steps and overpotential are built with basic electrostatics, they are largely valid regardless of the specific electrode materials after modifying the specific boundary conditions. In specific, the charge transfer rate for example in the traditional solid/liquid interface is formulated by B-V equation. Converting it to adapt the unique surface adsorption in SOFC MIEC electrode system, Fleig et al.[93] built a model to account for the relationship between surface coverage and the surface overpotential in cathode, which in turn mediate the charge transfer rate at the gas/solid interface showing a voltage-current (V-I) relationship different from the traditional B-V equation. The new V-I relationship for high surface adsorption case is much steeper than B-V, the symmetrical coefficients can be 2 to 4 times bigger than 0.5 since the surface overpotential can be even larger than the externally applied one as shown in Fig. 2.13. It therefore shows stronger effect on the surface reaction rate than the usual B-V relationship. 


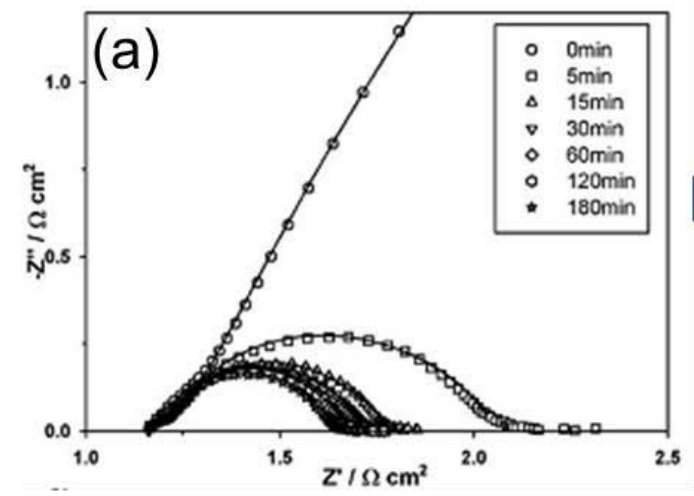

After initially cathodic-polarized at different duration

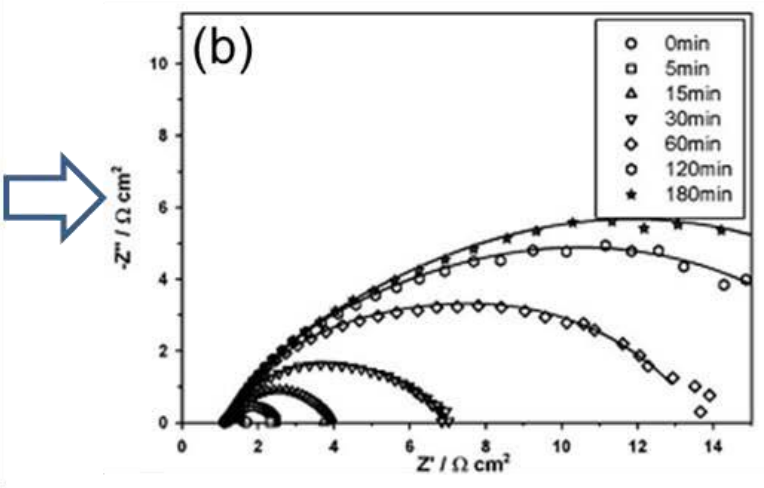

Followed by anodic-polarized at different duration

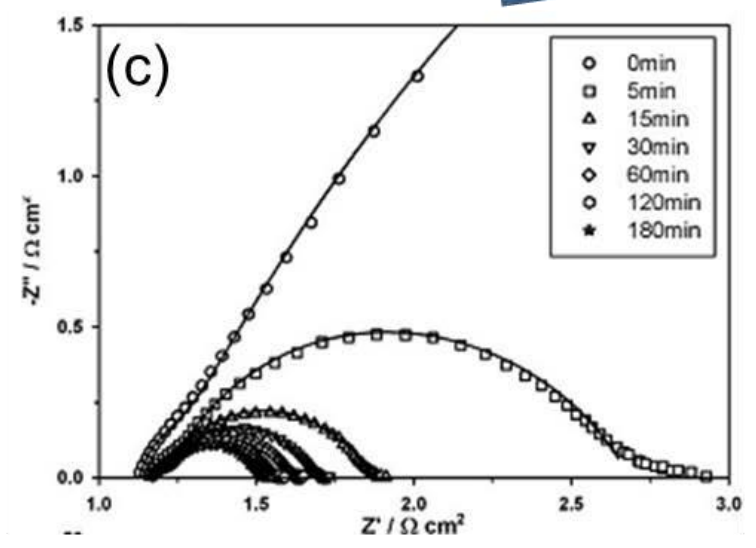

Followed again by cathodicpolarized at different duration

Fig. 2.14 Polarization resistance of LSM cathode under cathodic and anodic treatments by Wang et al: (a) initially treated a fresh cathode with $200 \mathrm{~mA} / \mathrm{cm}^{2}$ cathodic current with different duration, (b) followed by treated at $200 \mathrm{~mA} / \mathrm{cm}^{2}$ anodic current with different duration, (c) followed again by treated at $200 \mathrm{~mA} / \mathrm{cm}^{2}$ cathodic current with different duration.

Next, it is also well-known that in lots of cases overpotential is able to change the local chemical composition of electrode. Citing from large body of data on the most commonly studied LSM cathode, overpotential tends to dissolve the surface enriched element into the lattice structure, like Sr, to remove the inert layer towards adsorption as demonstrated by Wang et al.[94]in Fig. 2.14, or even is believed to bring some element from lattice to surface, like La, to activate the surface exchange process. By changing the chemical stoichiometry of the surface, 
overpotential has obviously enhanced or impaired the electrode performance significant compared to equilibrium condition. However, until so far, similar studies in anode side are missing.

At last, for the bulk process, even less information is available in literature on either oxide anode or cathode. The chemical stoichiometry and electrical environment of electrode materials can be influenced by applied overpotential, which in turn trigger the change in diffusion kinetics. According to the drift-diffusion equation, concentration gradient and electrical field forces are two driving forces for charged species diffusion in the homogeneous phase. The contribution from concentration gradient is determined by Fick's law and the electrical field contribution is governed by Ohm's law. As already been stressed in the MIEC electrode research, concentration gradient is believed as the only factor determining transport kinetics in bulk diffusion. Due to the local neutrality assumption, internal electrostatic potential gradient is usually neglected, and then the corresponding electrical driving force is left out. However, as we will see in detail later in the main section, such neutrality assumption, even though seems intuitively right, has oversimplified the essence of theoretical treatment on the diffusion process. Theoretical exploration of transport behavior in MIEC material can date back to Wagner's classic work in 1930s.[95-97] The framework built since then by Wagner and many others has been used to develop various models to determine the transport properties based mostly on $\operatorname{Ag}_{2} \mathrm{~S}$ media. More recently, transport in MIEC related to oxygen transport membrane (OTM) application has been studied by Liu et al.[98] Liu examined the physical treatment of those transport equations and obtained analytical solutions for charge carrier distributions in MIEC subject to definite boundary conditions on both sides of the sample. Jamnik and Maier mapped 
the electrochemical kinetics for MIEC bulk into equivalent circuit based on the transport equations for electronic and ionic defects.[99-100] Afterwards, Lai et al. derived the AC impedance response of MIEC exemplified by ceria-based oxides under chemical potential gradient using the same fundamental transport equation system. Liu later on indeed presented the electrochemical study on porous MIEC electrode for SOFC application, with taking account of the ion transport resistance, for an equivalent circuit approximation.[98]

Actually, despite of all the significant progress made in above works, the interest in oxygen transport behavior in MIEC electrodes either in anode or cathode conditions with detailed distribution profiles has not been investigated yet. Under steady state, the ionic flow inside the MIEC electrode is constant but in principle the electronic one is eventually blocked at the MIEC/electrolyte interface. The blocking of electronic species in fact can simplify the electron-ion coupled transport process drastically and makes the analytical solution possible under reasonable assumptions, which renders clear assessment of the driving forces and the corresponding prediction on the material stability at boundaries.

Considering the void of overpotential influence study on the oxide electrode and its potentially great impact on the bulk pathway, the oxygen transport is investigated by interpreting the general transport equation into the specific case with electron-blocking electrolyte combined with experimental study in Chapter 7, the defects distributions in MIEC and the impact of those results on the understanding of electrode stability under polarization are derived and discussed with a one dimensional model. 


\section{Chapter 3}

\section{RESEARCH OBJECTIVES}

Through the literature review, it is found that though certain oxide anodes, such as LSCM (1.1 $\Omega \mathrm{cm}^{2}$ at $800^{\circ} \mathrm{C} \mathrm{H}_{2}$ ), yield relatively good performances, most of the rest show polarization resistances much bigger than the application requirement $\left(\sim 0.5 \Omega \mathrm{cm}^{2}\right)$. Because of this barrier of energy loss in electrode reaction, lots of merits from those oxide materials cannot be utilized in SOFC anode, e.g. the high $\mathrm{H}_{2} \mathrm{~S}$ tolerance of $\mathrm{V}$-based materials at the present stage. Understanding the reaction mechanism and therefore the limiting factors can provide right direction for optimization in the future, making performance improvement highly possible and widening the choices in anode candidates with particular merits. Because that the mechanism exploration for those oxide anodes is scarce in literature, this study is devoted to this subject and investigate $\mathrm{H}_{2}$ oxidation pathway on oxide anode in both the fundamental of electrochemical reaction and evolution of geometry active area with chemical composition and overpotential. In specific, the following objectives are investigated:

* Characterize the electrochemical performance of doped chromite oxide anode with chosen dopants to point out the vital factors controlling the performance.

* In the reaction kinetics, propose a complete reaction chain with the elementary steps for $\mathrm{H}_{2}$ oxidation and identify the rate-determining step for those oxide anodes; 
* In the reactive microstructure, identify the primary reactive area and certify the possible broadened active site away from 3PB;

* In service condition with overpotential, investigate the influence of overpotential on the chemical and electrical profiles of oxide electrode; discuss the related consequence on the bulk reaction pathway and stability of oxide anode. 


\section{Chapter 4}

\section{EXPERIMENTAL METHODS}

\subsection{Synthesis of materials}

The chromites powders were synthesized by EDTA-citric Sol-Gel method as illustrated in Fig. 4.1. Standard nitrates (from Alfa Aesar or Acros Organics) in stoichiometric percentage together with citric acid (Alfa Aesar) were dissolved into distilled water. EDTA powders (Fisher Scientific) as complexant along with ammonia water (Alfa Aesar) was dissolved into the other set of distilled water. The above solutions were blended together followed by adjusting $\mathrm{pH}$ to 8 through ammonia water, then held at $\sim 80^{\circ} \mathrm{C}$ and stirred until gelation. The gel was heated to $400^{\circ} \mathrm{C}$ to decompose nitrates and organic residual. Resultant powders were calcined at different temperatures for several cycles with or without intermediate ground to crystallize.

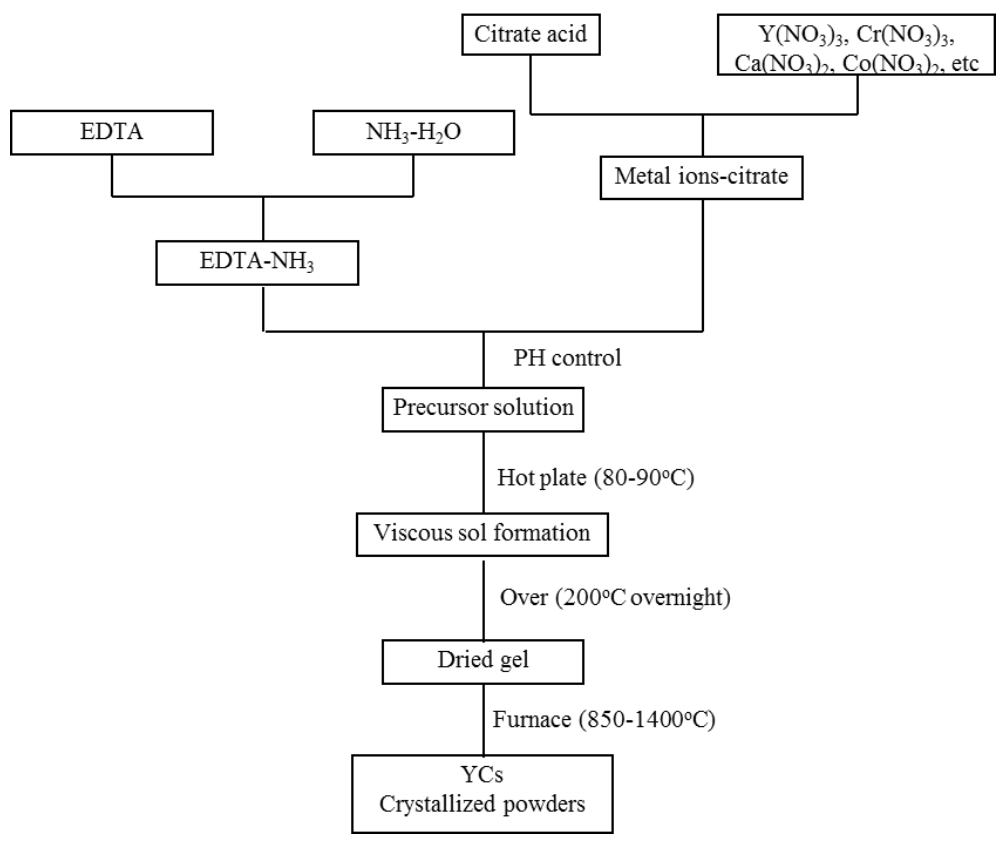

Fig. 4.1 Diagram of powder synthesis with Sol-gel method 


\subsection{Fabrication of cells}

Doped $\mathrm{YCrO}_{3}$ symmetrical porous cells---to make anode slurry, those anode powders were ground in ink vehicle (Fuel Cell Materials Co.) with the weight ratio of anode powders: vehicle 10:11. Anode slurry was screen printed onto both sides of YSZ electrolyte symmetrically. The electrolyte discs were made by pressing powders into pellets $(1 \mathrm{~mm}$ in thickness, $31 \mathrm{~mm}$ in diameter), followed by sintering at $1400^{\circ} \mathrm{C}$ for $4 \mathrm{~h}$. The number of screen printing cycles depended on the designed electrode thickness. Typically, a single printing resulted in $5 \mu \mathrm{m}$ in thickness after sintering. The effect electrode area was $0.7 \mathrm{~cm}^{2}$ at each side. The as-made symmetric cells were sintered at $1000^{\circ} \mathrm{C}$ for $2 \mathrm{~h}$ in air. Pt mesh was bonded to both electrodes as current collector using Pt paste, followed by heating at $700^{\circ} \mathrm{C}$ for $2 \mathrm{~h}$.

Dense LSCF(thick)/GDC(thin) half cells---GDC powders (Fuel Cell Materials Co.) was evenly mixed with 1 cat. $\% \mathrm{Co}\left(\mathrm{NO}_{3}\right)_{3}$ as sintering aid and heated to $400^{\circ} \mathrm{C}$ in order to decomposed $\mathrm{Co}\left(\mathrm{NO}_{3}\right)_{3}$ into $\mathrm{Co}_{2} \mathrm{O}_{3}$ and achieve initial firm bond with GDC particles. The resultant mixture along with polyvinyl butyral (PVB) and fish oil at the weight ratio of 100:2:1.5 was added into ethanol ( $5 \mathrm{~g}$ powders to $30 \mathrm{~mL}$ ethanol), then ball-milled for $24 \mathrm{~h}$ to produce suspension which was air-brushed onto one side of electrode to fabricate thin layer electrolyte. In brief, LSCF (Fuel Cell Materials Co.) in $1.5 \mathrm{~g}$ were dry pressed under $50 \mathrm{MPa}$ in a $16.5 \mathrm{~mm}$ die. The suspension was evenly sprayed to LSCF surface, followed by pressing at $300 \mathrm{MPa}$. The thickness of GDC layers can be controlled by the volume of suspension served to the gun and was set to $\sim 50 \mu \mathrm{m}$ for all samples. LSCF/GDC sandwiches were sintered to $1300^{\circ} \mathrm{C} 4 \mathrm{~h}$ for densification. Pt paste was applied to GDC surface as counter electrode and heated to $700^{\circ} \mathrm{C}$ for $2 \mathrm{~h}$. Silver wires were attached to both surfaces using silver past as lead wires heated to $600^{\circ} \mathrm{C}$ for $2 \mathrm{~h}$. 


\subsection{Electrical and electrochemical characterizations}

DC conductivity measurement---the electrical conductivity was measured using Van der Pauw 4 probe method as shown in Fig. 4.2.[101] Powders in $0.7 \mathrm{~g}$ were dry pressed into pellet with a $16.5 \mathrm{~mm}$ die, followed by sintering at $1300^{\circ} \mathrm{C}$ for $4 \mathrm{~h}$. Four silver contact points were located at on one side symmetrically. The testing was conducted from 600 to $850^{\circ} \mathrm{C}$ in both air and $5 \% \mathrm{H}_{2}$ balanced with $\mathrm{N}_{2}$ using Keithley 2400 SourceMeter. Current $I_{0}$ flows from $\mathrm{I}_{1}$ to $\mathrm{I}_{2}$ probe, voltage between $V_{1}$ and $V_{2}$ probes is measured with the configurations of Fig. $4 a$ and $b$. The resistance is calculated using Eq. 4.1.
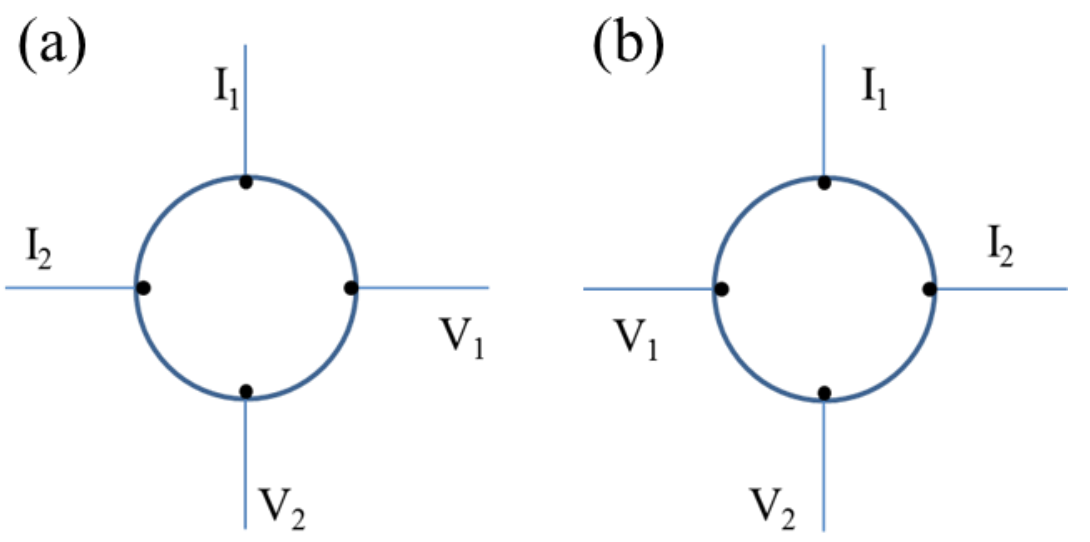

Fig. 4.2 Configuration of Van der Pauw measurement.

$$
\rangle_{\mathrm{e}}=\frac{\square d R_{1}+R_{2}}{\ln 2 \quad 2} f\left(\frac{R_{1}}{R_{2}}\right)
$$

where $\rho_{\mathrm{e}}$ is the resistivity, $d$ sample thickness, $R_{1}, R_{2}$ measured resistance from configuration a and $\mathrm{b}$ respectively. $f\left(R_{1} / R_{2}\right)$ is the function of the ratio $R_{1} / R_{2}$ in the range $(0,1)$.

The DC resistance of LSCF/GDC half cell was measured by standard 4-probe method with constant current flows in the range of $0.01-10 \mathrm{~mA}$ by Keithley 2400 SourceMeter and 2182A Nanovoltmeter at $700^{\circ} \mathrm{C}$. 
Electrochemical performance---EIS testing was carried out on these symmetric cells in various $\mathrm{H}_{2}$-containing and $\mathrm{O}_{2}$-containing atmospheres by Solartron 1287 and 1260 at open circuit condition over frequency range from $0.1 \mathrm{~Hz}$ to $99 \mathrm{MHz}$. The AC signal applied was $20 \mathrm{mV} . \mathrm{H}_{2}$ or $\mathrm{O}_{2}$ content in $\mathrm{H}_{2} / \mathrm{N}_{2}$ or $\mathrm{O}_{2} / \mathrm{N}_{2}$ mixture was adjusted by mass flow controller (Alicat Scientific). $\mathrm{H}_{2}$-containing gases were all moisturized by passing through a water bubbler at room temperature before feeding to samples and the vapor partial pressure is approximately $3 \%$.

\section{4 aterial structure characterization}

Crystal structure---the power phase purity or mixture powders compatibility was examined through X-ray diffraction (XRD, PANalytical X'pert PRO and Bruker AXS, $\mathrm{Cu}$ Ka radiation) Commercial software Jade 5 was used to analyze XRD spectra.

Microstructure---structure of the electrode and morphology of materials were inspected via scanning electron microscopy (SEM, JEOL JSM-7600F, Hitachi S-4700). 


\section{Chapter 5}

\section{FACTORS CONTROLLING $\mathrm{H}_{2}$ OXIDATION ON DOPED $\mathrm{YCrO}_{3}$}

Due to the excellent catalytic activity of $\mathrm{Ni}$ for $\mathrm{H}_{2}$ oxidation, the anodic polarization resistance is relatively small in the overall internal resistance of SOFC, which reasonably shifts the research effort to the cathode part in most cases. However, when it comes to the alternative oxide anode materials, the presently available materials will account for a major part of the overall resistance as shown in Table 2.2 and 2.5 , therefore, justifying extensive and systematic studies on anode performance to gain insight on how to understand and optimize electrode activity in the future. Unfortunately, most studies regarding oxide anodes are focused on the overall performance evaluation instead of the reaction mechanisms. To this end, this chapter is devoted to illustrate the possible factors controlling fuel oxidation on those oxide anodes using $\mathrm{H}_{2}$ as an example. The designed samples with compositions as
1) $\mathrm{YCrO}_{3}$,
2) $\mathrm{Y}_{0.8} \mathrm{Ca}_{0.2} \mathrm{CrO}_{3}$,
3) $\mathrm{YCr}_{0.8} \mathrm{Co}_{0.2} \mathrm{O}_{3}(\mathrm{YCC})$,
4) $\mathrm{Y}_{0.8} \mathrm{Ca}_{0.2} \mathrm{Cr}_{0.8} \mathrm{Co}_{0.2} \mathrm{O}_{3}(\mathrm{YCCC})$
5) $\mathrm{Y}_{0.8} \mathrm{Ca} 0.2 \mathrm{Cr}_{0.9} \mathrm{Ni}_{0.1} \mathrm{O}_{3}(\mathrm{YCCN})$

were synthesized by sol-gel method as stated before. Different element dopants were adopted at A and/or B site in order to separate the possible roles of those relevant parameters in the catalytic activity, in terms of electrical conductivity, lattice oxygen activity, reducibility and etc. The 
phase purity and electrical conductivities were first measured and the influence on electrode performance was evaluated with EIS. The model of $\mathrm{H}_{2}$ oxidation was finally proposed.

\subsection{Phase purity, compatibility and electrical conductivities}

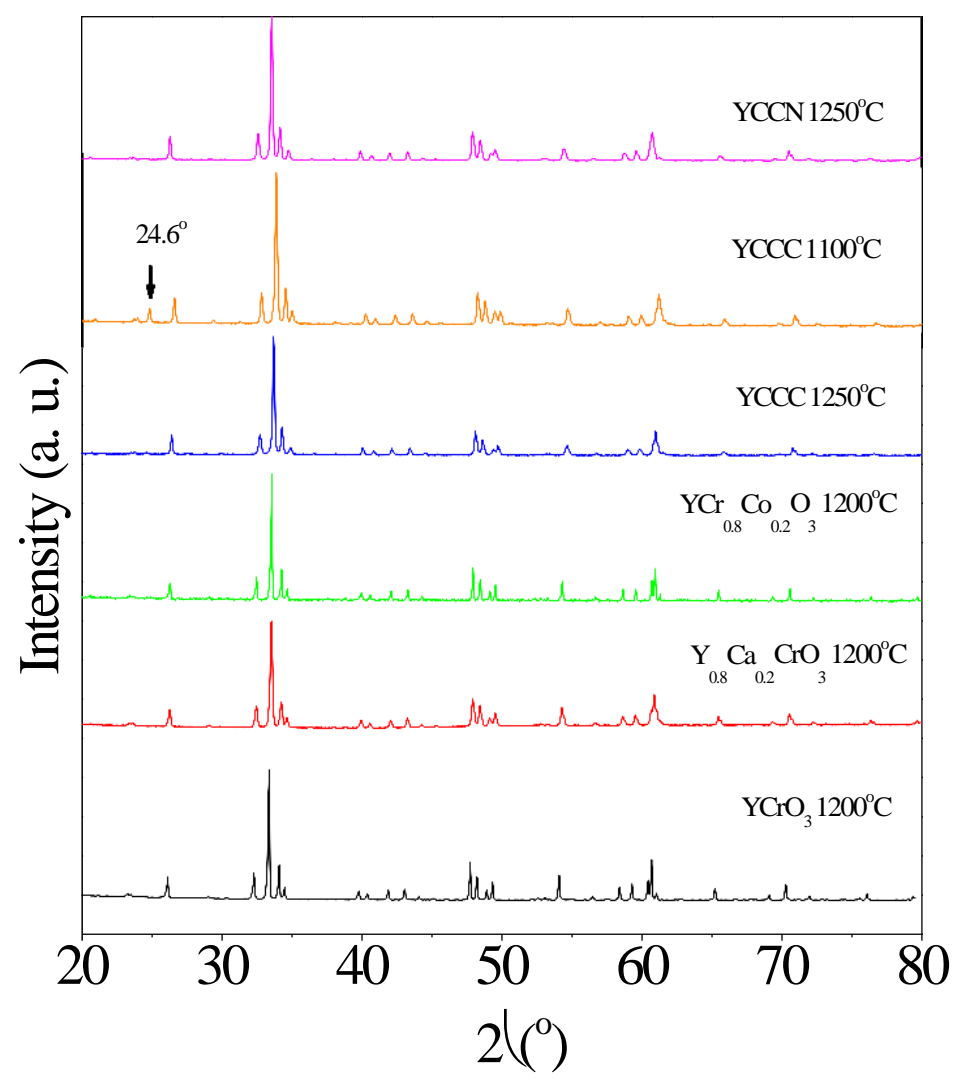

Fig. 5.1 XRD patterns for different YCs samples.

Fig. 5.1 shows the XRD spectra from the powder samples of pristine and doped $\mathrm{YCrO}_{3}$. Because the co-existence of $\mathrm{Ca}$ and $\mathrm{Co}$ in YCCC was found to make hard to obtain pure phase, it is worth a while to discuss such phenomenon in more detail. For YCCC treated at $1100^{\circ} \mathrm{C}$, a foreign peak marked with a triangle at around $24.6^{\circ}$ was detected and identified as the main peak of $\mathrm{Ca}_{2} \mathrm{Cr}_{2} \mathrm{O}_{5}$ (PDF\#48-0791) by Jade 5.0. It has been reported by K. J. Yoon etc. that pure phase 
Ca\&Co co-doped $\mathrm{YCrO}_{3}$ was obtained by glycine-nitrate method at $1200^{\circ} \mathrm{C}$.[72] And they also confirmed good chemical stability of such material in oxidizing and reducing atmosphere and good compatibility with YSZ. But in our study, it was observed that diffusion between YCCC pellet and YSZ felt holder occurred when sintered above $1200{ }^{\circ} \mathrm{C}$. The investigation of sintering behavior of Ca-Cr system has been conducted in lots of literature.[102-103] It was shown in those studies through the $\mathrm{CaO}-\mathrm{Cr}_{2} \mathrm{O}_{3}$ phase system, liquid phase would appear in $\mathrm{CaO}-\mathrm{Cr}_{2} \mathrm{O}_{3}$ when heating up to $\sim 1022^{\circ} \mathrm{C}$.[104] Therefore, doping Ca into Cr-based perovskite as a strategy was even employed to improve the sinterability because the transient liquid phase. $\mathrm{CaCrO}_{4}$, $\mathrm{Ca}_{3}\left(\mathrm{CrO}_{4}\right)_{2}, \mathrm{Ca} 5\left(\mathrm{CrO}_{4}\right)_{3}$, etc, appear at different sintering phrases, and will eventually dissolve into the lattice when elevated temperature along with prolonged sintering time is used. What's more, Co is found to be able to complicate the transition of transient liquid phase further. Doping Co into $(\mathrm{LaCa})(\mathrm{CrCo}) \mathrm{O}_{3}$ facilitates the formation of liquid phase, resulting in an above $94 \%$ sinterability at $1300^{\circ} \mathrm{C} .[105]$ Indeed, it also was confirmed herein that YCCC sample experienced a liquid sintering phrase in the middle of sintering process. Some area on the surface of YCCC pellet sintered at $1100{ }^{\circ} \mathrm{C}$ was coated by a glass-like phase, which can be seen by bare eye and also observed by SEM as shown in Fig. 5.2(a).
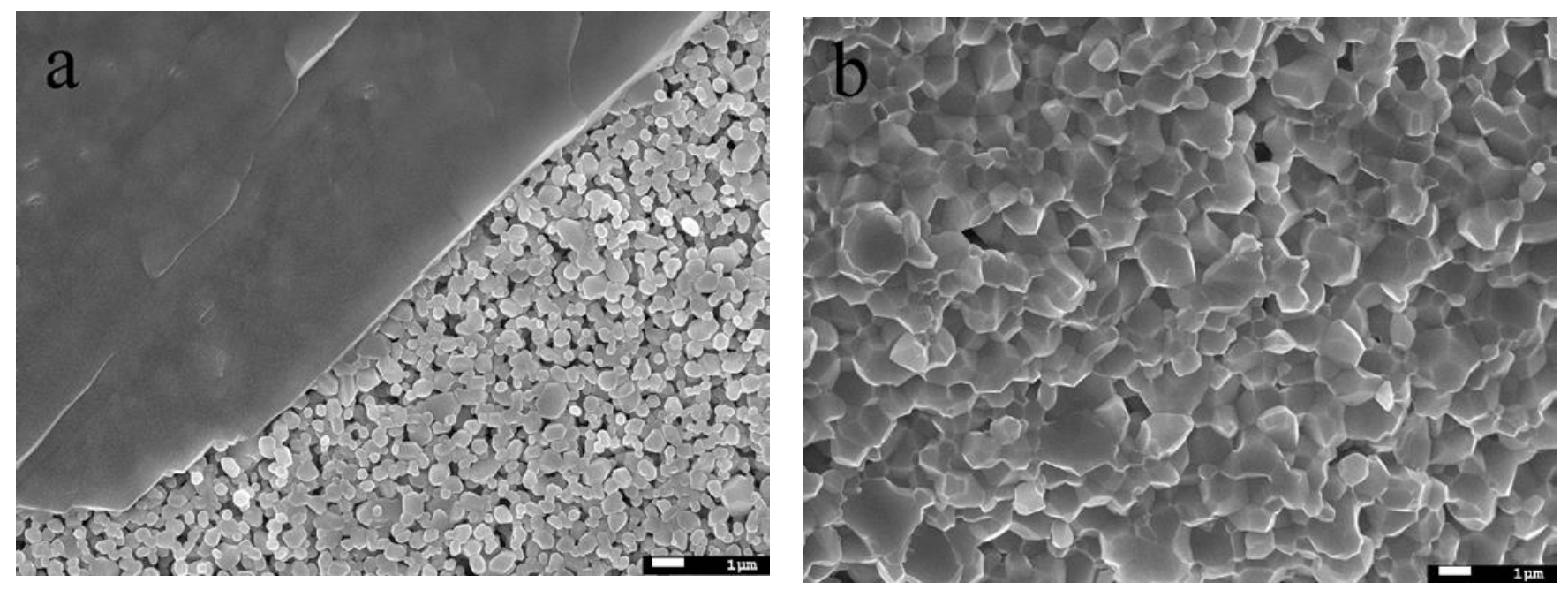

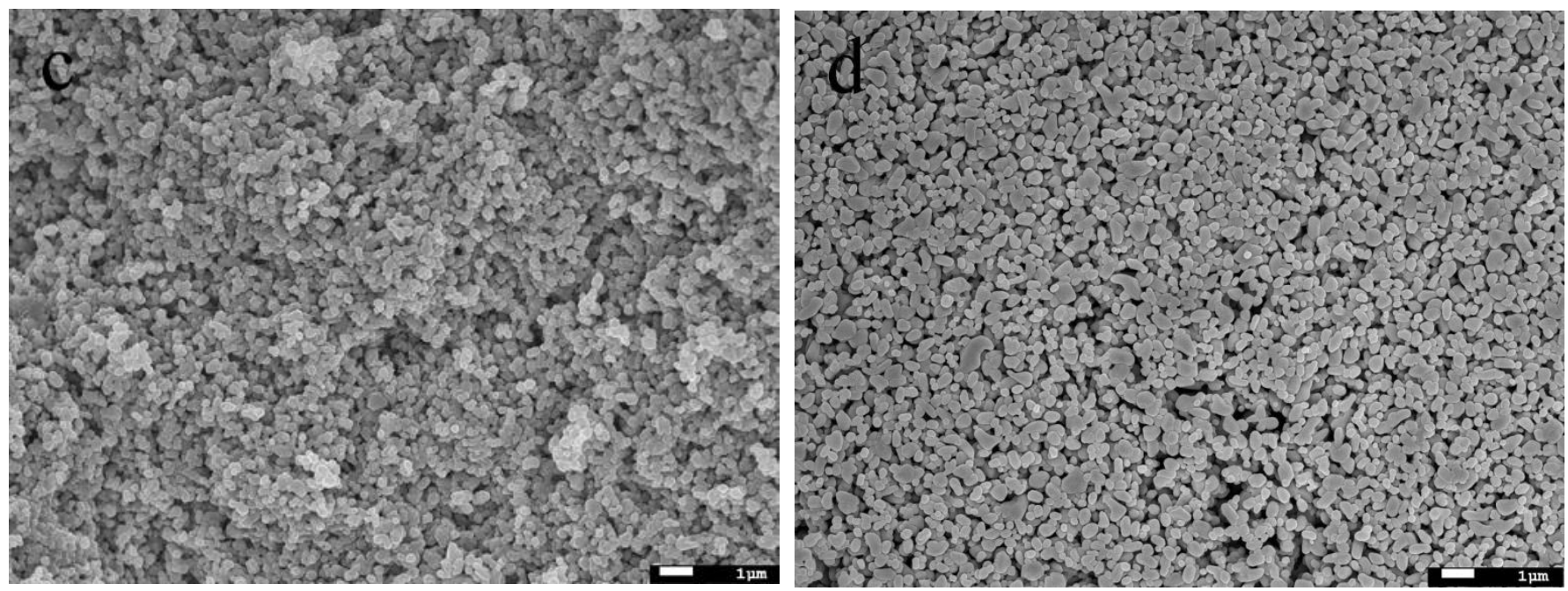

Fig. 5.2 Morphology of YCCC sintered at $1100^{\circ} \mathrm{C}$ (a), $1200^{\circ} \mathrm{C}(\mathrm{b}), \mathrm{Y}_{0.8} \mathrm{Ca}_{0.2} \mathrm{CrO}_{3}$ (c) and $\mathrm{YCCN}$ (d) sintered at $1200^{\circ} \mathrm{C}$.

Such phenomenon has not been observed on YCC or YCCN. The shrinkage simply calculated from the sizes of sample before and after sintering at $1400^{\circ} \mathrm{C}$, is $17 \%$ for $\mathrm{YCCC}$, compared to $15 \%$ for YCC and $12 \%$ for YCCN. Based on the facts above, it is clear that Co doping facilitates the formation of $\mathrm{Ca}-\mathrm{Cr}$ liquid phase, further improving the sinterability of yttrium chromites, even though Co itself somehow has not been significantly embraced into this phase. EDS was carried out and the results are shown in Fig. 5.3 and Table 2.1. This dense bulk phase shows the ratio of $\mathrm{Y}: \mathrm{Ca}: \mathrm{Cr}: \mathrm{Co}$ as $0.1: 1: 1.1: 0.03$, in which the $\mathrm{Ca}: \mathrm{Cr}$ ratio is consistent with the secondary phase $\mathrm{Ca}_{2} \mathrm{Cr}_{2} \mathrm{O}_{5}$ identified by XRD at $1100^{\circ} \mathrm{C}$. 


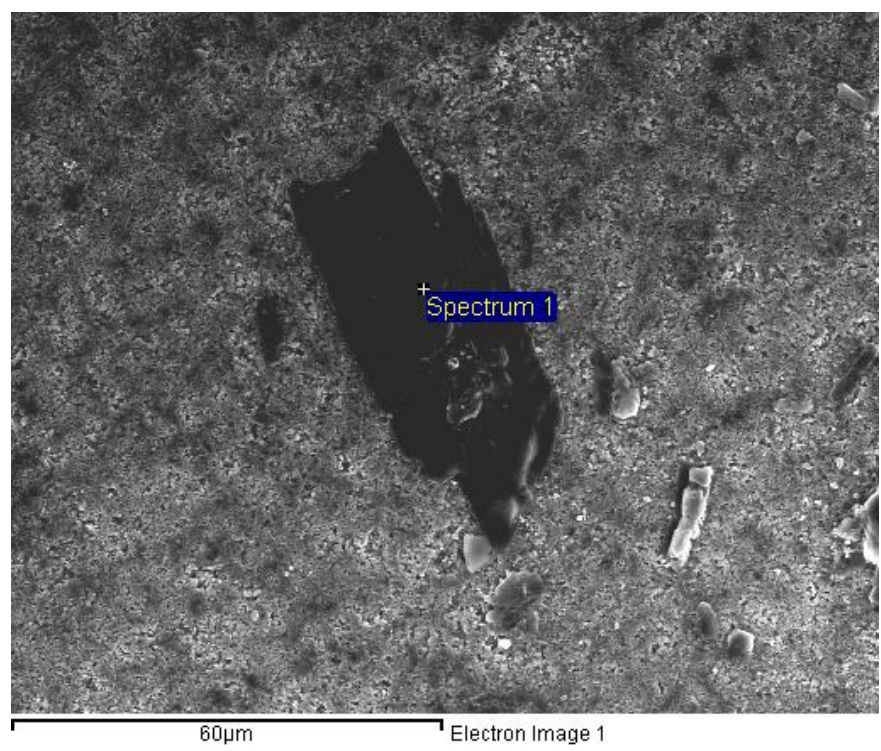

Fig. 5.3 EDS on impurity in YCCC.

Table 5.1 Composition of the impurity at spectrum 1 in YCCC.

\begin{tabular}{cccc}
\hline Element & Weight\% & Atomic\% & Relative ratio \\
\hline O K & 35.05 & 62.15 & 3.6 \\
Y L & 5.73 & 1.83 & 0.1 \\
Ca K & 23.37 & 16.54 & 1 \\
Cr K & 34.78 & 18.97 & 1.1 \\
Co K & 1.06 & 0.51 & 0.03 \\
\hline
\end{tabular}

Such phase in YCCC disappeared as shown in Fig. 5.2 (b) when calcined at $1200^{\circ} \mathrm{C}$. Accordingly, only a tiny peak at $24.6^{\circ}$ (the highest peak for $\mathrm{Ca}_{2} \mathrm{Cr}_{2} \mathrm{O}_{5}$ ) was detected by the XRD for $1200^{\circ} \mathrm{C}$ calcined YCCC powder. Another consequence of Co facilitating sintering is that the particle size of YCCC is larger than those of YCC and YCCN sintered at the same temperature. As can be seen in Fig. 5.2, the grain size is $0.2 \sim 0.5 \mu \mathrm{m}$ for YCC, $1 \sim 1.5 \mu \mathrm{m}$ for YCCC and 0.2 0.5 $\mu \mathrm{m}$ for YCCN respectively. At last, by sintering YCCC to $1250^{\circ} \mathrm{C}$ with 2 cycles of intermediate grinding, pure phase was obtained as shown by XRD in Fig. 5.1. For all other 
compounds under the marked calcined temperature, all patterns correspond to the orthorhombic perovskite structure (PDF\#48-0474), pure phase are at last obtained.

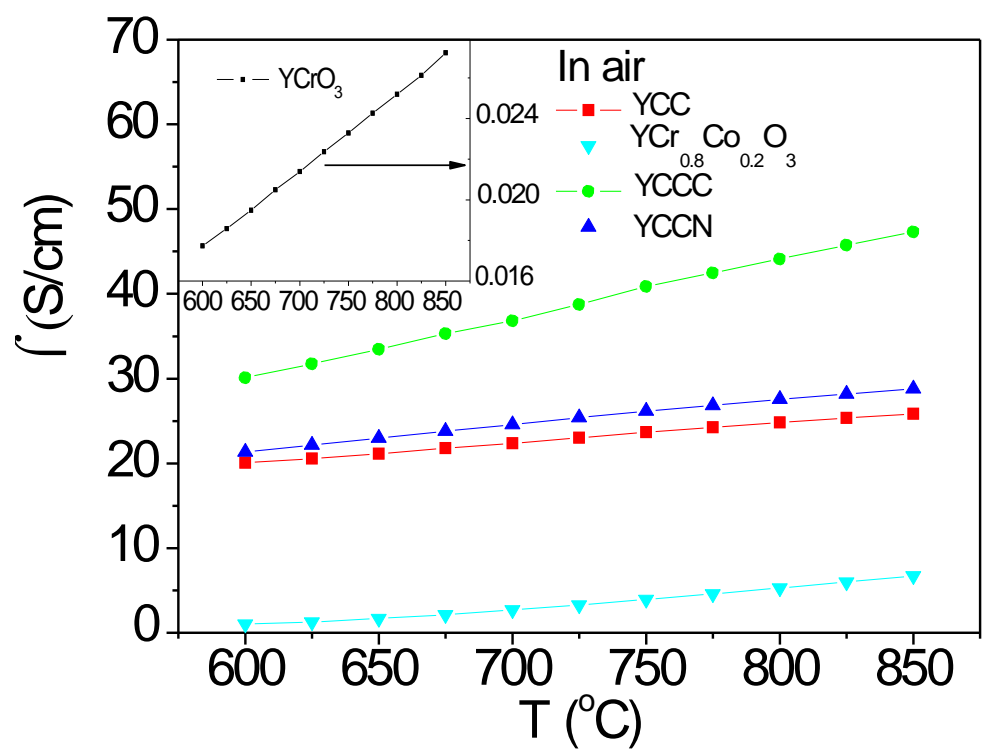

Fig. 5.4 Electrical conductivities for doped $\mathrm{YCrO}_{3}$ in air.

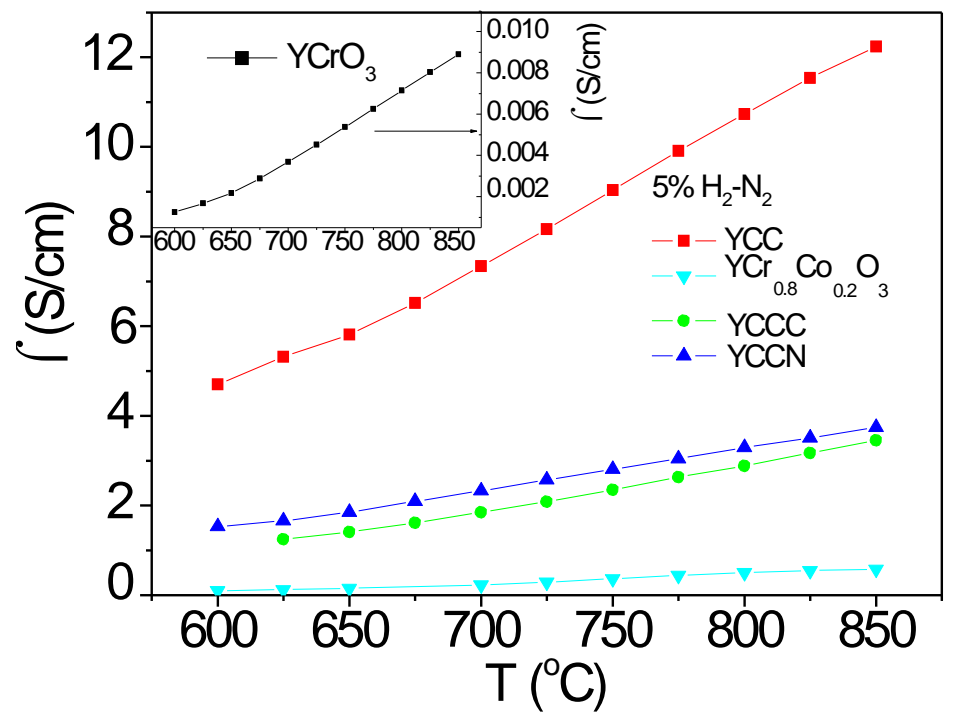

Fig. 5.5 Electrical conductivities for doped $\mathrm{YCrO}_{3}$ in $5 \% \mathrm{H}_{2}-\mathrm{N}_{2}$. 
Fig. 5.4 shows the electrical conductivities of $\mathrm{YCs}$ in air. $\mathrm{YCrO}_{3}, \mathrm{YCaCrO}_{3}, \mathrm{YCC}, \mathrm{YCCC}$ and YCCN pellets were all sintered in air at $1300^{\circ} \mathrm{C}$, except for YCCC at $1200^{\circ} \mathrm{C}$, resulting in $81 \%, 92 \%, 93 \%, 98 \%$, and $86 \%$ relative density. The data have been calibrated in terms of the porosity impact in a sphere sample.[106] Due to the very small concentration of intrinsic hole defects, $\mathrm{YCrO}_{3}$ exhibits electrical conductivity at $10^{-2} \mathrm{~S} / \mathrm{cm}$ order of magnitude. Doping regardless at A or B site as shown in Fig. 5.4 improves such value substantial by increase the hole concentration. Comparing YCCC and YCCN, the increase was much more pronounced for the former. The conductivity value reads $0.027,6.7,25,44$ and $28 \mathrm{Scm}^{-1}$ for $\mathrm{YCrO}_{3}$, $\mathrm{Y}_{0.8} \mathrm{Ca}_{0.2} \mathrm{CrO}_{3}$, YCC, YCCC and $\mathrm{YCCN}$ at $850^{\circ} \mathrm{C}$ respectively. The value of $\mathrm{YCCC}$ is comparable with published results, while for YCC, it almost doubles.[67] In reducing atmosphere as shown in Fig. 5.5, all the conductivities reduce tremendously because of the formation of vacancy and the resultant loss of holes because of the p-type nature of those semiconductors, which can be described in Kroger-Vink citation as:

$$
\begin{array}{rc}
\times & \times \\
2 \mathrm{M}_{\mathrm{M}}+\mathrm{O}_{\mathrm{O}}=2 \mathrm{M}_{\mathrm{M}}+\mathrm{V}_{\mathrm{O}}
\end{array}
$$

The conductivity reads $0.009,12,0.58,3.5$ and 3.7 for $\mathrm{YCrO}_{3}, \mathrm{Y}_{0.8} \mathrm{Ca}_{0.2} \mathrm{CrO}_{3}, \mathrm{YCC}$, YCCC and YCCN at $850^{\circ} \mathrm{C}$ respectively. Surprisingly, the highest value is from YCC. And even with further doping at $\mathrm{B}$ site, like YCCC and YCCN, the conductivity is not enhanced but instead reduced. Similar phenomenon has been reported on $\mathrm{Mn}$ doped $(\mathrm{LaSr}) \mathrm{CrO}_{3}$ by Raffaelle et al.[107] At doping level $<10 \%$ of $\mathrm{Mn}$ at $\mathrm{Cr}$ site, the conductivity reached its minimum. Such trend was explained by that the Mn site which possess lower energy level than $\mathrm{Cr}$ acts as hole trap that did not share the hole with its surrounding $\mathrm{Cr}$ sites once catching one, resulting in low hole concentration in the lattice. As Mn content increased, the chance of those trapped holes hopping between Mn sites rose, starting to building a conductive network again. In this sense, 
similar reason probably works here to mediate the conductivity. However, further experiment is needed to completely confirm this speculation.

Usually, the electrical conductivity of electrode materials is aimed at $\sim 100 \mathrm{~S} / \mathrm{cm}$. As in the traditional Ni/YSZ anode such conductivity has never been a problem, this criterion is only enforced upon the newly explored cathode materials. However, since the conductivities for those chromites are far below of $100 \mathrm{~S} / \mathrm{cm}$, its influence on electrode performance needs to be evaluated first. Even though $100 \mathrm{~S} / \mathrm{cm}$ is desirable, in more than few cases the newly developed materials cannot meet such standard which on the other hand still display modest to outstanding performance. Literally, electrical conductivity describes the easiness of transporting electronic charges (most of the time the ionic conductivity is much lower in the electrode materials) in the same medium. Therefore, it can be calculated how much the ohmic resistance is from the electrode part. Assuming the apparent conductivity of the practical porous electrode is $\sim 1 / 10$ of the dense bulk sample. For electrolyte-supported cell with electrode thickness of $50 \mu \mathrm{m}$, the ohmic resistance for $\mathrm{YCrO}_{3}, \mathrm{Y}_{0.8} \mathrm{Ca}_{0.2} \mathrm{CrO}_{3}, \mathrm{YCC}, \mathrm{YCCC}$ and $\mathrm{YCCN}$ anode at $850^{\circ} \mathrm{C}$ will be 5.5 , 0.004, 0.086, 0.014 and $0.014 \Omega \mathrm{cm}^{2}$, respectively. Compared to the allotment of $\sim 0.15 \Omega \mathrm{cm}^{2}$ for anode,[108] except for $\mathrm{YCrO}_{3}$ and $\mathrm{YCC}$, the others exhibit marginal ohimic resistance. If anodesupported configuration is used with a $300 \mu \mathrm{m}$ anode, those values increase up 6 times to 33, $0.024,0.516,0.084$ and $0.084 \Omega \mathrm{cm}^{2}$. It renders only YCCC and YCCN suitable for this application. However, except the ohmic resistance, the role of electrical conductivity has to be considered in the catalytic activity as will be shown below. 


\subsection{Factors determining catalytic activity in $\mathbf{H}_{2}$ oxidation}

The electrochemical performance evaluation was carried out on symmetrical cells. Before that, the compatibility between those chromites and YSZ electrolyte was checked by XRD. Fig. 5.6 displays the phase compatibility between doped $\mathrm{YCrO}_{3}$ and $\mathrm{YSZ}$ at fabrication and testing conditions. No chemical reaction is observed in the limit of XRD, showing good compatibility between those compounds.

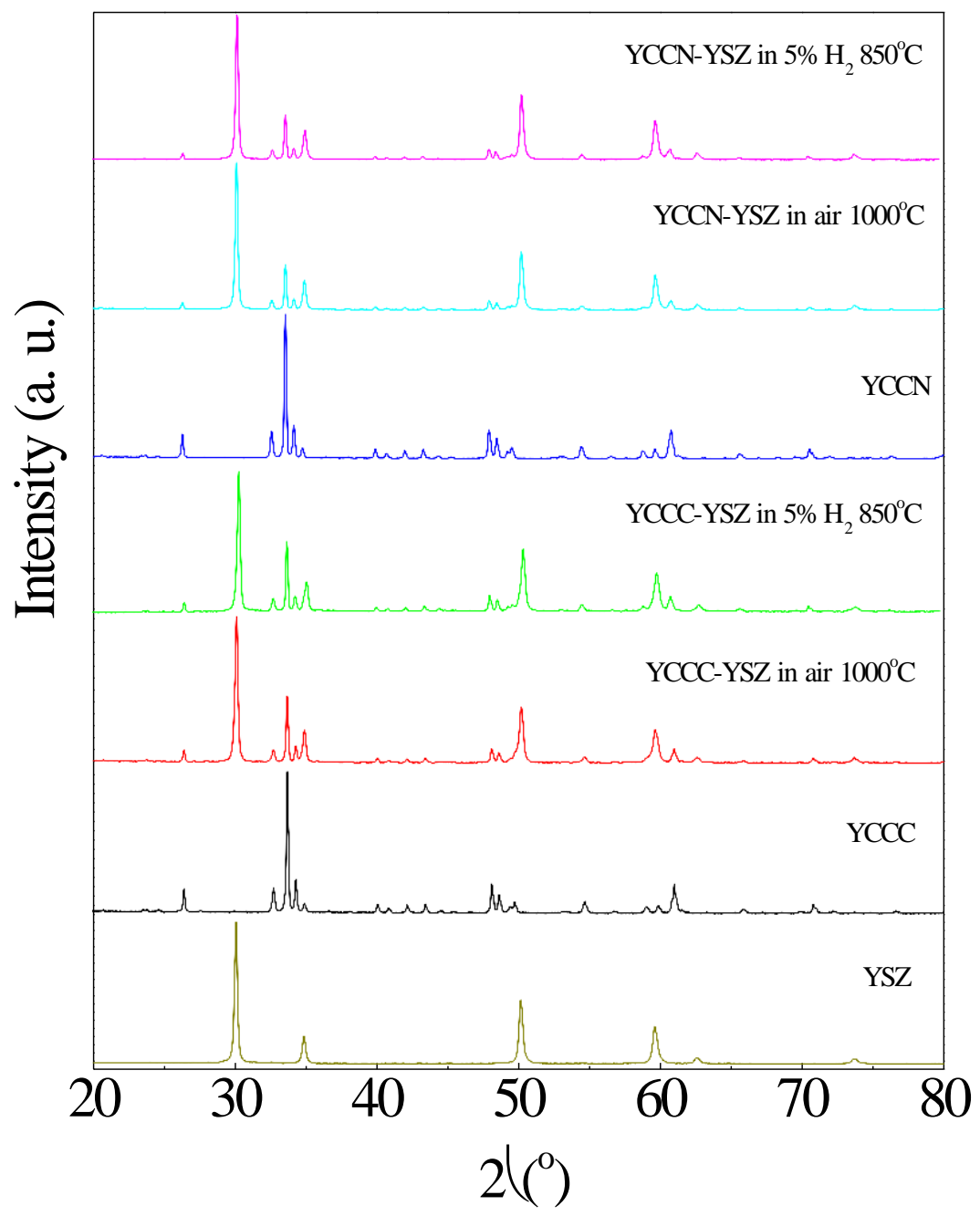

Fig. 5.6 XRD patterns for compatibility between YSZ and chromites in the electrode preparation condition and electrochemical testing condition. 

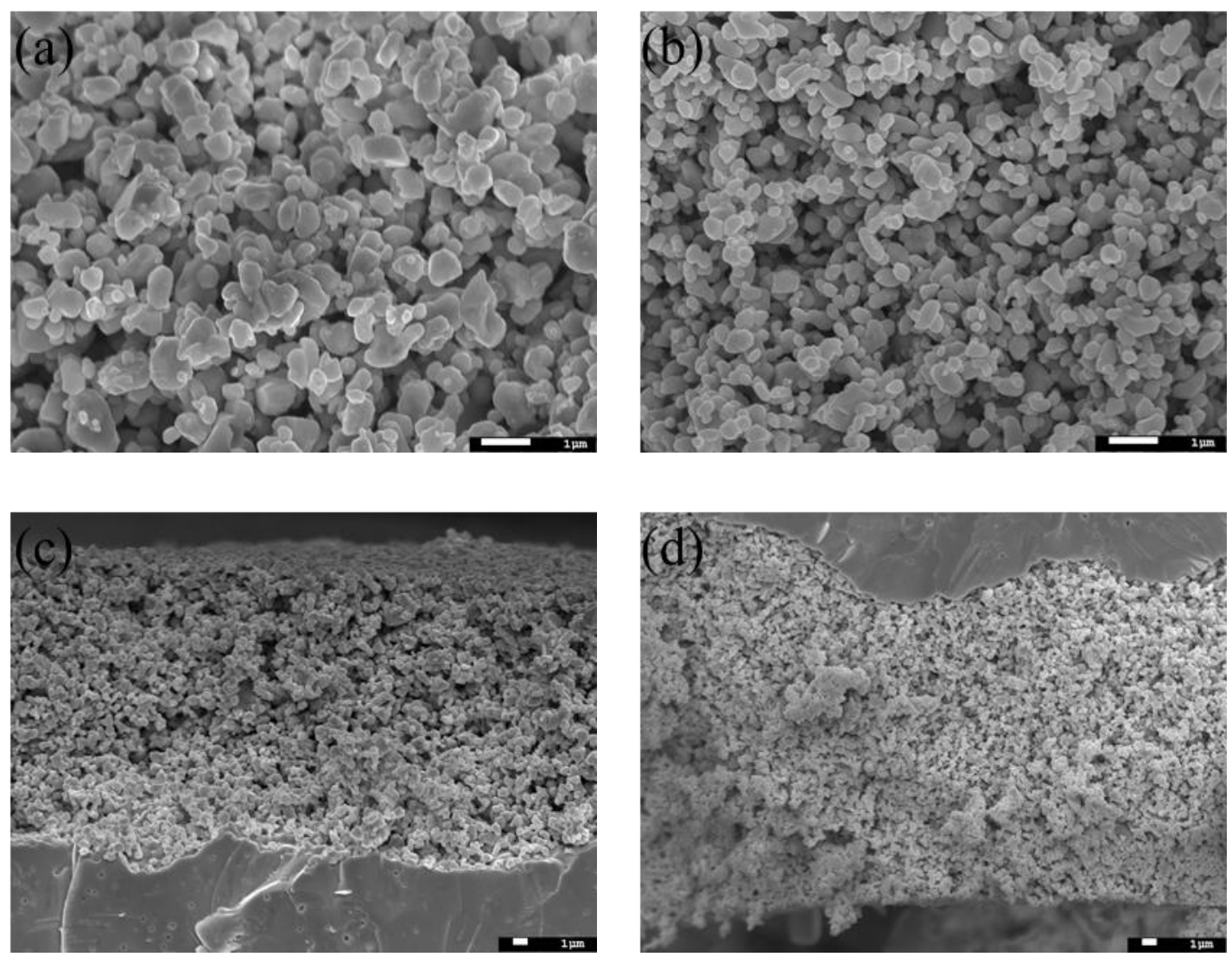

Fig. 5.7 morphology of YCCC (a), YCCN (b) and the microstructure of YCCC/YSZ (c), YCCN/YSZ (d) electrodes

Fig. 5.7 shows the morphology of YCCC (a) and YCCN (b) particles, and the microstructure of different electrodes (c for YCCC-YSZ, d for YCCN-YSZ). The particle size is 0.5 1 $\mu \mathrm{m}$ for YCCC and 0.3 0.5 $\mu \mathrm{m}$ for YCCN, separately. All electrodes have the similar thickness, $\sim 20 \mu \mathrm{m}$. No diffusion or reaction can be seen in the electrode/electrolyte interface, which is in agreement with the XRD results. The surface of electrolyte pellets was roughened during the dry-pressing process to improve the electrode/electrolyte bond, which can be seen clearly in c and $\mathrm{d}$. 
To illustrate the importance of electrical conductivity, two extremes, $\mathrm{Y}_{0.8} \mathrm{Ca}_{0.2} \mathrm{CrO}_{3}$ with the biggest and YCC with the smallest conductivity, were measured by EIS in wet $\mathrm{H}_{2}$ at different temperatures. Fig. 5.8a shows the performance for $\mathrm{Y}_{0.8} \mathrm{Ca}_{0.2} \mathrm{CrO}_{3}$. Even though the performance is thermally activated, it is around $240 \Omega \mathrm{cm}^{2}$ at $850^{\circ} \mathrm{C}$, too big to have any practical use in anode. In comparison, the performance for YCC in Fig. 5.8b at the same conditions is much better, which reads $8 \Omega \mathrm{cm}^{2}$ at $850^{\circ} \mathrm{C}$. This simple comparison unambiguously indicates that the electrical conductivity (mainly electronic conductivity for those chromites) is not the determining factor of performance, but the nature of B site element affects it substantially.
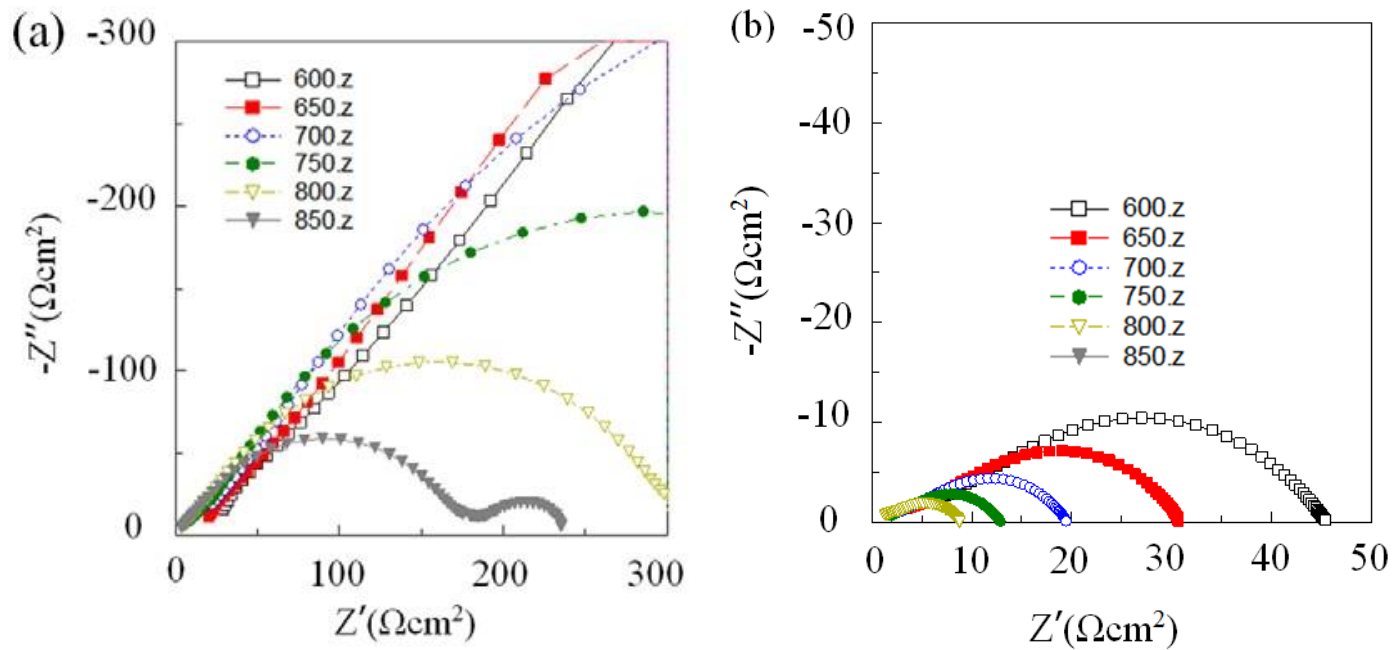

Fig. 5.8 EIS of (a) $\mathrm{Y}_{0.8} \mathrm{Ca}_{0.2} \mathrm{CrO}_{3}$ and (b) $\mathrm{YCC}$ in wet $\mathrm{H}_{2}$ at different temperatures. 


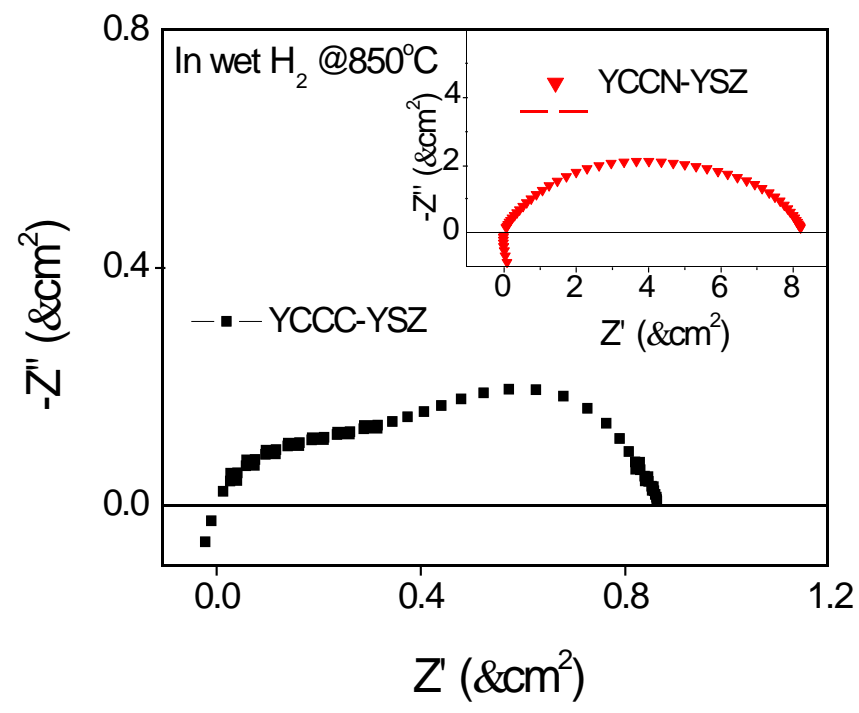

Fig. 5.9 Performance for YCCC and YCCN on YSZ electrolyte in wet $\mathrm{H}_{2}$.

Fig. 5.9 shows the performance for the rest samples, YCCC and YCCN. Good performance is obtained with YCCC anode. The polarization resistance $0.96 \Omega \mathrm{cm}^{2}$ is among the best ones available from literature. It means materials with good electrical conductivity and active B site elements give rise to good performance. However, as stated above, electrical conductivity can only cast a negligible influence on the ohmic resistance. Therefore, the correlation between electrical conductivity with polarization resistance is important. After doping $\mathrm{Ca}$ at $\mathrm{A}$ site to make YCC into YCCC, the performance is $\sim 10$ times better than before. Given the B site composition is totally the same, the difference should stem from the electron part. So, it is more appropriate to refer to the influence from electron part as electron activity instead of electrical conductivity. In all the element steps, charge transfer step is directly affected by the electron Fermi level in the anode materials. Therefore, charge transfer step could be a rate-limiting step in YCC and is improved in YCCC, which we will discuss in detail below. 


\subsection{Rate-limiting steps on doped $\mathrm{YCrO}_{3}$ anodes}
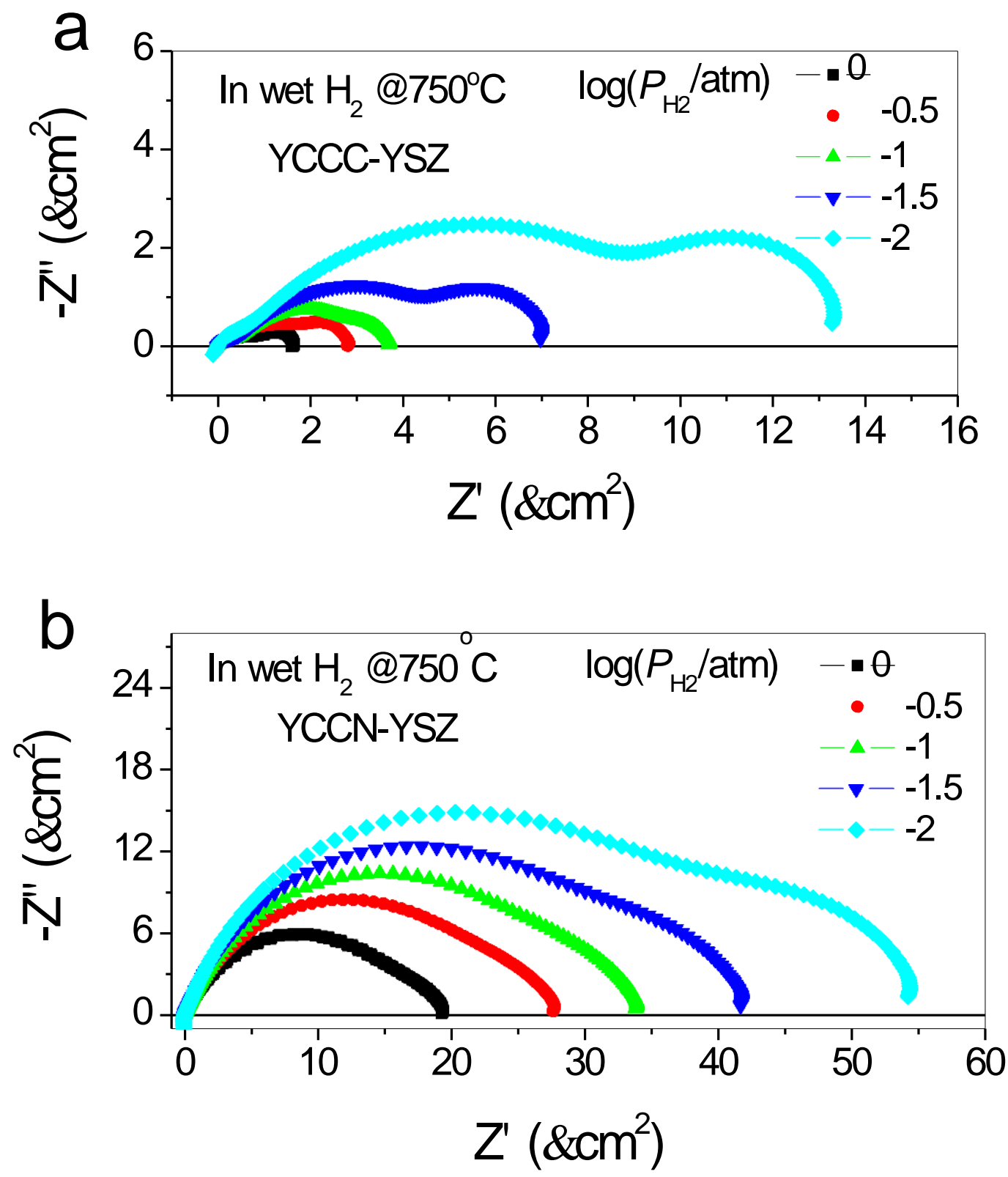

Fig. 5.10 $\mathrm{P}_{\mathrm{H} 2}$-dependent polarization resistances of YCCC (a) and YCCN (b) in $750^{\circ} \mathrm{C}$ on YSZ.

The electrochemical behaviors of YCCC and YCCN under different $P_{\mathrm{H} 2}$ are characterized. The high frequency intercept for the ohmic loss has been subtracted from the Cole-Cole plots. All spectra feature two-arc profile, as shown in Fig. 5.10. 

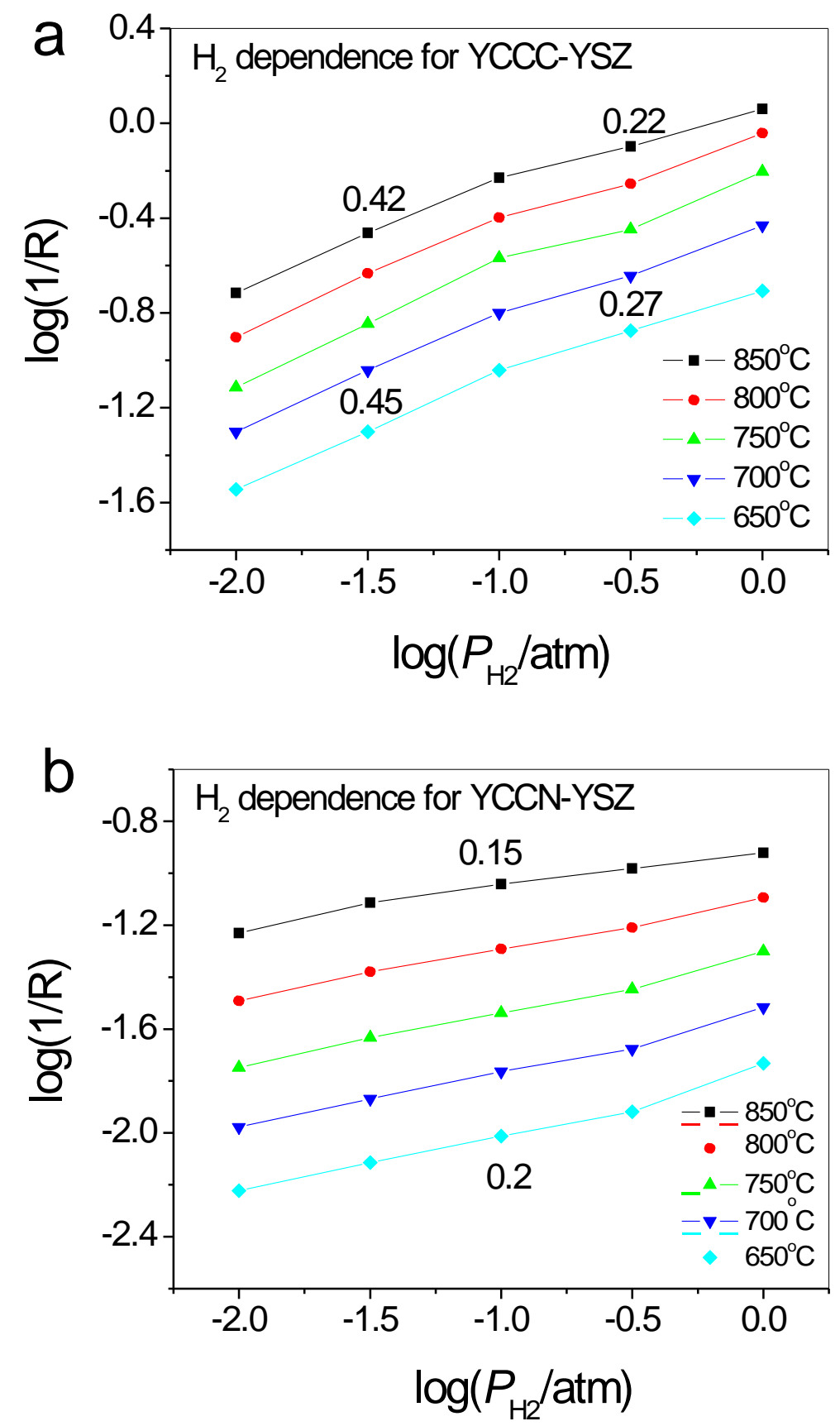

Fig. 5.11 Reaction orders of the overall polarization resistances for YCCC (a) and YCCN (b).

The corresponding reaction orders $(n)$ in the relationship of $1 / R \quad P_{\mathrm{H} 2}^{n}$ are plotted in Fig. 5.11. The overall polarization resistances demonstrate reaction orders of $0.2-0.45$ and $0.15-0.2$ 
for YCCC and YCCN at different temperatures, respectively. In the Ni-YSZ system, results on partial pressure dependence have been extensively reported in literature [77, 88, 109-112]. Jiang et al. reported the $\mathrm{HF}$ arc for $\mathrm{Ni} / \mathrm{YSZ}$ electrode decreased when $\mathrm{H}_{2}$ content in $\mathrm{H}_{2}-\mathrm{N}_{2}$ (with constant $2 \% \mathrm{H}_{2} \mathrm{O}$ ) mixture decreased from $98 \%$ to $10 \%$ [110]. It is suggested more O-Ni bond or sub-oxide at $\mathrm{Ni}$ surface stemmed from higher $P_{\mathrm{O} 2}$ facilitated dissociative adsorption and diffusion of $\mathrm{H}$ from electrode to $\mathrm{YSZ}$ surface near 3PB, which in turn elevated the rate of charge transfer at 3PB. M. Brown et al. found resistances for high frequency arc were complicatedly dependent with $P_{\mathrm{H} 2}[111,113]$. In their study reaction order of this arc towards $P_{\mathrm{H} 2}$ varied from 1.15 to 0.15 at constant $\mathrm{H}_{2} \mathrm{O}$ content when different configurations of Ni/YSZ anode were used. In addition, for the $\mathrm{Ni}$ film anodes used by $\mathrm{N}$. Nakagawa [112] $\mathrm{HF}$ arc exhibited no $\mathrm{H}_{2}$ dependence in the $P_{\mathrm{H} 2}$ range from $10^{-2}$ to 1 with constant $2 \% \mathrm{H}_{2} \mathrm{O}$. However, none of the observations in Ni-YSZ system can be easily applied to interpret the kinetic behavior of ceramic anodes and there have been very few studies on $\mathrm{H}_{2}$ oxidation mechanism in ceramic anodes in SOFC. In the studies of catalytic activity of anode material by J. Rossmeisl and T. setoguchi [114-115], it was concluded that for a desirable anode catalyst, the strength of oxygen-metal bond should be strong enough to get oxygen transported from electrolyte and weak enough to avoid poisoning the catalyst surface. Of all the metal elements investigated, Ni showed medium bind energy with $\mathrm{O}$, resulting in the highest catalytic activity. From this point of view, the intermediate binding energy between $\mathrm{Ni}$ and $\mathrm{O}$ might be the key for the O-Ni species to work out. In contrast, doped $\mathrm{YCrO}_{3}$ with mostly $\mathrm{Cr}$ at $\mathrm{B}$ site display poor $\mathrm{O}$ adsorption according to kinetics of $\mathrm{O}_{2}$ adsorption and non-stoichiometric surface behavior studies [116-117]. Therefore it is difficult for YCs to hold $\mathrm{O}$ stably on the surface especially in an extremely reducing 
atmosphere. In addition, relatively high surface $\mathrm{H}$ coverage is demanded in spillover effect. Otherwise the supply of $\mathrm{H}$ would be mitigated by lowering $P_{\mathrm{H} 2}$.

Because of the two-arc profiles exhibited by YCCC and YCCN, all spectra were fitted using the equivalent circuit as shown in Fig. 5.12, where $L_{1}$ represents the overall inductance from the test-stand, $R_{0}$ the total ohmic resistance composed of contributions from electrolyte, electrodes and lead wires, $R_{1}$ and $R_{2}$ represents the polarization resistance in HF and LF. The constant phase element (CPE) is adopted due to the frequency dispersion phenomenon in electrode processes.

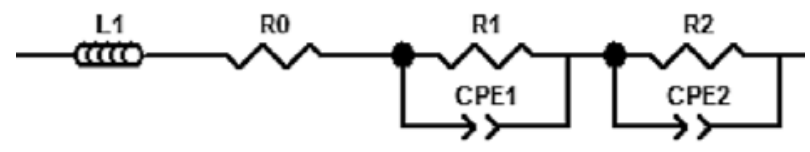

Fig. 5.12 Equivalent circuit used to fit the EIS of YCCC and YCCC anodes.

Table 5.2 $R, C$ and $f_{0}$ for HF and LF arcs after fitting YCCC and YCCN anodes tested in at $850^{\circ} \mathrm{C}$, and the corresponding $E$ a as well as reaction order $(n)$ in the temperature and $P_{\mathrm{H} 2}$ ranges used in the work.

\begin{tabular}{ccccccc}
\hline \multicolumn{2}{c}{$\begin{array}{c}\text { In wet } \mathrm{H}_{2} \\
\text { at } 850\end{array}$} & $R\left(\Omega \mathrm{cm}^{2}\right)$ & $C\left(\mathrm{~F} / \mathrm{cm}^{2}\right)$ & $f_{\mathrm{o}}(\mathrm{Hz})$ & $E \mathrm{Ca}(\mathrm{eV})$ & $n$ \\
\hline \multirow{2}{*}{$\mathrm{HF}$ arc } & YCCC & 0.65 & $5.2 \times 10^{-5}$ & 3500 & 1.0 & $0.25 \sim 0.33$ \\
& $\mathrm{YCCN}$ & 5.2 & $5.3 \times 10^{-5}$ & 530 & 1.6 & $0.10 \sim 0.16$ \\
\hline \multirow{2}{*}{$\begin{array}{l}\mathrm{LF} \\
\text { arc }\end{array}$} & $\mathrm{YCCC}$ & 0.33 & $6.9 \times 10^{-3}$ & 70 & 0.8 & $0.34 \sim 0.50$ \\
& YCCN & 3.2 & $1.1 \times 10^{-3}$ & 45 & 0.6 & $0.18 \sim 0.37$ \\
\hline
\end{tabular}

Table 5.2 summarizes the fitting results of the resistance $(R)$, capacitance $(C)$ and characteristic frequency $\left(f_{0}\right)$ for HF and LF arcs of two electrodes tested in the case of wet $\mathrm{H}_{2}$ 
(without $\mathrm{N}_{2}$ ) at $850^{\circ} \mathrm{C}$, as well as reaction order $(n)$ in the relationship of $1 / R P_{\mathrm{H} 2}$ and apparent activation energy $(\mathrm{Ea})$ obtained in the testing temperature $\left(650 \sim 850^{\circ} \mathrm{C}\right)$ and $P_{\mathrm{H} 2}(0.01 \sim 1$ atm) ranges. The overall $\mathrm{H}_{2}$ oxidation reaction in anode can be represented in Eq. 5.2,

$$
\mathrm{H}_{2}+\mathrm{O}_{\mathrm{O}} \leftrightarrow \mathrm{H}_{2} \mathrm{O}+\mathrm{V}_{\mathrm{O}}+2 \mathrm{e}
$$

Several sub-steps must occur before $\mathrm{H}_{2}$ is thoroughly oxidized as above. A model for the reaction path on YCs anodes can be presented in Table 5.3 as following:

Table 5.3 A model for $\mathrm{H}_{2}$ oxidation reaction at $\mathrm{YCs}$ anode.

\begin{tabular}{|c|c|c|}
\hline & $\mathrm{H}_{2}$ oxidation model & $n$ in $P_{\mathrm{H} 2}^{n}$ \\
\hline Step 1 & $\mathrm{H}_{2} \square 2 \mathrm{H}_{\mathrm{ads}, \mathrm{YCs}}$ & 1 \\
\hline Step 2 & $\mathrm{H}_{\mathrm{ads}, \mathrm{YCs}} \square \mathrm{H}_{\mathrm{ads}, 3 \mathrm{~PB}}$ & $1 / 2$ \\
\hline Step 3 & $\mathrm{H}_{\mathrm{ads}, 3 \mathrm{~PB}}+\mathrm{OH}_{\mathrm{ads}, 3 \mathrm{~PB}} \square \mathrm{H}_{2} \mathrm{O}+e$ & $1 / 4$ \\
\hline Step 4 & $\mathrm{H}_{\mathrm{ads}, 3 \mathrm{~PB}}+\mathrm{O}_{\mathrm{O}}^{\mathrm{X}} \square \mathrm{V} \underset{\mathrm{O}}{\square}+\mathrm{OH}_{\mathrm{ads}, 3 \mathrm{~PB}}+e$ & $1 / 4$ \\
\hline \multicolumn{3}{|c|}{ Split step 4: } \\
\hline Step 4' & $\mathrm{O}_{\mathrm{O}}^{\mathrm{X}} \square \mathrm{V}_{\mathrm{O}}^{\square \square}+\mathrm{O}_{\mathrm{ads}, 3 \mathrm{~PB}}+e$ & $-1 / 4$ \\
\hline Step 4” & $\mathrm{H}_{\text {ads, 3PB }}+\mathrm{O}_{\text {ads, 3PB }} \square \mathrm{OH}$ ads, 3РB & 0 \\
\hline
\end{tabular}

Four basic assumptions are taken:

1) these reactions are microscopic reversible;

2) the adsorption of any species is governed by Langmuir type isotherm; 
3) the surface coverage for all adsorbed species is low;

4) the stoichiometric change of oxygen in anode materials is neglected

to simplify the derivation. The corresponding reaction rate for step 1 4 can be written as:

$$
\begin{gathered}
r_{1}=k_{1} P_{\mathrm{H}_{2}} k_{1} a_{\mathrm{H}, \mathrm{YCs}}^{2} \\
r_{2}=k_{2} a_{\mathrm{H}, \mathrm{YCs}} k_{2} a_{\mathrm{H}, 3 \mathrm{~PB}} \\
r_{3}=k_{3} a_{\mathrm{H}_{3}, 3 \mathrm{~PB}} a_{\mathrm{OH}^{-}, 3 \mathrm{~PB}} \exp \left(\AA_{1} f E\right) \quad k_{3} P_{\mathrm{H}_{2} \mathrm{O}} \exp \left(\alpha_{1} f E\right) \\
r_{4}=k_{4} a_{\mathrm{H}, 3 \mathrm{~PB}} \exp \left(\otimes_{2} f E\right) \quad k_{4} a_{\mathrm{OH}^{-}, 3 \mathrm{~PB}} \exp (\alpha f E)
\end{gathered}
$$

where $k_{i}$ and $k_{i}$ are the rate constants for the corresponding anodic and cathodic reaction; $\mathrm{f}=F / R T(F, R$ and $T$ have their usual physical meaning $)$ and $E$ the electrode potential. $\alpha_{\mathrm{i}}$ and $\beta_{\mathrm{i}}$ are symmetric coefficients, $\alpha_{\mathrm{i}}+\beta_{\mathrm{i}}=1$. If first assuming step 4 the RDS other steps are in near equilibrium state. It follows:

$$
\begin{gathered}
a_{\mathrm{H}, \mathrm{YCs}}=\sqrt{\frac{k_{1} P_{\mathrm{H}_{2}}}{k_{1}}} \\
a_{\mathrm{H}, 3 \mathrm{~PB}}=\frac{k_{2} a_{\mathrm{H}, \mathrm{YCs}}}{k_{2}}=\frac{k_{2}}{k_{2}} \sqrt{\frac{k_{1}}{k_{1}} P_{\mathrm{H}_{2}}} \\
a_{\mathrm{OH}^{-}, 3 \mathrm{~PB}}=\frac{k_{3} P_{\mathrm{H}_{2} \mathrm{O}}}{k_{3} a_{\mathrm{H}, 3 \mathrm{~PB}}} \exp (f E)=\sqrt{\frac{k_{1}}{k_{1}}} \frac{k_{2}}{k_{2} k_{3}} \sqrt{\frac{P_{\mathrm{H}_{2} \mathrm{O}}^{2}}{P_{\mathrm{H}_{2}}}} \exp (f E)
\end{gathered}
$$

Inserting Eq. 5.7 9 into 5.6 gives 


$$
\begin{aligned}
& \left.r=\sqrt{\frac{k_{1} P_{\mathrm{H}}}{2}} \frac{k_{2}}{k} \exp _{\circledast}^{\exp } f E\right) \sqrt{\frac{k_{1}}{k_{2} k_{3} k_{4}} P} \quad \exp [(1+\alpha) f E] \\
& \begin{array}{lllllllll}
4_{1} & k_{2} & 2 & k_{1} P_{\mathrm{H}_{2}} & k_{2} k_{3} & \mathrm{H}_{2} \mathrm{O} & 2
\end{array}
\end{aligned}
$$

Eq. 5.10 represents the reaction rate of step 4 at the steady state, and the corresponding current density is $i=n F r$. In equilibrium conditions, no net current flows through the anode, i.e., $r_{4}=0$, which yields the Nernst potential

$$
E=\text { const }+\frac{R T}{2 F} \ln \frac{P_{\mathrm{H}_{2} \mathrm{O}}}{P_{\mathrm{H}_{2}}}
$$

Inserting Eq. 5.11 back into 5.10 we obtain the relationship $\underset{\mathrm{o}, 4}{i} \underset{\mathrm{H}_{2}}{P^{1 / 4}}$ (take $\alpha_{2}=\beta_{2}=0.5$ ), $i_{0,4}$ the exchange current density for step 4 in equilibrium. In the same way, all remaining reaction orders tabulated in the Table 5.3 above can be derived.

\subsection{H-must charge transfer reaction}

In the above model, step 4 seems not to be an elementary one and therefore could be split into two steps, step 4' and 4". By splitting step 4 into two simpler reactions, the reaction rates for step 4' and 4',

$$
\begin{gathered}
r_{4^{\prime}}=k_{4^{\prime}} \exp \left(\otimes_{2} f E\right) \quad k_{4^{\prime}} a_{\mathrm{O}^{-}, 3 \mathrm{~PB}} \exp \left(\alpha_{2} f E\right) \\
r_{4^{\prime \prime}}=k_{4^{\prime \prime}} a_{\mathrm{H}, 3 \mathrm{~PB}} a_{\mathrm{O}^{-}, 3 \mathrm{~PB}} \quad k_{4^{\prime \prime}} a_{\mathrm{OH}^{-}, 3 \mathrm{~PB}}
\end{gathered}
$$

Assuming step 4' the rate limiting step, step 1 3 yield the same relationship as in Eq. 
5.7 9 and step 4' gives: 


$$
\begin{aligned}
& a=\frac{k^{4 "} a_{\mathrm{OH}-, 3 \mathrm{~PB}}}{k a}=\frac{k_{1} \mid}{\mathrm{O}^{-}, 3 \mathrm{~PB}} \frac{\left.k_{2}\right)^{2}}{k} \frac{k^{3} k^{4} P^{\mathrm{H}_{2} \mathrm{O}}}{k k \quad P} \exp (\quad) \\
& \text { 4" } \left.\mathrm{H}, 3 \mathrm{~PB} \quad k_{1}\right\} 2_{2} \quad 34^{\prime \prime} \quad \mathrm{H}_{2}
\end{aligned}
$$

Substituting those expressions in Eq. 5.7 8, 3.14 for terms in 5.12 gives

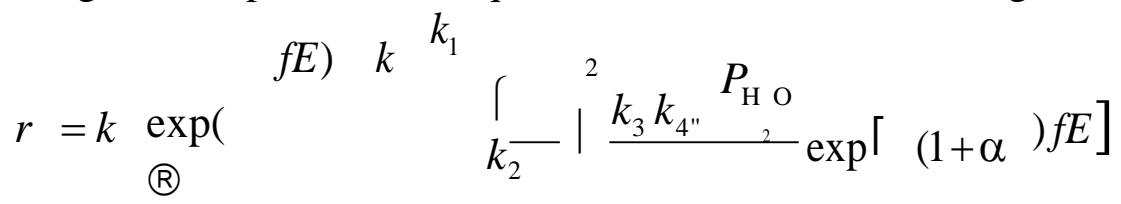

$$
\begin{aligned}
& \text { 4. } 4^{\prime} \quad 2 \\
& \left.\left.{ }^{4} k_{1}\right\}_{\{} k_{2}\right\} \underset{34^{\prime \prime}}{k_{\mathrm{H}_{2}}} P_{2}
\end{aligned}
$$

Similarly, the Nernst potential can be derived in equilibrium and the relationship $i_{0,4^{4}} \quad P_{\mathrm{H}_{2}}{ }^{1 / 4}$ can be readily obtained by inserting 5.11 back into 5.15 .

The compelling consequence found is whether writing the oxygen ion transfer step explicitly, as in step 4', affects the final $P_{\mathrm{H} 2}$ dependence of the charge transfer step. Step $4^{\prime}$ is exactly the same as that in the cathode reaction mechanism and the calculated $P_{\mathrm{H} 2}$ dependence is $-1 / 4$, consistent with the $P_{\mathrm{O} 2}$ dependence of $1 / 8$ in the cathode. Judging by the positive charge transfer reaction orders listed in Table 5.2 for YCCC and YCCN electrodes, it means either step 4' is nonexistent in the present anode system or must be faster than any other steps in any conditions so that it won't be detected. The latter is obviously impossible given the extremely low $P_{\mathrm{O} 2}$ in the anode conditions.

Because the charge carrier in the electrolyte is $\mathrm{O}^{2-}$, it might be fair for one to view the 
change of $P_{\mathrm{H} 2}$ in reducing conditions solely as a way to adjust the $\mathrm{O}_{2}$ content in these atmospheres. Indeed, the Nernst potential of a fuel cell can be written in the form of an $\mathrm{O}_{2}$ 
concentration cell by merely taking $P_{\mathrm{O} 2}$ into account.[88, 118] This consequently leads to the idea that $P_{\mathrm{O} 2}$ is the major factor which affects the electrode performance even when tested in anode conditions. Although this assumption is valid when testing cathodes, it is not true for the anode measurement made in reducing atmospheres. Here the resistances decrease as $P_{\mathrm{H} 2}$ increases, or in other words, as $P_{\mathrm{O} 2}$ decreases as shown in Fig. 5.11. As a result, it seems $\mathrm{H}_{2}$ not only works to lower $P_{\mathrm{O} 2}$ but also must participate in the reaction where charge transfer happens. This can explain that in the model in Table 5.3, the steps having electrons transferred but without involving $\mathrm{H}$ would give a negative reaction order. From this point of view, what matters is actually not how to rearrange the reaction step possibly but how to build the charge transfer step in anode appropriately. An available result that may be relevant to this idea is the modeling study on Ni/YSZ pattern anode by Vogler et al.[89]

To investigate the mechanism of charge transfer, five possible scenarios in the Ni-YSZ anode were proposed. The charge transfer steps they adopted for those oxygen spillover scenarios only included oxygen species on YSZ and $\mathrm{Ni}$, whereas the hydrogen spillover ones included both oxygen and hydrogen species. The calculation results showed that only a double hydrogen spillover pathway could reproduce the experimental trends of the $P_{\mathrm{H} 2}$ dependent polarization resistance, and all oxygen spillover mechanisms led to the opposite trends. In this regard, the $\mathrm{H}_{2}$ oxidation mechanisms proposed in literature can be divided into two categories according to how the charge transfer process is constructed: with $\mathrm{H}$ participating, and with only $\mathrm{O}$ involved. In reality, both cases have been used in the modeling work of Ni/YSZ anodes, but are sometimes classified as $\mathrm{H}$ [89, 119] and $\mathrm{O}$ [82] spillover mechanisms respectively. The positive $P_{\mathrm{H} 2}$ dependency has been used by Utz [120] as a rationale to choose the $\mathrm{H}$ instead of $\mathrm{O}$ 
spillover mechanism for their patterned $\mathrm{Ni}$ anode. The calculated negative reaction order in step 4' then implies the proposal of charge transfer steps involving only $\mathrm{O}$ species in the $\mathrm{H}_{2}$ oxidation models invalid in doped chromite anodes.

About such $P_{\mathrm{H} 2}$ dependency, besides YCCC and YCCN, the performance of other oxide anode materials was reported to apparently depend on it.[39, 121] $\mathrm{CeO}_{2}$ anode showed a reaction order of 0.5 towards $P_{\text {H2. }}[122]$ The resistance of $(\mathrm{LaSr})(\mathrm{CrFe}) \mathrm{O}_{3}$ introduced by Tao increased $50 \%$ when reducing $P_{\mathrm{H} 2}$ from 0.4 to $0.1 \mathrm{~atm}$.[58] It may seem no surprising to find that higher concentration of reactant $\left(\mathrm{H}_{2}\right)$ gives rise to larger exchange current and consequently smaller resistance. However, the adsorbed $\mathrm{H}$ species but not $\mathrm{H}_{2}$ molecule in ambient atmosphere is involved directly into electrode reaction after adsorption. In fact, the generally stronger $P_{\mathrm{H} 2}$ dependence of oxide anodes relative to Ni-based anodes could be from the different electrode configurations, microstructure, lattice structures of components and etc. In particular, of all these relevant factors, the coverage $(\theta)$ of adsorbed $\mathrm{H}$ species on an electrode should be an important factor. The linear relationship between the square root of partial pressure and surface coverage is assumed in most cases, which makes it valid to establish a simple power law dependence between the reaction rate and the partial pressure of certain reactive species.[123-124] But such a linear relationship would not hold at the high surface coverage level as shown in Langmuir adsorption isotherm. As reported by M. Mogensen and S. Skaarup,[76] the $\mathrm{H}$ coverage on a $\mathrm{Ni}$ surface was estimated to be 0.23 for 1 atm $\mathrm{H}_{2}$ pressure at $1000^{\circ} \mathrm{C}$, indicating that the commonly used assumption $\theta<<1$ is not necessarily true in the anode. In fact, under high surface coverage conditions, the influence of the partial pressure of $\mathrm{H}_{2}$ on the reaction rate of each elementary step will be damped because of the mitigated dependence of coverage on the partial pressure as 
predicted by Langmuir adsorption isotherm. That may be responsible for the weak $P_{\mathrm{H} 2}$ dependent resistances in a number of $\mathrm{Ni}$ anode studies. In the same sense, it results that the $\mathrm{H}$ coverage on neither YCCC nor YCCN is sufficient to eclipse the influence from $P_{\mathrm{H} 2}$ changes. But comparatively, $\mathrm{Ni}$ is more effective in improving the $\mathrm{H}$ adsorption.

The reaction orders for those anodes listed in Table 5.2 are roughly $1 / 4$ for the HF arcs and $1 / 2$ for the LF arcs. Judging from these dependency results, in addition with $C$ and $f_{0}$ values, the HF and LF can be accordingly assigned to charge transfer and $\mathrm{H}$ surface diffusion processes, respectively. The increased reaction order in YCCC electrodes with lowering $P_{\mathrm{H} 2}$ suggests that the eclipsing effect from surface coverage is reduced at low $P_{\mathrm{H} 2}$. Given charge transfer is still a rate limiting step in YCCC, the enhanced electron activity in YCCC is most probably one of the reasons for the great improvement of YCCC over YCC.

It has to be admitted that the agreement found for interpretation of experimental observance with the modeled reaction scenario does not totally exclude other reaction mechanisms for YCs, especially for reaction taking place out of 3PB. Doped YCs possess some level of ionic conductivity at very low $P_{\mathrm{H} 2}$ condition. They turn MIEC when working as anodes, and the charge transfer process (step 3 and 4) not only take place at 3PB area but also occur at $2 \mathrm{~PB}$ area as $\mathrm{O}$ ions can be transported through the bulk of YCCs. The activity of oxygen vacancy in step 3 for $2 \mathrm{~PB}$ reaction is no longer constant, but dependent to $P_{\mathrm{H} 2}$. Considering this fact, the reaction path in anode should be more than those equations above proposed for 3PB that in this model. 


\subsection{Summary}

In this chapter, the anode oxidation reaction process has been investigated on $\mathrm{YCrO}_{3}$ based perovskites materials as newly emerged oxide anodes. $\mathrm{Sr}$, $\mathrm{Co}$ and $\mathrm{Ni}$ were doped into $\mathrm{YCrO}_{3}$ to enable a systematic variation in terms of B site element, electrical conductivity and catalytic activity. The characterization was conducted by EIS at different $P_{\mathrm{O} 2}$ in temperature range from $650 \sim 850^{\circ} \mathrm{C}$. The rate-determining factors, difference and similarity between oxide anode and Ni metal anode and the possible $\mathrm{H}_{2}$ oxidation model have been discussed based on those results.

Good performance was yielded from YCCC, $0.9 \Omega \mathrm{cm}^{2}$ at $850^{\circ} \mathrm{C}$ which is among the best performance presently available from oxide anodes. According to the reaction order, charge transfer at the high frequency and hydrogen surface adsorption/diffusion at low frequency were identified as limiting factors in those doped $\mathrm{YCrO}_{3}$ anode. Similar to the perovskite used as cathode, B site element worked as a decisive role in determining catalytic activity. Such activity was proven to be $\mathrm{H}$-related, e.g. $\mathrm{H}$ surface adsorption/coverage was dependent to those $\mathrm{B}$ site elements. Compared to metal $\mathrm{Ni}$, the oxides displayed worse $\mathrm{H}$ adsorption ability judging by the apparent $P_{\mathrm{H} 2}$ dependent resistance. YCCN showed better adsorption ability than YCCC even with less dopant content at B site. A possible model was presented to describe the elementary steps in $\mathrm{H}_{2}$ oxidation. It was suggested that particularly for the charge transfer step, any hypothesis models presented without taking $\mathrm{H}$ into account were invalid. It was also found that high electrical conductivity ( $>100 \mathrm{~S} / \mathrm{cm})$, though usually cited as a prerequisite, was not necessary in those chromites to obtain a good electrode performance. High performance came from combination of high electrical conductivity and B site active element. As among all the 
element steps, charge transfer step was directly affected by the electron activity in the anode materials. 


\section{Chapter 6}

\section{EXTENDED ACTIVE AREA DUE TO LATTICE VACANCY AND ACTIVE ELECTROLYTE}

In the Chapter 5, the nature of $\mathrm{H}_{2}$ oxidation reaction on chromites has been investigated. The catalytic property of B site element has been partially associated to $\mathrm{H}$ surface adsorption ability. On the other hand, oxygen as the other reactant, whose activity could also be able to affect the reaction kinetics and even the available active area, will be discussed in this chapter. As mentioned in the Introduction, the activity of lattice oxygen could be viewed as one of the major virtues of those oxide anodes when it can give rise to a different pathway in $\mathrm{H}_{2}$ oxidation. It will be seen in this chapter that B site elements also work as the key roles in activate lattice oxygen. Due to the $\mathrm{B}$ site doping elements in those $\mathrm{YCrO}_{3}, 2 \mathrm{~PB}$ reaction is enabled, resulting in faster $\mathrm{H}_{2}$ oxidation kinetics. YSZ and SSZ electrolyte are employed to unveil the contribution from $2 \mathrm{~PB}$ enabled by bulk diffusion, based on the fact that $2 \mathrm{~PB}$ reaction is usually associated with a big chemical capacitance and not directly affected by the nature of electrolyte. The influence of electrolyte on extended surface adsorption/diffusion area for 3PB reaction due to enhanced oxygen activity in electrolyte is also discussed. Although such observation is not new in literature, no devoted study has been conducted to explain this phenomenon yet. To this end, a thorough polarization resistance analysis is made and a mechanism is proposed to unveil the real cause for this electrolyte effect. The potential of this advantage in electrolyte design to enable smaller $R_{\mathrm{p}}$ is briefly demonstrated on the SSZ/YSZ/SSZ sandwich structure, promising a new future for those materials that are not adequate in practical electrolyte use in terms of cost, mechanical strength and thermal expansion. 


\subsection{Manifest of 2PB contribution in the ionic conductive oxide anode}

For cathode materials, the activation of oxygen usually can be readily measured by electrical conductivity relaxation (ECR) method. Surface exchange $(k)$ and bulk chemical diffusion $(D)$ coefficients are obtained by fitting the relaxation curves with governing equation. Such effective method, however, cannot be used for anode oxide like doped $\mathrm{YCrO}_{3}$ here, because their stoichiometry will not change until a very low $P_{\mathrm{O} 2}$ is reached, (which is exactly one of the prerequisites with respect to the chemical stability of anode). For Cr-based materials, $P_{\mathrm{O} 2}$ of $10^{-18} \sim 10^{-16}$ is needed to have tangible stoichiometry change so as to conduct ECR measurement, $\mathrm{H}_{2} / \mathrm{H}_{2} \mathrm{O}$ mixture at $1 / 500$ at $700^{\circ} \mathrm{C}$ are needed to meet such low $P_{\mathrm{O} 2}$. In the presence of $\mathrm{H}_{2}$, the exchange process is not so much an oxygen evolution process as a deviation from $\mathrm{H}_{2} / \mathrm{O}_{2}$ reaction equilibrium since $\mathrm{H}$ adsorption will take place at the surface. In addition, only a small variation of $P_{\mathrm{O} 2}$ (increments in $1 / 20 \sim 1 / 10$ of the original $P_{\mathrm{O} 2}$ ) can be applied in the ECR methodology so that $k$ can be taken as a constant to simplify the governing equation. With a small $P_{\mathrm{O}}$ change, the electrical variation of those doped $\mathrm{YCrO}_{3}$ is too small to be accurately recorded with the presence of the system noise. Therefore, ECR is not applicable here. When it comes to determine the reaction kinetics, EIS in fact shows similar functionality as ECR except that the performance is evaluated in a form of resistance, not directly expressed in forms of $k$ and $D$. To handle the complexity in using EIS to clarity the oxygen activation of those doped $\mathrm{YCrO}_{3}$, we have to digress in the middle for a moment from $\mathrm{H}_{2}$ oxidation to oxygen reduction on those samples so that at last a full picture of how those oxide works can be conceived. To provide more supporting evidence, samples with SSZ electrolyte were also measured to do comparison. Since the 3PB reaction take place in the vicinity of electrode/electrolyte interface, the nature of electrolyte will directly affect its kinetics. In contrast, $2 \mathrm{~PB}$ reaction which is supported by the 
MIEC electrode itself and can expand to far from the interface, is much less influenced by the electrolyte. Based on such observation, the emerged contribution from 2PB will be distinguished through using different electrolytes.

Doped $\mathrm{YCrO}_{3} / \mathrm{SSZ} /$ doped $\mathrm{YCrO}_{3}$ symmetrical cells are made using $\mathrm{YCCC}$ and $\mathrm{YCCN}$ as anode. To differ them from YSZ-based sample, hereafter, they are denoted as YCCC-SSZ, YCCN-SSZ, in comparison to YCCC-YSZ, YCCN-YSZ. Those samples were prepared with the same procedure as described in Chapter 4 expect for the thickness for SSZ is set to $2 \sim 2.5 \mathrm{~mm}$ due to its weaker mechanical strength. The compatibility was checked first by XRD. As shown in Fig. 6.1, good chemical compatibility is confirmed between those anode compounds and SSZ electrolyte in both fabrication and testing conditions.

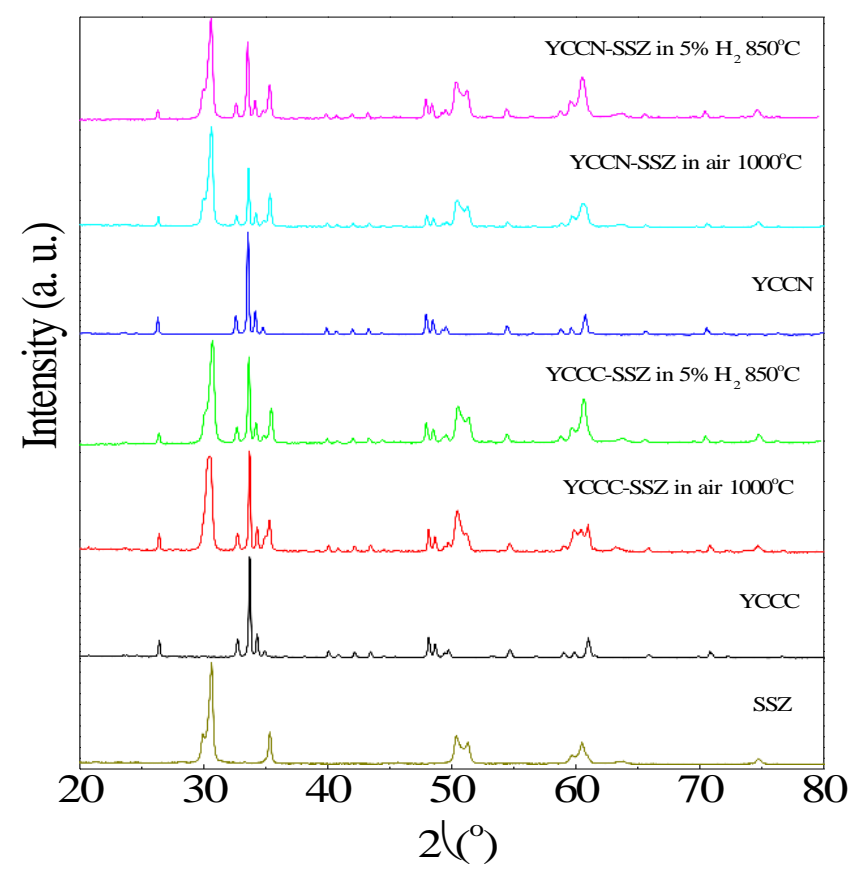

Fig. 6.1 XRD patterns for compatibility between YSZ and chromites in the electrode preparation condition and electrochemical testing condition. 

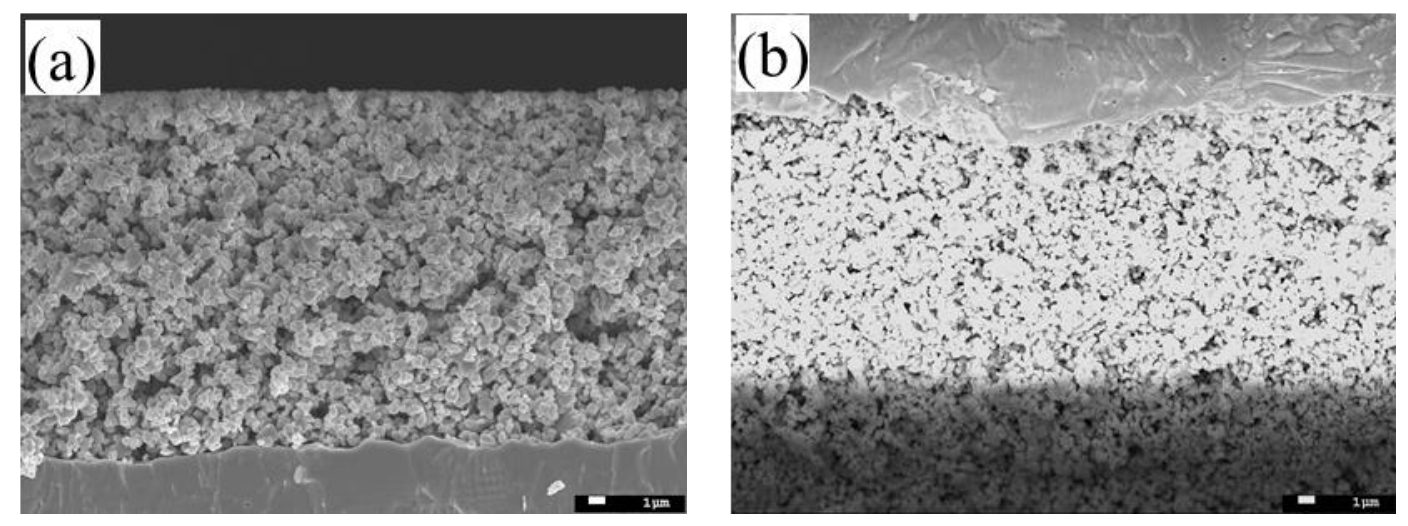

Fig. 6.2 Microstructure of YCCC/SSZ (a), YCCN/SSZ (b) electrodes.

Fig. 6.2 displays the microstructure of the cross-section of YCCC/SSZ, YCCN/SSZ. Good adhesion and suitable porosity are verified from those pictures.

YCCN and YCCC with YSZ and SSZ were characterized in reducing and oxidizing atmospheres. The results are shown as below first, followed by the detailed analysis with respect to the lattice oxygen activation and electrolyte effect.

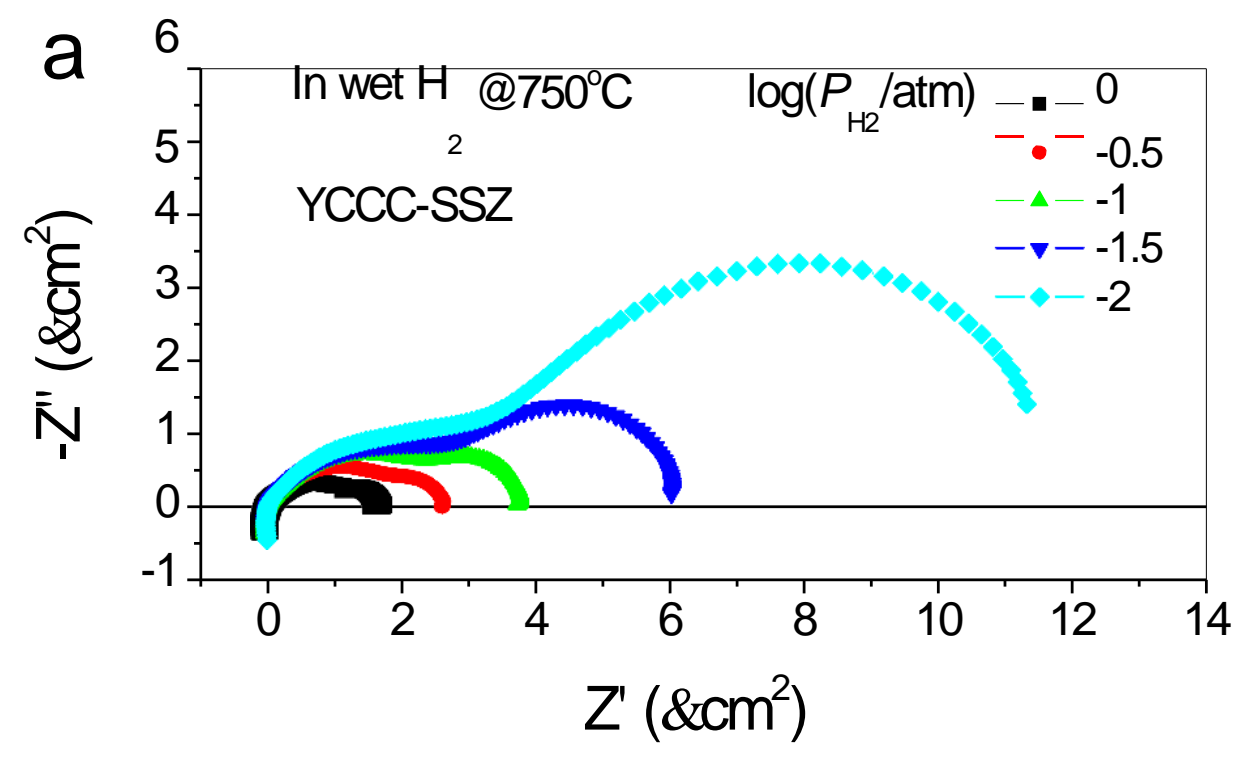




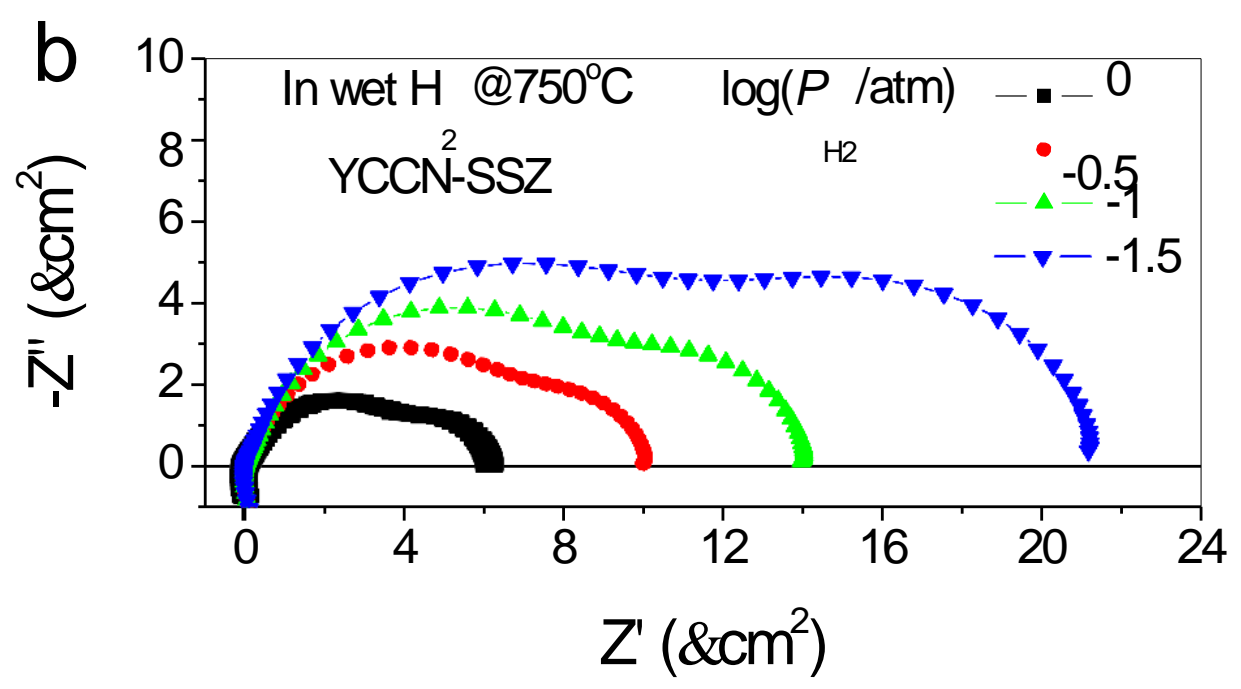

Fig. 6.3 $P_{\mathrm{H} 2}$-dependent polarization resistances of YCCC (a) and YCCN (b) in $750^{\circ} \mathrm{C}$ on SSZ.

Fig. 6.3 shows the $P_{\mathrm{H} 2}$ dependency of both anodes. Similar to the results from YSZ electrolyte, those spectra feature a two-arc profile also, indicating two rate-determining processes in the electrode reaction. They were fitted with the EC as shown in Fig. 5.12, and the resulting resistance and capacitance are summarized in Table 6.1. According to the derived reaction orders for different elementary steps in Chapter 5, the HF and LF process is assigned to the charge transfer and surface process respectively.

Table 6.1 Fitting results for YCCC and YCCN anodes on SSZ tested in wet $\mathrm{H}_{2}$ at $850^{\circ} \mathrm{C}$, and the corresponding $\mathrm{Ea}$ and reaction order $(n)$.

\begin{tabular}{ccccccc}
\hline \multicolumn{2}{c}{$\begin{array}{l}\text { In wet } \mathrm{H}_{2} \\
\text { at } 850^{\circ} \mathrm{C}\end{array}$} & $R\left(\Omega \mathrm{cm}^{2}\right)$ & $C\left(\mathrm{~F} / \mathrm{cm}^{2}\right)$ & $f_{\mathrm{o}}(\mathrm{Hz})$ & $E \mathrm{a}(\mathrm{eV})$ & $n$ \\
\hline $\mathrm{HF}$ & YCCC-SSZ & 0.22 & $1.1 \times 10^{-4}$ & 2300 & 1.1 & $0.16 \sim 0.30$ \\
arc & YCCN-SSZ & 0.96 & $8.3 \times 10^{-}$ & 1900 & 1.6 & $0.10 \sim 0.28$ \\
\hline LF & YCCC-SSZ & 0.27 & $1.6 \times 10^{-2}$ & 70 & 0.6 & $0.46 \sim 0.60$ \\
auc & YCCN-SSZ & 0.66 & $2.3 \times 10^{-}$ & 100 & 0.9 & $0.51 \sim 0.70$ \\
\hline
\end{tabular}


Fig. 6.4 displays the dependency of overall $R_{\mathrm{p}}$ on $P_{\mathrm{H} 2}$. The reaction order for YCCC-SSZ increases with decreasing $P_{\mathrm{H} 2}$. Such tendency can be explained considering under lower $P_{\mathrm{H} 2}$ the contribution of the surface process start to weigh more than the charge transfer step since the former is explicitly affected by the concentration of $\mathrm{H}_{2}$ in the atmosphere showing higher reaction order than the latter as derived in Table 5.3. For YCCN-SSZ, it almost keeps constant instead. Such result is actually in good agreement with the previous observation that $\mathrm{H}$ coverage on YCCN anode is larger than YCCC. With higher surface coverage due to the activity of $\mathrm{Ni}$ element, lowering $P_{\mathrm{H} 2}$ in the atmosphere will not apparently affect the concentration of $\mathrm{H}$ on the YCCN surface, therefore is not able to affect the subsequent steps significantly.
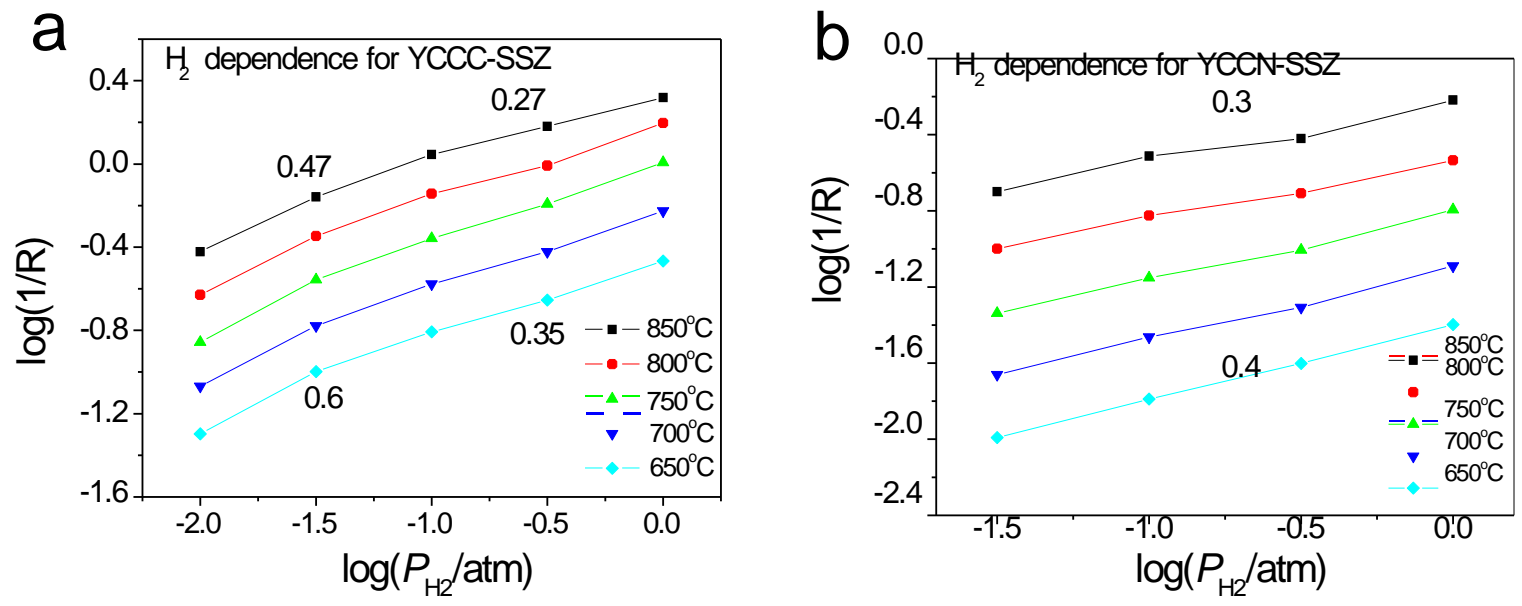

Fig. 6.4 $P_{\mathrm{H} 2}$ dependency of overall $R_{\mathrm{p}}$ for YCCC-SSZ (a) and YCCN-SSZ (b) from $650-850^{\circ} \mathrm{C}$. 


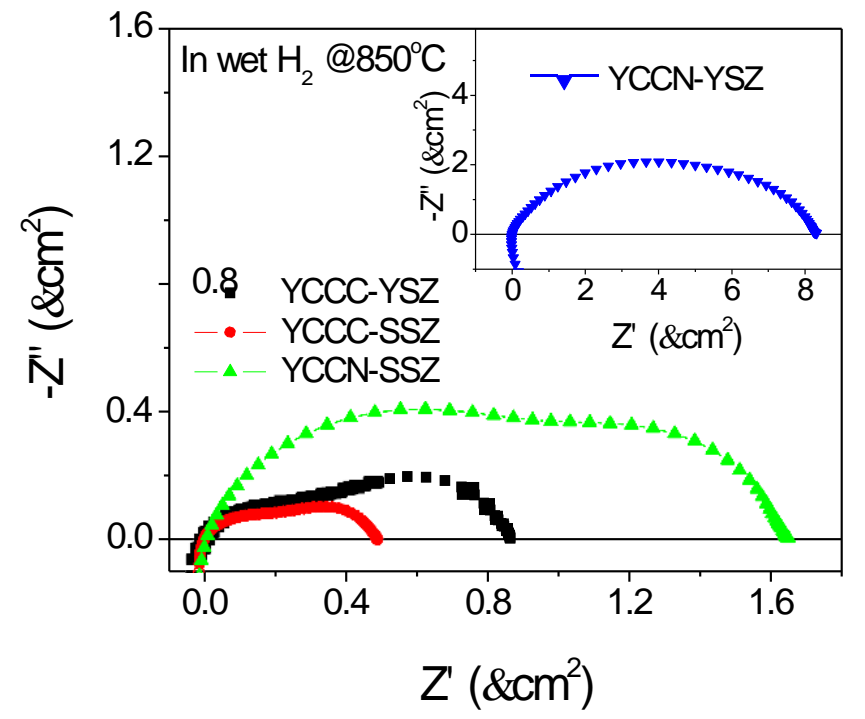

Fig. 6.5 Electrode polarization resistances of YCCC and YCCN on SSZ and YSZ.

Fig. 6.5 displays the polarization resistances for YCCC and YCCN. Using SSZ electrolyte yielded smaller $R_{\mathrm{p}}$ than YSZ. Compared to YCCC anode, it is found way more improvement is achieved with YCCN. As stated before, due to 3PB reaction takes place in the vicinity of electrolyte/anode interface, it naturally depends on the properties of both anode and electrolyte. Changing electrolyte will affect the kinetics of $3 \mathrm{~PB}$ reaction more than $2 \mathrm{~PB}$. In this regard the electrode reaction pathway can be suggested majorly as $3 \mathrm{~PB}$ for $\mathrm{YCCN}$, and 2PB\&3PB for YCCC. This point will be discussed with more details and supporting evidence after compared with results from the measurement conducted in oxidizing atmosphere. 


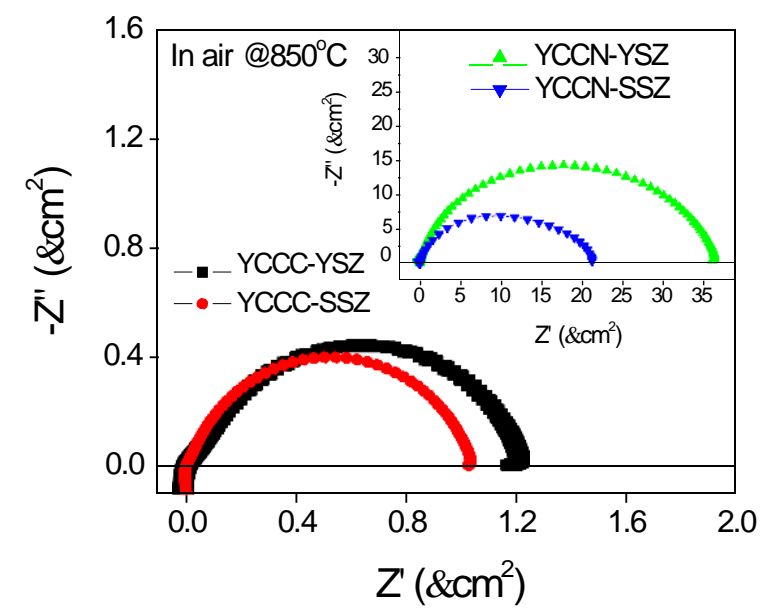

Fig. 6.6 Polarization resistances of YCCC and YCCN electrodes tested under OCV condition in air at $850{ }^{\circ} \mathrm{C}$
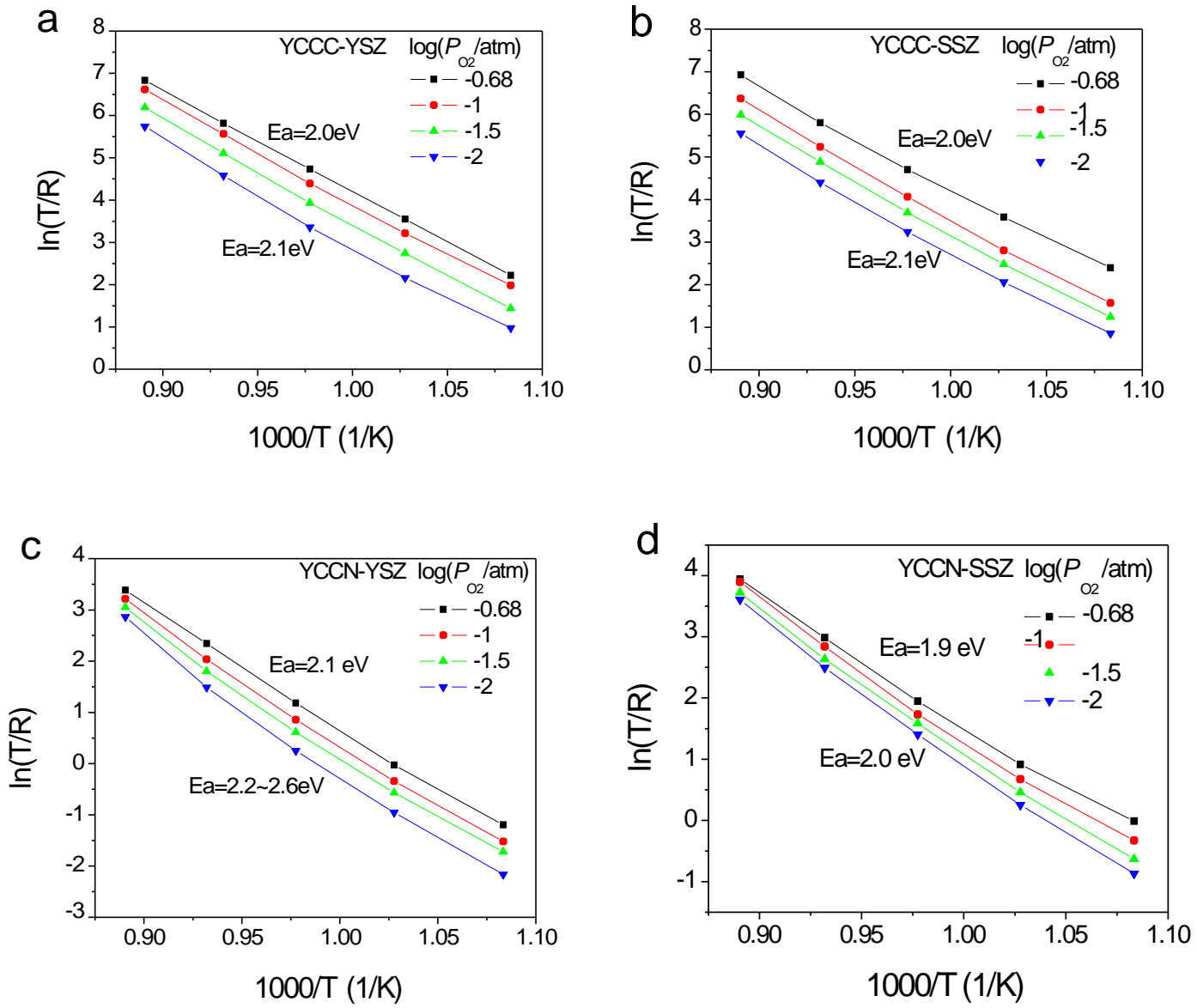

Fig. 6.7 Arrhenius plots for polarization resistances of four kinds of electrodes under various $P_{\mathrm{O} 2}$ values 

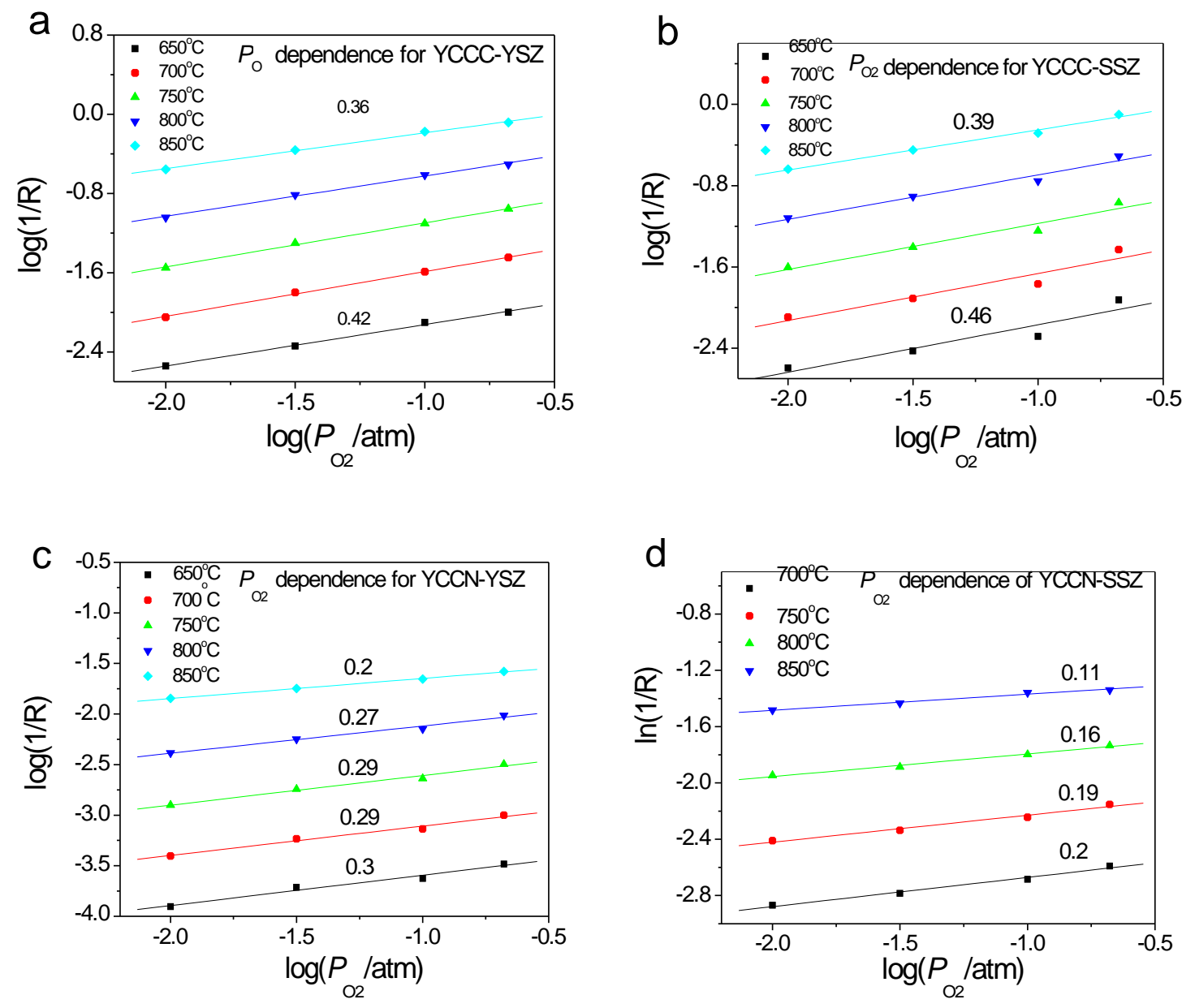

Fig. 6.8 $P_{\mathrm{O} 2}$ dependence of the overall polarization resistances for four different electrodes measured in oxidizing atmospheres.

Table 6.2 Summary of $R, C$ and $f_{0}$ for these four electrodes tested in air at $850^{\circ} \mathrm{C}$, as well as $E$ a in the temperature range of $650 \sim 850^{\circ} \mathrm{C}$.

\begin{tabular}{cccccc}
\hline $\begin{array}{c}\text { In air } \\
\text { at } 850^{\circ} \mathrm{C}\end{array}$ & & $\begin{array}{c}R \\
\left(\Omega \mathrm{cm}^{2}\right)\end{array}$ & $C\left(\mathrm{~F} / \mathrm{cm}^{2}\right)$ & $f_{\mathrm{o}}(\mathrm{Hz})$ & $E \mathrm{a}(\mathrm{eV})$ \\
\hline YCCC-YSZ & Single arc & 1.2 & $1.1 \times 10^{-3}$ & 112 & 2.0 \\
& & & & 50 & 2.0 \\
YCCC-SSZ & Single arc & 1.0 & $1.4 \times 10^{-3}$ & 30 & 2.0 \\
YCCN-YSZ & Single arc & 36.7 & $1.5 \times 10^{-4}$ & 32 & 2.1 \\
YCCN-SSZ & HF arc & 12.6 & $3.8 \times 10^{-4}$ & 5 & 1.7 \\
\hline
\end{tabular}


Fig. 6.6 shows the polarization resistance of those electrodes measured in air. Fig. 6.7 and 6.8 display the corresponding $E$ a and $P_{\mathrm{O} 2}$-dependency of the overall $R_{\mathrm{p}}$. Table 6.2 summaries the fitting results of measurement conducted in oxidizing atmospheres with different $P_{\mathrm{O} 2}$. For measurement in oxidizing atmospheres, the excellent catalytic activity of Co is well-known and it is very common to obtain decent oxygen reduction reaction (ORR) performance from Co based perovskite materials. Similarly, the Ni-based $\mathrm{ABO}_{3}$ and $\mathrm{K}_{2} \mathrm{NiF}_{4}$ structure materials such as $\mathrm{LaNiO}_{3-\delta}$ and $\mathrm{La}_{2} \mathrm{NiO}_{4+\delta}$ have been reported to be electro-catalytically active even if the stability is an issue.[125-127] As a result, it is not surprising to achieve performance enhancement on $\mathrm{YCrO}_{3}$ after $\mathrm{Co}$ and $\mathrm{Ni}$ doping. From cathode study a number of different reaction models have been developed in literature and may lead to different reaction orders in specific scenarios. However, in general, the processes dependent on $P_{\mathrm{O} 2}$ less than $1 / 4$ are most likely attributed to the charge transfer process and those displaying more than $1 / 2$ dependency are often attributed to processes involving diatomic oxygen species.[128-130] Judging from the reaction order for both YCCC-YSZ and -SSZ cathodes in Fig. 6.8a and b, the main process associated with the single arc is therefore attributed to the oxygen dissociative adsorption or surface diffusion of atomic oxygen, but not a charge transfer process since the capacitance of the single arc for each YCCC electrode in the order of $\mathrm{mF}$ is generally larger than those associated with charge transfer process, typically $10^{-3} \sim 10^{-1} \mathrm{mF}$. In addition, in the spectra of an $\mathrm{YCr}_{0.8} \mathrm{Co}_{0.2} \mathrm{O}_{3}-\mathrm{YSZ}$ electrode (not shown here) made in the same routine as in this work, three suppressed arcs were observed when tested in the same conditions and the one with the lowest characteristic frequency $(60 \mathrm{~Hz})$ possessed very similar capacitance $\left(1.3 \mathrm{mF} / \mathrm{cm}^{2}\right)$ and $E \mathrm{a}(1.8 \sim 2.0 \mathrm{eV})$ as the YCCC electrodes in this work, which cannot be the charge transfer process obviously. The dissociative adsorption of oxygen on $\mathrm{YCrO}_{3}$ can be enhanced after $\mathrm{Co}$ doping as $\mathrm{LaCoO}_{3}$ exhibits much better oxygen dissociative 
adsorption activity than $\mathrm{LaCrO}_{3} \cdot[117,131-132]$ But in most cases the corresponding adsorption $E$ a for either $\mathrm{LaCrO}_{3}$ or $\mathrm{LaCoO}_{3}$ is less than what we obtained here. A similar $E \mathrm{a}$ of $2.3 \mathrm{eV}$ has been obtained for doped $\mathrm{LaCoO}_{3}$ cathode,[133-134] but was attributed to the charge transfer process in that specific case due to the $1 / 4 P_{\mathrm{O} 2}$ dependency. On the other hand, given the enhanced adsorption ability of doped $\mathrm{YCrO}_{3}$, the diffusion process could possibly arise as a limiting factor because even though Co doping can be expected to increase the diffusion kinetics as well, the $20 \%$ Co doping level is not enough to overcome the penetrating threshold. The performance of $(\mathrm{LaSr}) \mathrm{CrO}_{3}$ has been reported to be controlled by the surface diffusion process, it however showed a much smaller Ea of $\sim 1.3 \mathrm{eV}$.[133] A similar situation can be found in LSM. An arc with $E$ a of $1.5 \sim 2.0 \mathrm{eV}$ is often observed in medium or low frequency EIS for LSM. The medium frequency arc with $\mathrm{Ea}$ of $2.0 \mathrm{eV}$ in Kim 's work [135] was related to the surface diffusion of $\mathrm{O}^{-}$.

Based on the $n$ values in Fig. $6.8 \mathrm{c}$ and d as well as the fact that two suppressed arcs are present in the spectra of YCCN cathodes, we assign the same surface process in YCCC along with another atomic oxygen process to these spectra of YCCN. Considering the poor surface adsorption/diffusion ability of $\mathrm{Cr}$ and the low level of Ni doping, the limitation of such surface processes on YCCN should not be less severe than YCCC. As the overall reaction order is smaller than other atomic processes (for $\mathrm{O}^{-}$diffusion, $n=3 / 8$ ), such an atomic process in $\mathrm{YCCN}$ is possibly related to the charge transfer process $(n=0$ or $1 / 8)$. Another interesting phenomenon for the YCCN is that the Ea in Fig. 6.7c and d increase with temperature, which is also visible for YCCC electrodes at lower $P_{\mathrm{O} 2}$. It cannot be explained by the change in ratio of two limiting processes with different $E$ a, because the overall $E$ a will predictably approach the smaller one as 
temperature increases. A possible cause could be the enlarged active sites resulting from the formation of oxygen vacancy at lower $P_{\mathrm{O} 2}$. Low $P_{\mathrm{O} 2}$ at high temperature facilitates the formation of oxygen vacancy in yttrium chromites,[136] leading to the increase in surface/bulk oxygen defect, which may in turn broaden the active zone due to enhanced mass transportation. The corresponding Ea then not only includes the reaction activation energy but also is influenced by the formation energy of oxygen vacancy.

The chemical capacity featured at low frequency has been observed in a number of electrode studies. Such capacitance is attributed either to the surface adsorption of reactive species or the dissolution of $\mathrm{O}_{2}$ into metal electrode bulk ( $\mathrm{Ag}$ or even $\mathrm{Pt}$ ) or the change of stoichiometry of the oxide electrodes when they experience the change of overpotential during EIS testing.[137-139] For a typical ( $\mathrm{LaSr}) \mathrm{CoO}_{3}$ cathode, such capacitance ranges from 10 500 $\mathrm{mF}$ which are too big to be associated to any other process without involvement of the electrode bulk, and it also increases with the thickness of electrode until 10 50 $\mu \mathrm{m}$. Alder et al.[140] have addressed this issue in detail and formulated a relationship between the chemical capacitance and the oxygen non-stoichiometry $\delta$. It was also used by Kawada to directly determine the oxygen vacancy concentration in the $\mathrm{Sr}$ doped $\mathrm{LaCoO}_{3}$ material.[137] As the chemical capacity corresponds to the ease of stoichiometry change and oxygen vacancy concentration, it was used by Adler as an indicator suggesting the involvement of electrode bulk in the electrode reaction.[140] Based on these observations, the small capacitance of YCCC and YCCN cathodes as shown in Table 6.2 suggests that the activation of lattice oxygen under oxidizing atmosphere is difficult for those compounds and the involvement of electrode bulk must be limited due to 
lack of ionic conductivity, and therefore 3PB is the primary active zone when without lattice oxygen vacancy.

One may question, since 3PB is the essential active zone for both YCCC and YCCN in cathode conditions, why the charge transfer process that is a rate-limiting process in YCCN electrodes just disappears in the YCCC electrodes. Van et al.[108, 141] systematically investigated LSM/YSZ electrode to visualize 3PB area. Two possible 3PB areas, (1) extension from electrode/electrolyte boundary to the electrolyte bare surface, (2) extension into the electrode/electrolyte interface, were proposed. The weight of each depends mainly on the ionic conductivity of electrode. In this sense, owing to the different nature between YCCC/YSZ and YCCN/YSZ interfaces and/or the difference between YCCC and YCCN surface nature, the charge transfer kinetics could vary from one to another. Such supposition is actually supported by the results obtained in the reducing atmosphere, showing different charge transfer $E$ a for YCCC and YCCN.

When it comes back to anode condition, the activity of O in YCCC and YCCN lattice will manifest itself in the performance of those anodes. The reducibility introduced by Co doping activates lattice $\mathrm{O}$ in $\mathrm{YCCC}$ to react with $\mathrm{H}$ adsorbed on the surface. This is more significant to the performance when part of the YCCC bulk is activated as described above and the $\mathrm{O}^{2-}$ can be transported through YCCC bulk to $2 \mathrm{~PB}$. The activity of $\mathrm{O}$ will directly affect the charge transfer step carried out on electrodes. Ni doping is expected to work in a similar manner, but with a lower doping level, higher charge transfer Ea was obtained. As clearly shown in Table 6.1 and 6.2, the capacitances of LF arcs for YCCC are much greater under reducing than oxidizing 
atmospheres, which clearly indicates the involvement of YCCC bulk as an active site for the $\mathrm{H}_{2}$ oxidation reactions. Since the hypostoichiometry of oxygen for $\mathrm{Y}_{0.8} \mathrm{Ca}_{0.2} \mathrm{CrO}_{3-\delta}$ under $P_{\mathrm{O} 2}$ of $10^{-}$ ${ }^{18}$ at $1000{ }^{\circ} \mathrm{C}$ is $0.06,[68]$ for $\mathrm{La}_{0.7} \mathrm{Sr}_{0.3} \mathrm{CoO}_{3-\delta}$ at $10^{-4} \mathrm{P}_{\mathrm{O} 2}$ and $800^{\circ} \mathrm{C} 0.12,[142]$ it is reasonable to expect more vacancy after B site Co doping then the resultant enhancement in ionic conductivity of YCCC in the reducing atmosphere compared to oxidizing one. Indeed, the reactants now are different in reducing atmosphere after switching from oxidizing conditions. Species like $\mathrm{OH}^{-}, \mathrm{H}$ and $\mathrm{H}_{2} \mathrm{O}$ will be newly present. But the capacitance from surface adsorption of neither $\mathrm{OH}^{-}$nor $\mathrm{H}$ is sufficient to solely account for the big capacitances for the LF arc listed in Table 6.1.[111] Furthermore, neither YCCC nor YCCN are believed to possess proton conductivity. As a result, the chemical capacitance mainly originates from the incorporation/exsolution of oxygen from the electrode bulk, thus indicating apparent 2PB contribution in YCCC. Unlike the YCCC electrodes, the capacitance of YCCN electrodes did not change much in the reducing atmospheres (note: we used one arc to represent YCCN-YSZ electrode in air in Table 6.2, which is actually two arcs in series. If fitted into two arcs, the capacitance for the LF arc would display a similar value to that of YCCN-SSZ electrode). That implies the ionic conductivity of YCCN in reducing condition is still very limited. Despite the fact that the reducibility of Ni-based perovskite is very good, the enhancement of ionic conductivity and stoichiometric flexibility are limited by the low doping level in YCCN. The active zone for $\mathrm{H}_{2}$ oxidation reaction in this case is essentially the 3PB area.

Recalling the judgment of $2 \mathrm{~PB}$ or $3 \mathrm{~PB}$-dominant based on the improvement from changing electrolyte, it is found that the analysis from chemical capacitance (associated to the readiness of stoichiometry change) finally converges with it in terms of the $2 \mathrm{~PB} / 3 \mathrm{~PB}$ reaction pathways on those two different candidates: only the one with 3PB dominant feature can be 
apparently changed in $R_{\mathrm{p}}$ by using different electrolyte, e.g. YCCN; if the reaction pathway is mixed 2PB/3PB, less apparent effect is observed, like YCCC.

Nevertheless, the LF part which is associated to the surface process is improved as well by changing the electrolyte, which seems not quite possible since electrolyte is not likely involved in adsorption/diffusion process directly. In this regard, the next section is focused to explain such phenomenon.

\subsection{Extended surface adsorption area due to active electrolyte}

The improvement of electrode performance testing with YSZ and SSZ as shown in Table 6.1 on the LF resistances is to be derived to associate with the enlargement of the surface active areas on the electrode in following.

It was reported by Watanabe et al.[143] that in the $\mathrm{Sm}$ doped $\mathrm{CeO}_{2}$ anode not only the ohmic loss but also the polarization resistances were reduced by using an electrolyte with higher ionic conductivity. The influence of the electrolyte was also observed on the cathode part.[144145] Uchida et al.[146] obtained the highest performance for a Pt cathode by using the electrolyte with the best ionic conductivity. While the DC polarization measurement used in the above studies effectively displayed the enhancement of polarization, it cannot decisively distinguish which part of the polarization resistance has been changed. A possible explanation for this improvement proposed by Watanabe was that the electrode kinetics could be limited by the rate of $\mathrm{O}^{2-}$ supply to the anode via the electrolyte. Such an explanation unless implies that the resistance of $\mathrm{O}^{2-}$ transfer between electrode/electrolyte interface belongs to the polarization 
resistance, otherwise it is merely talking out ohmic resistance and therefore not really relevant to the finding. With the EIS technique, more features of such an effect can be revealed. Kungas et al.[147] studied the effect of electrolyte in a composite cathode. The impedance varied not only in the magnitude but also in the profile when coupling the cathode with different electrolytes. Liu [148] observed in the investigation of the importance of 3PB in LSCF cathode that both HF and LF arcs in the spectra changed a lot in size and shape upon changing electrolytes. However, neither of the works has stated explicitly how the properties of the electrolytes will affect the polarization resistance. The ohmic resistance will of course be reduced due to high conductivity. The charge transfer (Eq. 6.1 or 6.2) and ionic transfer (Eq. 6.3) processes since related to electrolyte will also be affected by the nature of electrolyte because it is one of the sources for reactant components.

$$
\begin{gathered}
\mathrm{H}_{\text {ads,3PB }}+\mathrm{O}_{\text {O electrolyte }}^{\mathrm{X}} \square \mathrm{V}_{\mathrm{O} \text { electrolyte }}^{\square}+\mathrm{OH}_{\text {ads,3PB }}+e \\
\mathrm{O}_{\text {O electrolyte }}^{\mathrm{X}} \square \mathrm{V}_{\mathrm{O} \text { electrolyte }}+\mathrm{O}_{\text {ads }}+e \\
\mathrm{O}_{\text {O electrolyte }}^{\mathrm{X}}+\mathrm{V}_{\mathrm{O} \text { electrode }}^{\square} \square \mathrm{V}_{\mathrm{O} \text { electrolyte }}+\mathrm{O}_{\mathrm{O} \text { electrode }}^{\mathrm{x}}
\end{gathered}
$$

But can the electrolyte impact any processes which we suppose here are not directly related to the electrolyte, such as surface adsorption or diffusion on electrode itself? 


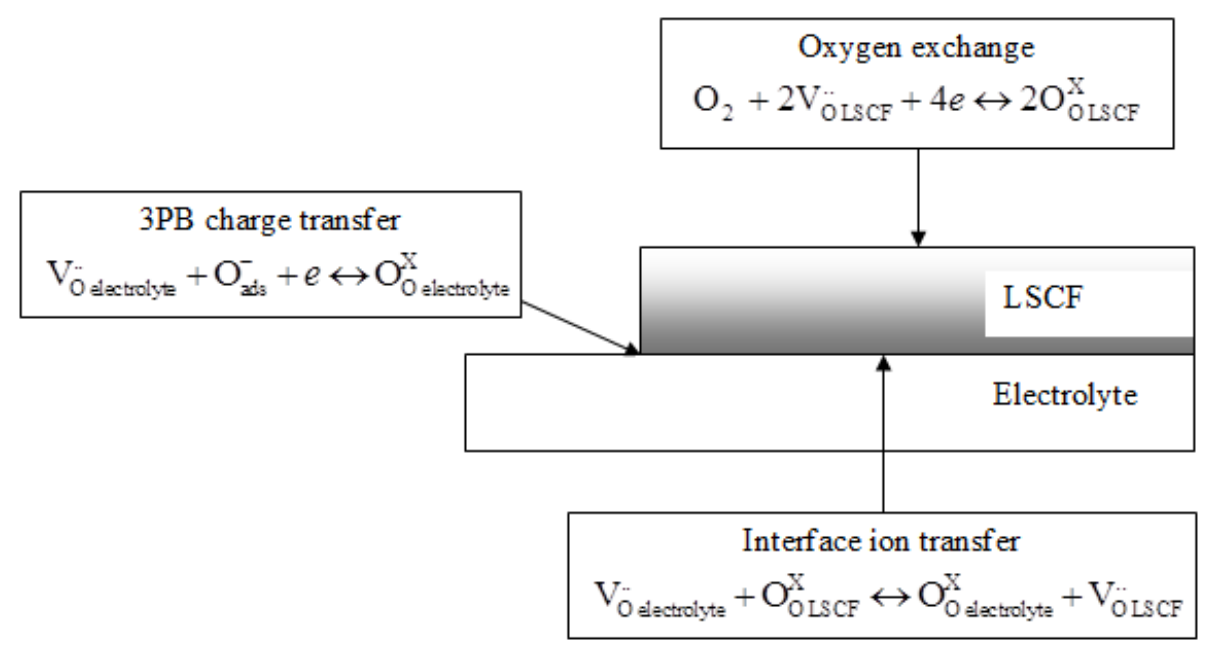

Fig. 6.9 Schematic diagram of reactions for LSCF electrode.

Since really good MIEC anode is rarely reported, let us look at the case of ORR on a mixing conductive cathode---a dense LSCF electrode supported by YSZ or SSZ electrolyte. The results derived from cathode is applicable to anode because the principle behind is the same. As shown in Fig. 6.9, the exchange current density $j_{\mathrm{i}}$ for interface ion transfer reaction will be enhanced by using an electrolyte with higher ionic conductivity, or more relevantly, has a readier availability of $\mathrm{V}_{\mathrm{O} \text { electrolyte }}$. The $\mathrm{V}_{\mathrm{OLSCF}}$ will keep the same in equilibrium condition because the oxygen vacancy in LSCF depends only on the ambient atmosphere. Significant amounts of oxygen vacancies may only be obtained under a very large overpotential. Consequently, the oxygen exchange reaction on the dense LSCF surface (that is, 2PB area) won't be directly influenced by the kinetics at the interface since it is only determined by ambient atmosphere and the activity of $\mathrm{V}_{\mathrm{OLSCF}}^{\square}$. Such reasoning can be verified by the similar case in Baumann's study of LSCF surface kinetics.[92] After inserting a thin GDC layer in between YSZ and a dense LSCF electrode, the medium frequency arc corresponding to an interface ion transfer resistance 
disappeared, but the LF arc corresponding to oxygen exchange on LSCF surface remained virtually unchanged.

For a charge transfer reaction occurring at $3 \mathrm{~PB}$, the exchange current density $j_{\mathrm{ct}}^{0}$ will certainly increase when using a higher ion conducting electrolyte just as stated before. Let's now imagine a reaction chain to clarify the effect of such an enhancement in charge transfer on other surface processes not directly related to the electrolyte. Supposing charge transfer is one of the rate-limiting steps of the LSCF/YSZ cathode, the net current can be expressed as:

$$
j_{\mathrm{ct}}=j_{\mathrm{ct}}^{0}\left\{\frac{c_{\mathrm{O}}}{c_{\mathrm{O}}^{0}} \exp (-\alpha \mathrm{f} \mid)-\exp [(1-\alpha) \mathrm{f} \mid]\right\}
$$

Under a given applied cathodic overpotential $\eta_{1}$ (in the linear polarization zone), the net current is $j_{1}$ and the corresponding $\mathrm{O}^{-}$concentration outside of the electrolyte is $c_{1}$. Then, keep everything else the same, but suddenly change the electrolyte from YSZ to SSZ. With the same $\mathrm{O}^{-}$concentration and then the same overpotential $\eta_{1}$, the charge transfer reaction on LSCF/SSZ electrode now must proceed faster $\left(j^{0}{ }_{\text {ct }}\right.$ in Eq. 6.4 for SSZ is larger than that for YSZ under the same initial concentration of $\mathrm{O}^{-}$). The net current increases to $j_{2}$ and the steady state is lost. The $\mathrm{O}^{-}$concentration starts to reduce accompanied by reducing current. But the $\mathrm{O}^{-}$gradient keeps increasing, extending the surface diffusion area in order to collect more $\mathrm{O}^{-}$to balance the change. Meanwhile, the declining current reduces the consumption of $\mathrm{O}^{-}$, and the enlarged active surface area provides more $\mathrm{O}^{-}$. A new steady state will be established in the midpoint soon, with $\mathrm{O}^{-}$ concentration outside electrolyte of $c_{2}\left(c_{2}<c_{1}\right)$ and net current of $j_{2}{ }^{\prime}\left(j_{2}>j_{2}{ }^{\prime}>j_{1}\right)$. The polarization ${ }^{2}$
resistance $\mathrm{y} /\left(j^{\prime}\right)$ is finally reduced and the active zone for surface diffusion and adsorption
enlarged by changing YSZ to SSZ. From this point of view, the nature of the electrolyte will 
affect not only the reactions involving the electrolyte but also those related to it indirectly. Such change works out in a chain, just as the variation of $P_{\mathrm{O} 2}$ changes each step in the ORR process. Obviously, such reasoning is not only valid in cathode but also applicable to the oxidation reaction at the anode simply by rearranging Eq. 6.4 . What may need to be stressed here is that, when mentioning ionic conductivity of the electrolyte, we are not dealing with the ohmic resistance change of electrolyte at all, but just using it as the indicator of the availability of $\mathrm{O}$ source in the electrolyte, which is intrinsically associated to the apparent conductivity.

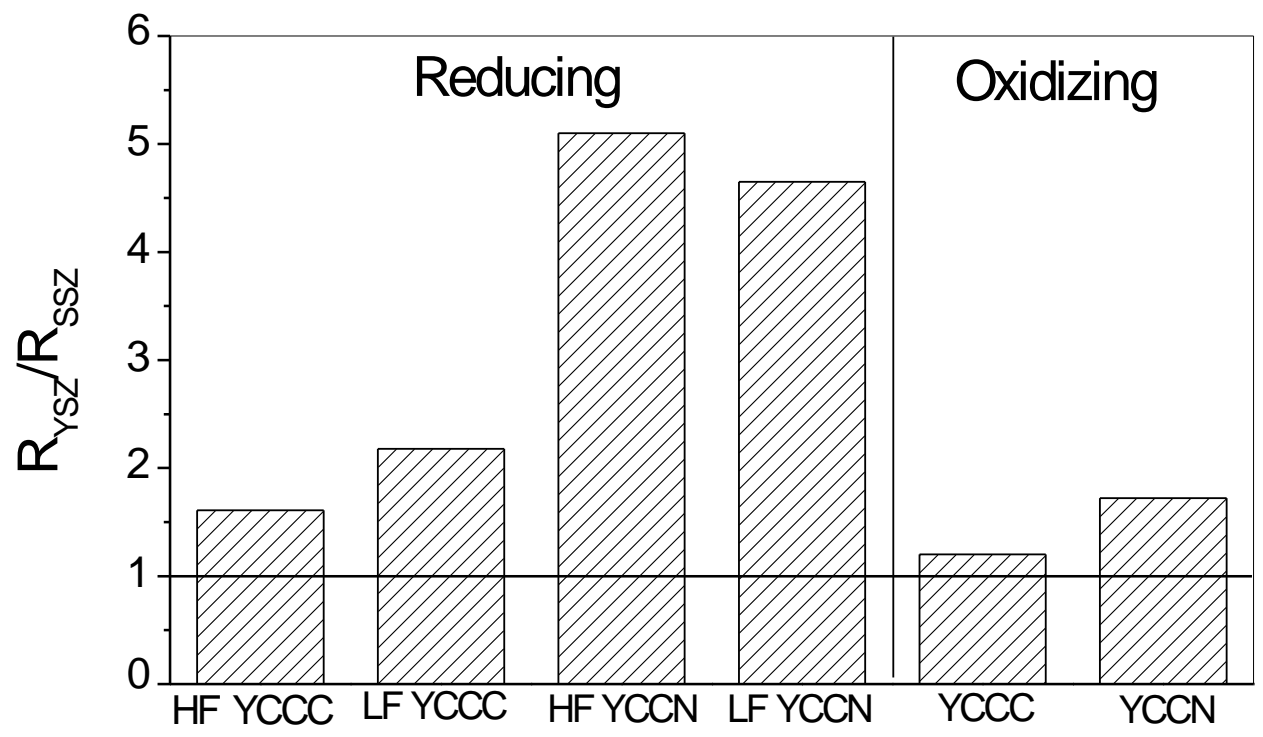

Fig. 6.10 Improvement of electrode performance for YCCC and YCCZ upon change YSZ to SSZ electrolyte

Fig. 6.10 shows the comparison of performance for YCCC and YCCN as either anode or cathode on YSZ vs. on SSZ electrolyte. In anode part, besides the HF charge transfer process, the LF process ascribed to the diffusion process was also improved by using SSZ electrolyte on both materials as predicted above. Much more significant enhancement was achieved on the YCCN anode. It is because the active zone for YCCN is limited to 3PB, but in YCCC anode it extends 
to a small portion of electrode bulk. Changing have a less significant effect on the processes that take place at the $2 \mathrm{~PB}$ area as stated before. In the cathode part, even though improvement still can be observed, it is less substantial, especially for the YCCC cathode. The RDS for YCCC was ascribed to either surface dissociative adsorption or the diffusion process, but not the charge transfer step. Therefore, the first ring in the chain is missing, thus less improvement can be anticipated.

\subsection{Demonstration of practical application for active electrolyte}

The above illustrated electrolyte effect opens a wide door for the application of novel electrolyte materials (in a form of coupling with other refractory electrolyte into bilayer or sandwich structure) that otherwise cannot be used by themselves alone due to instability in either oxidizing or reducing atmospheres, mechanical fragility, high cost or etc. For example, stabilized bismuth electrolyte showing excellent ionic activity cannot be exposed to the anode compartment

directly since its instability below $10^{-13} P_{\mathrm{O} 2}$. [149] However, if coupled with other electrolyte to protect it from anode atmosphere, bismuth can be a superior electrolyte decoration layer to promote the polarization resistance drastically. In a wider perspective, even those materials which are not technically electrolyte due to their tangible electronic conductivity can be used as electrolyte decoration based on this idea as long as they show sufficient ionic activity for the purpose of electrode performance enhancement.

Even for the SSZ used in this study, due to the fragility, it is usually not adequate to be made into thin electrolyte pellet in the electrolyte-supported fuel cell. A YSZ/SSZ/YSZ sandwich structure has been adopted by some co-workers to gain both high ionic conductivity 
from SSZ and mechanical strength from YSZ. However, after the finding in this above section, the advantage from SSZ is far more than its higher ionic conductivity but majorly the so-called ionic activity. Thus, it is wiser to design a SSZ/YSZ/SSZ sandwich to utilize good support from YSZ and at the same time outstanding polarization resistance from electrode/SSZ interface. According to the explanation on the presented finding, what alters the $R_{\mathrm{p}}$ is only related to the interface composition of electrode/electrolyte. No necessarily a bulk SSZ pellet, a very thin layer of SSZ deposited on thicker YSZ should also be able to realize the same effect. In the following such concept is demonstrate on the SSZ/YSZ/SSZ sandwich structure using YCCN anode. The sandwich structure is produced by a spray-modified pressing method.

SSZ powders along with polyvinyl butyral (PVB) and fish oil at the weight ratio of 100:2:1.5 was added into ethanol ( $5 \mathrm{~g}$ powders to $30 \mathrm{~mL}$ ethanol), then ball-milled for $24 \mathrm{~h}$ to produce suspension which was air-brushed onto both sides of YSZ electrolyte to fabricate thin layer SSZ. In brief, YSZ in $\sim 2 \mathrm{~g}$ were dry pressed under $50 \mathrm{MPa}$ in a $31 \mathrm{~mm}$ die. The suspension was evenly sprayed to YSZ surface, followed by an intermediate pressing of $200 \mathrm{MPa}$. The sample was taken out and inserted back to the die carefully with the uncoated surface facing outside this time. The spray process was repeated, followed by a final pressing at $300 \mathrm{MPa}$. The thickness of SSZ layers can be controlled by the volume of suspension served to the gun and was set to $\sim 50 \mu \mathrm{m}$ for all samples. SSZ/YSZ/SSZ sandwich were sintered to $1400^{\circ} \mathrm{C} 4 \mathrm{~h}$ for densification. 
(a)

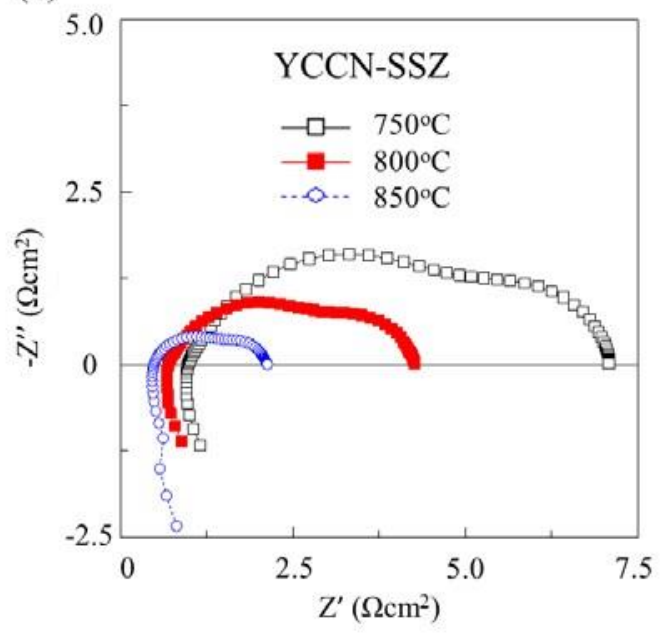

(b)

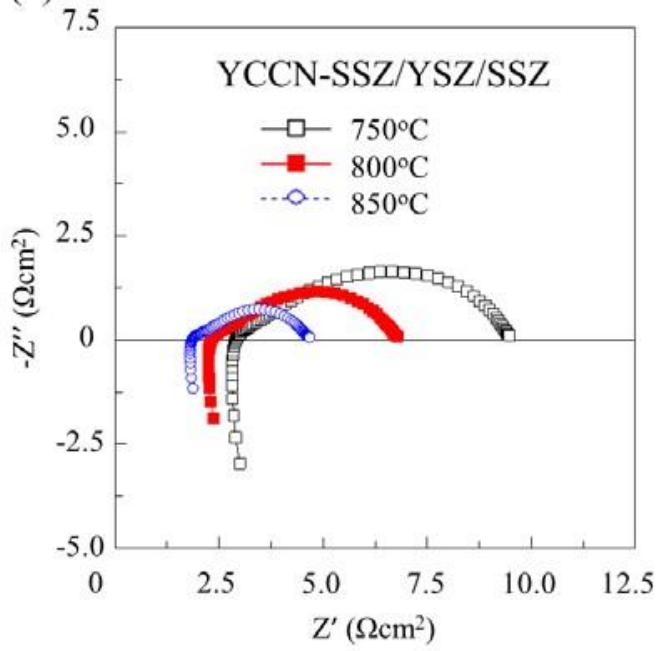

(c)

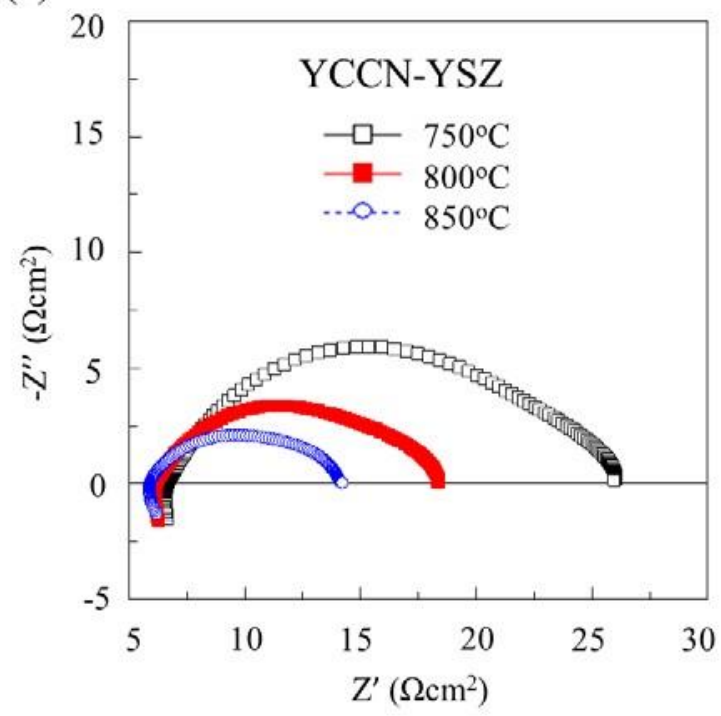

Fig. 6.11 Comparison between $R_{\mathrm{p}}$ for YCCN-SSZ (a), YCCN-SSZ/YSZ/SSZ (b) and YCCNYSZ symmetrical cells (c) measured in wet $\mathrm{H} 2$ at different temperatures.

Fig. 6.11 shows $R_{\mathrm{p}}$ for YCCN on pure SSZ, SSZ/YSZ/SSZ sandwich and pure YSZ measured at wet $\mathrm{H}_{2}$. The resistance obtained from SSZ/YSZ/SSZ sandwich in Fig. $6.11 \mathrm{~b}$ is very close to that obtained from pure SSZ electrolyte. In contrast, pure YSZ electrolyte yielded much 
larger $R_{\mathrm{p}}, \sim 4$ times bigger than the other two. Those results clearly demonstrate that the electrolyte effect is really associated with the electrode/electrolyte interface composition. Thus, thin layer decoration of active electrolyte is indeed able to promote the electrode performance as well as bulk of pure electrolyte of the same kind, which can conserve the use of expensive electrolyte material, and also make fragile electrolytes like erbium doped bismuth adequate in real application.

\subsection{Summary}

In this chapter, by extending the electrode response from $P_{\mathrm{H} 2}$ in Chapter 5 to $P_{\mathrm{O} 2}$ when measuring in $\mathrm{O}_{2}$-containing gases and using SSZ to replace YSZ electrolyte, the activation of lattice oxygen, the contribution from $2 \mathrm{~PB}$ and $3 \mathrm{~PB}$ and the beneficial effect of electrolyte in $R_{\mathrm{p}}$ for those oxide anodes were investigated. Judged by the chemical capacitance along with the improvement from changing electrolyte, YCCC was confirmed to be both $2 \mathrm{BP}$ and $3 \mathrm{~PB}$ active, and YCCN 3PB dominant. The activation of 2PB depended on the ionic conductivity and then the nonstoichiometry of oxide under reducing atmospheres. A big capacitance for YCCC was observed and associated to the variation of lattice oxygen under EIS measurement, confirming the activity of bulk transport. The overall performance was less affected by the nature of electrolyte when both $3 \mathrm{~PB}$ and $2 \mathrm{~PB}$ pathways were effectively working, but on the 3PB dominant YCCN, reaction kinetics was largely influenced by the electrolyte. What's more, for YCCN, not only the charge transfer step, but also the surface process anode was promoted. Such effect of electrolyte on surface process was explained by a chain-transmit mechanism. Basically, by enlarging the exchange current of charge transfer reaction at the electrolyte/anode interface, bigger gradient in the adsorbed species was resulted, which in turn broadened the adsorption area 
then diffusion and adsorption rates. The significance of this phenomenon in practical application was demonstrated on the SSZ/YSZ/SSZ sandwich electrolyte which showed almost the same $R_{\mathrm{p}}$ as from pure SSZ electrolyte. Such results could be able to rewrite the concept of electrolyte design and open a wide door for the utilization of novel electrolyte materials that otherwise cannot be used by themselves alone due to instability in either oxidizing or reducing atmospheres, mechanical fragility, high cost or etc. 
Chapter 7

\section{ACTIVATION/DEACTIVATION AND STABILITY OF THE BULK PATHWAY UNDER OVERPOTENTIAL}

The reaction kinetics of $\mathrm{H}_{2}$ oxidation is investigated on equilibrium in those chapters above. While the basic principles governing the reaction rates can be extrapolated into nonequilibrium condition with steady net current after taking into account the effect of overpotential in the form of Butler-Volmer (B-V) equation at the activation polarization region, the change of physical properties locally in the materials bulk is not covered either in the equilibrium state treatment or B-V equation application. It is well-known that overpotential is capable of changing the surface adsorption composition of electrodes, which has been documented by Fleig et al. into dedicated models to illustrate the surface overpotential. On the other hand, the other side of the coin, e.g. the bulk properties of oxide anode, has not been address under the influence of potential before to the best of our knowledge. Under service condition usually $\sim 0.3 \mathrm{~V}$ overpotential, significant electronic current is transformed into ionic current through the electrodes. For those oxide anodes, as proven in chapter 6 , it occur through both traditional 3PB area and also newly emerged $2 \mathrm{~PB}$ area. In the $2 \mathrm{~PB}$ area, a big portion of the overpotential will be consumed by the bulk transport, which can possibly alter the local chemical composition of the electrode materials and electrical boundary conditions. The consequence of such alternation would be able to cast a great impact on both performance and stability of the electrode. In this regard, the present chapter is dedicated to the influence of overpotential on the bulk pathway, 
which will be discussed and compared to the Nernst equation that is generally applied to treat any oxide electrodes under equilibrium. The relevant potentials controlling electrode processes include electrostatic potential, electrochemical potential of electron and ion. The distributions of those potentials and resultant influence on electrode processes are treated with drift diffusion equations. It is found that the electrode bulk is not locally electroneutral and the resultant electrostatic gradient can be established in the region near electrolyte due to the uneven distributions of ions and electrons. Therefore, besides the concentration gradient, electrical field force produced by the electrostatic potential is also the driving forces in the ion diffusion and introduces new concepts in handling chemical and electrical contributions in the overall electrochemical response of electrode system.

\subsection{Oxygen transport at oxide anode bulk: 1-dimensinal model}

Considering oxygen reduction reaction as an example, the electrode process under steady state on MIEC is schematically sketched in Fig. 7.1a. The oxygen ions are transported through the MIEC bulk and react with $\mathrm{H}_{2}$ on the surface. A column drawn arbitrarily at the left shows the transition from electronic current to ionic current through $\mathrm{H}_{2}$ oxidation on the inner surface within the active length. Such electron-ion current transition starts from the upper boundary of the active length, finishes outside electrolyte with electronic current finally blocked. The active length estimated from chemical capacitance for cathode material (not available now for oxide anodes) by Adler et al. can be as big as $7 \sim 15 \mu \mathrm{m}$ depending mainly on $D / k$ and microstructure. The transport path in MIEC near electrolyte actually can be illustrated as in Fig. 7.1b. Though 3PB reaction in lots of cases is important to the overall electrode kinetics as well, it is ignored here in order to focus our topic to $2 \mathrm{~PB}$ exclusively. Oxygen ions are transported inside the MIEC 
from the MIEC/electrolyte interface to MIEC inner surface, as indicated by the red lines. According to the current density inside different portion of MIEC, the electrochemical equipotential lines (ELs) for oxygen is drawn qualitatively also. For segment between any two ELs, the transport behavior inside it can be simplified into a 1-dimensional case as shown in Fig. 7.1c, which renders simpler mathematical treatment without loss the important physical essence. The driving force of such transport has in lots of cases been ascribed to the oxygen vacancy gradient alone, and the influence or even the existence of electrical field was neglected, most probably because it seems impossible to build electrical field inside the bulk of a conductive material. The existence of electrical field in MIEC bulk and the distributions of defects and potentials herein will be analytically derived first; then independently solved from the governing equations also based on the 1-dimensinoal model.

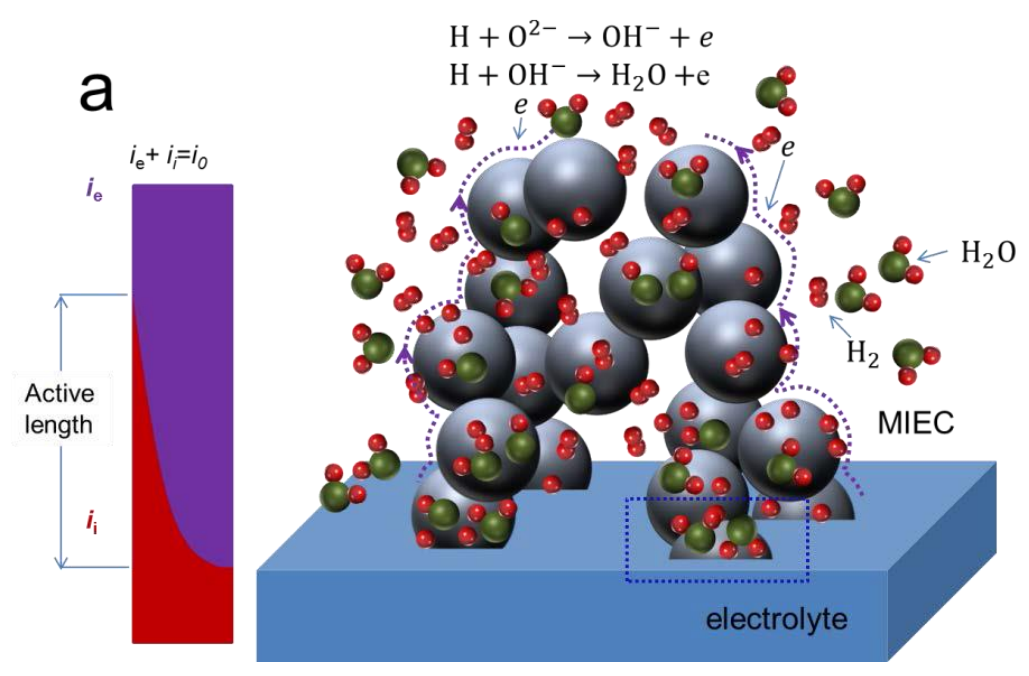



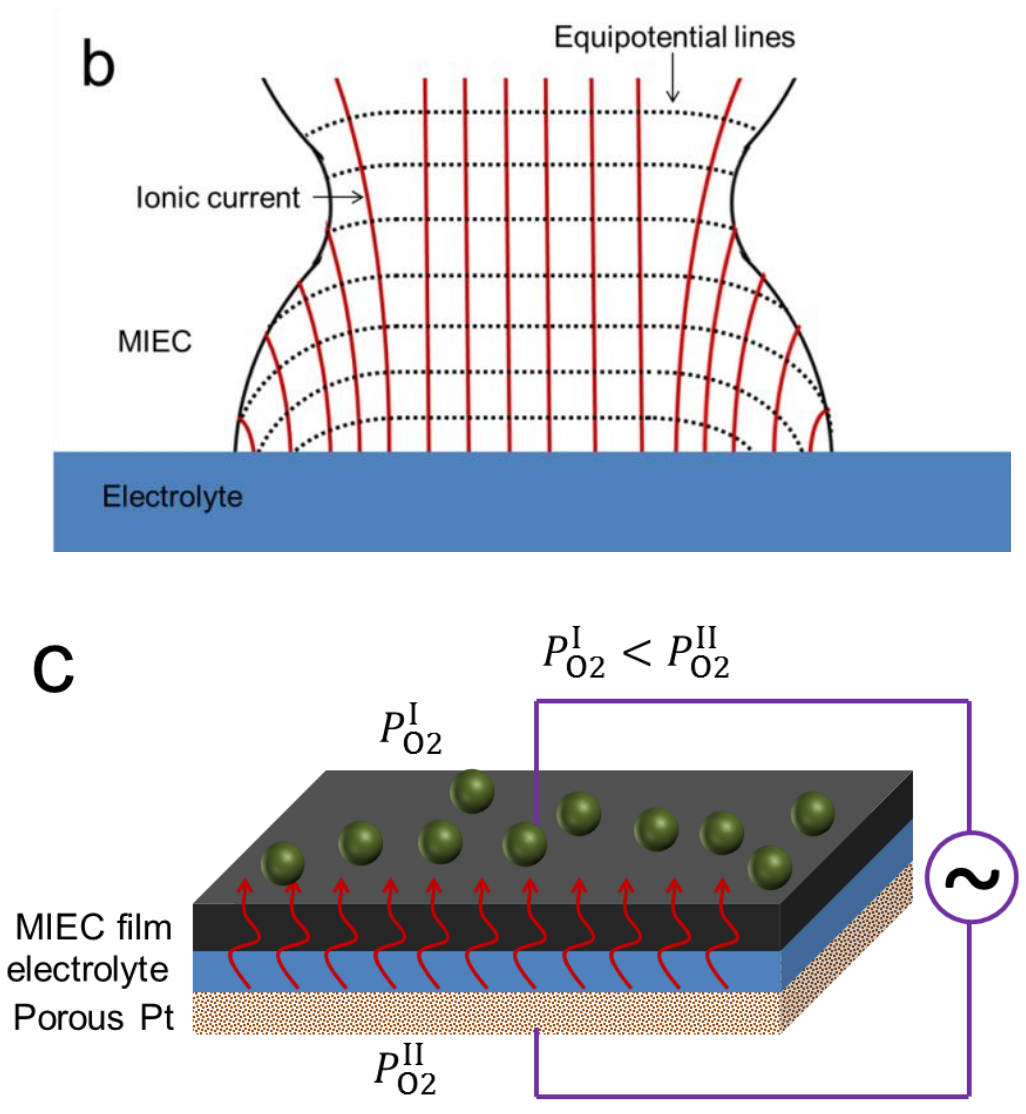

Fig. 7.1 Schematic diagram for MIEC anode operation (a), the ionic flowing and equipotential lines at MIEC anode near the interface area (b), and the 1-D model derived based on it (c).

\subsection{Qualitative analysis on $c_{\mathrm{e}}, c_{\mathrm{v}}$ and $\phi$ in bulk pathway}

The motion of chemical species in MIEC electrode is governed by the Nernst-Planck equation. For one-dimension case, the mass flux of species $i$ under steady state takes the form as:

$$
j_{i}^{\text {mass }}(x)=D_{i} \frac{c_{i}(x)}{x} \frac{\left.\int_{i}\right)(x)}{z_{i} e} \quad x
$$

where $x$ is the position, $D_{i}$ the chemical diffusion coefficient, $c_{i}$ the concentration, $\sigma_{i}$ the conductivity, $\phi$ the galvanic potential, $z_{i}$ the valence, e the electron charge. The first term in RHS represents the diffusion, and second term migration. 
According to the Nernst-Einstein relationship, the equation above can be rearranged as:

$$
j_{i}^{\text {mass }}(x)=\frac{\int_{i}}{\tilde{\mu}_{i}}
$$

where

$$
\begin{gathered}
\tilde{\mu}_{i}(x)=\mu_{i}(x)+z_{i} e(x) \\
\mu_{i}(x)=\mu_{i}^{0}(x)+\mathrm{k}_{\mathrm{B}} T \ln c_{i}(x)
\end{gathered}
$$

is the electrochemical and chemical potentials, respectively. $\mathrm{k}_{\mathrm{B}}$ and $T$ remain the usual physical meanings.

The current density, $I_{i}=z_{i} \mathrm{e} j^{i}$ mass, is then

The current of charged species in the solid bulk is determined by its electrochemical potential gradient.

For clarity, the electronic species is henceforth indicated by the subscript "e", and the ionic one by " $\mathrm{v}$ " in view of oxygen vacancy being the most common ionic defect in MIEC electrode materials. Assuming the electrolyte is purely ionic conductive at this moment, when a certain current, $I_{0}$, is flowing through the electrolyte, the ionic and electronic currents in the MIEC film will be $I_{0}$ and 0 , respectively, given that there is no sink or source for either electrons or ions in MIEC under steady state. According to Eq. 7.5, the electrochemical potential of electrons, $\tilde{\mu}_{\mathrm{e}}(x)$, is constant along the thickness of electrode.

Partial differentiation of Eq. 7.3 with respect to $\mathrm{x}$ for electron is 


$$
\frac{\tilde{\mu}_{\mathrm{e}}(x)}{x}=\frac{\mu_{\mathrm{e}}(x)}{x} \quad e \frac{\lambda(x)}{x}=0
$$

In order to investigate the galvanic potential term above, let us make an assumption on the electron chemical potential as $\frac{\mu_{\mathrm{e}}(x)}{x}=0$, that is, the electrons are evenly distributed in the anode bulk. Such assumption yields $\frac{\backslash(x)}{x}=0$ accordingly, meaning no electrical field inside the bulk.

With this result, for the ionic current on the other hand, the ionic concentration gradient in anode bulk serves as the only driving force for ionic flux as in Eq. 7.7:

$$
\frac{\tilde{\mu}_{\mathrm{v}}(x)}{x}=\frac{\mu_{\mathrm{v}}(x)}{x}+2 e \frac{\eta(x)}{x}=\frac{\mu_{\mathrm{v}}(x)}{x}=\frac{2 e}{\int_{\mathrm{v}}} i_{0}
$$

Inserting Eq. 4 for ion into Eq. 7.7, one obtains

$$
\frac{\mathrm{k}_{\mathrm{B}} T}{c_{\mathrm{v}}(x)} \frac{c_{\mathrm{v}}(x)}{x}=\frac{2 e}{\int_{\mathrm{v}}} i_{0}
$$

As a result, the oxygen ion defects are not uniformly distributed in the anode bulk. Given the even cation charge background and the assumed uniform distribution of electrons, the local charge density at position $\mathrm{x}$ in the bulk, $\rho(x)$, is

$$
\rangle(x)=\left(z_{\text {cations }} e c_{\text {cations }} \quad c_{\mathrm{e}} \quad 2 e \mathrm{~A}_{0}+2 e c_{\mathrm{v}}(x)=2 e c_{\mathrm{v}}(x)+\text { const } \not \alpha 0\right.
$$

where $A_{0}$ is the theoretical volume density of oxygen lattice sites. 
Poisson's equation for one-dimension case writes

$$
\frac{\left.{ }^{2}\right)(x)}{x^{2}}=\frac{\lambda(x)}{\sum_{0}}
$$

Inserting Eq. 7.9 into Poisson's equation, it ends up with $\frac{1(x)}{x} \overline{0}$, which is contradictory to the deviation before under the assumption of $c_{\mathrm{e}}(x)=$ constant. Such contradiction clearly demonstrates this assumption is not self-consistent, therefore cannot be true. There exist local net charges and electrical field inside the MIEC anode bulk. Such logical reasoning is illustrated in Fig. 7.2

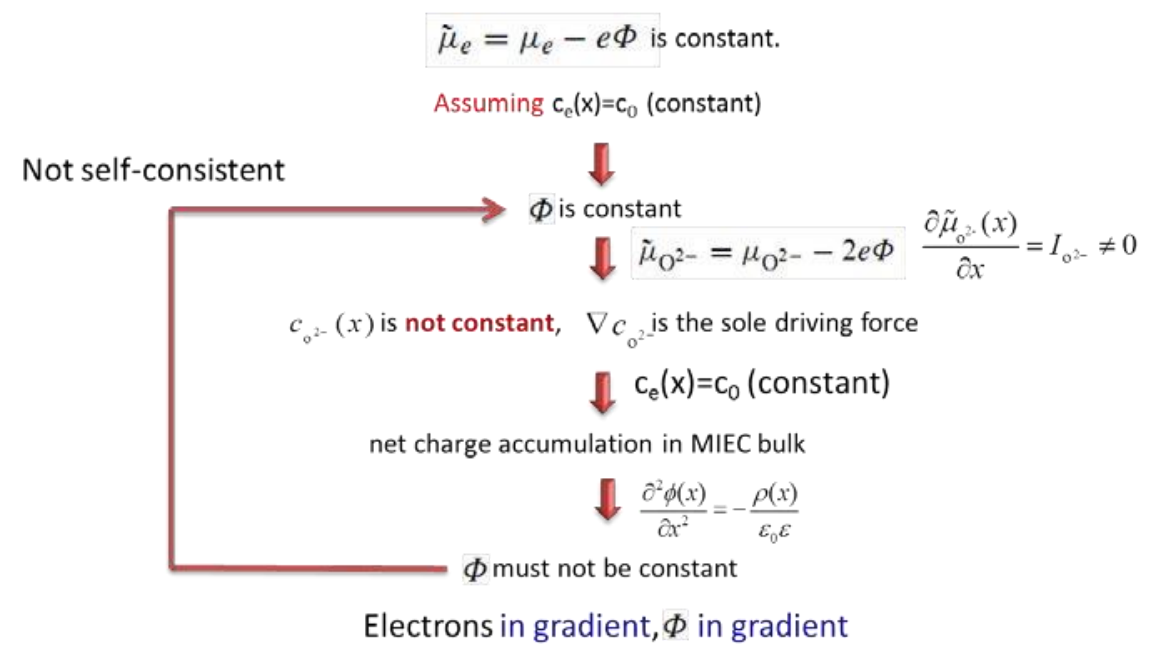

Fig. 7.2 logical flow chart for the possible distribution of electronic defects and the existence of galvanic potential in MIEC bulk.

With regard to the theoretical analysis above, a couple of points in the reasoning process need to be remarked. The first is the purely ionic conductivity for electrolyte. In reality, no matter how small it is, the electronic conductivity in electrolyte material will not be 0 strictly. The significance of the electronic conductivity in electrolyte has been addressed by Virkar.[150] It was shown that such conductivity is one of the most important parameters for one to determine 
the profile of $\tilde{\mu}_{\mathrm{e}}(x)$ and the equivalent oxygen partial pressure inside electrolyte. However, assuming an ideal ion-conductive electrolyte will not affect the validity of the analysis above, because, in principle, the ion transport from electrolyte to anode and the building-up of voltage difference between cathode and anode in Fig. 7.1c, or in other words, the applicability of Nernst equation, do not exclude the existence of electronic conductivity in the electrolyte. Secondly, we leave out the charges located at boundaries but only focus on the local charges in bulk. The abrupt change in electrical properties at the boundary of two phases leads to the relocation of charges, which breaks the local neutrality as a result. From the viewpoint of traditional electrode investigation, where the charge neutrality is always assumed in the bulk, one would believe that those boundary charges may strongly affect the specific value of electrical field inside the anode. However, in the present case, studied is the very relationship between charges and electrical field. The local neutrality assumption is not adopted here, since it is actually one of the subjects to be addressed as will be shown later. Poisson's equation is the governing law, theoretically formulizing the relationship between charges and the change of electrical field. Therefore, making use of this equation will neither omit nor double-count the influence from any relevant charges. In this regard, boundary charges need not to be considered additionally. At last, the conductivities have been implicitly taken as constant and independent to the concentration of charge carriers. Such practice is adopted to keep equations tidy and will not affect the nature of this problem qualitatively. With those issues clarified, it is clear to us now that the analysis above is physically rigorous and the electrical field is built inside the anode bulk regardless of the high electrical conductivity the anode materials may possess. 
To determine the correct electron distribution profile and other related properties in MIEC bulk, three simplified scenarios are tried. The first scenario is drawn as Fig. 7.3a. For uneven distribution, the population of electrons is assumed to decrease from anode surface (S) to anode/electrolyte interface (I), which leads to a tendency of electron flux from S to I due to the concentration gradient. Cancelling out such tendency to reach a zero net electron current requests the electrical field to be established as illustrated in Fig. 7.3a. The corresponding local positive and negative charges inside the bulk come from the relocation of electronic and ionic defects.

Then, the population of ionic defects, $\mathrm{V}^{*}$, must increase from I to $\mathrm{S}$ in order to yield the electrical field as such. The ionic current corresponding to the influence from vacancy gradient and electrical field is denoted as $I_{\text {grad }}$ and $I_{\text {fld }}$ respectively. One can easily find both $I_{\text {grad }}$ and $I_{\text {fld }}$ flow from $S$ to $I$ in this circumstance, and the overall ionic current as a sum of $I_{\text {grad }}$ and $I_{\text {fld }}$ will be from $\mathrm{S}$ to I also, which is in consistence with the real situation at marked by the arrow above. The second scenario is drawn as Fig. 7.3b. The population of electrons is assumed to increase from $S$ to I this time. With the same routine, it ends up with two ionic current flowing from I to $S$, making the overall current opposite with the real one in direction, therefore is impossible. Monotonic change of electron population from one side to the other has been used in those two cases. In the last case, a nonmonotonic change will be tried. As displayed in Fig. 7.3c, the electron population from S to I first increases to the peak then starts to decrease. Likewise, it can be readily determined that the overall current will flow from the middle of the MIEC to the sides, which is nonsense. Of course, the electron population can decreases first, and then rises back from $S$ to I, which just changes the detail and will not bring anything new. In fact, there are countless different examples for the nonmonotonic case, but the particular example used here along with those two monotonic ones can represent all scenarios. Among them, only the case 
shown in Fig. 7.3a coincides with the real situation. The finding that electrons cannot be uniformly distributed in the anode bulk and an electrical field must exist is obtained without any boundary condition restriction, which simply means that the MIEC segment subject to study can be the whole anode bulk, or any pieces of volume inside the bulk. Therefore, whatever the specific nonmonotonic distribution looks like, it will end up with contradictory result.
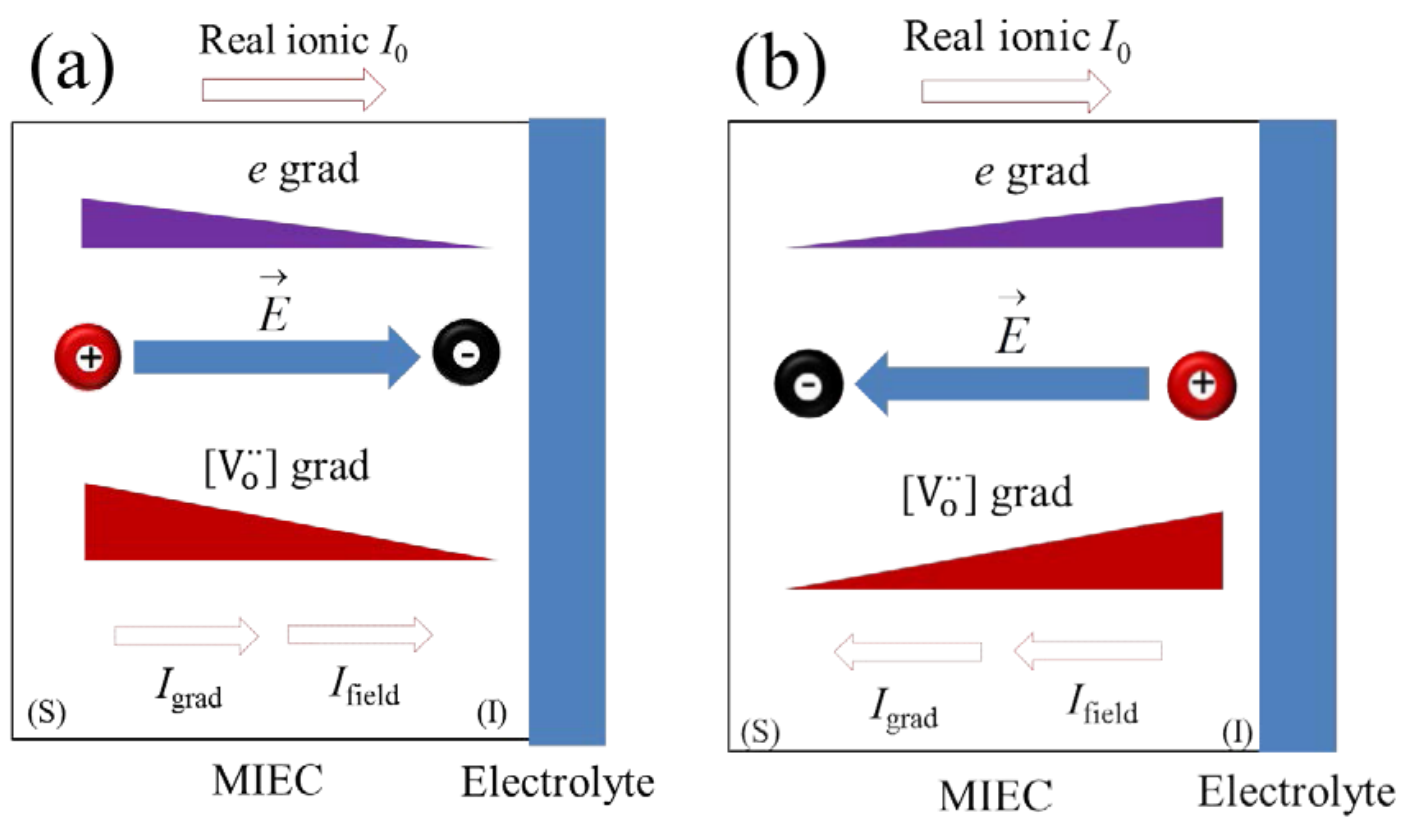


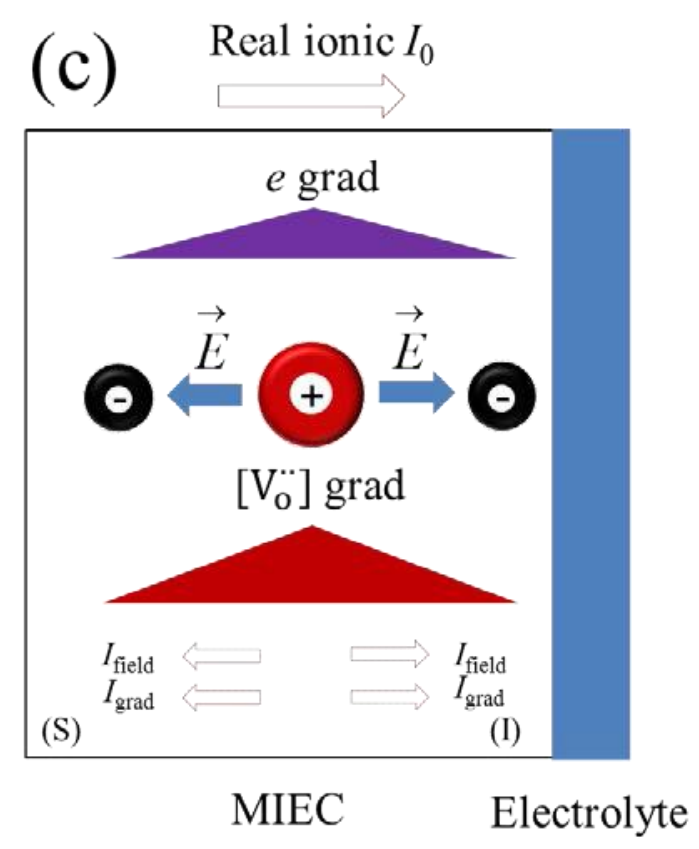

Fig. 7.3 Three scenarios for the defects distribution in MIEC anode under steady state with current $I_{0}$.

By making use of Eq. 7.4 and 7.5, the scenario in Fig. 7.3a can be interpreted into Fig. $7.4 \mathrm{~b}$ with specific parameters including $c_{\mathrm{v}}, c_{\mathrm{e}}, \phi$ and etc. The situation under OCV is also described in Fig. 7.4a for comparison. As the ion transport behavior in MIEC cathode is not different from anode here in terms of the governing equations, those properties are extended into the cathode for the sake of completeness. The transition of those parameters from anode to cathode through electrolyte is arbitrarily illustrated. And the complexity concerning the interface properties, though very important, is left out here in order to focus on the MIEC bulk. For more informative study regarding the interface and electrolyte, one is recommended to refer to Virkar's work.[150-151] Under OCV, all parameters display a uniform profile through out the MIEC film in both cathode and anode sides. The Nernst potential $E_{\mathrm{N}}$ represented as

$$
E_{\mathrm{N}}=\frac{R T}{4 F} \ln \frac{P_{\mathrm{O}_{2}}^{\mathrm{I}}}{P \mathrm{O}_{2}^{\mathrm{II}}}
$$


is equal to $V_{\text {ocv }}$ under the assumption of zero electronic conductivity in electrolyte.

$$
E_{\mathrm{N}}=V_{\mathrm{ocv}}=\frac{\tilde{\mu}_{\mathrm{e}}}{F} \tilde{\mu}_{\mathrm{e}}
$$

As can be seen in Fig. 7.4a, both $E_{\mathrm{N}}$ and the galvanic potential are built up inside the electrolyte. Under steady state with a certain current flowing, the transport of ion is positively driving by both electrical field and $c_{\mathrm{v}}$ gradient. The contribution from each of them trade off with one another to yield a certain difference in $\tilde{\mu}_{v}$ from surface to interface that can be determined from impedance measurement. Decreasing in $c_{\mathrm{v}}$ from surface to interface may limit the MIEC performance by a resultant reduced ionic conductivity in the most active area, but on other hand also be able to stabilize the material near interface if $c_{\mathrm{v}}$ is small enough. Therefore, $c_{\mathrm{v}}$ is of particular interest with respect to the performance reduction/enhancement upon polarization and electrode reliability under large load. As $c_{\mathrm{v}}(x)$ is tied to $\phi(x)$, it cannot be simply determined from the material stoichiometry data at the calculated $P_{\mathrm{O} 2}$ through Eq. 7.11, since the contribution from $\phi$ will decrease the change in $c_{\mathrm{v}}$. Quantification of $c_{\mathrm{v}}$ and $\phi$ requires to solve those equations analytically or numerically. 

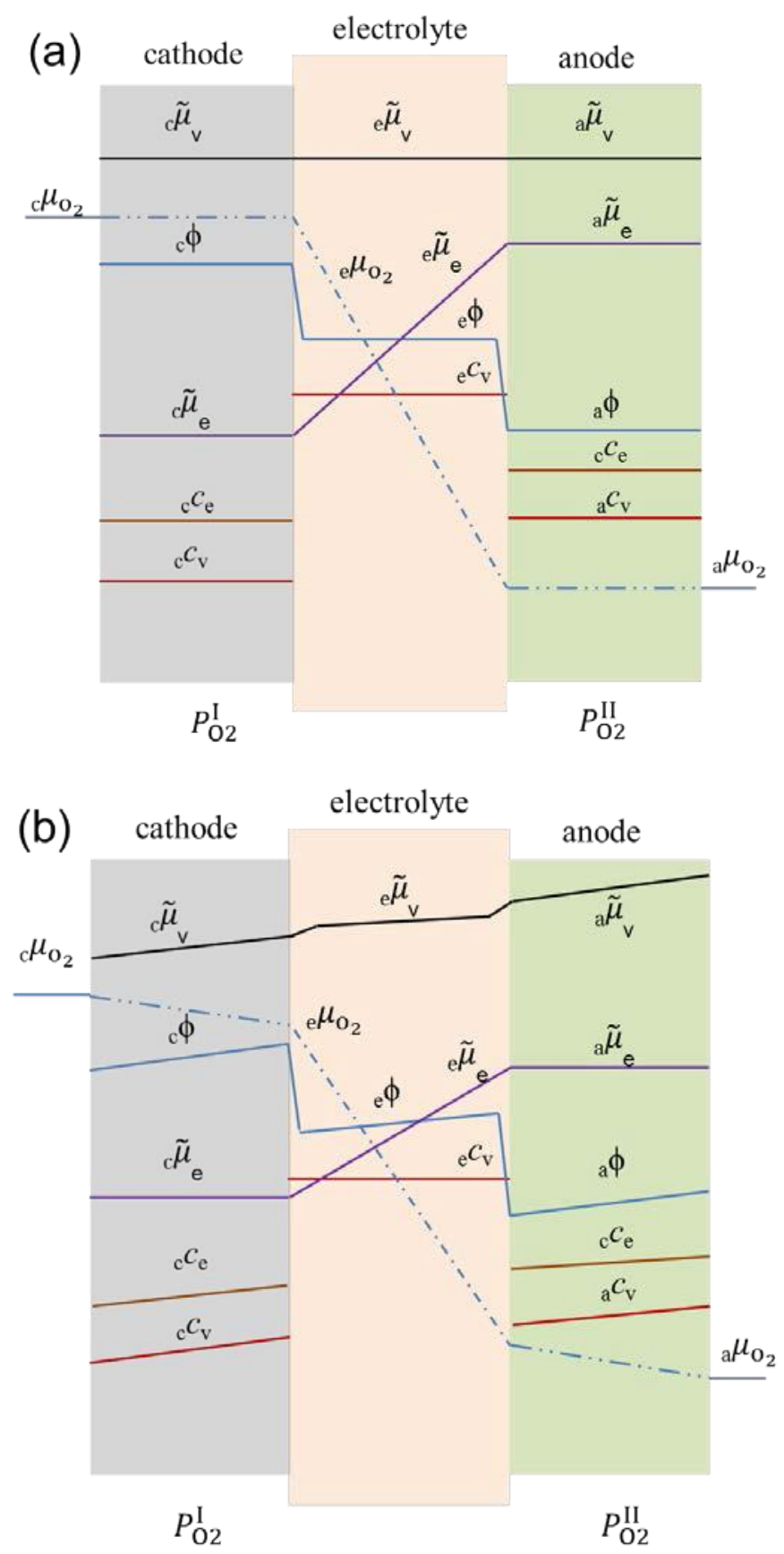

Fig. 7.4 Distributions of concentrations and potentials under OCV (a) and steady state (b).

\subsection{Quantitative solutions for $c_{\mathrm{e}}, c_{\mathrm{v}}$ and $\phi$}

In the 1-dimensinal MIEC cathode model, if assuming electron and oxygen vacancy as charge carrier, the governing equation set under steady state can be rearranged as: 


$$
\begin{aligned}
& \frac{c_{\mathrm{v}}(x)}{x}+\frac{2 F}{R T} c_{\mathrm{v}} \frac{\nearrow(x)}{x}=\frac{j_{\mathrm{v}}^{\text {mass }}}{D_{\mathrm{v}}} \\
& \frac{c_{\mathrm{e}}(x)}{x} \quad \frac{F}{R T} c_{\mathrm{e}} \frac{\backslash(x)}{x}=0 \\
& \frac{\left.{ }^{2}\right)(x)}{x^{2}}=\frac{\lambda(x)}{\sum_{0}}
\end{aligned}
$$

The difficulty in solving such so-called Nernst-Planck-Poisson system lies in the nonlinearity. To obtain analytical solutions, assumptions need to be made to replace Poisson's equation. Two assumptions have been used widely in the pertaining studies, namely electroneutrality and constant field assumption. As one can readily find that electroneutrality leads to constant field and vice verse when inserting it back to Poisson's equation, it may be confusing to understand the difference between those two assumptions. In this regard, the related background will be briefly reviewed here. Electroneutrality was adopted by Planck himself in 1890 to develop solution for the steady state Nernst-Planck equation. Such assumption seems largely reasonable in view of basic physical conceptions on conductive materials. And justification for it is usually realized by the fact that if under appropriate use, inserting back the obtained galvanic potential into Poisson's equation yields small, though not constantly zero, charge density. On the other hand, Goldman in 1943 introduced the constant field assumption to solve the transport properties in a conductive membrane under steady state.[152] Such assumption reduces the 2-order differential Poisson's equation into 1-order, and allows one to integrate the Nernst-Planck equations (7.13) and (7.14) directly. Despite the simplicity brought by these two assumptions, the fundamental concerns associated with the validity of them can be summarized as: (1) why in the first place they can be consistent with Poisson's equation; (2) and 
if they are, do they cover all the circumstances where Eq.7.10 is applicable. Later on, MacGillivray et al. clarified above concerns,[153] and demonstrated with the perturbation theory that the electroneutrality and constant field assumptions are nothing else but two extreme cases of Poisson's equation. The applicability of each hypothesis can be evaluated based on a dimensionless factor,

$$
\underset{\lambda_{\mathrm{D}}}{\alpha^{2}}=\left(\frac{\sum \sum_{0} \mathrm{k}_{\mathrm{B}} T}{z^{2} e^{2} c} / l^{2}\right) \text { or } \alpha=
$$

where $\lambda_{\mathrm{D}}$ is the Debye length and $l$ sample thickness.

When

$\alpha<<1$, local electroneutrality applicable;

$\alpha>>1$, constant field applicable;

$\alpha \cong 1$, neither assumption is correct.

As can be seen now, electroneutrality and constant field hypotheses are used under totally opposite circumstances.

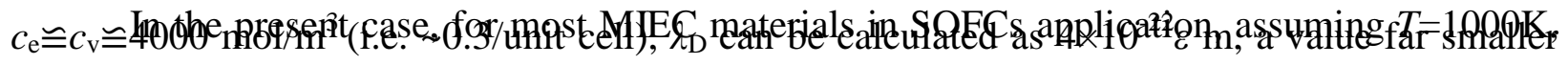
than the active length of $1 \sim 10 \mu \mathrm{m}$ for MIEC cathode given $\varepsilon$ in the range of $10^{12} \sim 10^{14}$. 
Therefore the electroneutrality can be the appropriate approximation here. Poisson's equation is replaced by

$$
2 c_{\mathrm{v}}-c_{\mathrm{e}}-c_{\mathrm{a}}=0
$$

where $c_{\mathrm{a}}$ is positive for the acceptor dopant and negative for donor dopant.

Inserting Eq. 7.16 into 7.13 to eliminate $c_{\mathrm{v}}$, then subtracting $0.5 \times$ Eq. 7.14 , one obtains

$$
\frac{\left(\begin{array}{c}
3 \\
\left.2^{\mathrm{e}}+c\right)
\end{array}\right) \frac{F}{R T}}{x}=\frac{j_{\mathrm{v}}^{\text {mass }}}{D_{\mathrm{v}}}
$$

Inserting Eq. 7.14 into Eq. 7.17,

$$
\left(\frac{3}{2}+\frac{c_{\mathrm{a}}}{c_{\mathrm{e}}}\right) \frac{c_{\mathrm{e}}}{x}=\frac{j_{\mathrm{v}}^{\text {mass }}}{D_{\mathrm{v}}}
$$

Integrating Eq. 7.18 yields

$$
x=\frac{D_{\mathrm{v}}}{j_{\mathrm{v}}^{\mathrm{mass}}}\left(\frac{3}{2}{ }_{\mathrm{e}}+c_{\mathrm{a}} \ln c_{\mathrm{e}}\right)+\text { const }
$$

where const is a constant determined by boundary conditions.

The explicit solution of $c_{\mathrm{e}}$ towards $x$ cannot be developed as the inverse function is not applicable. Therefore Matlab computing is introduced to display the profiles of $c_{\mathrm{e}}$, then $c_{\mathrm{v}}$ and $\phi$. In particular, the contribution comparison between electrical field and chemical gradient for ion transport can be evaluated now. According to Eq. 7.13, the ratio can be represented as

$$
r=\frac{f}{\text { ele }}=\frac{\frac{2 F}{R T} c \frac{1}{\mathrm{v}}}{x}=\frac{4 c_{\mathrm{v}}}{f_{\text {che }}}
$$


For a clear contrast, the distribution of $c_{\mathrm{v}}$ under the assumption of no electrical field contribution is also provided based on Fick's $1^{\text {st }}$ law,

$$
\begin{aligned}
D_{\mathrm{v}} & c_{\mathrm{v}}(x) \quad j_{\mathrm{v}}^{\text {mass }} \text { or } c_{\mathrm{v}}(x)=\frac{j_{\mathrm{v}}^{\text {mass }}}{D_{\mathrm{v}}} x+\text { const } \\
& =x
\end{aligned}
$$

In principle, there are four combinations of electronic/ionic defects in MIEC materials (though not all can be found in or belong to the presently available anode category):

1) e-V, electron-vacancy, e.g. ( $\mathrm{LaSr}) \mathrm{TiO}_{3}$ anode;

2) h-V, hole-vacancy, e.g. YCCC, YCCN anodes, or $(\mathrm{LaSr})(\mathrm{CoFe}) \mathrm{O}_{3-\delta}$ cathode;

3) e-O, electron-interstitial oxygen;

4) h-O, hole-interstitial oxygen, e.g. $\mathrm{La}_{2} \mathrm{NiO}_{4+\delta}$ in O-hyperstoichiometry regime;

Similar to the e-V case, the solutions for the rest combinations can be derived via the same route. To answer the question whether the results solved from equations above and that from the previous qualitatively analysis as in Fig. 7.4 is consistent with each other or not, e-V case is exhibited first. 

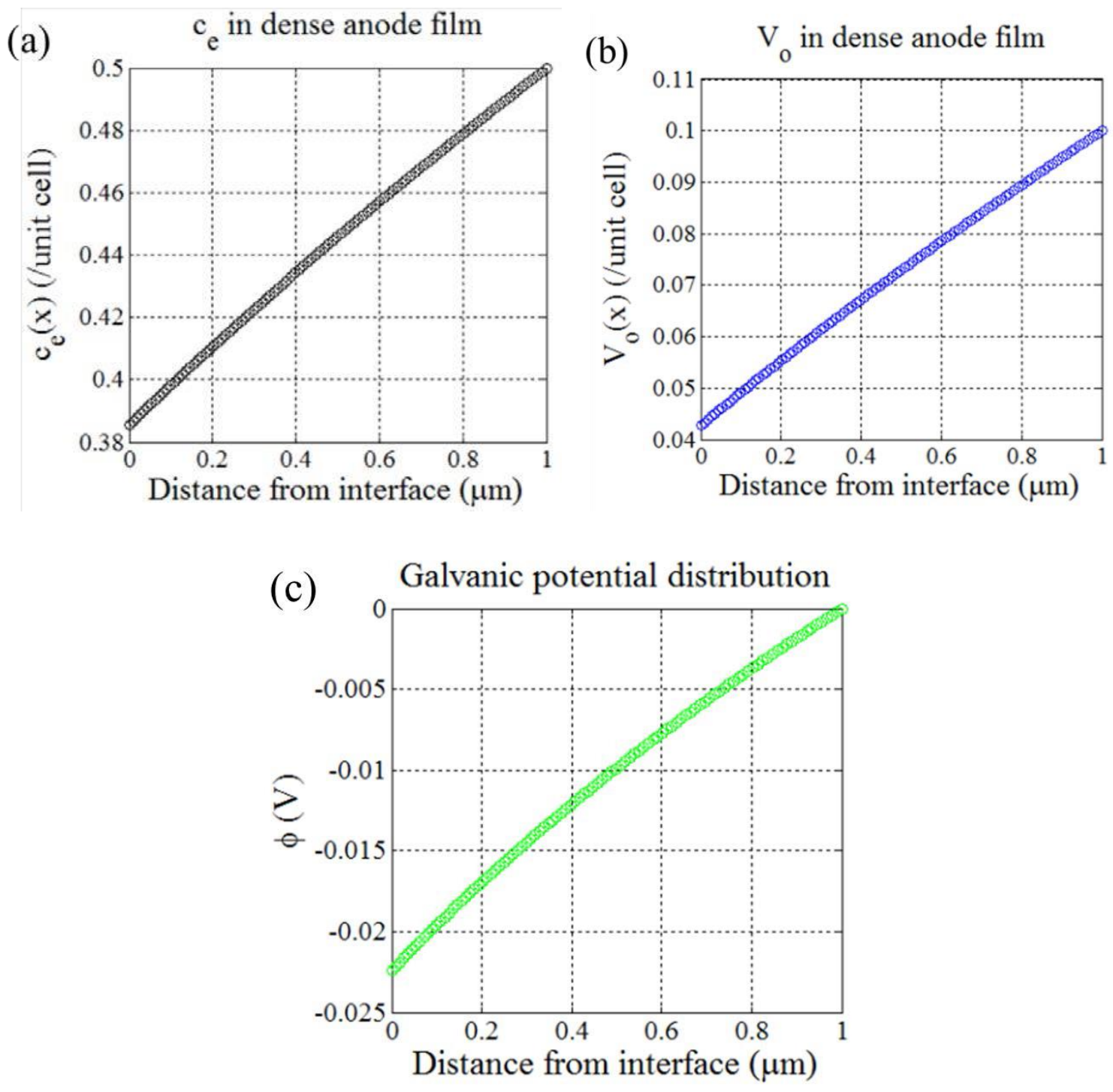

Fig. 7.5 Electron (a) and vacancy (b) and galvanic potential distributions in a $1 \mu \mathrm{m} \mathrm{La}_{0.3} \mathrm{Sr}_{0.7} \mathrm{TiO}_{3}$ anode film as the e-V type.

Using $\mathrm{La}_{0.3} \mathrm{Sr}_{0.6} \mathrm{TiO}_{3}$ (LST) to represent the e-V type, and setting the boundary condition $c_{\mathrm{e}}=0.5 /$ unit cell at the anode surface, and $i=0.5 \mathrm{~A} / \mathrm{cm}^{2}, D_{\mathrm{v}}=10^{-7} \mathrm{~cm}^{2} / \mathrm{s}, T=1000 \mathrm{~K}$, the local concentration of charge carriers and galvanic potential in LST can be solved. The results are displayed in Fig. 7.5. Under steady state $c_{\mathrm{e}}, c_{\mathrm{v}}, \phi$ all increase from surface to interface, showing perfect agreement with the case in Fig. $7.4 \mathrm{~b}$. The galvanic potential $\phi$ is set as 0 at the anode/electrolyte surface since only the potential difference matters. Obviously $\phi$ is not even 
inside the MIEC bulk, challenging the usual wisdom that no electrical field is possible inside such a conductor. It should be point out that $D_{\mathrm{v}}$ for LST is roughly set since the real number is still not available in literature. However, it is good enough to show the theoretical principle here. When increasing the current to $1 \mathrm{~A} / \mathrm{cm}^{2}$, the corresponding change in those parameters can be shown in Fig. 7.6.
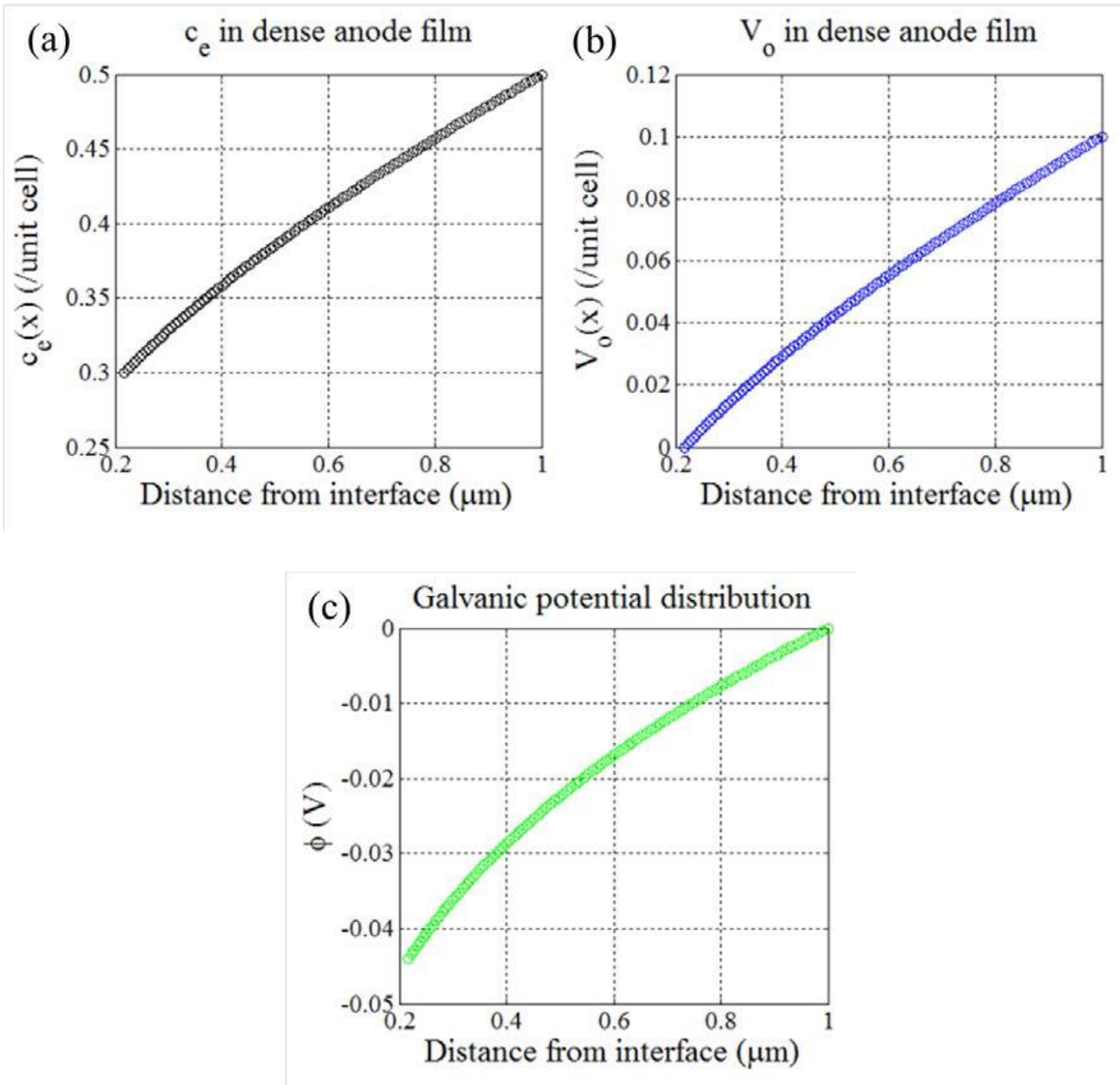

Fig. 7.6 Limiting current in LST and the electron (a) and vacancy (b) and galvanic potential distributions (c). 
In Fig. 7.6, the current is increased from 0.5 to $1 \mathrm{~A} / \mathrm{cm}^{2}$ compared to Fig. 7.5 with other parameters remain unchanged. Those curves are found to stop at $0.2 \mu \mathrm{m}$ instead of reaching the interface. Surface instead of interface is chosen as boundary to yield boundary conditions since during electrode operation under different conditions, surface exposed to fixed $P_{\mathrm{O} 2}$ or $P_{\mathrm{H} 2}$ is more likely to be known in term of the charge carriers densities. Therefore, such phenomenon in fact means the limiting current is arrived with those given parameters for LST, which reasonably represents the real situation that the bulk diffusion process does not literally obey ohm's law (appears in the polarization response of EIS instead of $\mathrm{x}$-axis intercept), and limiting current can be reach easily with small ion diffusion coefficient.

The results for the rest three cases are displayed in Fig. 7.7-9. Cell volumes are set to 200 $\AA^{3}$ and $D_{\mathrm{v}}=10^{-6} \mathrm{~cm}^{2} / \mathrm{s}, T=1000 \mathrm{~K}, i=1 \mathrm{~A} / \mathrm{cm}^{2}$ and thickness $10 \mu \mathrm{m}$. The others parameters used in calculation are listed behind.
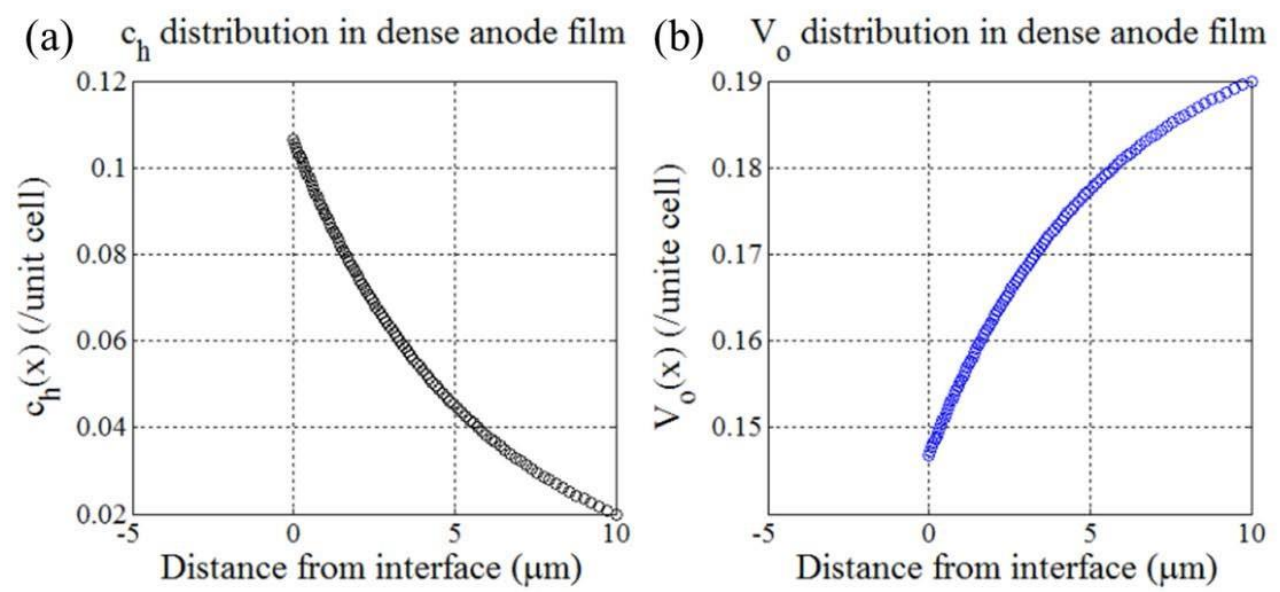

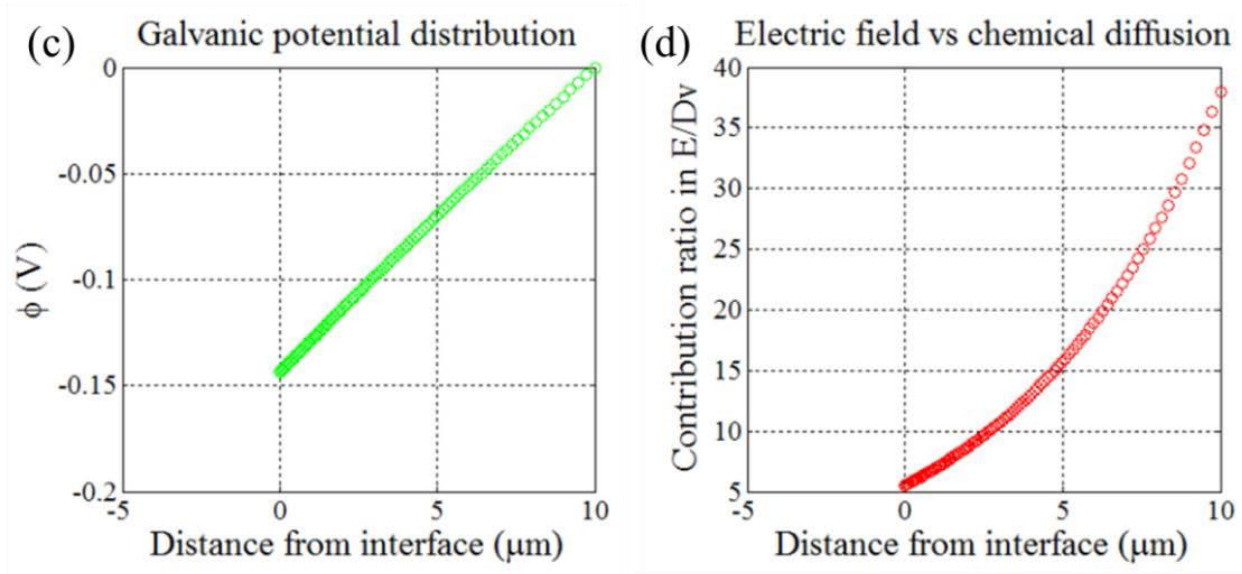

Fig. 7.7 Profiles for $c_{\mathrm{h}}(\mathrm{a}), \mathrm{VO}(\mathrm{b}), \phi(\mathrm{c})$ and $r_{\mathrm{E} / \mathrm{C}}(\mathrm{d})$ in h-V type with acceptor doping 0.4 /unit cell and $0.02 /$ unit cell of $c_{\mathrm{h}}$ at surface.
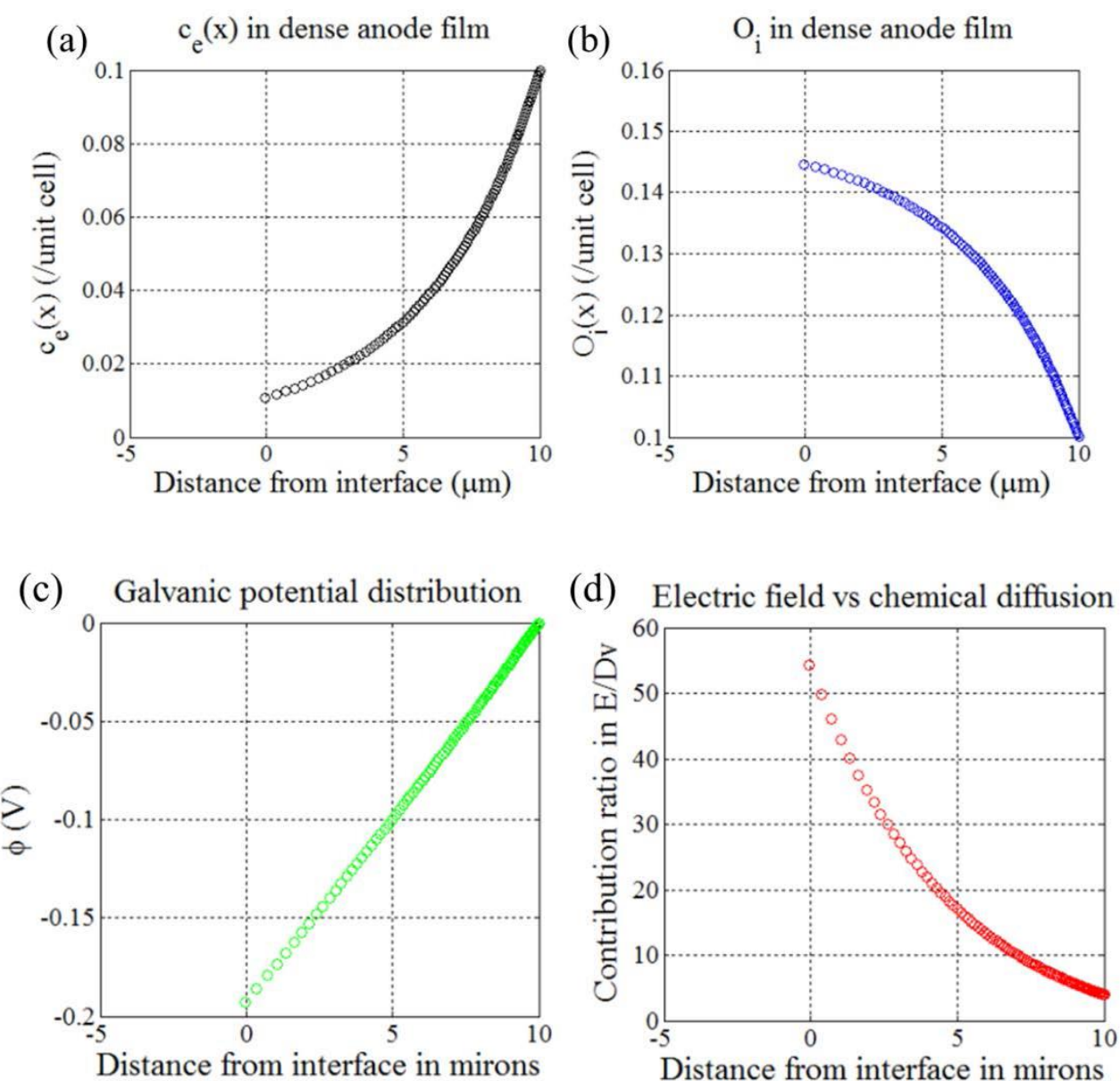

Fig. 7.8 Profiles for $c_{\mathrm{e}}(\mathrm{a}), \mathrm{O}_{\mathrm{i}}^{\prime \prime}(\mathrm{b}), \phi(\mathrm{c})$ and $r_{\mathrm{E} / \mathrm{C}}(\mathrm{d})$ in e-O type with donor doping 0.3 /unit cell and 0.1 /unit cell of $c_{\mathrm{e}}$ at surface. 

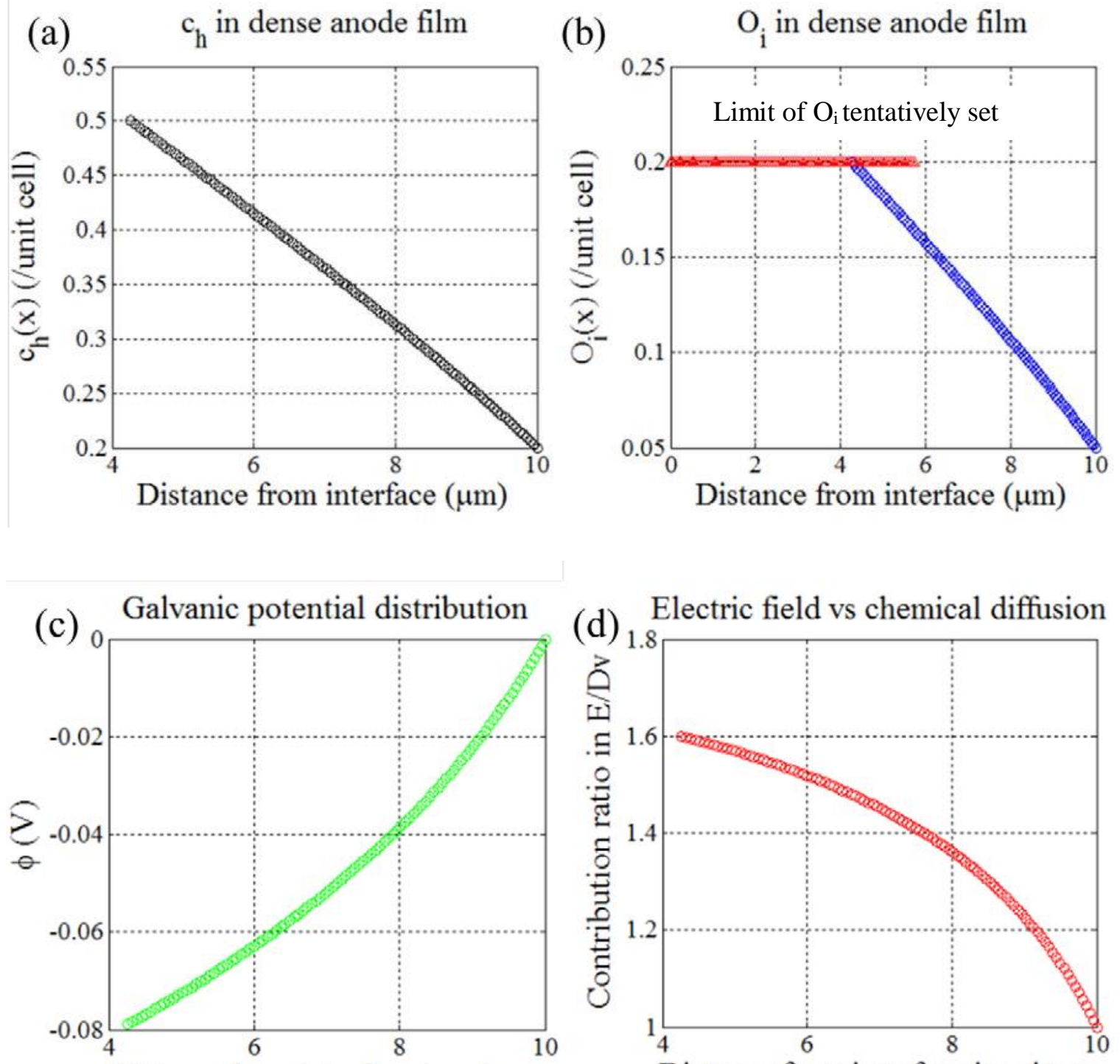

Distance from interface in mirons

Distance from interface in mirons

Fig. 7.9 Profiles for $c_{\mathrm{h}}(\mathrm{a}), \mathrm{O}_{\mathrm{i}}^{\prime \prime}(\mathrm{b}), \phi(\mathrm{c})$ and $r_{\mathrm{E} / \mathrm{C}}(\mathrm{d})$ in h-O type with acceptor doping 0.1 /unit cell and 0.2 /unit cell of $c_{\mathrm{h}}$ at surface.

From those figures, it is found that if hole as the opponent of electron is the charge carriers, e.g. in YCCC, the profile shows exactly opposite tendency of electron as shown in Fig.

7.7, the same is also valid when $\mathrm{O}^{\mathrm{i}, \prime}$ replacing $\mathrm{V}^{\mathrm{O}}$ as the ionic defects as shown in Fig. 7.8. That is in good consistence with the qualitative analysis where only the net charge matters regardless of 
what the specific form the charge carrier takes. It is also noted that the galvanic potential built inside the bulk with given current $1 \mathrm{~A} / \mathrm{cm}^{2}$ is not small at all, but could account for a big portion of the total anode overpotential. The contribution from electrical field in ion transport shown by those figures is even bigger than that from chemical diffusion.

It is worth noting that in the derivation above $D_{\mathrm{v}}$ in Eq. 7.13 is taken as constant regardless of the change of $c_{\mathrm{v}}$ along MIEC film. According to the random-walk theory by Goodenough,

$$
\begin{aligned}
& D_{\mathrm{v}}=D_{\mathrm{v}}^{0} \exp \left(\frac{\Delta G_{\mathrm{m}}}{k_{\mathrm{B}} T}\right) \\
& D_{\mathrm{v}}^{0}=\frac{\underline{l}^{2}}{6} z\left(1 \quad n_{\mathrm{v}}\right) f v_{0}
\end{aligned}
$$

where $l$ is distance between two oxygen sites, $z$ the number of near-neighbor oxygen sites surrounding one oxygen, $n_{\mathrm{v}}$ the fraction of vacancy site (proportional to $c_{\mathrm{v}}$ ), $f$ a geometrical factor depending on the jump path, $v_{0}$ the attempt frequency. As $c_{\mathrm{v}}(x)<<3$ under the present

situation for perovskite MIEC, $1-n_{\mathrm{v}} \approx 1$, thus making $D_{\mathrm{v}}$ being constant a reasonable approximation.

\subsection{Experimental verification through the $h-V$ type MIEC electrode}

To verify those results experimentally, LSCF/GDC half cells were measured. Though anode bulk transport is the subject here, experiment was conducted in the cathode mode, because firstly, the principle in the above qualitative/quantitative treatment is not unique to anode but also applicable to cathode; secondly, there is a large body of data regarding MIEC cathode but 
almost nothing there for anode part, from which the necessary input parameter is readily available.

An $\mathrm{La}_{0.6} \mathrm{Sr}_{0.4} \mathrm{Co}_{0.2} \mathrm{Fe}_{0.8} \mathrm{O}_{3}(\sim 1.2 \mathrm{~mm}) / \mathrm{GDC}(\sim 30 \mu \mathrm{m})$ bilayer was fabricated through the spray-modified dry pressing method as described in experimental section. The sample was tested in the configuration shown in Fig. 7.10a. In order to avoid the electronic conductivity in GDC, testing was carried out in air instead in anode- $\mathrm{H}_{2} /$ cathode-air. To simulate cathode mode on LSCF, positive and negative potential was applied to $\mathrm{Pt}$ counter electrode and LSCF, respectively. Constant currents flew through this bilayer. Fig. 7.10b shows the microstructure of the cross-section. The adhesion between GDC/LSCF is good and GDC was successfully densified to ensure no electron current or gas leaking. The goal of this experiment is to see whether a current which is too high to be realized by mere chemical diffusion in LSCF/GDC pellet can be flew through it without damaging the sample, therefore proving the extra contribution from electrical field.

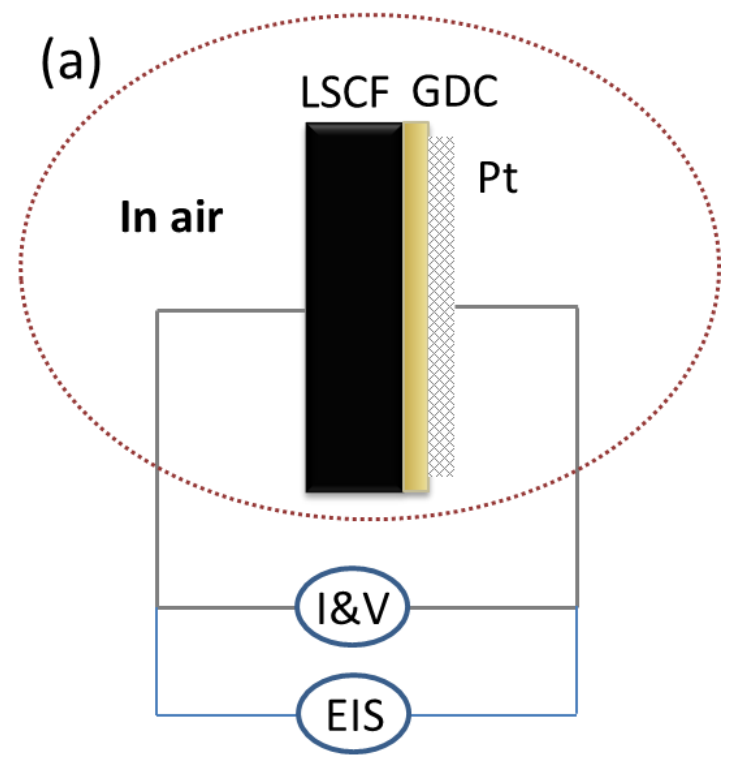




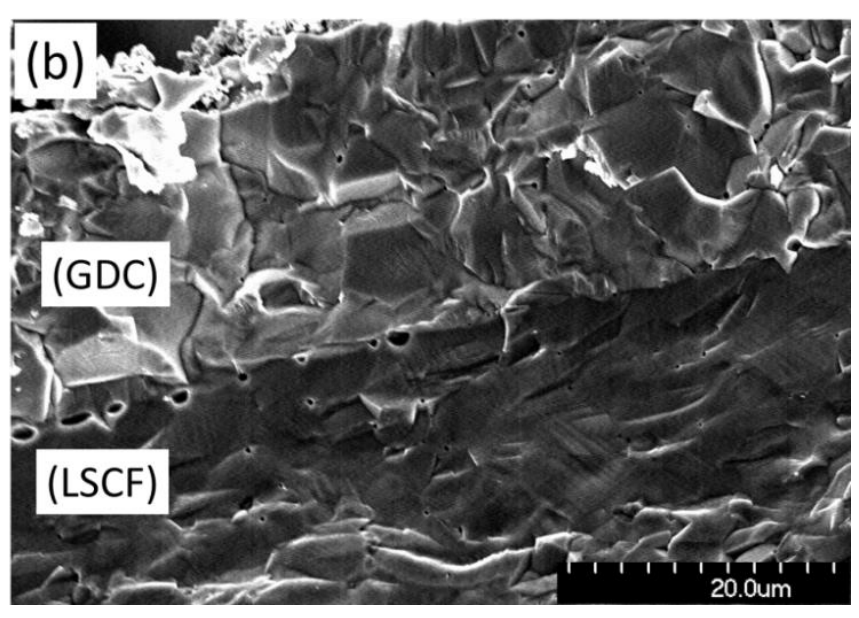

Fig. 7.10 The configuration of LSCF/GDC measurement (a) and cross-sectional LSCF/GDC (d).

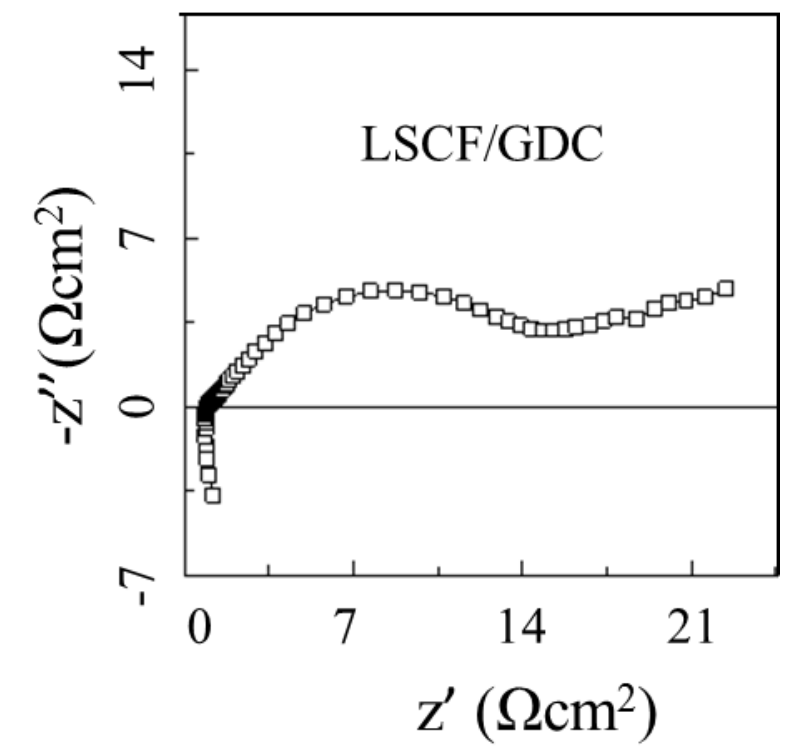

Fig. 7.11 EIS of LSCF/GDC bilayer in air $700^{\circ} \mathrm{C}$ 

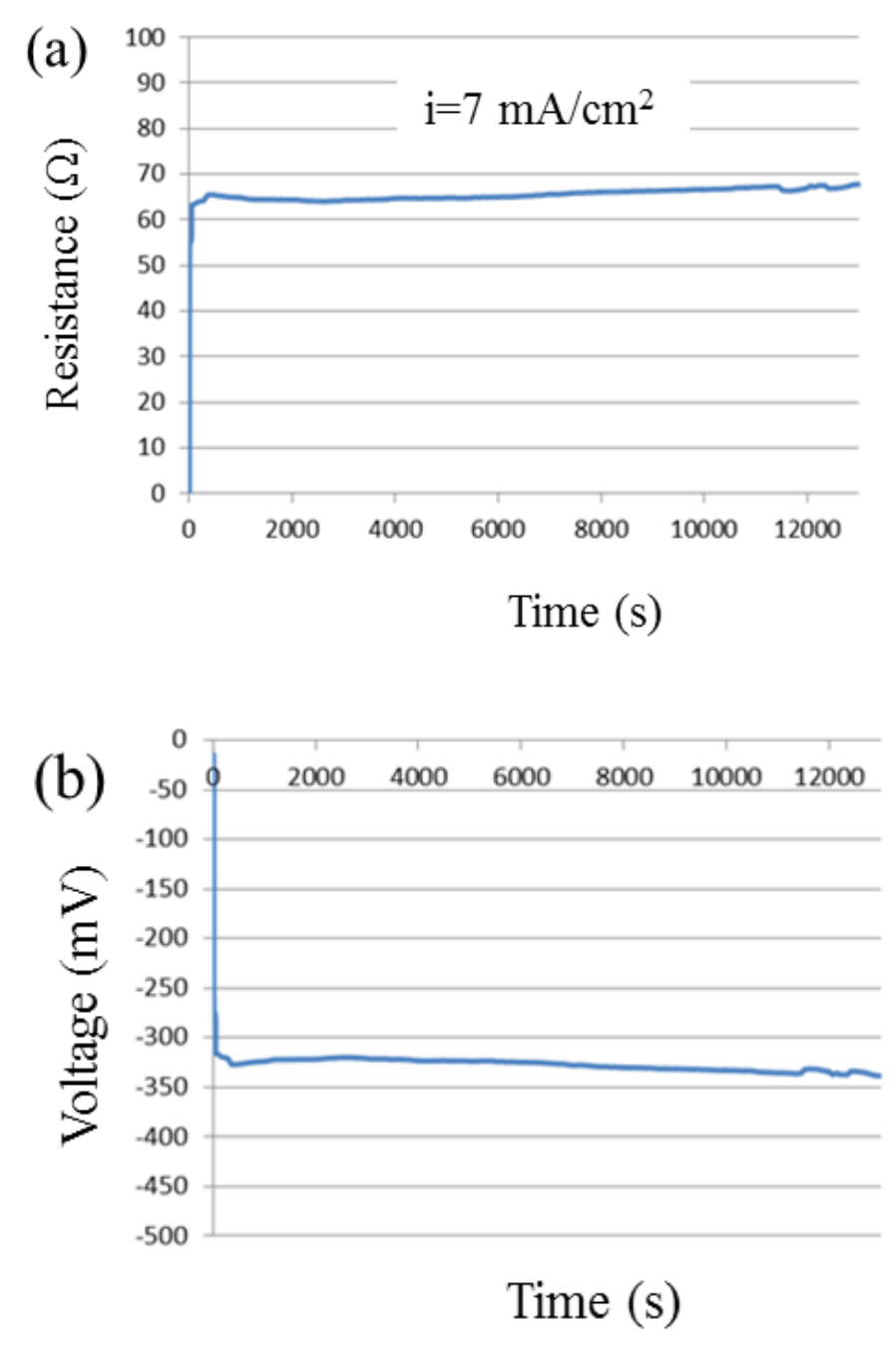

Fig. 7.12 DC resistance under constant current loading for LSCF/GDC bilayers (a), and the variation of applied voltage (b).

Fig. 7.11 shows the EIS of such bilayer measured in air at $700^{\circ} \mathrm{C}$. The arc represents the surface reaction, i.e. $14 \Omega \mathrm{cm}^{2}$, and the tail the transport resistance that cannot be known from this spectrum. Fig. 7.12a shows the DC resistance under a constant current loading, $7 \mathrm{~mA} / \mathrm{cm}^{2}$, on the sample. The total resistance is $\sim 66 \Omega$ (or $46 \Omega \mathrm{cm}^{2}$ ), which means $32 \Omega \mathrm{cm}^{2}$ is for oxygen transport. Fig. $7.12 \mathrm{~b}$ shows voltage vs. time, which clearly demonstrates the stability of this sample under this current. The potential applied to the transport process can be calculated as 226 $\mathrm{mV}$. Based on this condition, the distribution of charge carriers under traditional chemical 
diffusion only assumption and chemical diffusion/electrical field driving co-control assumption can be resolved.

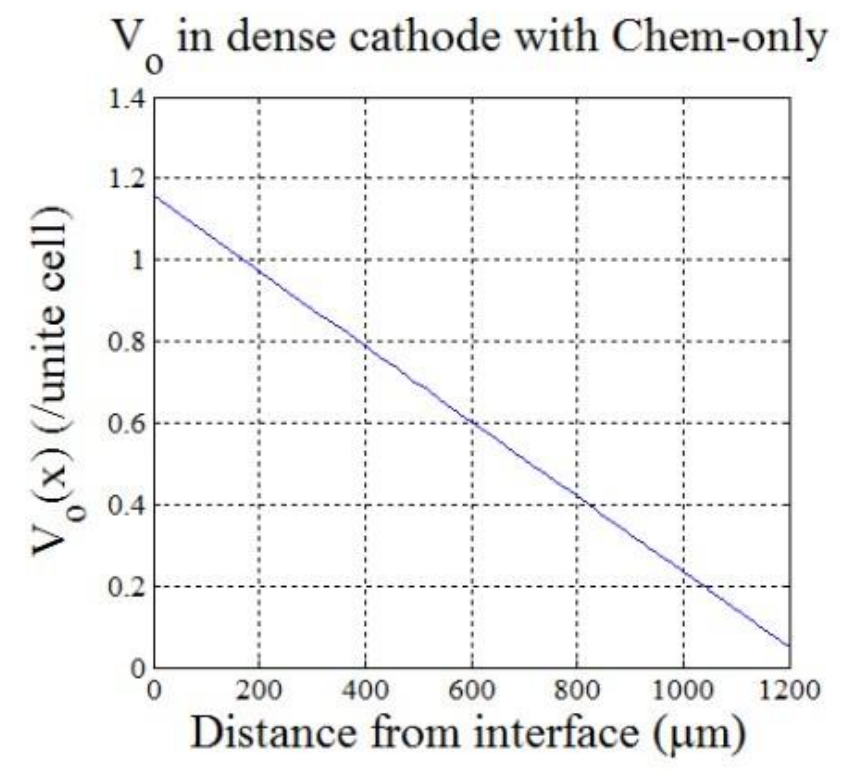

Fig. 7.13 Calculated profiles for V" (b) in LSCF under chemical diffusion only assumption based on the same experimental conditions.

According to literature data, the boundary condition on $\mathrm{V}^{\mathrm{O}}$ is set to $0.05 / \mathrm{unit}$ cell, $D_{\mathrm{v}}$ $2.5 \times 10^{-6} \mathrm{~cm}^{2} / \mathrm{s}$ at $700^{\circ} \mathrm{C}$. Fig. 7.13 shows the profile of $\mathrm{V}_{0}$ under the chemical diffusion only assumption with the same input conditions as in experiment. The vacancy concentration increases linearly from surface to interface. The final concentration near interface is $\sim 1.2$ unit cell, which in fact is high enough to give rise to decomposition of LSCF, therefore is not consistent with experiment result. On the other hand, Fig. 7.14 shows the corresponding calculations on those charge carriers and potentials according to the analytic solutions above with the same condition. It can be found that in most of the active length ion migration driven by electrical field instead of chemical diffusion dominates the ion transport as shown in Fig. 7.14d. 
Due to such contribution, the concentration gradient turns less steep accordingly and yields much smaller vacancy concentration at the interface; therefore avoid the decomposition of LSCF.

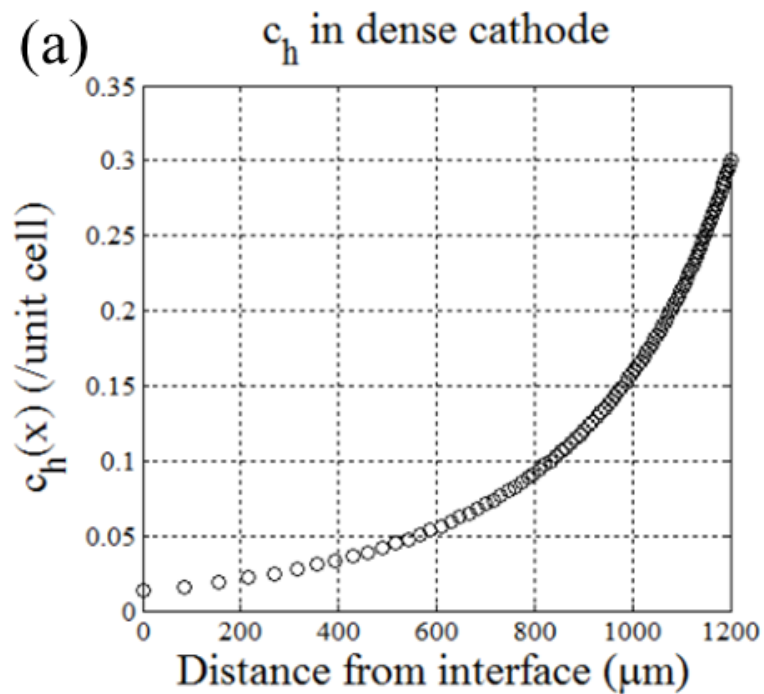

(c)

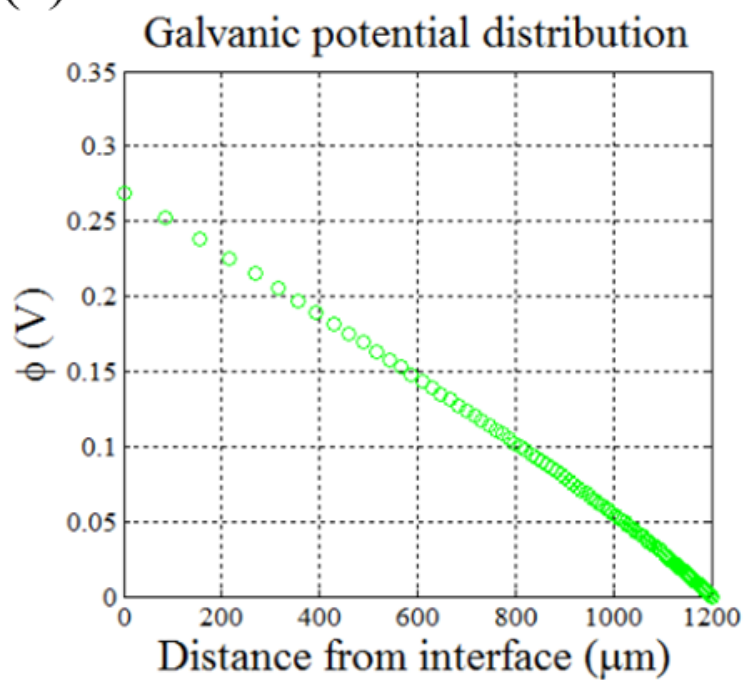

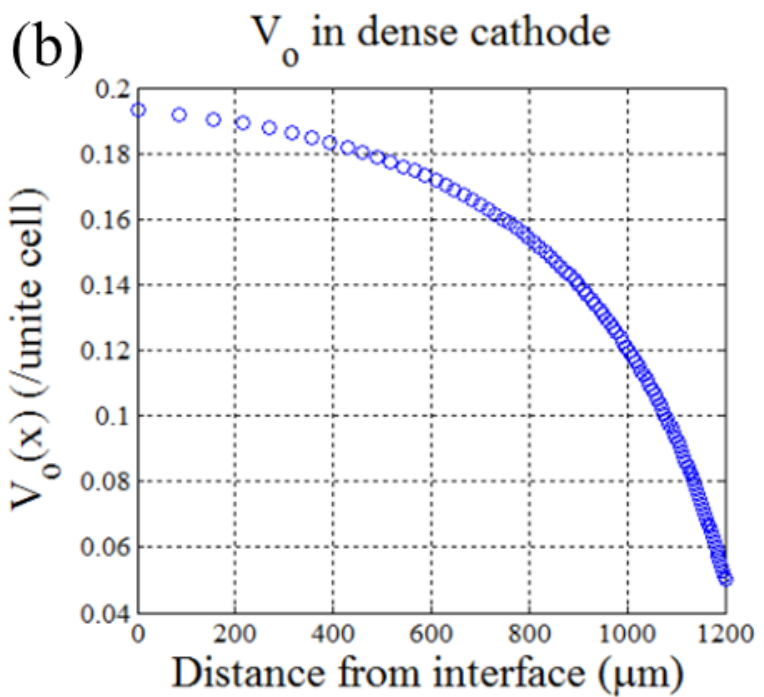

(d)

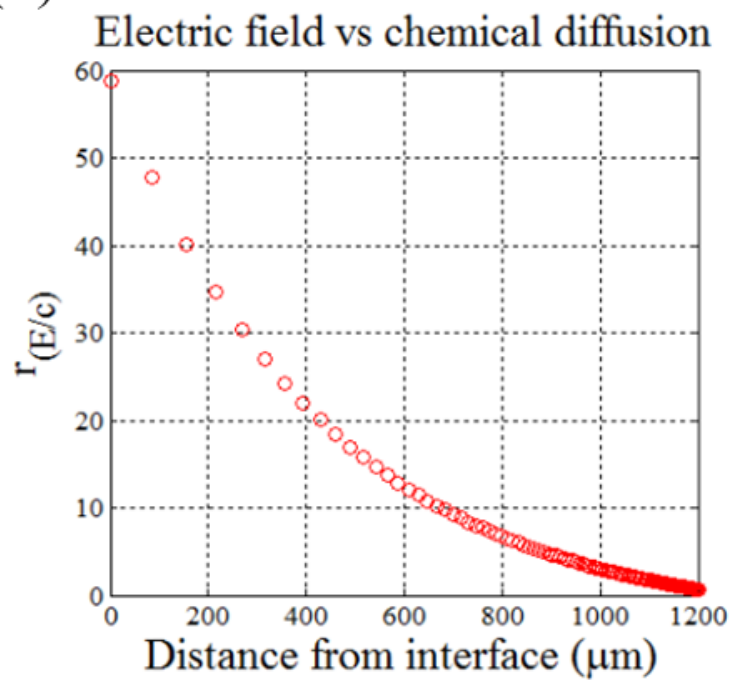

Fig. 7.14 Calculated profiles for $c_{\mathrm{h}}(\mathrm{a}), \mathrm{V}_{\mathrm{O}}$ (b), $\phi(\mathrm{c})$ and $r_{\mathrm{E} / \mathrm{C}}(\mathrm{d})$ in LSCF based on the experimental conditions.

In the above content, the transport behavior is studied independently by analysis based on sound physical knowledge and by solving the Nernst-Planck-Poisson equations mathematically. 
Two routes are confirmed to be consistent with each other without sharing common restrictive assumptions, lending credibility to those treatments. However, the role of the first route is more than being used to check the consistency. It shows the basic concept in the MIEC bulk transport that the mathematical treatment is not able to convey. Since the electroneutrality is adopted in the latter (as also in lots of similar studies), it then becomes superfluous to ask and also impossible to answer whether the MIEC bulk is really electroneutral or in fact locally charged but with electroneutrality being an appropriate approximation in some cases. Through the first route, it is clearly demonstrated that MIEC bulk under steady state is not neutral but with local charges anywhere, which could be viewed as a complement to the conventional conception on this subject that only chemical diffusion is believed to be true. The validity of analytical solutions for $c_{\mathrm{e}}, c_{\mathrm{v}}$ and $\phi$ is further verified through experiment, given without $E$ contribution, either the current flow of $7 \mathrm{~mA} / \mathrm{cm}$ in the dense LSCF pellets measured here or the constant current load $\sim 0.6 \mathrm{~A} / \mathrm{cm}^{2}$ in the practical porous LSCF cathode can be realized. It is unveiled by those results that $E$ contribution is significant in most cases and usually greater than the chemical diffusion.

In the other hand, for local chemical composition, it has been shown by above calculations and can be briefly summarized that the real concentration of ionic defects (vacancy or interstitial oxygen) under service condition in either anode or cathode are less deviated from the as-prepared composition compared to estimated from the Nernst equation using equivalent $P_{\mathrm{O} 2}$-stoichiometry data. The schematic diagram is displayed in Fig. 7.15. As a result, the stability of anode material toward the relatively high $P_{\mathrm{O} 2}$ in anode/electrolyte interface, or cathode towards the relatively low $P_{\mathrm{O} 2}$ in cathode/electrolyte interface is less severe due to the existence of electrical field in the bulk. 
(a)

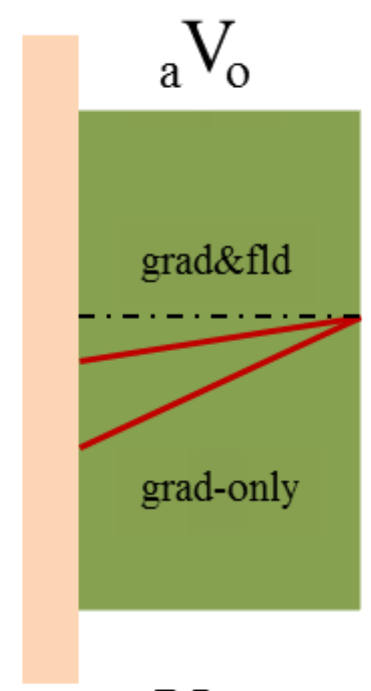

(c)

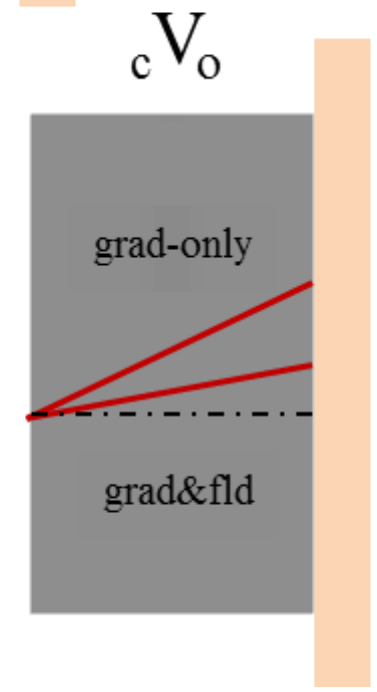

(b)

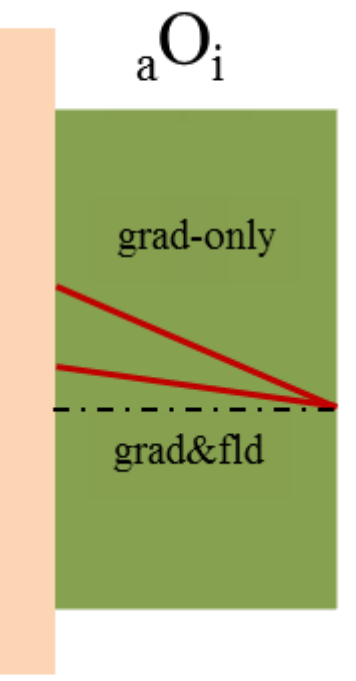

(d)
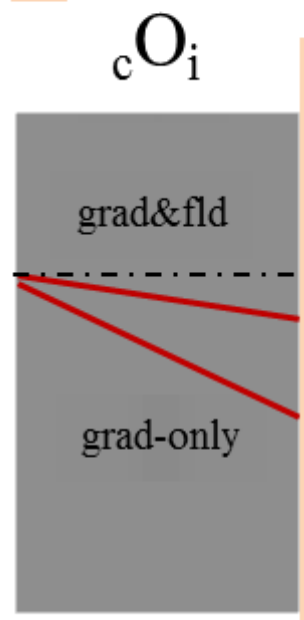

Fig. 7.15 schematic drawing of oxygen defect profiles in anode and cathode, vacancy in anode (a), interstitial oxygen in anode (b), vacancy in cathode (c), interstitial oxygen in cathode (d).

According to the profiles of $\phi$ in Fig. 7.6-9 representing all types of MIEC materials, it is clear that the electrical fields in both anode and cathode work to facilitate the transport of oxygen defects. However, as shown in Fig. 7.15, only for anode materials with $0^{{ }^{i} \text {, }}$ and cathode materials 0 with $\mathrm{V}^{\prime \prime}$ defects, the overpotential and then the electrical field will maintain higher ionic conductivities for those materials under polarization relative to equilibrium status, while for the 
opposite cases, anode materials with $\mathrm{V}_{\mathrm{O}}$ and cathode materials with $\mathrm{O}_{\mathrm{i}}$, e.g. $\mathrm{YCCC}$ anode and $\mathrm{La}_{2} \mathrm{NiO}_{4+\delta}$ cathode, the overpotential will shut down the bulk pathway gradually.

At last, besides the influence on the anion transport, the electrical field introduces a new concept for the cation transport in electrode which has never been appreciated before, for it not only drives the anions but inevitably drives the cations movement in the electrode as well. In fact, the diffusion of cation has been mention as one of the causes for the performance relaxation after different treatments in literature, but no firm theoretical support had been provided. With the framework exhibited here, such process could be well-grounded.

\subsection{Summary}

In this chapter, the relation between of the bulk reaction pathway and the overpotential was investigated. The bulk overpotential in MIEC anode was consumed in form of concentration gradient driven diffusion and electrical field driven migration. As only the former is appreciated by co-workers on the transport studies, the existence of electrical field and then the resultant impact on the bulk reaction pathway and durability of electrode under service were thoroughly studied here. Qualitative analysis was conducted first, followed by quantitative treatment for analytical solutions. It was proven that the electrode bulk was not electroneutral through the qualitative analysis. With electron blocked at the electrode/electrolyte interface, the appearance of electrical field was an inevitable consequence of the ion transport process. The analytic solutions were pursued independently with appropriate assumption taken. Results from both methods were compared, and show perfect consistency with one another, lending credibility to those treatment. Ion transport in LSCF/GDC as h-V type MIEC was measured under cathode 
mode to verify the theoretical results experimentally. The results disproved the general chemical diffusion-only conception in SOFC community, and proved the newly introduced chemical diffusion\&electrical field driving co-determined ion transport process. Due to the presence of electrical field, the real stoichiometry variation in ionic defects under service conditions in either anode or cathode was much smaller than estimated from the Nernst equation using equivalent $P_{\mathrm{O} 2}$-stoichiometry data. The stability concern in terms of high $P_{\mathrm{O} 2}$ at anode/electrolyte interface and low $P_{\mathrm{O} 2}$ at cathode/electrolyte interface was therefore much less severe. The electrical fields in both anode and cathode worked positively to facilitate the transport of oxygen defects. However, only for anode materials with $\mathrm{O}_{\mathrm{i}}$ or cathode materials with $\mathrm{V}_{\mathrm{o}}$ defects, it maintained higher ionic conductivities under polarization with the presence of electrical field compared to equilibrium status. In other words, overpotential would broaden the electrode pathway effectively for those electrodes. The electrical field also opens a new concept for the cation transport in electrode, for it not only drives the anions but inevitably also drives the cations movement in the electrode. With such framework exhibited here, the cation movement proposed in electrode performance relaxation is well-grounded. 


\section{Chapter 8}

\section{CONCLUSIONS}

The anode oxidation reaction pathway was investigated on $\mathrm{YCrO}_{3}$-based perovskites materials in terms of the origin of catalytic activity for oxide anode, the reactive area and rate determining steps, the effect of electrolyte on interface resistance and the evolution of bulk pathway under overpotential in practical operation conduction.

In Chapter 5, $\mathrm{Sr}, \mathrm{Co}$ and $\mathrm{Ni}$ were doped into $\mathrm{YCrO}_{3}$ to enable a systematic variation in terms of B site element, electrical conductivity and catalytic activity. Good performance was yielded from YCCC, $0.9 \Omega \mathrm{cm}^{2}$ at $850^{\circ} \mathrm{C}$ which was among the best performance presently available from oxide anodes. Charge transfer and hydrogen surface adsorption/diffusion were identified as limiting factors in those doped $\mathrm{YCrO}_{3}$ anode. $\mathrm{B}$ site element worked as a decisive role in determining catalytic activity. Such activity was proven to be H-related, e.g. H surface adsorption/coverage was dependent to those $\mathrm{B}$ site elements. Compared to metal $\mathrm{Ni}$, the oxides displayed lower $\mathrm{H}$ adsorption ability judged by the apparent $P_{\mathrm{H} 2}$-dependent resistance. YCCN showed higher adsorption ability than YCCC even with less dopant content at B site. A model was presented to describe the elementary steps in $\mathrm{H}_{2}$ oxidation. It was suggested that for the charge transfer step, any hypothesis models presented without taking $\mathrm{H}$ into account were invalid. It was also found that high electrical conductivity $(>100 \mathrm{~S} / \mathrm{cm})$, though usually cited as a prerequisite, was not necessary in those chromites to obtain a good electrode performance. High 
performance came from combination of decent electrical conductivity $(>1 \mathrm{~S} / \mathrm{cm})$ and $\mathrm{B}$ site active element.

In Chapter 6, by extending the electrode response from $P_{\mathrm{H} 2}$ in Chapter 5 to $P_{\mathrm{O} 2}$ measuring in $\mathrm{O}_{2}$-containing gases and using SSZ to replace YSZ electrolyte, the activation of lattice oxygen, the contribution from $2 \mathrm{~PB}$ and $3 \mathrm{~PB}$ and the beneficial effect of electrolyte in $R_{\mathrm{p}}$ for those oxide anodes was investigated. Judging from the chemical capacitance along with the improvement from changing electrolyte, YCCC was confirmed to be both $2 \mathrm{BP}$ and $3 \mathrm{~PB}$ active, and YCCN 3PB dominant. The activation of 2PB depended on the ionic conductivity and then the nonstoichiometry of oxide under reducing atmospheres. A big capacitance for YCCC was observed and associated to the variation of lattice oxygen under EIS measurement, confirming the activity of bulk transport. The overall performance was less affected by the nature of electrolyte when both $3 \mathrm{~PB}$ and $2 \mathrm{~PB}$ pathways were effectively working, but on the 3PB dominant YCCN, reaction kinetics was largely influenced by the electrolyte. For YCCN, not only the charge transfer step, but also the surface process anode was promoted. Such effect of electrolyte on surface process was explained by a chain-transmit mechanism. Basically, by enlarging the exchange current of charge transfer reaction at the electrolyte/anode interface, bigger gradient in the adsorbed species was resulted, which in turn broadened the adsorption area then the adsorption rates. The significance of this phenomenon in practical application was demonstrated on the SSZ/YSZ/SSZ sandwich electrolyte which showed almost the same $R_{\mathrm{p}}$ as from pure SSZ electrolyte. Such results could be able to rewrite the concept of electrolyte design and open a wide door for the utilization of novel electrolyte materials that otherwise cannot be 
used by themselves alone due to instability in either oxidizing or reducing atmospheres, mechanical fragility, high cost or etc.

In Chapter 7, the influence of the overpotential on the bulk reaction pathway was investigated. The bulk overpotential in MIEC anode was consumed in form of concentration gradient driven diffusion and electrical field driven migration. As only the former is appreciated by co-workers on the transport studies, the existence of electrical field and then the resultant impact on the bulk reaction pathway and durability of electrode under service were thoroughly studied here. Qualitative analysis was conducted first, followed by quantitative treatment for analytical solutions. It was proven that the electrode bulk was not electroneutral through the qualitative analysis. With electron blocked at the electrode/electrolyte interface, the appearance of electrical field was an inevitable consequence of the ion transport process. The analytic solutions were pursued independently with appropriate assumption taken. Results from both methods were compared, and show perfect consistency with one another, lending credibility to those treatment. Ion transport in LSCF/GDC as h-V type MIEC was measured under cathode mode to verify the theoretical results experimentally. The results disproved the general chemical diffusion-only conception in SOFC community, and proved the newly introduced chemical diffusion\&electrical field driving co-determined ion transport process. Due to the presence of electrical field, the real stoichiometry variation in ionic defects under service conditions in either anode or cathode was much smaller than estimated from the Nernst equation using equivalent $P_{\mathrm{O} 2}$-stoichiometry data. The stability concern in terms of high $P_{\mathrm{O} 2}$ at anode/electrolyte interface or low $P_{\mathrm{O} 2}$ at cathode/electrolyte interface was therefore much less severe. The electrical fields in both anode and cathode worked positively to facilitate the transport of oxygen defects. However, 


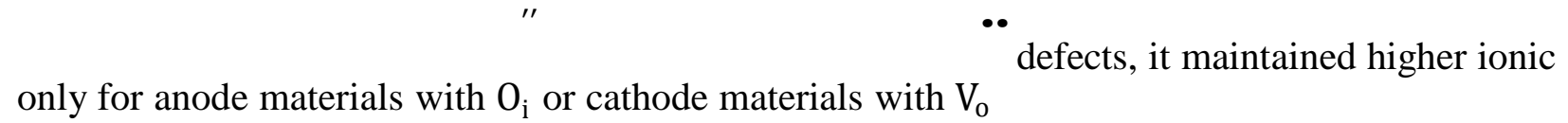
conductivities under polarization with the presence of electrical field compared to equilibrium status. In other words, overpotential would broaden the electrode pathway effectively for those electrodes. The electrical field also introduces a new concept for the cation transport in electrode, for it not only drives the anions but inevitably also drives the cations motion in the electrode. With such framework exhibited here, the cation separation proposed in electrode performance relaxation is well-grounded. 


\section{REFERENCES}

[1] S. McIntosh, R. J. Gorte, Direct hydrocarbon solid oxide fuel cells, Chemical Reviews 104 (2004) 4845-4866.

[2] T. Fukui, K. Murata, S. Ohara, H. Abe, M. Naito, K. Nogi, Morphology control of NiYSZ cermet anode for lower temperature operation of SOFCs, Journal of Power Sources 125 (2004) 17-21.

[3] M. Gong, X. Liu, J. Trembly, C. Johnson, Sulfur-tolerant anode materials for solid oxide fuel cell application, Journal of Power Sources 168 (2007) 289-298.

[4] W. Li, Z. Lü, X. Zhu, B. Guan, B. Wei, C. Guan, W. Su, Effect of adding urea on performance of $\mathrm{Cu} / \mathrm{CeO}_{2} / y$ ttria-stabilized zirconia anodes for solid oxide fuel cells prepared by impregnation method, Electrochimica Acta 56 (2011) 2230-2236.

[5] T. Takeguchi, Y. Kani, T. Yano, R. Kikuchi, K. Eguchi, K. Tsujimoto, Y. Uchida, A. Ueno, K. Omoshiki, M. Aizawa, Study on steam reforming of CH4 and C2 hydrocarbons and carbon deposition on Ni-YSZ cermets, Journal of Power Sources 112 (2002) 588-595.

[6] Y. Matsuzaki, I. Yasuda, The poisoning effect of sulfur-containing impurity gas on a SOFC anode: Part I. Dependence on temperature, time, and impurity concentration, Solid State Ionics 132 (2000) 261-269.

[7] R. Voorhoeve, D. Johnson, J. Remeika, P. Gallagher, Perovskite oxides: Materials science in catalysis, Science 195 (1977) 827-833.

[8] T. Nakamura, G. Petzow, L. Gauckler, Stability of the perovskite phase $\mathrm{LaBO}_{3}(\mathrm{~B}=\mathrm{V}, \mathrm{Cr}$, $\mathrm{Mn}, \mathrm{Fe}, \mathrm{Co}, \mathrm{Ni})$ in reducing atmosphere I. Experimental results, Materials research bulletin 14 (1979) 649-659.

[9] H. U. Anderson, Review of p-type doped perovskite materials for SOFC and other applications, Solid State Ionics 52 (1992) 33-41.

[10] O. A. Marina, N. L. Canfield, J. W. Stevenson, Thermal, electrical, and electrocatalytical properties of lanthanum-doped strontium titanate, Solid State Ionics 149 (2002) 21-28.

[11] O. A. Marina, N. L. Canfield, J. W. Stevenson, Thermal, electrical, and electrocatalytical properties of lanthanum-doped strontium titanate, Solid State Ionics 149 (2002) 21-28. 
[12] F. Horikiri, L. Han, N. Iizawa, K. Sato, K. Yashiro, T. Kawada, J. Mizusaki, Electrical Properties of Nb-Doped SrTiO3 Ceramics with Excess TiO2 for SOFC Anodes and Interconnects, Journal of the Electrochemical Society 155 (2008) B16-B20.

[13] Q. X. Fu, F. Tietz, D. Stöver, $\mathrm{La}_{0.4} \mathrm{Sr}_{0.6} \mathrm{Ti}_{1-\mathrm{x}} \mathrm{Mn}_{\mathrm{x}} \mathrm{O}_{3-\delta}$ Perovskites as Anode Materials for Solid Oxide Fuel Cells, Journal of the Electrochemical Society 153 (2006) D74-D83.

[14] J. S. Yoon, M. Y. Yoon, C. Kwak, H. J. Park, S. M. Lee, K. H. Lee, H. J. Hwang, $\mathrm{Y}_{0.08} \mathrm{Sr}_{0.92} \mathrm{Fe}_{\mathrm{x}} \mathrm{Ti}_{1-\mathrm{x}} \mathrm{O}_{3-\delta}$ perovskite for solid oxide fuel cell anodes, Materials Science and Engineering: B 177 (2012) 151-156.

[15] L. Yang, L. C. De Jonghe, C. P. Jacobsen, S. J. Visco, B-Site Doping and Catalytic Activity of $\mathrm{Sr}(\mathrm{Y}) \mathrm{TiO}_{3}$, Journal of the Electrochemical Society 154 (2007) B949-B955.

[16] M. J. Escudero, J. T. S. Irvine, L. Daza, Development of anode material based on Lasubstituted $\mathrm{SrTiO}_{3}$ perovskites doped with manganese and/or gallium for SOFC, Journal of Power Sources 192 (2009) 43-50.

[17] J. C. Ruiz-Morales, J. Canales-Vázquez, C. Savaniu, D. Marrero-López, W. Zhou, J. T. S. Irvine, Disruption of extended defects in solid oxide fuel cell anodes for methane oxidation, Nature 439 (2006) 568-571.

[18] D. N. Miller, J. T. S. Irvine, B-site doping of lanthanum strontium titanate for solid oxide fuel cell anodes, Journal of Power Sources 196 (2011) 7323-7327.

[19] J. Canales-Vázquez, S. W. Tao, J. T. S. Irvine, Electrical properties in $\mathrm{La}_{2} \mathrm{Sr}_{4} \mathrm{Ti}_{6} \mathrm{O}_{19-8}$ : A potential anode for high temperature fuel cells, Solid State Ionics 159 (2003) 159-165.

[20] A. Ovalle, J. C. Ruiz-Morales, J. Canales-Vázquez, D. Marrero-López, J. T. S. Irvine, Mn-substituted titanates as efficient anodes for direct methane SOFCs, Solid State Ionics 177 (2006) 1997-2003.

[21] J. Canales-Vázquez, J. C. Ruiz-Morales, J. T. S. Irvine, W. Zhou, Sc-Substituted Oxygen Excess Titanates as Fuel Electrodes for SOFCs, Journal of the Electrochemical Society 152 (2005) A1458-A1465.

[22] K. Yashiro, T. Kobayashi, L.-Q. Han, A. Kaimai, K. Kawamura, Y. Nigara, T. Kawada, J. Mizusaki In Electrochemical Properties of Oxide-Anode Materials for SOFC, Electrochemical Society Proceedings, 2001; pp 678-683. 
[23] P. Blennow, K. K. Hansen, L. R. Wallenberg, M. Mogensen, Electrochemical characterization and redox behavior of Nb-doped SrTiO3, Solid State Ionics 180 (2009) 63-70.

[24] H. Kurokawa, L. Yang, C. P. Jacobson, L. C. De Jonghe, S. J. Visco, Y-doped $\mathrm{SrTiO}_{3}$ based sulfur tolerant anode for solid oxide fuel cells, Journal of Power Sources 164 (2007) $510-518$.

[25] G. Xiao, X. Dong, K. Huang, F. Chen, Synthesis and characterizations of A-site deficient perovskite $\mathrm{Sr}_{0.9} \mathrm{Ti}_{0.8-\mathrm{x}} \mathrm{Ga}_{\mathrm{x}} \mathrm{Nb}_{0.2} \mathrm{O}_{3}$, Materials research bulletin 46 (2011) 57-61.

[26] N. Suzuki, T. Noritake, N. Yamamoto, T. Hioki, Crystal structure and physical properties of layered perovskite compound $\mathrm{Sr}_{3} \mathrm{~V}_{2} \mathrm{O}_{7.01}$, Materials research bulletin 26 (1991) 1-9.

[27] J. Huang, A. W. Sleight, Crystal structure of high temperature strontium pyrovanadate, Materials research bulletin 27 (1992) 581-590.

[28] M. Sayer, H. Erdogan, C. D. Cox, Oxygen Transport and Charge Storage in Calcium Orthovanadate, Journal of the Electrochemical Society 119 (1972) 265-270.

[29] M. Cyrot, B. Lambert-Andron, J. L. Soubeyroux, M. J. Rey, P. Dehauht, F. CyrotLackmann, G. Fourcaudot, J. Beille, J. L. Tholence, Properties of a new perovskite ox yde Sr2VO4, Journal of Solid State Chemistry 85 (1990) 321-325.

[30] M. Cooper, K. Channa, R. De Silva, D. J. Bayless, Comparison of LSV/YSZ and LSV/GDC SOFC Anode Performance in Coal Syngas Containing $\mathrm{H}_{2} \mathrm{~S}$, Journal of the Electrochemical Society 157 (2010) B1713-B1718.

[31] S. Hui, A. Petric, Conductivity and stability of $\mathrm{SrVO}_{3}$ and mixed perovskites at low ox ygen partial pressures, Solid State Ionics 143 (2001) 275-283.

[32] A. Aguadero, C. de la Calle, J. A. Alonso, D. Pérez-Coll, M. J. Escudero, L. Daza, Structure, thermal stability and electrical properties of $\mathrm{Ca}\left(\mathrm{V}_{0.5} \mathrm{Mo}_{0.5}\right) \mathrm{O}_{3}$ as solid oxide fuel cell anode, Journal of Power Sources 192 (2009) 78-83.

[33] A. Aguadero, C. de la Calle, D. Pérez-Coll, J. A. Alonso, Study of the Crystal Structure, Thermal Stability and Conductivity of $\operatorname{Sr}\left(\mathrm{V}_{0.5} \mathrm{Mo}_{0.5}\right) \mathrm{O}_{3+\delta}$ as SOFC Material, Fuel Cells 11 (2011) 44-50.

[34] C. G. Petit, R. Lan, P. Cowin, A. Kraft, S. Tao, Structure, conductivity and redox stability of solid solution $\mathrm{Ce}_{1-\mathrm{x}} \mathrm{Ca}_{\mathrm{x}} \mathrm{VO}_{4}(0 \leq \mathrm{x} \leq 0.4125)$, Journal of materials science 46 (2011) 316-326. 
[35] C. T. G. Petit, R. Lan, P. I. Cowin, J. T. S. Irvine, S. Tao, Novel redox reversible oxide, Sr-doped cerium orthovanadate to metavanadate, Journal of Materials Chemistry 21 (2011) 525-531.

[36] N. Danilovic, J.-L. Luo, K. T. Chuang, A. R. Sanger, Effect of substitution with $\mathrm{Cr}^{3+}$ and addition of $\mathrm{Ni}$ on the physical and electrochemical properties of $\mathrm{Ce}_{0.9} \mathrm{Sr}_{0.1} \mathrm{VO}_{3}$ as a $\mathrm{H}_{2} \mathrm{~S}$ active anode for solid oxide fuel cells, Journal of Power Sources 194 (2009) 252-262.

[37] Z. Cheng, S. Zha, L. Aguilar, M. Liu, Chemical, electrical, and thermal properties of strontium doped lanthanum vanadate, Solid State Ionics 176 (2005) 1921-1928.

[38] N. Danilovic, J.-L. Luo, K. T. Chuang, A. R. Sanger, $\mathrm{Ce}_{0.9} \mathrm{Sr}_{0.1} \mathrm{VO}_{\mathrm{x}}(\mathrm{x}=3$, 4) as anode materials for $\mathrm{H}_{2} \mathrm{~S}$-containing $\mathrm{CH}_{4}$ fueled solid oxide fuel cells, Journal of Power Sources 192 (2009) 247-257.

[39] S. Tao, J. T. S. Irvine, Synthesis and Characterization of $\left(\mathrm{La}_{0.75} \mathrm{Sr}_{0.25}\right) \mathrm{Cr}_{0.5} \mathrm{Mn}_{0.5} \mathrm{O}_{3-8}$, a Redox-Stable, Efficient Perovskite Anode for SOFCs, Journal of the Electrochemical Society 151 (2004) A252-A259.

[40] G. Kim, S. Lee, J. Shin, G. Corre, J. Irvine, J. Vohs, R. J. Gorte, Investigation of the structural and catalytic requirements for high-performance SOFC anodes formed by infiltration of LSCM, Electrochemical and Solid-State Letters 12 (2009) B48-B52.

[41] S. Tao, J. T. S. Irvine, A redox-stable efficient anode for solid-oxide fuel cells, Nature materials 2 (2003) 320-323.

[42] D. M. Bastidas, S. Tao, J. T. S. Irvine, A symmetrical solid oxide fuel cell demonstrating redox stable perovskite electrodes, Journal of Materials Chemistry 16 (2006) 1603-1605.

[43] S. Primdahl, J. R. Hansen, L. Grahl-Madsen, P. H. Larsen, Sr-Doped $\mathrm{LaCrO}_{3}$ Anode for Solid Oxide Fuel Cells, Journal of the Electrochemical Society 148 (2001) A74-A81.

[44] J. Sfeir, P. A. Buffat, P. Möckli, N. Xanthopoulos, R. Vasquez, H. Joerg Mathieu, J. Van herle, K. Ravindranathan Thampi, Lanthanum Chromite Based Catalysts for Oxidation of Methane Directly on SOFC Anodes, Journal of Catalysis 202 (2001) 229-244.

[45] H. Arai, T. Yamada, K. Eguchi, T. Seiyama, Catalytic combustion of methane over various perovskite-type oxides, Applied catalysis 26 (1986) 265-276.

[46] P. Vernoux, E. Djurado, M. Guillodo, Catalytic and Electrochemical Properties of Doped Lanthanum Chromites as New Anode Materials for Solid Oxide Fuel Cells, Journal of the American Ceramic Society 84 (2001) 2289-2295. 
[47] J. Wan, J. H. Zhu, J. B. Goodenough, $\mathrm{La}_{0.75} \mathrm{Sr}_{0.25} \mathrm{Cr}_{0.5} \mathrm{Mn}_{0.5} \mathrm{O}_{3-\delta}+\mathrm{Cu}$ composite anode running on $\mathrm{H}_{2}$ and $\mathrm{CH}_{4}$ fuels, Solid State Ionics 177 (2006) 1211-1217.

[48] X. Zhu, Z. Lü, B. Wei, K. Chen, M. Liu, X. Huang, W. Su, Enhanced performance of solid oxide fuel cells with $\mathrm{Ni} / \mathrm{CeO}_{2}$ modified $\mathrm{La}_{0.75} \mathrm{Sr}_{0.25} \mathrm{Cr}_{0.5} \mathrm{Mn}_{0.5} \mathrm{O}_{3-} \delta$ anodes, Journal of Power Sources 190 (2009) 326-330.

[49] X. Zhu, Z. Lü, B. Wei, K. Chen, M. Liu, X. Huang, W. Su, Fabrication and performance of membrane solid oxide fuel cells with $\mathrm{La}_{0.75} \mathrm{Sr}_{0.25} \mathrm{Cr}_{0.5} \mathrm{Mn}_{0.5} \mathrm{O}_{3-\delta}$ impregnated anodes, Journal of Power Sources 195 (2010) 1793-1798.

[50] V. V. Kharton, A. A. Yaremchenko, E. N. Naumovich, Research on the electrochemistry of oxygen ion conductors in the former Soviet Union. II. Perovskite-related oxides, Journal of Solid State Electrochemistry 3 (1999) 303-326.

[51] S. P. Jiang, L. Liu, K. P. Ong, P. Wu, J. Li, J. Pu, Electrical conductivity and performance of doped $\mathrm{LaCrO}_{3}$ perovskite oxides for solid oxide fuel cells, Journal of Power Sources 176 (2008) 82-89.

[52] G. Pudmich, B. A. Boukamp, M. Gonzalez-Cuenca, W. Jungen, W. Zipprich, F. Tietz, Chromite/titanate based perovskites for application as anodes in solid oxide fuel cells, Solid State Ionics 135 (2000) 433-438.

[53] V. Vashook, S. Tolochko, I. Yushkevich, L. Makhnach, I. Kononyuk, H. Altenburg, J. Hauck, H. Ullmann, Oxygen nonstoichiometry and electrical conductivity of the solid solutions $\mathrm{La}_{2-\mathrm{x}} \mathrm{Sr}_{\mathrm{x}} \mathrm{NiO}_{\mathrm{y}}(0 \leq \mathrm{x} \leq 0.5)$, Solid State Ionics 110 (1998) 245-253.

[54] P. Zhuk, A. Vecher, V. Samokhval, E. Naumovich, A. Viskup, Properties of iron-doped lanthanum chromite, Inorg. Mater.(Engl. Transl.);(United States) 24 (1988).

[55] S. Tolochko, I. Kononyuk, Preparation and electric properties of $\mathrm{La}_{1-x} \mathrm{Ca}_{\mathrm{x}} \mathrm{Cr}_{\mathrm{y}} \mathrm{Co}_{1-\mathrm{y}} \mathrm{O}_{3}$ solid solutions $(0 \leq \mathrm{x} \leq 0,3$; 0 , (1986).

[56] S. Tolochko, I. Kononyuk, Poluchenie i electricheskie svoistva tverdykh rastvorov La $1-$ ${ }_{\mathrm{x}} \mathrm{Ca}_{\mathrm{x}} \mathrm{Cr}_{\mathrm{y}} \mathrm{Co}_{1-\mathrm{y}} \mathrm{O}_{3} \quad(0 \leq \mathrm{x} \leq 0.3 ; 0<\mathrm{y} \leq 1)$ [Production and Electrical Properties of Solid Solutions $\left.\mathrm{La}_{1-\mathrm{x}} \mathrm{Ca}_{\mathrm{x}} \mathrm{Cr}_{\mathrm{y}} \mathrm{Co}_{1-\mathrm{y}} \mathrm{O}_{3}(0 \leq \mathrm{x} \leq 0.3 ; 0<\mathrm{y} \leq 1)\right]$, Izvestiya AN SSSR. Neorganicheskie materialy 22 (1986) 1696-1700.

[57] P. Vernoux, M. Guillodo, J. Fouletier, A. Hammou, Alternative anode material for gradual methane reforming in solid oxide fuel cells, Solid State Ionics 135 (2000) 425431. 
[58] S. Tao, J. T. Irvine, Catalytic Properties of the Perovskite Oxide $\mathrm{La}_{0.75} \mathrm{Sr}_{0.25} \mathrm{Cr}_{0.5} \mathrm{Fe}_{0.5} \mathrm{O}_{3-\delta}$ in Relation to Its Potential as a Solid Oxide Fuel Cell Anode Material, Chemistry of Materials 16 (2004) 4116-4121.

[59] A. L. Sauvet, J. Guindet, J. Fouletier, $\mathrm{La}_{0.8} \mathrm{Sr}_{0.2} \mathrm{Cr}_{0.95} \mathrm{Ru}_{0.05}$ as a new anode material for SOFC using natural gas, Ionics 5 (1999) 150-155.

[60] X. C. Lu, J. H. Zhu, $\mathrm{Cu}(\mathrm{Pd})$-impregnated $\mathrm{La}_{0.75} \mathrm{Sr}_{0.25} \mathrm{Cr}_{0.5} \mathrm{Mn}_{0.5} \mathrm{O}_{3-\delta}$ anodes for direct utilization of methane in SOFC, Solid State Ionics 178 (2007) 1467-1475.

[61] S. P. Jiang, X. J. Chen, S. H. Chan, J. T. Kwok, K. A. Khor, $\left(\mathrm{La}_{0.75} \mathrm{Sr}_{0.25}\right)\left(\mathrm{Cr}_{0.5} \mathrm{Mn}_{0.5}\right) \mathrm{O}_{3} / \mathrm{YSZ}$ composite anodes for methane oxidation reaction in solid oxide fuel cells, Solid State Ionics 177 (2006) 149-157.

[62] S. P. Jiang, X. J. Chen, S. H. Chan, J. T. Kwok, GDC-Impregnated ( $\left.\mathrm{La}_{0.75} \mathrm{Sr}_{0.25}\right)\left(\mathrm{Cr}_{0.5} \mathrm{Mn}_{0.5}\right) \mathrm{O}_{3}$ Anodes for Direct Utilization of Methane in Solid Oxide Fuel Cells, Journal of the Electrochemical Society 153 (2006) A850-A856.

[63] Y. Ye, T. He, Y. Li, E. H. Tang, T. L. Reitz, S. P. Jiang, Pd-Promoted

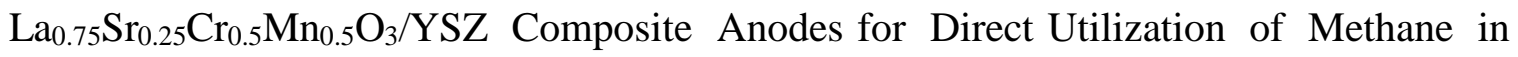
SOFCs, Journal of the Electrochemical Society 155 (2008) B811-B818.

[64] S. W. Tao, J. T. S. Irvine, J. A. Kilner, An Efficient Solid Oxide Fuel Cell Based upon Single-Phase Perovskites, Advanced Materials 17 (2005) 1734-1737.

[65] K. J. Yoon, J. W. Stevenson, O. A. Marina, High performance ceramic interconnect material for solid oxide fuel cells (SOFCs): Ca-and transition metal-doped yttrium chromite, Journal of Power Sources 196 (2011) 8531-8538.

[66] S. Wang, B. Lin, Y. Dong, D. Fang, H. Ding, X. Liu, G. Meng, Stable, easily sintered $\mathrm{Ca}-\mathrm{Zn}$-doped $\mathrm{YCrO}_{3}$ as novel interconnect materials for co-fired yttrium-stabilized zirconia-based solid oxide fuel cells, Journal of Power Sources 188 (2009) 483-488.

[67] K. J. Yoon, C. N. Cramer, E. C. Thomsen, C. A. Coyle, G. W. Coffey, O. A. Marina, Calcium-and Cobalt-Doped Yttrium Chromites as an Interconnect Material for Solid Oxide Fuel Cells, Journal of the Electrochemical Society 157 (2010) B856-B861.

[68] T. R. Armstrong, J. W. Stevenson, D. E. McCready, S. W. Paulik, P. E. Raney, The effect of reducing environments on the stability of acceptor substituted yttrium chromite, Solid State Ionics 92 (1996) 213-223. 
[69] G. Carini, H. Anderson, D. Sparlin, M. Nasrallah, Electrical conductivity, seebeck coefficient and defect chemistry of Ca-doped $\mathrm{YCrO}_{3}$, Solid State Ionics 49 (1991) 233243.

[70] W. J. Weber, C. W. Griffin, J. L. Bates, Effects of cation substitution on electrical and thermal transport properties of $\mathrm{YCrO}_{3}$ and $\mathrm{LaCrO}_{3}$, Journal of the American Ceramic Society 70 (1987) 265-270.

[71] K. J. Yoon, J. W. Stevenson, O. A. Marina, Effect of nickel substitution on defect chemistry, electrical properties, and dimensional stability of calcium-doped yttrium chromite, Solid State Ionics 193 (2011) 60-65.

[72] K. J. Yoon, C. A. Coyle, O. A. Marina, Doped yttrium chromite-ceria composite as a redox-stable and sulfur-tolerant anode for solid oxide fuel cells, Electrochemistry Communications 13 (2011) 1400-1403.

[73] A. Bieberle, L. Gauckler, Reaction mechanism of Ni pattern anodes for solid oxide fuel cells, Solid State Ionics 135 (2000) 337-345.

[74] P. Holtappels, L. De Haart, U. Stimming, Reaction of Hydrogen/Water Mixtures on Nickel-Zirconia Cermet Electrodes: I. DC Polarization Characteristics, Journal of the Electrochemical Society 146 (1999) 1620-1625.

[75] P. Holtappels, I. C. Vinke, L. G. J. de Haart, U. Stimming, Reaction of Hydrogen/Water Mixtures on Nickel-Zirconia Cermet Electrodes: II. AC Polarization Characteristics, Journal of the Electrochemical Society 146 (1999) 2976-2982.

[76] M. Mogensen, S. Skaarup, Kinetic and geometric aspects of solid oxide fuel cell electrodes, Solid State Ionics 86-88 (1996) 1151-1160.

[77] J. Mizusaki, H. Tagawa, T. Saito, T. Yamamura, K. Kamitani, K. Hirano, S. Ehara, T. Takagi, T. Hikita, M. Ippommatsu, S. Nakagawa, K. Hashimoto, Kinetic studies of the reaction at the nickel pattern electrode on $\mathrm{YSZ}$ in $\mathrm{H}_{2} / \mathrm{H}_{2} \mathrm{O}$ atmospheres, Solid State Ionics 70-71 (1994) 52-58.

[78] M. Mogensen, J. Hogh, K. V. Hansen, T. Jacobsen, A critical review of models of the $\mathrm{H}_{2} / \mathrm{H}_{2} \mathrm{O} / \mathrm{Ni} / \mathrm{SZ}$ electrode kinetics, ECS Transactions 7 (2007) 1329-1338.

[79] J. Mizusaki, H. Tagawa, T. Saito, K. Kamitani, T. Yamamura, K. Hirano, S. Ehara, T. Takagi, T. Hikita, M. Ippommatsu, Preparation of Nickel Pattern Electrodes on YSZ and 
Their Electrochemical Properties in $\mathrm{H}_{2}-\mathrm{H}_{2} \mathrm{O}$ Atmospheres, Journal of the Electrochemical Society 141 (1994) 2129-2134.

[80] N. Q. Minh, T. Takahashi, Science and technology of ceramic fuel cells. Elsevier: 1995.

[81] J. Mizusaki, H. Tagawa, K. Tsuneyoshi, K. Mori, A. Sawata, Electrode thickness, microstructure, and properties of air electrode for high-temperature solid oxide fuel-cells, $\mathrm{La}_{0.6} \mathrm{Ca}_{0.44} \mathrm{MnO}_{3}, \mathrm{La}_{0.6} \mathrm{Ca}_{0.4} \mathrm{CoO}_{3}$, Nippon Kagaku Kaishi (1988) 1623-1629.

[82] A. Bieberle, L. Gauckler, State-space modeling of the anodic SOFC system Ni, $\mathrm{H}_{2}-$ $\mathrm{H}_{2} \mathrm{O}$ IYSZ, Solid State Ionics 146 (2002) 23-41.

[83] P. A. Thiel, T. E. Madey, The interaction of water with solid surfaces: Fundamental aspects, Surface Science Reports 7 (1987) 211-385.

[84] K. Christmann, Interaction of hydrogen with solid surfaces, Surface Science Reports 9 (1988) 1-163.

[85] B. Hellsing, B. Kasemo, V. P. Zhdanov, Kinetics of the hydrogen-oxygen reaction on platinum, Journal of Catalysis 132 (1991) 210-228.

[86] E. Fridell, A. Rosen, B. Kasemo, Laser-induced fluorescence study of OH desorption from $\mathrm{Pt}$ in $\mathrm{H}_{2} \mathrm{O} / \mathrm{O}_{2}$ and $\mathrm{H}_{2} \mathrm{O} / \mathrm{H}_{2}$ mixtures, Langmuir 10 (1994) 699-708.

[87] A. Bieberle, L. P. Meier, L. J. Gauckler The Electrochemistry of Ni Pattern Anodes Used as Solid Oxide Fuel Cell Model Electrodes, Journal of the Electrochemical Society 148 (2001) A646-A656.

[88] S. Jiang, S. Badwal, Hydrogen Oxidation at the Nickel and Platinum Electrodes on Yttria-Tetragonal Zirconia Electrolyte, Journal of the Electrochemical Society 144 (1997) 3777-3784.

[89] M. Vogler, A. Bieberle-Hütter, L. Gauckler, J. Warnatz, W. G. Bessler, Modelling Study of Surface Reactions, Diffusion, and Spillover at a Ni/YSZ Patterned Anode, Journal of the Electrochemical Society 156 (2009) B663-B672.

[90] W. Li, M. Gong, X. Liu, H2 Oxidation on Doped Yttrium Chromites Anode of Solid Oxide Fuel Cell, ECS Transactions 57 (2013) 1479-1489.

[91] W. Li, M. Gong, X. Liu, Characterization of Doped Yttrium Chromites as Electrodes for Solid Oxide Fuel Cell by Impedance Method, Journal of the Electrochemical Society 161 (2014) F551-F560. 
[92] F. S. Baumann, J. Fleig, H.-U. Habermeier, J. Maier, Impedance spectroscopic study on well-defined (La,Sr) $(\mathrm{Co}, \mathrm{Fe}) \mathrm{O}_{3-\delta}$ model electrodes, Solid State Ionics 177 (2006) 10711081.

[93] J. Fleig, On the current-voltage characteristics of charge transfer reactions at mixed conducting electrodes on solid electrolytes, Physical Chemistry Chemical Physics 7 (2005) 2027-2037.

[94] W. Wang, S. P. Jiang, A mechanistic study on the activation process of ( $\mathrm{La}, \mathrm{Sr}) \mathrm{MnO}_{3}$ electrodes of solid oxide fuel cells, Solid State Ionics 177 (2006) 1361-1369.

[95] C. Wagner, Equations for transport in solid oxides and sulfides of transition metals, Progress in solid state chemistry 10 (1975) 3-16.

[96] C. Wagner, Investigations on silver sulfide, The Journal of Chemical Physics 21 (1953) 1819-1827.

[97] K. Kiukkola, C. Wagner, Measurements on galvanic cells involving solid electrolytes, Journal of the Electrochemical Society 104 (1957) 379-387.

[98] M. Liu, Distributions of Charged Defects in Mixed Ionic-Electronic Conductors I. General Equations for Homogeneous Mixed Ionic-Electronic Conductors, Journal of the Electrochemical Society 144 (1997) 1813-1834.

[99] J. Jamnik, J. Maier, Treatment of the Impedance of Mixed Conductors Equivalent Circuit Model and Explicit Approximate Solutions, Journal of the Electrochemical Society 146 (1999) 4183-4188.

[100] W. Lai, S. M. Haile, Impedance spectroscopy as a tool for chemical and electrochemical analysis of mixed conductors: a case study of ceria, Journal of the American Ceramic Society 88 (2005) 2979-2997.

[101] L. Van der Pauw, A method of measuring the resistivity and Hall coefficient on lamellae of arbitrary shape, Philips Technical Review 20 (1958) 220-224.

[102] L. A. Chick, J. Liu, J. W. Stevenson, T. R. Armstrong, D. E. McCready, G. D. Maupin, G.

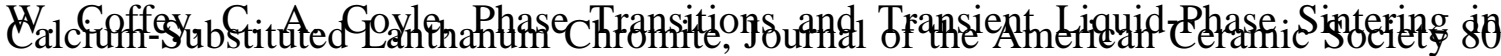
(1997) 2109-2120.

[103] J. Carter, C. Appel, M. Mogensen, Reactions at the calcium doped lanthanum chromiteyttria stabilized zirconia interface, Journal of Solid State Chemistry 122 (1996) 407-415. 
[104] A. Kaiser, B. Sommer, E. Woermann, The System $\mathrm{CaO}-\mathrm{CaCr}_{2} \mathrm{O}_{4}-\mathrm{CaAl}_{2} \mathrm{O}_{4}$ in Air and under Mildly Reducing Conditions, Journal of the American Ceramic Society 75 (1992) 1463-1471.

[105] R. Koc, H. U. Anderson, Liquid phase sintering of $\mathrm{LaCrO}_{3}$, Journal of the European Ceramic Society 9 (1992) 285-292.

[106] H. Juretschke, R. Landauer, J. Swanson, Hall effect and conductivity in porous media, Journal of Applied Physics 27 (1956) 838-839.

[107] R. Raffaelle, H. Anderson, D. Sparlin, P. Parris, Transport anomalies in the hightemperature hopping conductivity and thermopower of Sr-doped $\mathrm{La}(\mathrm{Cr}, \mathrm{Mn}) \mathrm{O}_{3}$, Physical Review B 43 (1991) 7991.

[108] B. C. Steele, Survey of materials selection for ceramic fuel cells II. Cathodes and anodes, Solid State Ionics 86 (1996) 1223-1234.

[109] J. Mizusaki, H. Tagawa, T. Saito, K. Kamitani, T. Yamamura, K. Hirano, S. Ehara, T. Takagi, T. Hikita, M. Ippommatsu, S. Nakagawa, K. Hashimoto, Preparation of Nickel Pattern Electrodes on YSZ and Their Electrochemical Properties in $\mathrm{H}_{2}-$ $\mathrm{H}_{2} \mathrm{O}$ Atmospheres, Journal of the Electrochemical Society 141 (1994) 2129-2134.

[110] S. P. Jiang, S. P. S. Badwal, An electrode kinetics study of $\mathrm{H}_{2}$ oxidation on $\mathrm{Ni} / \mathrm{Y}_{2} \mathrm{O}_{3}-\mathrm{ZrO}_{2}$ cermet electrode of the solid oxide fuel cell, Solid State Ionics 123 (1999) 209-224.

[111] M. Brown, S. Primdahl, M. Mogensen, Structure/Performance Relations for Ni/YttriaStabilized Zirconia Anodes for Solid Oxide Fuel Cells, Journal of the Electrochemical Society 147 (2000) 475-485.

[112] N. Nakagawa, H. Sakurai, K. Kondo, T. Morimoto, K. Hatanaka, K. Kato, Evaluation of the effective reaction zone at $\mathrm{Ni}(\mathrm{NiO}) /$ zirconia anode by using an electrode with a novel structure, Journal of the Electrochemical Society 142 (1995) 3474-3479.

[113] S. Primdahl, M. Mogensen, Oxidation of Hydrogen on Ni/Yttria-Stabilized Zirconia Cermet Anodes, Journal of the Electrochemical Society 144 (1997) 3409-3419.

[114] J. Rossmeisl, W. G. Bessler, Trends in catalytic activity for SOFC anode materials, Solid State Ionics 178 (2008) 1694-1700.

[115] T. Setoguchi, K. Okamoto, K. Eguchi, H. Arai, Effects of Anode Material and Fuel on Anodic Reaction of Solid Oxide Fuel Cells, Journal of the Electrochemical Society 139 (1992) 2875-2880. 
[116] J. Fierro, L. G. Tejuca, Non-stoichiometric surface behaviour of $\mathrm{LaMO}_{3}$ oxides as evidenced by XPS, Applied surface science 27 (1987) 453-457.

[117] J. Fierro, L. G. Tejuca, Surface properties of $\mathrm{LaCrO}_{3}$ : Equilibrium and kinetics of $\mathrm{O}_{2}$ adsorption, Journal of Catalysis 87 (1984) 126-135.

[118] B. De Boer, SOFC Anode. Hydrogen oxidation at porous nickel and nickel/yttriastabilised zirconia cermet electrodes, (1998).

[119] W. G. Bessler, M. Vogler, H. Stormer, D. Gerthsen, A. Utz, A. Weber, E. Ivers-Tiffee, Model anodes and anode models for understanding the mechanism of hydrogen oxidation in solid oxide fuel cells, Physical Chemistry Chemical Physics 12 (2010) 13888-13903.

[120] A. Utz, H. Störmer, A. Leonide, A. Weber, E. Ivers-Tiffée, Degradation and Relaxation Effects of Ni Patterned Anodes in $\mathrm{H}_{2}-\mathrm{H}_{2} \mathrm{O}$ Atmosphere, Journal of the Electrochemical Society 157 (2010) B920-B930.

[121] T. Nakamura, T. Kobayashi, K. Yashiro, A. Kaimai, T. Otake, K. Sato, J. Mizusaki, T. Kawada, Electrochemical behaviors of mixed conducting oxide anodes for solid oxide fuel cell, Journal of the Electrochemical Society 155 (2008) B563-B569.

[122] W. C. Chueh, Y. Hao, W. Jung, S. M. Haile, High electrochemical activity of the oxide phase in model ceria-Pt and ceria-Ni composite anodes, Nature materials 11 (2011) 155161.

[123] W. Li, M. Gong, X. Liu, H2 Oxidation on Doped Yttrium Chromites/Yttrium Stabilized Zirconia Anode of Solid Oxide Fuel Cell, Journal of Power Sources 241 (2013) 494-501.

[124] F. H. Heuveln, H. Bouwmeester, Electrode Properties of Sr-Doped $\mathrm{LaMnO}_{3}$ on YttriaStabilized Zirconia II: Electrode kinetics, Journal of the Electrochemical Society 144 (1997) 134-140.

[125] K. Zhao, Q. Xu, D.-P. Huang, M. Chen, B.-H. Kim, Electrochemical evaluation of $\mathrm{La}_{2} \mathrm{NiO}_{4+\delta}$-based composite electrodes screen-printed on $\mathrm{Ce}_{0.8} \mathrm{Sm}_{0.2} \mathrm{O}_{1.9}$ electrolyte, Journal of Solid State Electrochemistry 16 (2012) 2797-2804.

[126] S. Choi, S. Yoo, J.-Y. Shin, G. Kim, High Performance SOFC Cathode Prepared by Infiltration of $\mathrm{La}_{\mathrm{n}+1} \mathrm{Ni}_{\mathrm{n}} \mathrm{O}_{3 \mathrm{n}+1} \quad(\mathrm{n}=1,2$, and 3) in Porous YSZ, Journal of the Electrochemical Society 158 (2011) B995-B999. 
[127] M. Escudero, A. Aguadero, J. Alonso, L. Daza, A kinetic study of oxygen reduction reaction on $\mathrm{La}_{2} \mathrm{NiO}_{4}$ cathodes by means of impedance spectroscopy, Journal of Electroanalytical Chemistry 611 (2007) 107-116.

[128] J. Maier, On the correlation of macroscopic and microscopic rate constants in solid state chemistry, Solid State Ionics 112 (1998) 197-228.

[129] W. C. Chueh, S. M. Haile, Electrochemistry of Mixed Oxygen Ion and Electron Conducting Electrodes in Solid Electrolyte Cells, Annual Review of Chemical and Biomolecular Engineering 3 (2012) 313-341.

[130] S. B. Adler, X. Y. Chen, J. R. Wilson, Mechanisms and rate laws for oxygen exchange on mixed-conducting oxide surfaces, Journal of Catalysis 245 (2007) 91-109.

[131] J. Fierro, J. Tascon, L. G. Tejuca, Physicochemical properties of $\mathrm{LaMnO}_{3}$ : Reducibility and kinetics of $\mathrm{O}_{2}$ adsorption, Journal of Catalysis 89 (1984) 209-216.

[132] J. Tascon, L. G. Tejuca, Adsorption of Oxygen on the Perovskite-Type Oxide $\mathrm{LaCoO}_{3}$, Zeitschrift für Physikalische Chemie 121 (1980) 79-93.

[133] Y. Takeda, R. Kanno, M. Noda, Y. Tomida, O. Yamamoto, Cathodic polarization phenomena of perovskite oxide electrodes with stabilized zirconia, Journal of the Electrochemical Society 134 (1987) 2656-2661.

[134] Y. Takeda, R. Kanno, M. Noda, O. Yamamoto, Perovskite Electrodes for High Temperature Solid Electrolyte Fuel Cells, Bulletin of the Institute for Chemical Research, Kyoto University 64 (1986) 157-169.

[135] J. D. Kim, G. D. Kim, J. W. Moon, Y. Park, W. H. Lee, K. Kobayashi, M. Nagai, C. E. Kim, Characterization of LSM-YSZ composite electrode by ac impedance spectroscopy, Solid State Ionics 143 (2001) 379-389.

[136] J. Mizusaki, S. Yamauchi, K. Fueki, A. Ishikawa, Nonstoichiometry of the perovskitetype oxide $\mathrm{La}_{1-\mathrm{x}} \mathrm{Sr}_{\mathrm{x}} \mathrm{CrO}_{3-\delta}$, Solid State Ionics 12 (1984) 119-124.

[137] T. Kawada, J. Suzuki, M. Sase, A. Kaimai, K. Yashiro, Y. Nigara, J. Mizusaki, K. Kawamura, H. Yugami, Determination of Oxygen Vacancy Concentration in a Thin Film of $\mathrm{La}_{0.6} \mathrm{Sr}_{0.4} \mathrm{CoO}_{3-8}$ by an Electrochemical Method, Journal of the Electrochemical Society 149 (2002) E252-E259. 


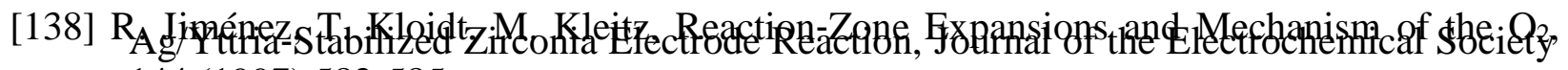
144 (1997) 582-585.

[139] S. B. Adler, Factors governing oxygen reduction in solid oxide fuel cell cathodes, Chemical Reviews-Columbus 104 (2004) 4791-4844.

[140] S. Adler, J. Lane, B. Steele, Electrode Kinetics of Porous Mixed-Conducting Oxygen Electrodes, Journal of the Electrochemical Society 143 (1996) 3554-3564.

[141] F. H. v. Heuveln, H. J. M. Bouwmeester, F. P. F. v. Berkel, Electrode Properties of SrDoped $\mathrm{LaMnO}_{3}$ on Yttria-Stabilized Zirconia-TPB, Journal of the Electrochemical Society 144 (1997) 126-133.

[142] B. C. Steele, Survey of materials selection for ceramic fuel cells II. Cathodes and anodes, Solid State Ionics 86 (1996) 1223-1234.

[143] J. Mizusaki, Y. Mima, S. Yamauchi, K. Fueki, H. Tagawa, Nonstoichiometry of the perovskite-type oxides $\mathrm{La}_{1-x} \mathrm{Sr}_{x} \mathrm{CoO}_{3-\delta}$, Journal of Solid State Chemistry 80 (1989) 102111.

[144] M. Watanabe, H. Uchida, M. Yoshida, Effect of Ionic Conductivity of Zirconia Electrolytes on the Polarization Behavior of Ceria-Based Anodes in Solid Oxide Fuel Cells, Journal of the Electrochemical Society 144 (1997) 1739-1743.

[145] M. Verkerk, M. Hammink, A. Burggraaf, Oxygen Transfer on Substituted $\mathrm{ZrO}_{2}, \mathrm{Bi}_{2} \mathrm{O}_{3}$, and $\mathrm{CeO}_{2}$ Electrolytes with Platinum Electrodes I. Electrode Resistance by D-C Polarization, Journal of the Electrochemical Society 130 (1983) 70-78.

[146] M. J. Verkerk, A. J. Burggraaf, Oxygen Transfer on Substituted $\mathrm{ZrO}_{2}, \mathrm{Bi}_{2} \mathrm{O}_{3}$, and $\mathrm{CeO}_{2}$

Electrolytes with Platinum Electrodes: II . A-C Impedance Study, Journal of the Electrochemical Society 130 (1983) 78-84.

[147] H. Uchida, M. Yoshida, M. Watanabe, Effect of ionic conductivity of zirconia electrolytes on the polarization behavior of various cathodes in solid fuel cells, Journal of the Electrochemical Society 146 (1999) 1-7.

[148] R. Küngas, J. M. Vohs, R. J. Gorte, Effect of the Ionic Conductivity of the Electrolyte in Composite SOFC Cathodes, Journal of the Electrochemical Society 158 (2011) B743B748. 
[149] M. Liu, Z. Wu, Significance of interfaces in solid-state cells with porous electrodes of mixed ionic-electronic conductors, Solid State Ionics 107 (1998) 105-110.

[150] N. M. Sammes, G. A. Tompsett, H. Näfe, F. Aldinger, Bismuth based oxide electrolytesstructure and ionic conductivity, Journal of the European Ceramic Society 19 (1999) 1801-1826.

[151] A. V. Virkar, Theoretical analysis of the role of interfaces in transport through oxygen ion and electron conducting membranes, Journal of Power Sources 147 (2005) 8-31.

[152] A. V. Virkar, Transport through mixed proton, oxygen ion and electron (hole) conductors: Goldman-Hodgkin-Katz-type equation, Journal of Power Sources 194 (2009) 753-762.

[153] D. E. Goldman, Potential, impedance, and rectification in membranes, The Journal of General Physiology 27 (1943) 37-60.

[154] A. D. MacGillivray, Nernst-Planck Equations and the Electroneutrality and Donnan Equilibrium Assumptions, The Journal of Chemical Physics 48 (1968) 2903-2907. 